\title{
Storytelling and Teaching English to Young \\ Learners: A Vietnamese case study
}

\author{
by \\ Hong Phuong Thao Le
}

\begin{abstract}
A thesis
submitted to Victoria University of Wellington

in fulfilment of the requirement for the degree of

Doctor of Philosophy in Applied Linguistics
\end{abstract}

Victoria University of Wellington, New Zealand 


\begin{abstract}
Storytelling, which is often promoted as a suitable methodological approach in teaching young learners, has been under-used and under-researched in EFL primary schools. This study introduces a storytelling innovation to put the young learner-oriented approach in practice. The innovation provides a structure to redesign textbook lessons into storytelling lessons in order to offer young learners interactive opportunities to use language in meaningful contexts. The research was conducted in two phases.
\end{abstract}

The first phase employed a qualitative approach to examine the current state of using stories and storytelling in teaching EFL in state primary schools in Vietnam. This phase involved the participation of 21 teachers and groups of Grade 5 students from 18 primary schools. Classroom observations, in-depth interviews with teachers, and group interviews with students were conducted to collect data. The results showed that stories were mainly used to introduce target language items in the presentation stage of the textbook lessons which had a presentation-practice-production structure. The lessons consisted mainly of mechanical practice and, ineffective group work, and afforded learners few opportunities for interactive activities.

The second phase was an intervention study to examine the implementation of storytelling innovation lessons. Two teachers and two classes, who participated in Phase 1, joined Phase 2 of the study. One teacher and one class were used as the comparison group while the others employed the innovation for one teaching term. Data were collected from pre-and poststorytelling speaking tests, classroom observations, in-depth interviews with teachers, and group interviews with students. The quantitative findings revealed that at the end of the study the intervention group significantly outperformed the comparison group in their oral language production. The qualitative data showed that the students in the intervention group were highly engaged in storytelling activities as well. A feature contributing to the learners' engagement was found to be effective cooperation in group work, as the students were afforded opportunities for meaningful interactions. Both the teacher and the students perceived the positive change in their teaching and learning practices.

The innovation could transform a mechanical teaching practice to a more interactive and meaningful learning approach. The results indicate the storytelling innovation as a successful model for introducing change into teaching English in primary schools and contributing to an understanding of the implementation of storytelling, the nature of interactions and learning engagement in EFL contexts. 


\section{ACKNOWLEDGEMENTS}

I would like to express my deepest gratitude to my primary supervisor, Professor John Macalister, for giving me a chance to study in such an excellent environment in VUW and for his professional guidance, insightful feedback, valuable support and patience throughout my $\mathrm{Ph}$.D. process. His timely assistance and encouragement kept me motivated. I would also like to thank my second supervisor, Dr Jean Parkinson, for her enthusiasm, kindness and moral support throughout this project. Without John's and Jean's assistance, this thesis would have not been possible.

I am especially indebted to the VUW-VIED scholarship for granting me a doctoral scholarship to pursue this study. I am grateful for the financial support provided by the Faculty of Humanities and Social Sciences, which allowed me to carry out my data collection in Vietnam.

I would like to express my heartfelt thanks to the Vietnamese teachers and students who participated in my research. I highly appreciate their contributions to my study. I am grateful to parents who gave me permission to invite their children to join my study. I sincerely thank the Bureaus of Education and Training, the schools' principals and teaching staff for their support and encouragement during my data collection.

My sincere thanks go to the staff at the school of Linguistics and Applied Language Studies for creating a supportive and friendly academic environment, and VUW student advisors, particularly Dr Deborah Laurs, Louise Falepau and Dr T. J. Boutorwick for their useful advice on my writing, and Dr Lisa Woods for her statistical consulting.

I am thankful to my LALS PhD thesis group for their research stories. Special thanks go to Nurul Aini Mohd Jelani, Trang Ngoc Hoang and Say Phonekeo for the friendship, kindness and suggestions they offered at important moments.

I would also like to thank Madeleine Collinge, my thesis copy editor, for all her comments and suggestions, which helped me a lot to improve the manuscript of this study.

I deeply thank my big family, who always provided me with their encouragement and support during the entire period of my study.

Finally, I would like to send my sincere gratitude to Dong Thap University for giving me the chance to go to New Zealand to pursue this PhD study. 


\section{TABLE OF CONTENTS}

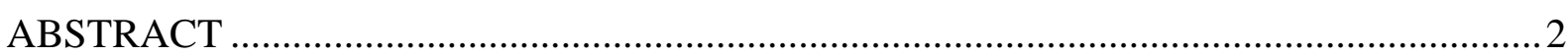

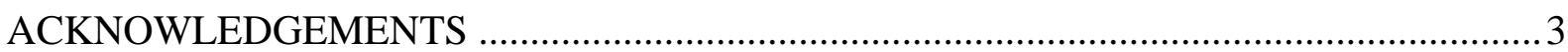

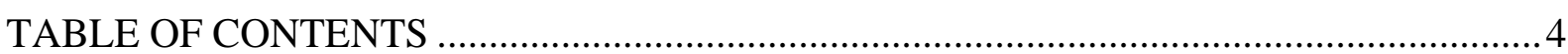

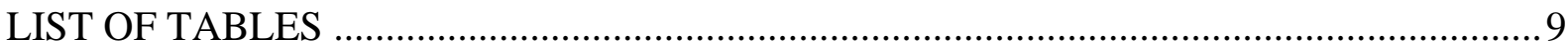

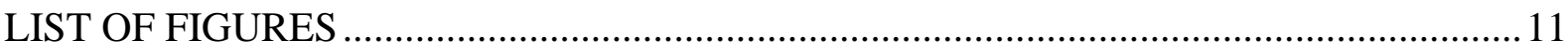

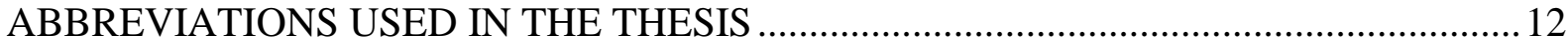

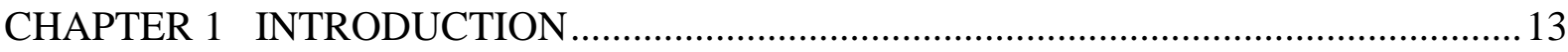

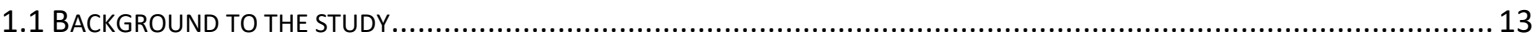

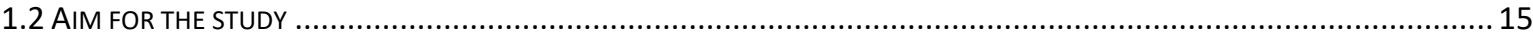

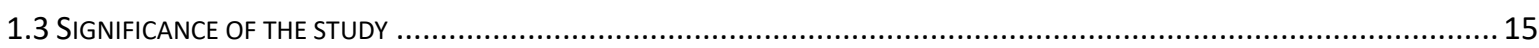

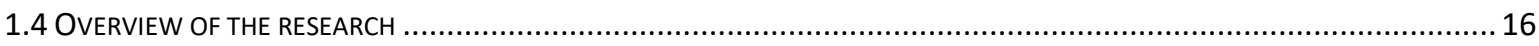

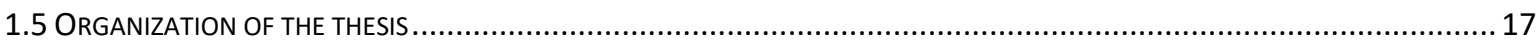

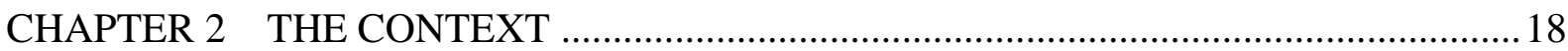

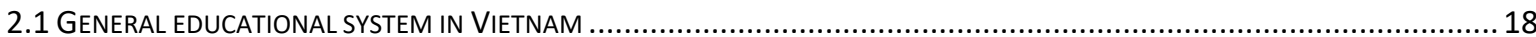

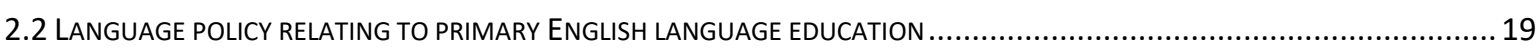

2.2.1 Primary English education policy before 2008 ...................................................................... 19

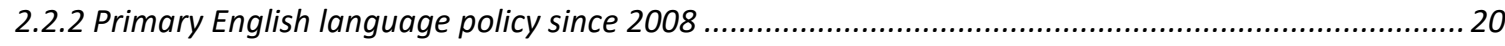

2.3 KEYS POINTS IN THE 2010 AND 2018 CURRICULA FOR PRIMARY ENGLISH LANGUAGE EDUCATION................................21

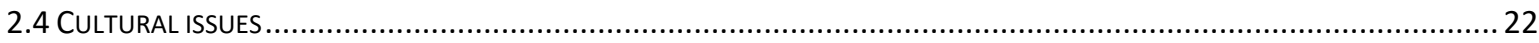

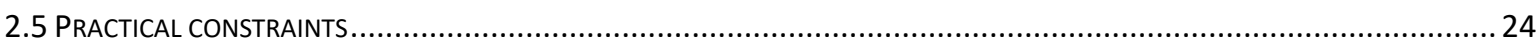

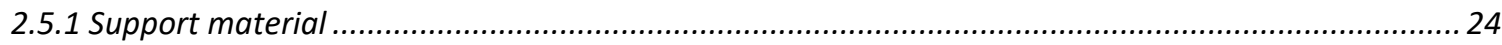

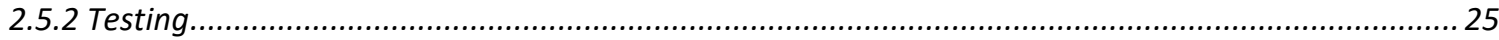

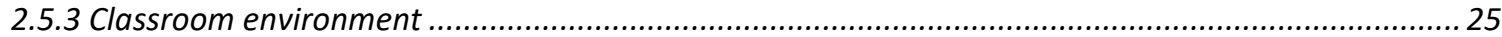

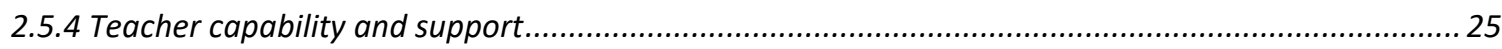

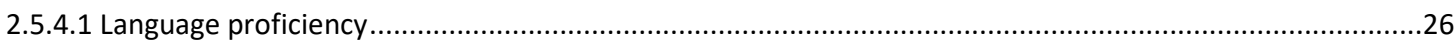

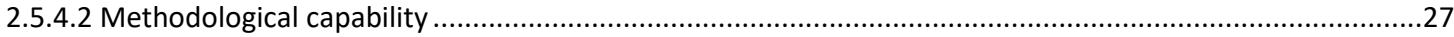

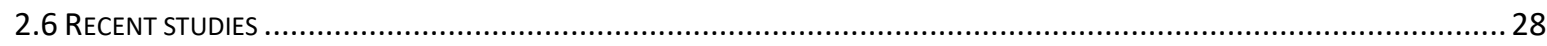

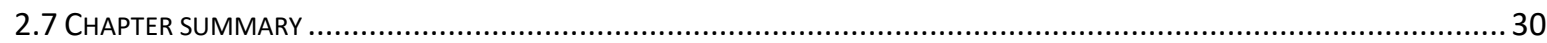

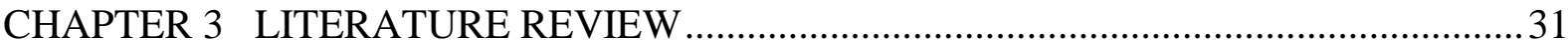

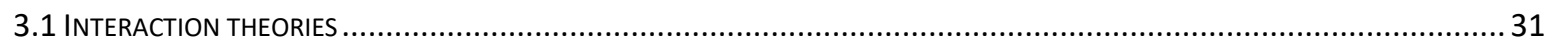

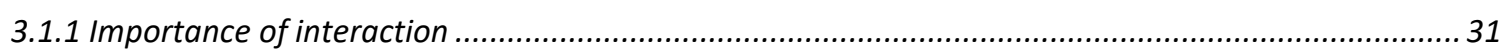

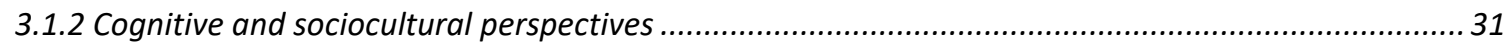

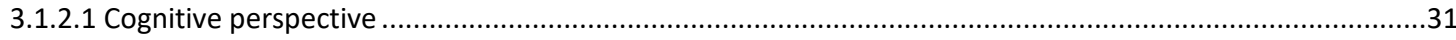


3.1.2.2 Sociocultural perspective

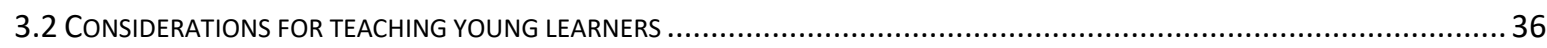

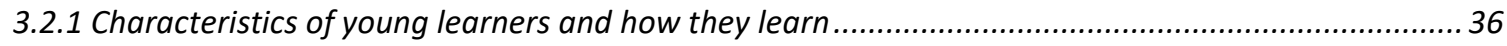

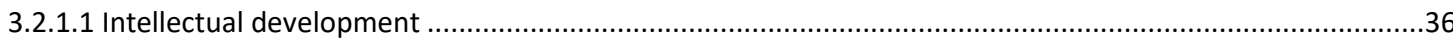

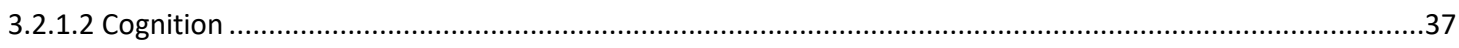

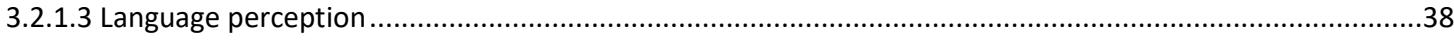

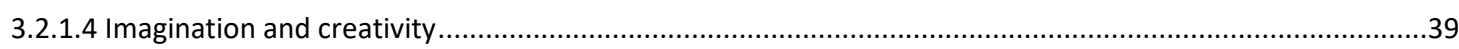

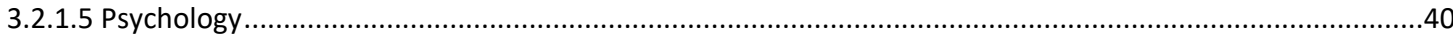

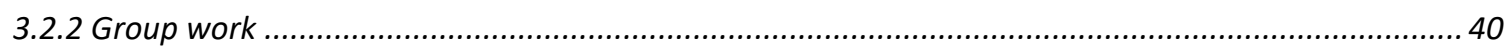

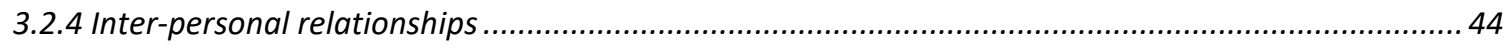

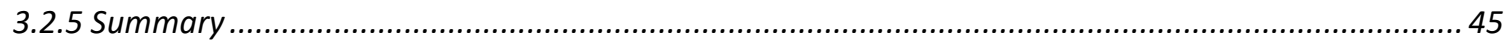

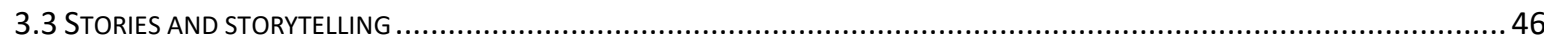

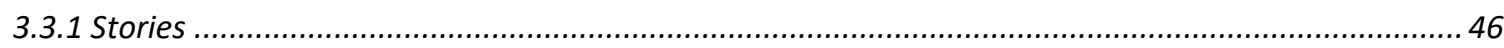

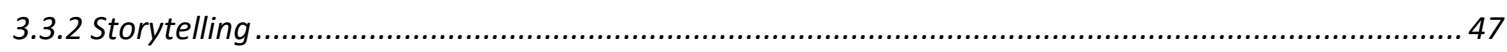

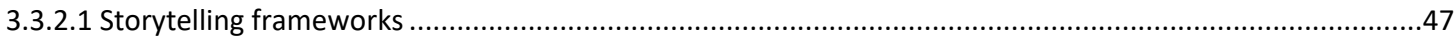

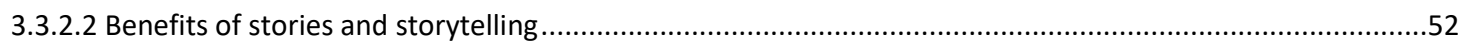

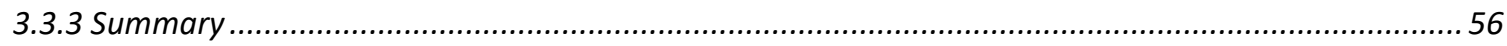

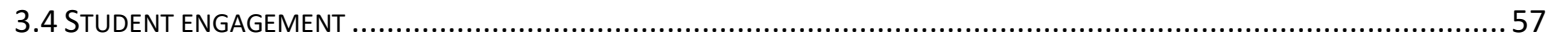

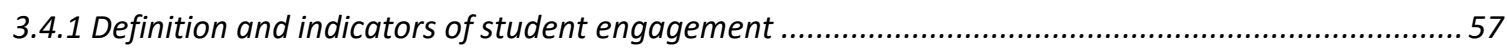

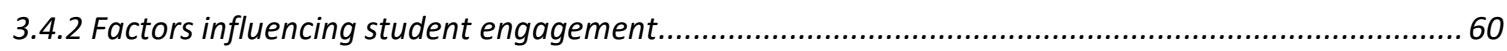

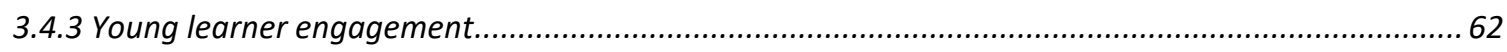

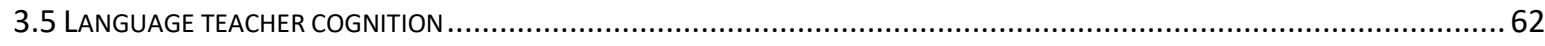

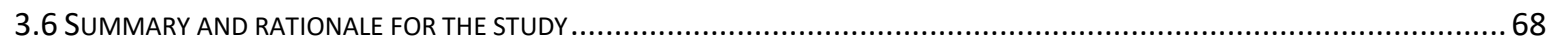

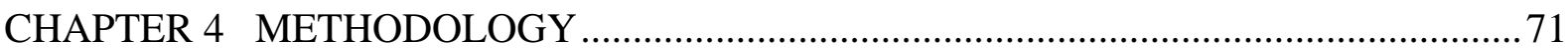

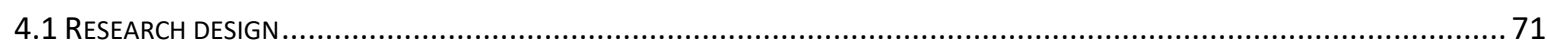

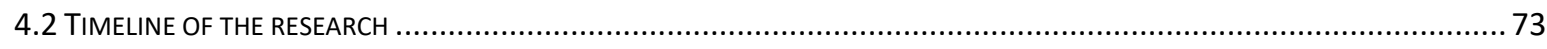

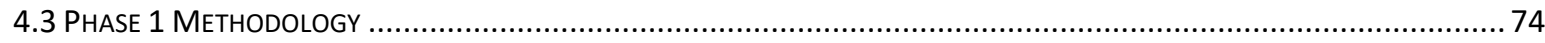

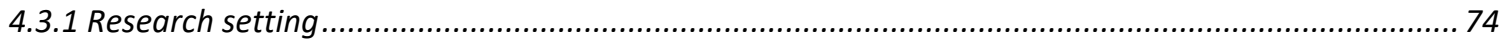

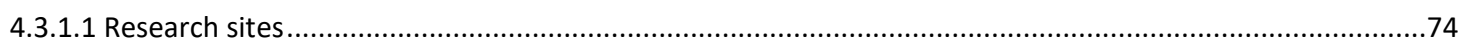

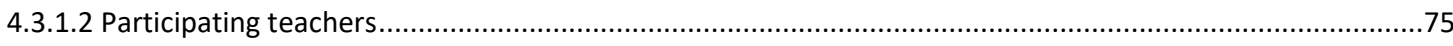

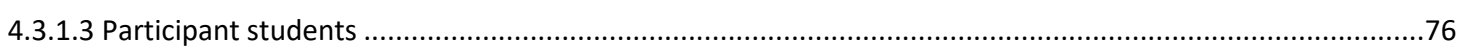

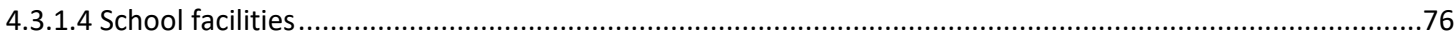

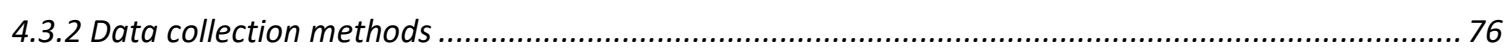

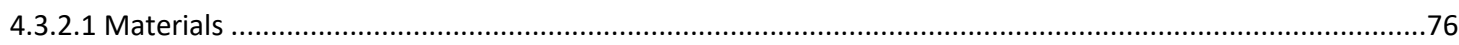

4.3.2.2 Classroom observation, audio-recording and field notes...................................................................77

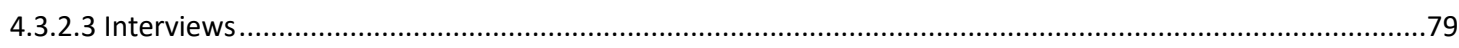

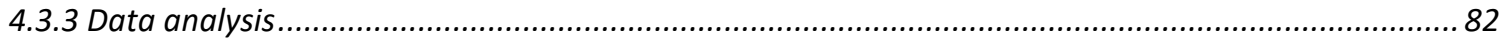

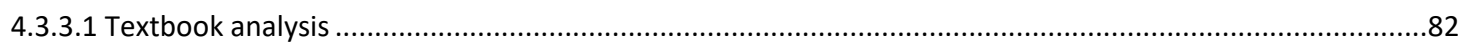

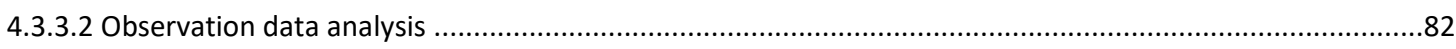

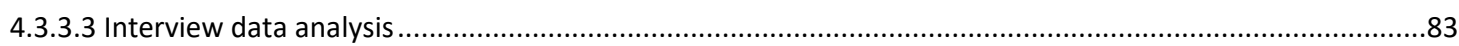




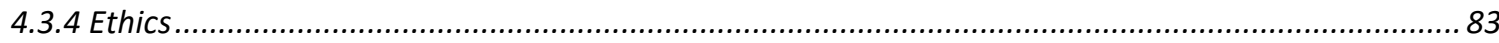

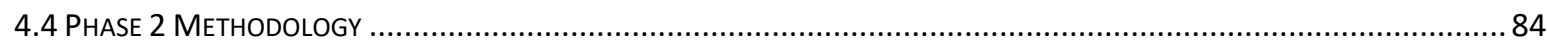

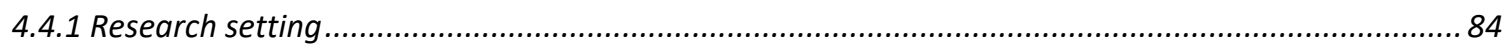

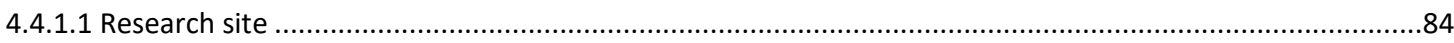

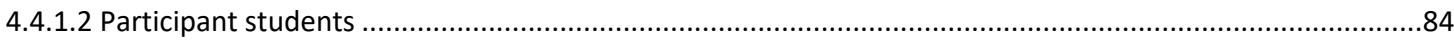

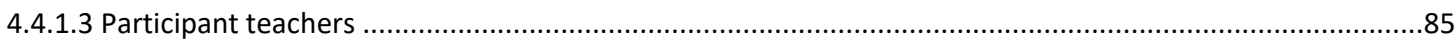

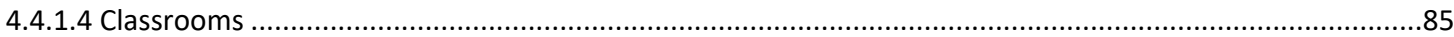

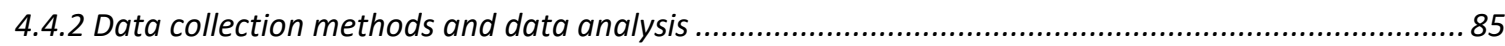

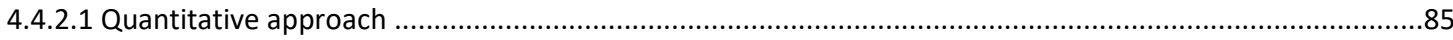

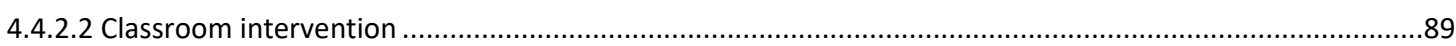

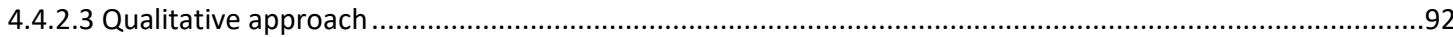

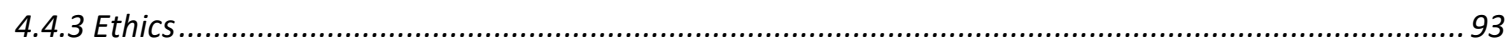

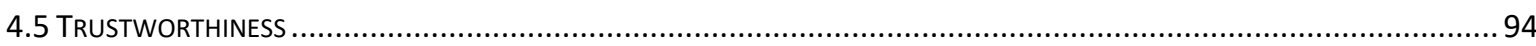

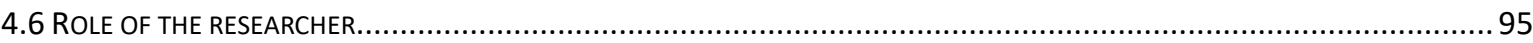

CHAPTER 5 FINDINGS FROM TEXTBOOK ANALYSIS ............................................ 98

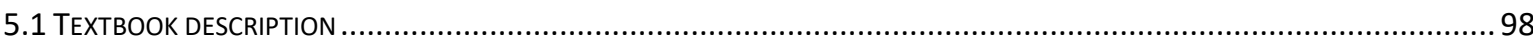

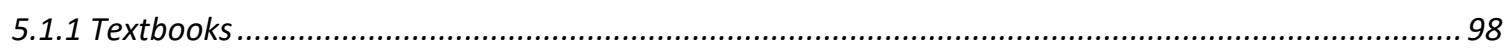

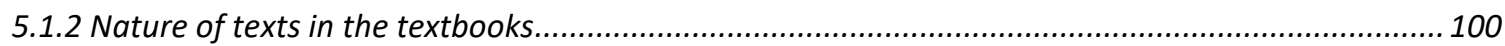

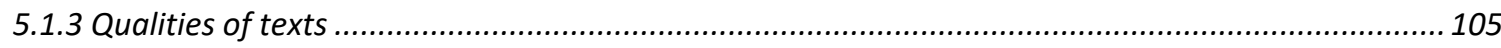

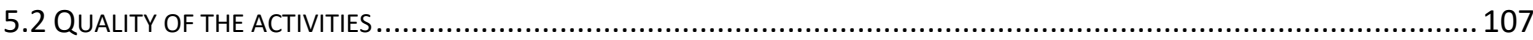

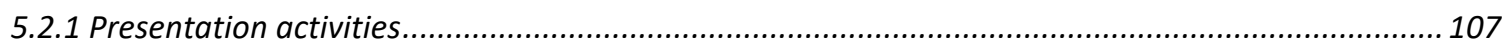

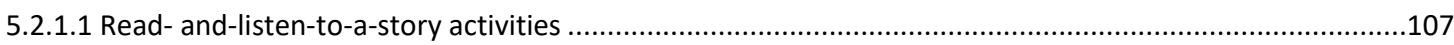

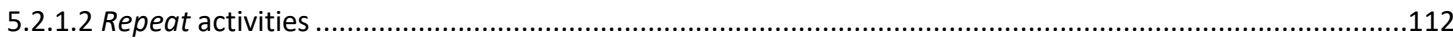

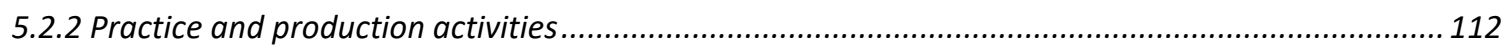

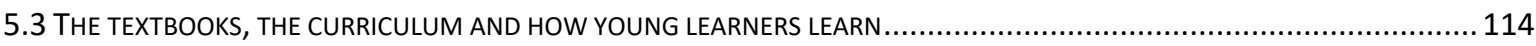

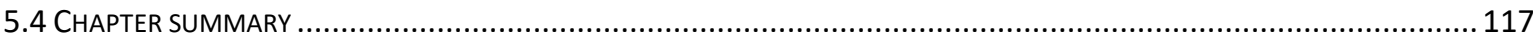

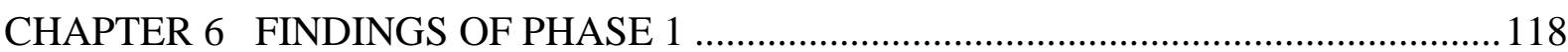

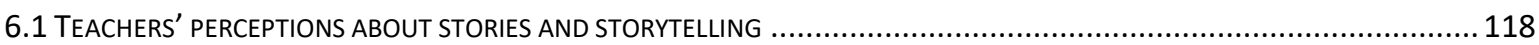

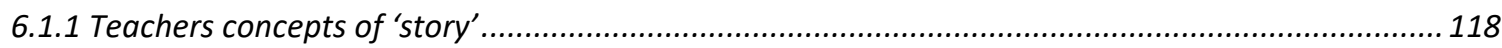

6.1.2 Teachers' opinions on the roles of stories in their lessons ....................................................... 120

6.1.3 The teacher's perceptions and experiences of storytelling ................................................. 121

6.2 LEARNERS' PRIOR LEARNING EXPERIENCE WITH STORIES AND STORYTELLING .................................................... 126

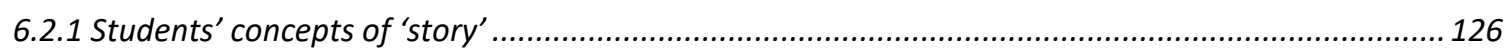

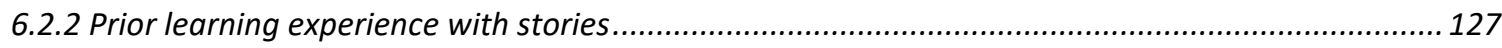

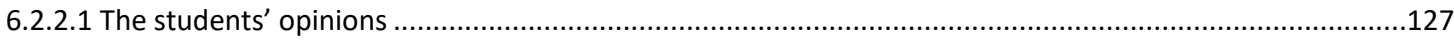

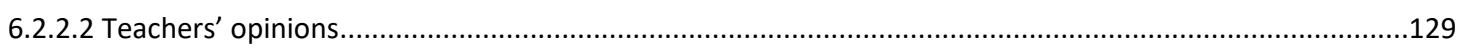

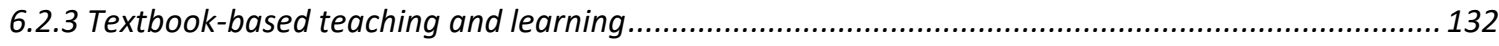

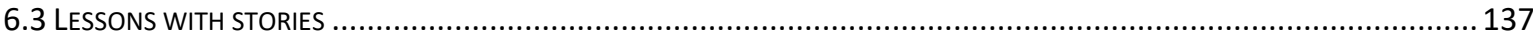


6.3.1 Detailed description of lesson activities ................................................................................ 137

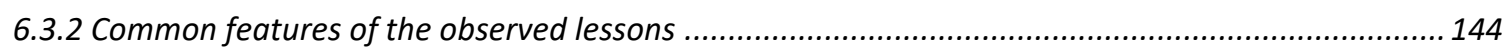

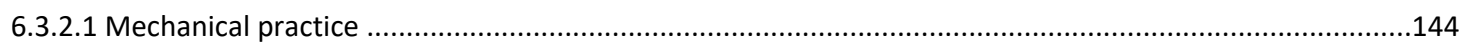

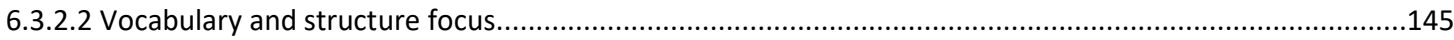

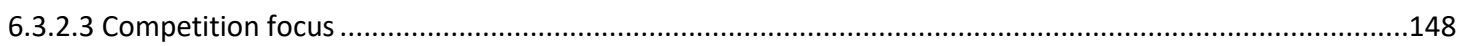

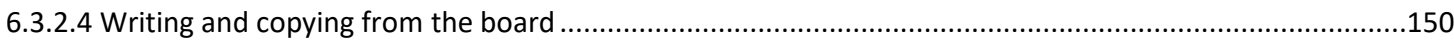

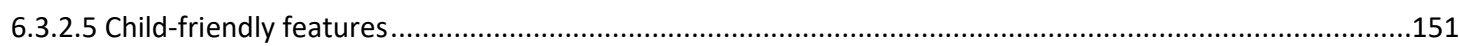

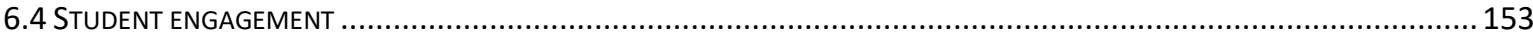

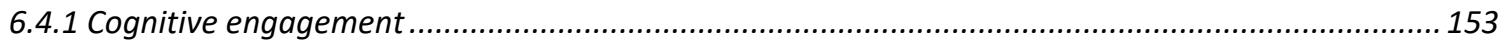

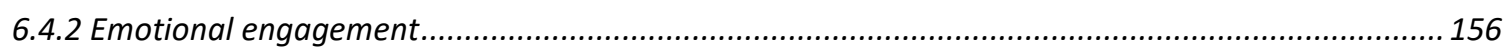

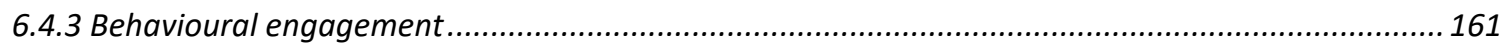

6.4.4 Teachers' opinions about students' engagement ................................................................. 161

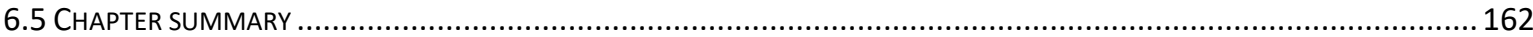

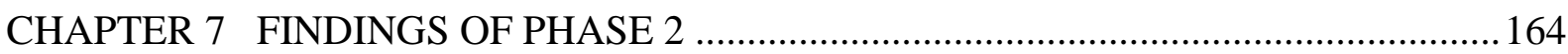

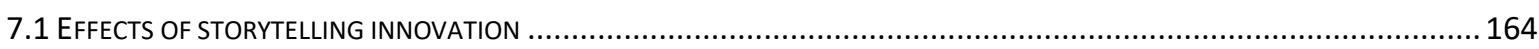

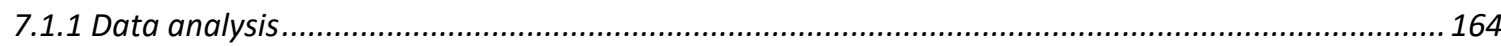

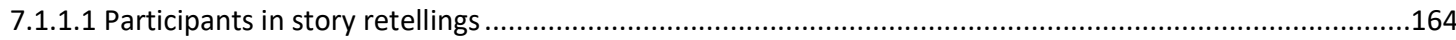

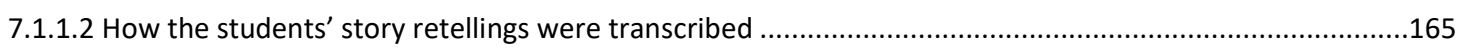

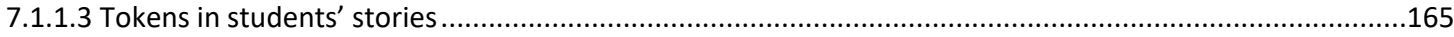

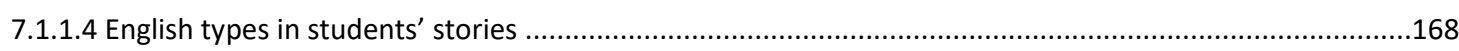

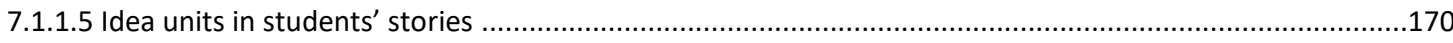

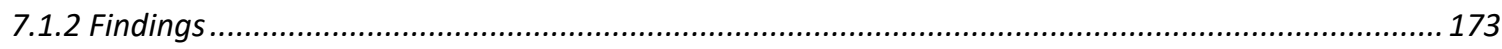

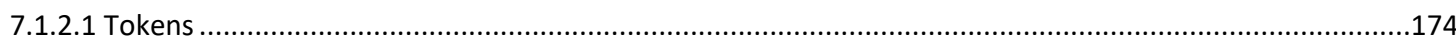

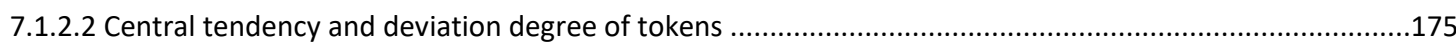

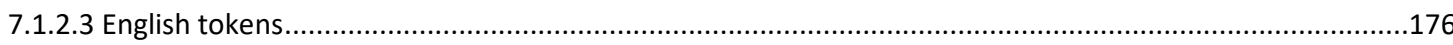

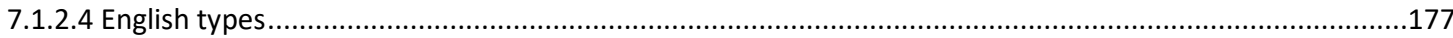

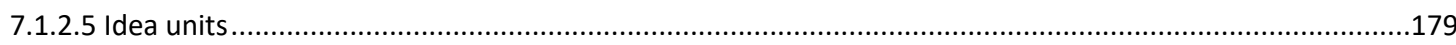

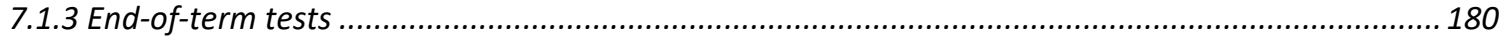

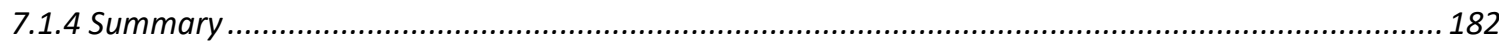

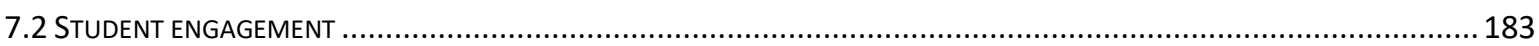

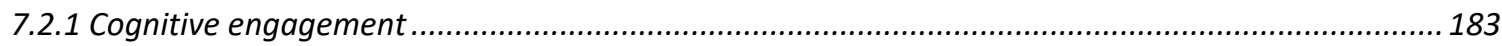

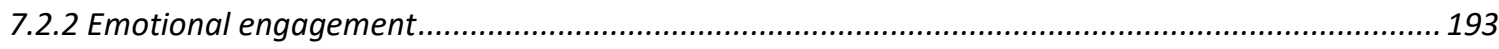

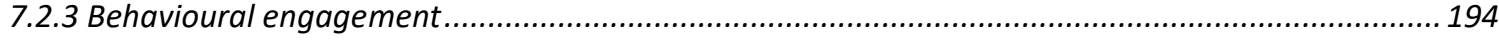

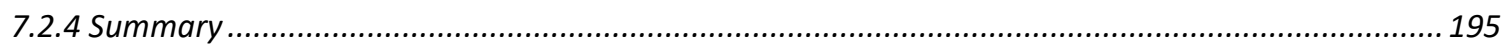

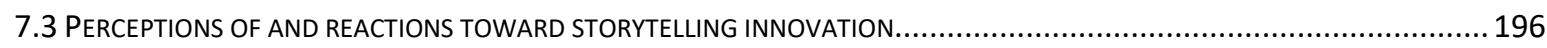

7.3.1 Teacher's perceptions and reactions toward the storytelling innovation .................................... 196

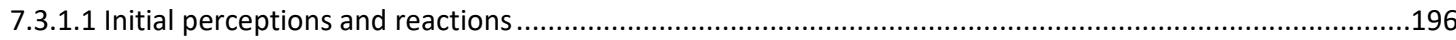

7.3.1.2 Perceptions and reactions to the whole storytelling innovation...........................................................199

7.3.2 Students' perceptions of and reactions toward the storytelling innovation ................................ 211

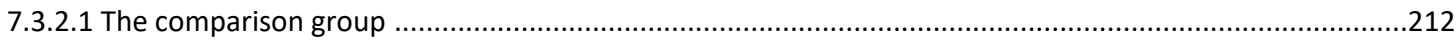




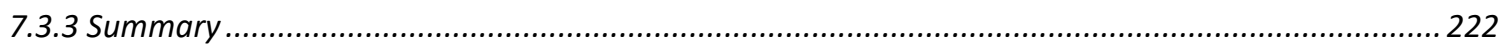

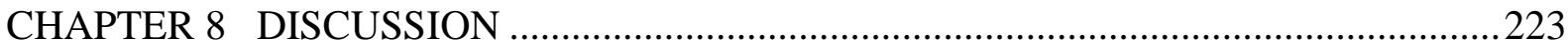

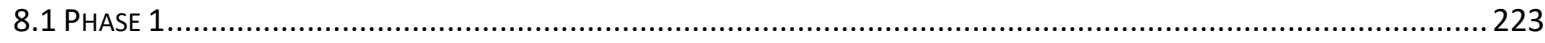

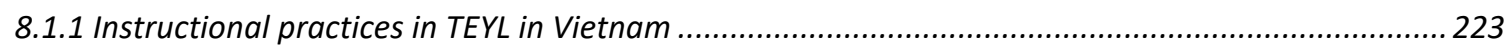

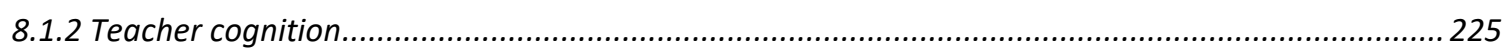

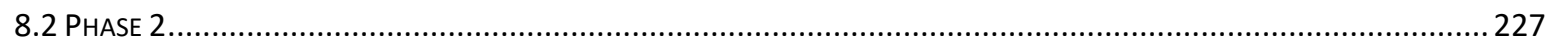

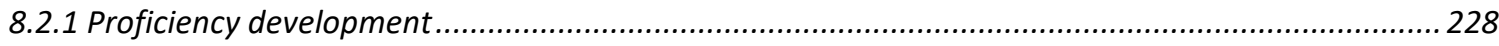

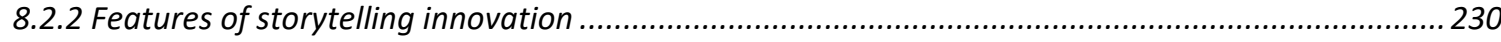

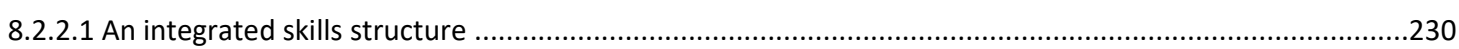

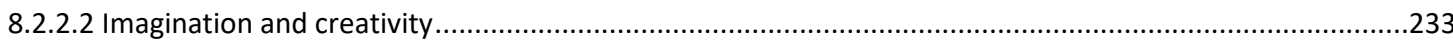

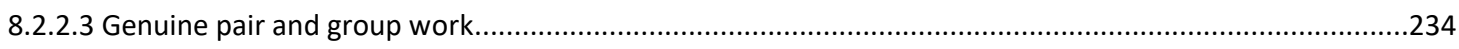

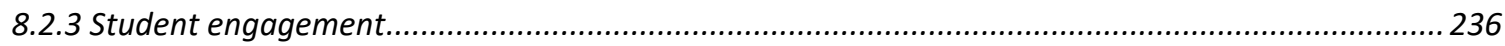

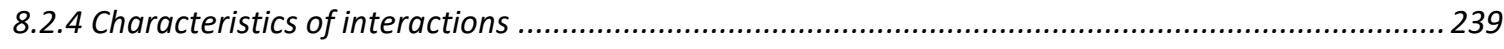

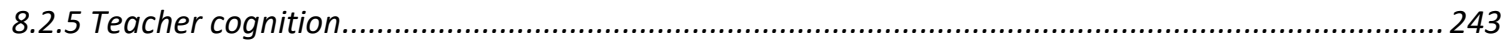

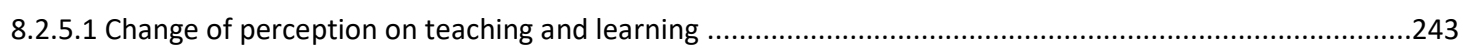

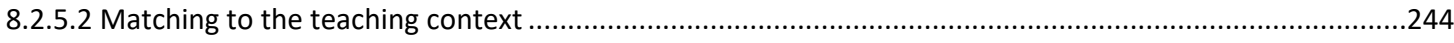

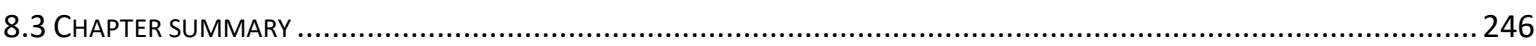

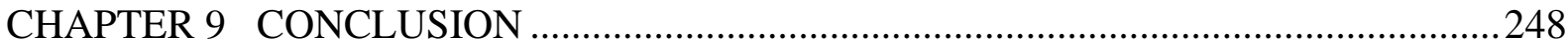

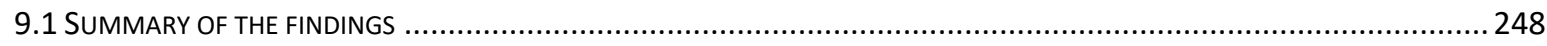

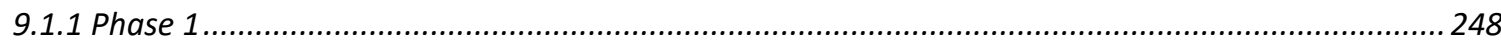

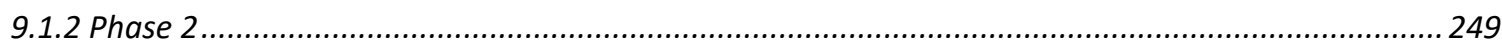

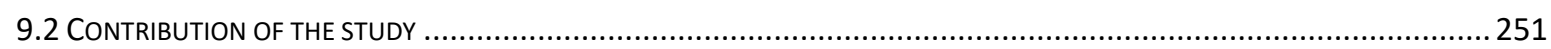

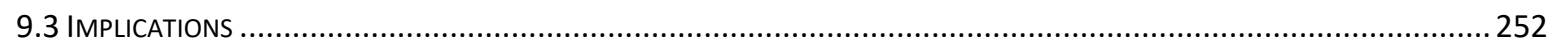

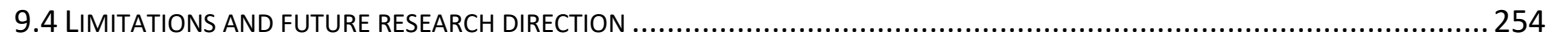

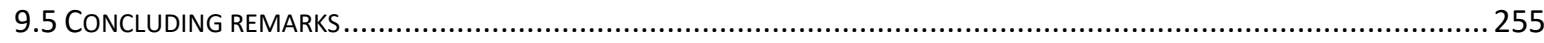

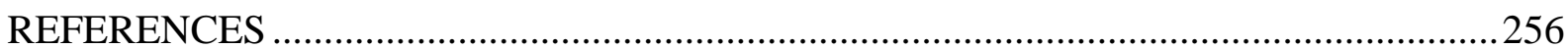

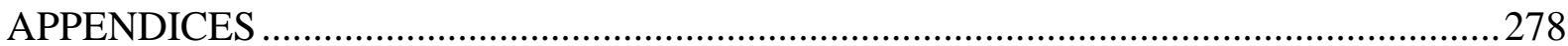




\section{LIST OF TABLES}

Table 3.1 Indicators of cognitive engagement.

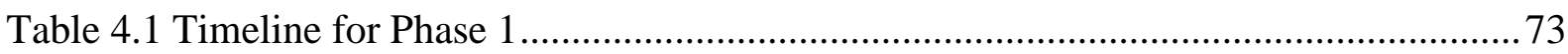

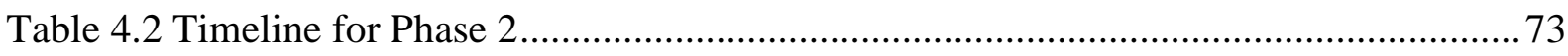

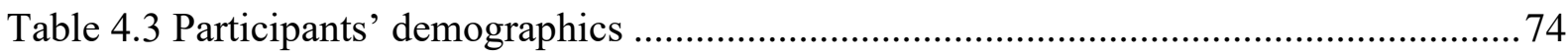

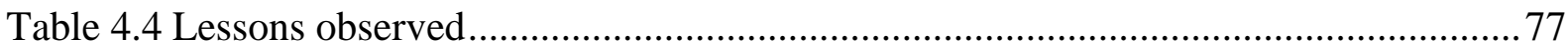

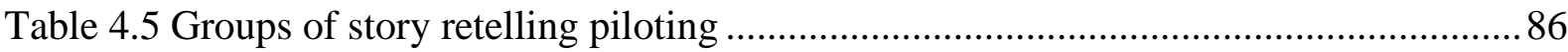

Table 4.6 Structure of a storytelling innovation lesson ........................................................90

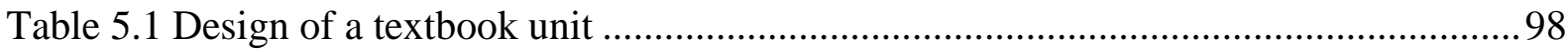

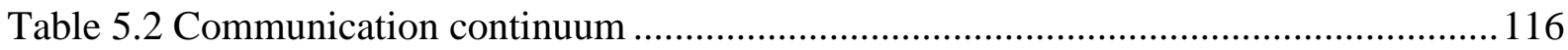

Table 6.1 Teachers' perceptions of stories in the current textbooks .................................. 118

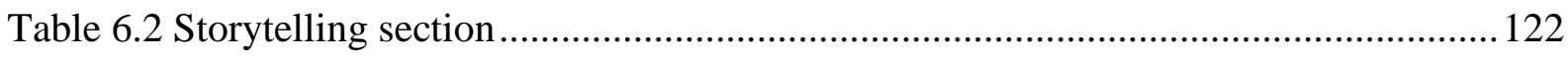

Table 6.3 Teaching and learning content allocation plan for Grade 5 ................................ 124

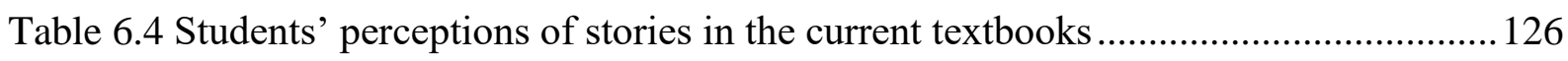

Table 6.5 Teachers' first cycle of activities.................................................................... 130

Table 6.6 Teachers' second cycle of activities ............................................................ 131

Table 6.7 A lesson with a human-dialogue story .......................................................... 139

Table 6.8 A lesson with an animal-dialogue story ....................................................... 142

Table 6.9 A part of a lesson with a narrative text............................................................. 143

Table 6.10 Indicators of cognitive engagement............................................................ 154

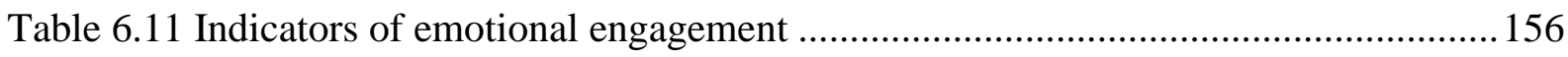


Table 7.1 Subgroups and numbers of students who joined story retellings 165

Table 7.2 Indicators of cognitive engagement in the intervention class 184

Table 7.3 Indicators of emotional engagement in the intervention class 193 


\section{LIST OF FIGURES}

Figure 3.1 The framework of a task-based storytelling lesson............................................50

Figure 3.2 Elements and processes in language teacher cognition: Borg's (2003) model .......64

Figure 3.3 Elements and processes in language teacher cognition: Macalister's (2010) model

Figure 5.1 A human-dialogue text in the Tieng Anh textbook .......................................... 100

Figure 5. 2 A human-dialogue text in the Family and Friends textbook ............................. 101

Figure 5.3 An animal-dialogue text in the Tieng Anh textbook ........................................ 102

Figure 5.4 A fable story in the Tieng Anh textbook ...................................................... 103

Figure 5.5 A fable story in the Family and Friends textbook ........................................... 103

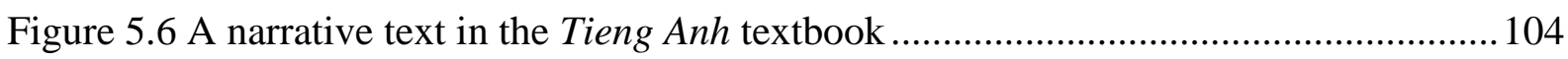

Figure 5.7 A narrative text in the Family and Friends textbook........................................ 104

Figure 5.8 A lesson in the Tieng Anh textbook ............................................................ 108

Figure 5.9 A lesson in the Family and Friends textbook ................................................. 109

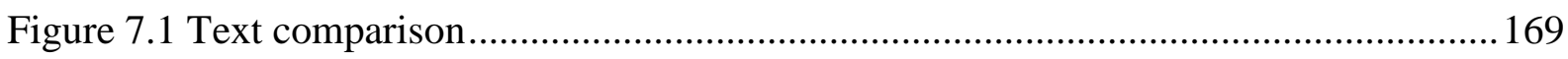

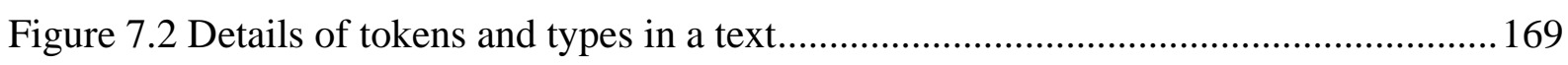

Figure 7.3 Medians of total tokens in each kind of stories ........................................... 174

Figure 7.4 Medians of total tokens in each kind of stories in each group ........................... 175

Figure 7.5 Medians of tokens in each story in pre-test and post-test ................................ 176

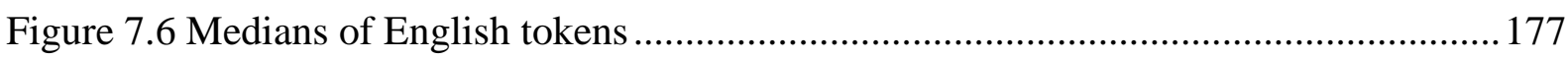

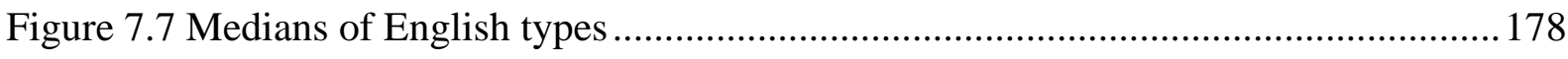

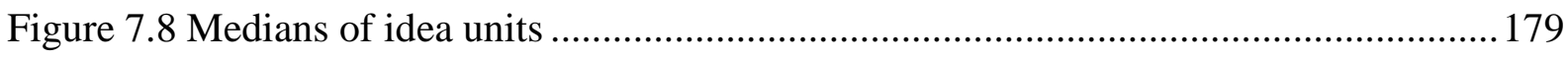

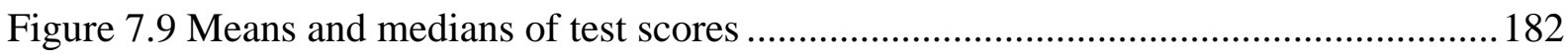




\section{ABBREVIATIONS USED IN THE THESIS}

BAK Beliefs, assumptions and knowledge

BOET Bureau of Education and Training

CLT Communicative Language Teaching

DOET Department of Education and Training

EFL English as a Foreign Language

$\mathrm{H} \& \mathrm{~T} \quad$ Hare and the Tortoise

IRF Initiate-Response-Feedback

IRE Initiate-Response-Evaluate

L1 First Language (Mother Tongue)

L2 Target (language second, third or foreign)

LRRH Little Red Riding Hood

MOET Ministry of Education and Training

PLC Professional learning communities

PELT Primary English language teachers

PPP Presentation-Practice-Production

TEYL Teaching English to Young Learners

T\&J Tom and Jerry

VSTEP Vietnamese Standardised Test of English Proficiency

ZPD Zone of Proximal Development 


\section{CHAPTER 1 INTRODUCTION}

\subsection{Background to the study}

\section{Personal experience of storytelling for young learners}

In 2008, the Ministry of Education and Training (MOET) launched the National Foreign Language 2020 Project to improve the foreign language learning and teaching system in Vietnam. One task of the project was to formally introduce English at Grade 3, which required significant re-training in both English proficiency and methodology for a large number of primary English language teachers (PELT). The reason behind the re-training was that PELT had trained to teach high school learners and their English proficiency did not meet the requirements set by MOET.

In 2011, I and some of my colleagues in the university where I was working were chosen to take part in a two-week training programme. In this workshop, we learned how to teach young learners, and we were expected to conduct the same workshops for PELT. The objectives were to help PELT improve their knowledge in teaching English for young learners (TEYL), especially to develop appropriate teaching methods for young learners. The workshops were conducted with the expectation that PELT would apply their newly learned methodology and skills in their teaching practices.

In 2012, a PELT workshop started at my university. The course had two phases and lasted about two months. The first was the English proficiency improvement phase. The second involved professional improvement to introduce methods and techniques in TEYL. One of my main roles was to train PELT to use stories and storytelling to improve young learners' speaking competence. I used three famous Vietnamese folktales to demonstrate the theory on stories and storytelling. The lessons were 'successful' because the PELT understood the theories and finished all the activities. The PELT seemed to enjoy the lessons and they commented that it was an effective method for teaching young learners.

At the end of the professional development workshop, the PELT had to take a teaching knowledge test that measured their knowledge and understanding of the key concepts. In addition, each teacher had to teach two lessons in their real classes, and they were evaluated on how well they applied what they had learned. I was one of the trainers who observed and evaluated these lessons. The PELT did use child-friendly techniques in their classrooms such as stirring-up and setting-down management, getting attention, games, chants and/or songs and the classroom atmosphere was exciting. However, no teachers used storytelling. At that 
time, they told me that they did not want to try anything 'completely new' in their only two evaluated lessons and said that they would find a way to apply stories and storytelling after the workshop.

Three years later, I met some of the PELT who took part in the workshop and asked whether they had applied the workshop learning. Their typical response to using stories and storytelling was: "What you trained us in was a good method, but I cannot apply it because I have not had any opportunities". The teachers' opinions reflected the common phenomenon that primary school teachers do not apply methodological innovations to TEYL in Vietnam (Le, 2020b; Pham, 2013). In addition, there was a general belief that PELT lacked willingness to make the necessary pedagogical changes and lacked ability to change.

I did not share this general belief and the teachers' answer made me feel uneasy. I could not help wondering about the barriers the teachers had experienced. I reflected on what I had done in the workshop, thinking back to my understanding of the primary school teaching context. I then searched the literature on similar workshops in other areas in Vietnam. I realized that the main cause behind the failure of the storytelling application was linked to me, as a trainer. I neither had a clear understanding of current teaching and learning contexts in primary schools nor practical knowledge of TEYL. For example, teachers are not free to use any materials outside the textbooks but, in the workshop, the stories in the demonstration lessons were chosen from outside the textbook. Furthermore, the normal classrooms were crowded with unmovable chairs and desks, while, in the workshop, I asked the PELT to create activities that required rearranging the classroom.

The lack of practical application was found in most similar workshops in Vietnam (Huong \& Yeo, 2016; Le, 2020b; Pham, 2013). My reading of literature told me that I had transmitted theories to PELT rather than discussing their teaching issues and how to deal with the issues so that they could improve their teaching (Nguyen, 2017; Vu \& Pham, 2014). I realized that I had been eager to share with the teachers what I had learned without studying the PELT's teaching environment. What I did was not consistent with the idea that "teacher education should focus less on introducing teachers to general approaches to English language teaching and more on supporting teachers to meet the challenges that they have identified" (Copland, Garton, \& Burns, 2014, p. 738).

Due these practical issues not being taken into consideration, what I did in the workshop made PELT think that storytelling lessons were used to add enjoyment to the main lessons. As a result, PELT did not adopt storytelling as an effective instructional approach. PELT's 
lessons still mainly focus on language forms in mechanical practice (Bui, 2019; Grassick, 2016; Vi, 2018), which hinders the development of students' communicative competence. This cannot help to fulfil the main goal in the new curriculum (see Section 2.3).

From literature on interaction theories, storytelling, and young learners' characteristics, I found an effective way for storytelling application in EFL contexts full of challenges and where teachers do not have freedom in their teaching. I call it storytelling innovation. Motivated by an interest in primary education with a strong belief that young learners deserve to learn in a way that fits their characteristics, and driven by a desire to be the best teacher trainer I can be, and a strong belief in PELT's ability to change (if they experience appropriate training with practical application), I decided to embark on my research journey, which would help me put the potential approach into practice.

\subsection{Aim for the study}

Taking account of the impetus for the study outlined in the previous section, the current study aims to introduce a model of change, the storytelling innovation, for TEYL in state primary schools in Vietnam. Specifically, the study first investigates the current implementation of textbook lessons with stories and storytelling. This thesis then investigates the effects of the storytelling innovation lessons on oral performance, student engagement and teachers' and students' perceptions of stories and storytelling. This study aims to meet the requirement of the Vietnamese curriculum to make communicative outcomes a key goal for primary English education. Broadly, this responds to a recent call for more classroom-based studies to change current mechanical teaching practices to an approach that is appropriate for young learners' characteristics and language learning (Copland \& Garton, 2014; Jin \& Cortazzi, 2018; Le, 2019; Nikolov \& Djigunovic, 2019).

\subsection{Significance of the study}

The significance of this study lies in the enhanced understanding it can provide about different aspects of teaching young learners. First, it will give a picture of the current state of using stories and storytelling in primary schools in the Vietnamese EFL context. This research contributes to recent national goals to develop primary school students' communicative competence and motivation to communicate in English. Second, this will contribute to the field of using stories and storytelling in TEYL in EFL contexts. Scholars and researchers in the field of TEYL have shown an increased interest in using storytelling to offer young learners' enjoyment, cooperation and creativity in their learning. Third, this research will compare how students engage in learning activities in two different learning conditions. 
Therefore, it will add to the understanding of student engagement. Few studies have explored teachers' perceptions and practices with reference to storytelling in order to gain an insightful account of their mental lives and teaching practices in primary school contexts. It will add to the literature on teacher cognition in the Vietnamese context. This study will contribute to transforming a traditional classroom approach into communicative, meaningful and innovative EFL teaching practices.

\subsection{Overview of the research}

My study had two main phases. In Phase 1, a qualitative study was conducted to better understand the use of stories in teaching and learning in Vietnamese primary schools. Phase 2 consisted of collecting both quantitative and qualitative data in order to explore the effectiveness of the storytelling innovation. The employment of a quantitative method was to discover whether the storytelling innovation can improve learners' oral communication performance. The implementation of the qualitative method during and after the intervention aims for a better understanding of classroom engagement and of the intervention results by incorporating and integrating teachers' and students' perspectives, behaviours and reactions. The current research plans to answer the following research questions:

1. What is the current state of using stories and storytelling in teaching EFL in primary schools in Vietnam?

1.1. What are the primary school EFL teachers' perceptions about stories and storytelling?

1.2. What is the primary school Vietnamese EFL learners' prior learning experience with stories and storytelling?

1.3. How do the primary school EFL teachers implement storytelling in their classroom practice?

1.4. What indicators are there of primary school EFL learners' engagement and participation with storytelling?

2. What is the effectiveness of the storytelling innovation on teaching and learning EFL young learners' oral communicative competence?

2.1. To what extent does the storytelling innovation improve primary school students' oral communicative competence?

2.2. What indicators are there of primary EFL students' engagement and participation? 
2.3. What are the teachers' and students' perceptions of and reactions toward the storytelling innovation?

\subsection{Organization of the thesis}

The thesis has nine chapters. Chapter 2 describes the context of English language education in Vietnam. It provides readers with an overview of the 2008-2020 and 2017-2025 National Foreign Language Project, the new primary English language curricula (issued in 2010 and 2018) and a brief account of current primary English language teaching and learning conditions. Chapter 3 examines the relevant literature in five main sections. The first reviews perspectives on interaction in language learning. The second looks at factors affecting classroom interactions. It also analyses young learners' characteristics and effective ways to teach young learners. The third section concerns stories and storytelling. The fourth reviews student engagement theory, as a way to identify whether learning is happening. The fifth section concerns teacher cognition, which enables understanding of teachers' decisions in the classrooms. This chapter also highlights gaps in the literature in the fields of TEYL, stories and storytelling, student engagement and teacher cognition. Chapter 4 introduces the research design and the methodology of the study. It also describes the data gathering methods and procedures for collecting and analysing the data in each phase. Ethical issues and trustworthiness are addressed in this chapter. Chapter 5 reports the results of the textbook analysis to understand the rationale behind the teachers' textbook dependent teaching. Chapter 6 presents the results of Phase 1 of the study to answer the research questions about the current state of using stories and storytelling in teaching and learning English in state primary schools in four areas: teachers' and students' perceptions, students' prior learning experience, teachers' implementation of storytelling in their classroom practice, and learners' engagement and participation. Chapter 7 presents the results of Phase 2 of the study to answer the research questions about the effects of the storytelling innovation in three areas of the students' oral communication performance, engagement and participation, and teachers' and students' perceptions of and reactions toward the storytelling innovation. Chapter 8 discusses the findings of the two phases. It highlights the main features of the storytelling lessons, student engagement and features of interactions. Chapter 9 summarizes the main findings of the thesis and discusses the main implications of the findings. It identifies limitations of the study as well as proposing potential areas for future research. 


\section{CHAPTER 2 THE CONTEXT}

This chapter describes the context of the current study. Section 2.1 begins with general information about education in Vietnam. Section 2.2 concerns language policy relating to Vietnamese primary English language education. Section 2.3 identifies the main points in the two new curricula for primary English education. Cultural issues are discussed in Section 2.4. Section 2.5 focuses on the discussion of four main practical constraints in the implementation of the curriculum and efforts to deal with the constraints. Section 2.6 analyses two recent local studies. The information presented in this chapter will indicate the significance of the current study.

\subsection{General educational system in Vietnam}

Education in Vietnam has three levels: (1) primary, from Grade 1 to 5 (6-11 years); (2) lower secondary, from Grade 6 to 9 (12-15 years); and (3) upper secondary, from Grade 10 to 12 (16-18 years).

The educational system in Vietnam is a highly centralized one and has been described as "topdown inflexible management” (Le, 2015, p. 183). Management has three layers: Ministry of Education and Training (MOET), Department of Education and Training (DOET) and Bureau of Education and Training Division (BOET).

MOET has direct responsibility for macro-educational policy. MOET designs educational strategies, and long-term and annual master plans for training and developing human resources in education. It also sets up curriculum goals, designing a curriculum for each subject for all school levels, and guidelines for curriculum implementation. MOET controls assessment and testing at the national level and the setting up of criteria of teacher and educational administrator qualifications. It regulates decisions on the official textbooks used by schools in general education throughout the country. MOET decides a list of books and schools decide the textbooks they want to use. Although there is freedom for schools to choose textbooks, schools still prefer to choose textbooks designed by MOET.

DOET in each province conducts meso-level administrative duties. It determines the policies in its province in line with MOET's educational goals, curriculum guidelines and content for education and training. DOET is responsible for managing in-service teacher training programmes, the criteria for teacher and educational administrator qualifications, school facilities, teaching aids, assessment regulations, certificates and qualification of education and 
training. DOET has direct responsibility for upper secondary education in a province and provides technical and professional support to the provincial People's Committee.

BOET determines the educational policies in a district or town. BOET's goals and plans align with those at the national and provincial levels. BOET is responsible for teaching and learning at pre-school, primary and lower secondary levels (I needed permission from BOET before collecting my data). English education in primary schools is managed at the district level. An English language specialist working in a BOET is in charge of teaching and learning English in primary schools. The role of the English language specialist is to ensure the quality of English education in the district through supervising, observing, and advising on English language teaching at pre-school, primary and junior secondary levels. DOET also has an English language specialist in charge of teaching and learning English in senior secondary schools at the provincial level. This specialist often plans and organizes workshops and conferences on primary English education. In Asian culture, principles of honour and respect (Nguyen, Terlouw, \& Pilot, 2006) mean that teachers are expected to obey authorities such as BOET and DOET English language specialists. Therefore, their voices are considered as guiding instructions (Phan, 2017). Most BOET and DOET English language specialists are trained to teach at secondary level and have little experience of TEYL (Grassick, 2016; Phan, 2017).

\subsection{Language policy relating to primary English language education}

Many Asian governments have introduced English at the primary level expecting that an early introduction of English will better develop learners' English ability (Jin \& Cortazzi, 2018). New curricula have been introduced and communicative approaches adopted to replace memorizing vocabulary and grammar with meaningful interactions. Similarly, over the last two decades, primary English education in Vietnam has been significantly reformed.

\subsubsection{Primary English education policy before 2008}

Since the 1990s, English was taught in language centres and primary schools in some big cities in Vietnam (Nguyen \& Nguyen, 2007). In 1996, MOET issued a guideline on foreign language teaching in primary school. MOET then promulgated a curriculum for primary English education and stipulated English as an optional subject at primary level. Although these policies brought about a revolutionary change in teaching English and have been widely accepted and supported, primary English education has not been effective. Some of the problems related to unclear goals in the curriculum, poor teaching methods, lack of teaching 
materials, and lack of teachers who were qualified in language proficiency and teaching skills (Moon, 2009; Nguyen \& Nguyen, 2007). Research (Hayes, 2008; Loc, 2007; Moon, 2009) suggested extensive re-training for primary English teachers and rewriting the curriculum and the textbooks.

\subsubsection{Primary English language policy since 2008}

To improve foreign language education, including English education, in the national education system, in 2008 the Vietnamese government issued Decision No.1400/ QĐ-TTg as part of the National Foreign Languages Project 2008-2020 (Project 2020). The project highlights the need to renovate all foreign language teaching and learning in Vietnam. The general goals were to (1) increase the students' foreign language ability, giving them better preparation to live, work and study in a globalized world; (2) to enable young Vietnamese to communicate confidently in foreign languages in an integrated and multicultural environment; and (3) to fulfil the country's needs for industrialization and modernization.

To achieve these goals, MOET introduced some changes in teaching and learning. For primary English language education, these were: (1) making English in primary schools a compulsory rather than elective subject; (2) doubling the learning time in the classroom (MOET set a target that $70 \%$ of Grade 3 students nation-wide would receive four English classes per week by 2016); and (3) introducing a new curriculum. Key points of the new curriculum will be introduced in Section 2.3.

After nine years of implementation, Project 2020 has not achieved the desired outcomes. MOET reported to the National Assembly that the project failed to fulfil the targets within the planned 2008-2020 period (Le, 2020a). One failure was that in 2016 only around $20 \%$ of elementary school students were receiving the desired number of instruction hours (Phuong, 2016). Therefore, the expected achievement of doubling English teaching hours was not reached. The biggest failure was that the outcomes of improving English language teaching quality and enhancing students' English language proficiency levels were not achieved.

A modified plan for studying and teaching foreign language nationwide during 2017-2025 was approved (Vietnamese Prime Minister, 2017). The aim of the modified plan is to prolong the implementation of the national foreign language project to 2025 with adjustments to some targets. For example, by 2025, 100\% of students nationwide from Grade 3 will receive four English classes per week. 


\subsection{Keys points in the 2010 and 2018 curricula for primary English language education}

In 2018, MOET issued an updated primary English language curriculum together with the new national general education curriculum (MOET, 2018a), updating the 2010 curriculum (MOET, 2010a). English is stated as one of the core subjects. The goal of the two curricula is to improve young learners' communicative competencies.

Teaching and learning English at primary level aims to equip students with a new communicative tool, an initial ability to communicate with confidence, creating the foundation for them to use English in their learning, establishing a habit for their lifelong learning toward becoming global citizens in the integration era.

(MOET, 2010a, p. 5) (my translation)

In the curricula, the performance objectives for each grade are described in can-do statements that detail what learners are expected to do for listening, speaking, reading and writing, with a particular focus on listening and speaking. This reflects the social-cultural theoretical perspective that language use and acquisition co-occur in teaching and learning from an early age.

The 2018 curriculum describes the learners and teachers' roles, requiring teachers to change their role from being a knowledge transmitter to becoming a facilitator of learning activities (MOET, 2018). Teachers are required to create interactive and meaningful contexts for language use:

Teaching practices should be organized through a diverse and rich communication environment using interactive activities (games, chants, songs, plays, storytelling, puzzles, painting, etc.) in the form of individual, pair- and group-work.

(MOET, 2010a, p. 5) (my translation)

The curricula also require students to become less dependent on teachers, and to be active and creative in learning. Teaching should aim to create maximum opportunities for students to use English in the classroom.

The curricula also promulgate new assessment criteria. The expected learning outcome is that Grade 5 primary school students will reach Level 1 of Vietnam's 6 levels in English language ability framework: 
Can understand and use everyday expressions and very basic phrases in concrete communicative situations. Can introduce himself/herself and others; can answer questions about places of living, relatives, friends, ... Can interact in a simple way provided the speaker talks slowly, clearly and is ready to help.

(MOET, 2018, p. 8) (my translation)

The extracts above indicate that learning should be assessed in terms of learners' abilities to communicate in English. This reflects the government's emphasis on promoting young learners' communicative competence across a range of contexts.

In brief, the curricula expect teachers to employ communicative language teaching methods, to improve the active role of learners in learning and to enhance their communicative competencies. Teachers are expected to change from a teacher-centred to a learner-centred approach. Change has not been easy, which is common in ELT. Schweisfurth (2011) considered 72 studies of educational change in developing countries and identified many barriers to change from teacher- to learner-centred education. These barriers included teacher-learner power relations, teacher-authority relations, teacher training quality, examination-focused teaching, teaching materials, physical environment and the need for inclusion of all learners.

The slow progress in achieving the objectives of Project 2020 stems from the fact that Vietnam has experienced similar barriers together with cultural and practical challenges specific to Vietnam, which are discussed below.

\subsection{Cultural issues}

Culture is identified as important in the failure to change from teacher-to learner-centred education (Schweisfurth, 2011). Education in Vietnam, like many East Asia countries, is based on Confucian principles of honour and respect, collectivism and face protection (Nguyen, Terlouw, \& Pilot, 2006). These principles influence relationships and group activities in the classroom.

There are strongly hierarchical relationships between Vietnamese teachers and students. Teachers are highly respected and considered holders of all knowledge and the only transmitter of knowledge in the classroom (Le, 2007). Students are portrayed as passive learners. They should be submissive and respectful to teachers. Knowledge passes along a one-way-street from the teacher to students. It creates a style of learning that requires memorizing knowledge provided by the teacher which students must then reproduce 
accurately. The concept of peer learning is not popular. This helps to explain why mechanical practice in English classrooms is still popular in Vietnam.

Group work in Asian countries is more collectivistic than individualistic (Nguyen, 2019; Nguyen et al, 2006). This dimension (individualism versus collectivism) refers to the degree to which individuals are integrated into groups. In individualist classrooms, the priority is on achievement and the rights of individuals in participation for the group outcomes. Open-ended group activities play a very important role in the learning process. Learners are encouraged to be open to new ideas and, willing to take risks. In collectivist classrooms, group harmony is pre-eminent. In activities, group harmony is built through structured tasks like repeating dialogues, and answering closed questions initiated by the teacher. Vietnam is highly collectivist (Nguyen, Terlouw, \& Pilot, 2006) and learners feel comfortable with structured learning.

Face protection is an important concern in Asian society (Nguyen, 2019; Peng, 2014). Face concern may particularly influence students' communication behaviours in class. Face, understood as public image, is key to the promotion of group harmony (Nguyen 2019). Asian students are not familiar with learning from mistakes. They are afraid of making mistakes, which are viewed as bad and not tolerated. This means that students are not often expected to express their own meaning individually or give ideas beyond the textbook dialogues. This way of learning helps students avoid making mistakes and saves students from losing face. Group harmony and keeping face are additional reasons why a teacher-fronted approach with mechanical practice still prevails.

Communicative Language Teaching (CLT) requires a change from traditional education values and pedagogy toward a new understanding of teaching and learning. CLT views language as a means of communication, and interaction is the means and goal of study. CLT is a learner-centred approach in which knowledge is not transmitted; rather learners create their own meaning and knowledge from information received from teachers and their own lived experiences (Nunan, 1999; Tudor, 1993) and by using language to communicate interactively in life-like situations.

CLT requires different teacher-student relationships which give students more control and responsibility in their learning. The teacher's role is to facilitate language learning rather than to transmit knowledge. Knowledge can begin with the students themselves and within the group, and teachers' knowledge can be brought into question. Group work in CLT prioritizes individual participation and contribution rather than group harmony. Students are encouraged 
to work cooperatively for group outcomes. Students join in creative and meaningful language practice using language to express their own meaning and support their peers. Some mistakes "are signs of developing competence" (Nation \& Newton, 2009, p. 142).

The new curriculum requires a change of knowledge and pedagogy, and a change in the outlook and educational culture of the community. In Vietnam, CLT is considered a Western import and implies a different culture of teaching and learning. Asian values, such as hierarchical relationships, respect for authority, group harmony and face protection, are viewed as “in direct conflict with imported 'Western' values inherent in learner-centred pedagogy" (Grassick, 2016, p. 30). The new teacher-student relationship and the new concept of group work activities could lead to tensions and contradictions within existing Vietnamese society. Cultural conflicts could thus be a hindrance to the process of change from mechanical teaching and learning to communicative language teaching.

\subsection{Practical constraints}

Research (Copland et al., 2014; Jin \& Cortazzi, 2018; Schweisfurth, 2011) shows that teachers experience many practical constraints. In this section, I present four practical constraints together with support provided by MOET and DOET to lessen the constraints in implementing the new curricula.

\subsubsection{Support material}

Textbooks are teaching language resources that provide support for teachers (Ferlazzo \& Sypnieski, 2018). To deliver the new curriculum, textbooks were developed and piloted according to the MOET (2010b) guidelines and some new commercial textbooks were chosen to replace the old textbooks.

However, precise following of textbooks is "a danger" (Ferlazzo \& Sypnieski, 2018, p. 423). Sadly, textbook-dependent teaching is a popular phenomenon in Vietnam. Like many EFL contexts, textbooks have been viewed as the only curriculum by teachers and administrators; therefore, what is taught adheres closely to the textbook (Bui, 2019; Le \& Do, 2012). Teaching plans are also based on the content of the textbook and covering the textbook content becomes a must. Textbook-dependent teaching hinders teachers from dealing with the needs of diverse students who may be at different proficiency levels and from altering their practices to improve learners' competencies (Ferlazzo \& Sypnieski, 2018). 


\subsubsection{Testing}

To fulfil the assessment requirement of the curricula (see Section 2.3) and to evaluate English learning achievement, learners take end-of-term tests. English tests at primary school level need to follow the matrix of end-of-term tests designed by DOET, based on MOET's (MOET, 2016) instruction. For Grade 3 and 4, the tests focus on listening. For Grade 5, the focus is equally on the four skills. Tests are designed at school level and are used to evaluate students' primary achievement. In reality, tests are designed mainly based on the content in the textbooks (Grassick, 2016). Therefore, students are required to understand and repeat the textbook and knowledge in a test. This leads to the popularity of textbook reliance in teaching and learning.

\subsubsection{Classroom environment}

Class size and physical settings are important in the success of a TEYL programme and should be suitable for conducting activities for young learners. Large class size is common in TEYL around the world (Copland et al., 2014; Jin \& Cortazzi, 2018; Song, 2015) and in Vietnam (Le \& Do, 2012). Large classes limit classroom management, cause problems of noise and prevent teachers from being able to attend to individual needs. These issues are obstacles to the successful implementation of CLT. In addition, physical classroom settings are also likely not to support communicative activities. Commonly, there are two to four rows of desks facing the board, with two to five students on each desk (Behr, 2005; Cao, 2019). This rigid set configuration reduces opportunities for different types of interactions that are essential for group work activities. Large class sizes and physical settings pose a challenge for teachers to manage class activities and create a positive and productive atmosphere for learning.

\subsubsection{Teacher capability and support}

Teacher quality is essential to any educational innovation (Hamid \& Erling, 2016; Le, 2020a; Wedell, 2008). Teacher capability is crucial in implementing a communicative curriculum, particularly in primary English language education (Copland et al., 2014; Enever, 2016; Nunan, 2003). Primary English teachers need to develop their English proficiency, knowledge of and skills for how children learn language and for an appropriate communicative pedagogy (Copland et al., 2014). Teachers' lack of English proficiency and expertise for teaching young learners are important obstacles in the implementation of the new curricula in Vietnam (Le, 2020a; Le \& Do, 2012; Trang, 2012) 


\subsubsection{Language proficiency}

In the guideline for the implementation of the new curriculum, PELT should have an English language proficiency at Level 4, which is equivalent to Level B2 in the Common European Framework of References for Languages. However, at the beginning of the 2010 curriculum, many of the teachers did not meet the requirement. Assessment statistics from 2011-2012 show that $83 \%$ of primary school teachers were under-qualified (Ngoc Hung, 2015). Reasons for the teachers' low proficiency include poor pre-service training and language attrition (Mai, 2014). The weakening of language proficiency results from little exposure to English and minimal English use outside the classrooms.

Low English language proficiency impacts negatively on teaching methods (Nunan, 2011). Teachers are unlikely to adopt the CLT principles (Le \& Do, 2012) as suggested in MOET's 2010 curriculum, or to use English as a language of instruction to provide good models to their students (Moon, 2009). General English proficiency does not guarantee effective teaching, but it affects the way they use language in the classroom to promote learning (Le \& Renandya, 2017).

Within the Project 2020 framework, training and in-service workshops have been conducted at national and provincial levels to provide language proficiency support for PELT. A large number of teachers have improved their English at universities or language centres. Their English proficiency was reported to improve. According to MOET (Quynh, 2019), in 2018 2019 , statistics indicated that $69 \%$ of primary school teachers were qualified to teach English. However, two concerns have been raised. First, use of the Vietnamese Standardized Test of English Proficiency (VSTEP) is problematic. VSTEP has been criticized for inaccurately assessing teacher's language proficiency because authorized test providers vary in test administration and scoring (Dudzik \& Nguyen, 2015). Whether the measures of language proficiency are reliable, and, more importantly, whether teachers who achieve the mandated proficiency level can effectively use English to promote learning is still a question (Manh, Nguyen, \& Burns, 2017). Helping teachers to avoid language attrition is the second concern. Heavy teaching loads, teaching private classes to compensate for low salary, family responsibilities and lack of opportunities for language use prevent them from maintaining and improving their language proficiency. 


\subsubsection{Methodological capability}

In Vietnam, most teachers originally did not have proper qualifications for teaching English in primary schools. Most primary English teachers were not trained to teach young learners, but rather older learners at secondary level (Chinh, Quynh, \& Ha, 2014; Le, 2019; Le \& Do, 2012). MOET had plans to support teachers' pedagogy. Specifically, three forms of professional learning and development have been conducted: in-service teacher training courses, workshops on textbooks and attending professional groups.

As mentioned earlier, the effectiveness of the in-service teacher training courses is debatable. The first reason is that the trainers had little experience of TEYL and provided little practical application (see Section 1.1). The second reason is that PELT did not have high motivation to attend the courses (Le, 2020b). Studies found in-service training on TEYL did not bring many changes in teaching practice. Pham (2013) lists many obstacles, including workload, occupational instability, low pay, professional inferiority, ignorance of curriculum, limited resource and large class size. A study by Le (2020b) investigating whether the mandatory inservice training could reshape the teachers' teaching practices indicates that the teachers' uptake was limited. Primary school teachers reported they could make the lesson more interesting by employing games or singing with actions but they did not understand the underlying rationale for most of the techniques they used in their lessons. Le (2020b) noted they used "pointless activities that took up valuable class time in the name of fun and engagement" (p. 70) and stated that in-service training could "make teachers more knowledgeable but no more effective in their follow-up instructional practices" (p. 74).

Besides the workshops on TEYL, DOET also organized yearly training workshops, conducted by the textbook designers and EFL consultants, on using the new MOET English language textbooks. However, these workshops were criticized for being short and focused on separate techniques in teaching a few parts of the books. The workshop trainers were more interested in advertising their books than training teachers (Phan, 2017).

Teachers were often alone or isolated because many primary schools had only one teacher of English (Grassick, 2016; Le, 2019). To avoid teachers' isolation in the profession, professional learning groups (a group of about 15-20 teachers from different schools) were developed to create an environment for gaining support from colleagues. To make professional learning groups work, each province in Vietnam mandated monthly meetings to discuss professional activities. In each professional group meeting, a more experienced PELT 
facilitates its activities. Professional group meetings aim to create a social interaction environment for PELT.

The purpose of professional groups is for peer professional learning without any evaluation, but teachers did not gain many benefits for their professional learning. First, no real reflection on their practices was conducted because they followed teaching models that were all prepared to show a perfect lesson (Phan, 2017). Second, collegiality among the PELT in the professional communities did not fully develop. They observed each other's teaching but there was no purpose for their observation. Their lessons followed the model provided by the textbook designers and the BOET and DOET consultants (Phan, 2017). Therefore, the teachers gave similar general comments during the observations to finish the job of the day. Third, teachers had no chance to view teaching from different angles or to review the underlying theoretical knowledge of their teaching and learning (Farrell, 2019).

In brief, only a low percentage of PELT meet the specific requirements of both proficiency and TEYL pedagogy (Huong \& Yeo, 2016; Le, 2019). Therefore, various attempts have been made to improve primary English teachers' language proficiency and teaching methods. Teachers' professional development has been supported through in-service training workshops to enhance their language proficiency as well as teaching skills with the expectation that teachers are empowered to change their instructional practice. However, these top-down mandatory initiatives have brought limited improvement to teachers' capability. As a result, classroom activities have not changed: "teaching and learning methods seem stable but static, often as largely teacher-centred or directed whole-class activities" (Jin \& Cortazzi, 2018, p. 477).

\subsection{Recent studies}

So far, there have been only two studies offering models of innovation for improving learners' proficiency in state primary schools.

Minh (2016) redesigned 18 lessons in six units in the textbook for Grade 4 students. Her redesigned lessons added drama activities ${ }^{1}$. A drama-based lesson consisted of four stages: warm-up, pre-drama, drama, and calming down. New vocabulary, grammar structures and functions were taught in the pre-drama stage. 'Look, listen and repeat' and 'Look and say'2 were presented in this stage. In the drama stage, students worked in pairs and role-played. For

\footnotetext{
${ }^{1}$ In her study, drama is defined as any activity where the participant had to portray themselves or another person in a given situation.

${ }^{2}$ These are textbook activities.
} 
example, one of the lesson plan instructions was "Ask students to look at the pictures in the book and role play with the pictures in tasks 1-3. Call some pairs to act out" (p. 121). A drama activity was added for the students to practise the target vocabulary and structures. A game, a song or a chant to review the target language items constituted the calming-down stage. Although the results from the pre- and post- speaking tests and pre-and post-questionnaires showed that the students' speaking competence in, attitudes to and motivation for English language learning before and after the intervention were significantly different, the study had two constraints. First, the designed lessons had much mechanical practice such as repetition and structural practice which is inappropriate for young learner learning (Cameron, 2001; Pinter, 2017; Shin \& Crandall, 2014). Second, the researcher did the study in a 34-student class which was divided into two groups: a control group and the experimental group. The division of the class made the context of the study different from the challenge of large classes in real contexts, reducing the relevance to real contexts of large classes in Vietnam. Bui (2019) also redesigned the lessons in the textbooks for Grade 4 students, changing two of the speaking lessons into two task-based versions. First, like the normal lessons, the taskbased versions started with a warm-up activity. Second, the 'listen and repeat' activity was changed to an input listening task. Third, the question and answer drill was changed into an information gap task. Fourth, the communicative drill was changed into a public performance of the main task. Three teachers joined the study, and each taught the same two task-based lessons designed by the researcher. The implementation of the two lessons was positive. The results show that task-based activities increased students' classroom interaction and the students were able to use scaffolding strategies such as co-construction, self- and othercorrection, negotiation of meaning and L1 use to complete the main tasks. A constraint is that experiencing only two task-based lessons may not be convincing enough for practical application due to the complexity of tasks.

Both these studies redesigned textbook lessons to offer communicative practices and to enhance the communicativeness of the textbook lessons. In this way, the innovative lessons met the lesson objectives and also covered the content of the textbook that is necessary for textbook-based tests and administration. However, these studies lacked sufficient focus on suitability for young learners. 


\subsection{Chapter summary}

This chapter examined the context of primary English language education in Vietnam. While the policy itself is not problematic, policy outcomes are unlikely to be fully met because of cultural issues and obstacles in the educational system and in the implementation of the new curricula. Cultural challenges to the change of pedagogy are organizational hierarchies rooted in Vietnamese culture. Hierarchical teacher-student relationships influence classroom activities and those between teachers and authorities force teachers to follow the predesigned methodology. Practical challenges include barriers such as availability of resources (textbook), testing, physical setting and teacher capability. Although the authorities have provided much support, teachers' knowledge and skills have not improved much. Within this context, it seems too great a challenge for teachers to make any innovation as required for the implementation of the new curricula. Teachers need support to meet the challenges they have identified to improve their teaching (Copland et al., 2014). An effective and successful model of change is suggested to be a way to encourage innovation. It is crucial to conduct more research into a model of innovation that matches the curriculum, the current textbook and young learners' characteristics and language learning. 


\section{CHAPTER 3 LITERATURE REVIEW}

As stated in the introduction chapter, as my study focuses on using stories and storytelling in TEYL, it is important to develop the conceptual framework for this study. Section 3.1 of this chapter reviews the literature regarding interaction theories. Section 3.2 covers factors influencing classroom interaction, focusing on young learner characteristics, including the current understanding of their intellectual development, cognition, language and psychology.

Section 3.3 reviews the theoretical literature on the concept of stories and storytelling together with the presentation of approaches to storytelling and related studies. Section 3.4 considers the theory and practice in light of research on student engagement. Section 3.5 discusses the importance of research on teacher cognition related to stories and storytelling, and Section 3.6 presents the rationale for the current study.

\subsection{Interaction theories}

\subsubsection{Importance of interaction}

Interaction in the classroom refers to teacher-student and student-student conversations, in which active participation and students' learning becomes vital (Myhill, Jones, \& Hopper, 2006). In order to acquire a language, it is necessary for students to interact naturally in the target language in the classroom. By doing so, they are concerned less on forms, focusing instead on what they wish to express (Krashen \& Terrell, 1995). Brown (2001) believes that "interaction is, in fact, the heart of communication: It is what communication is all about" (p. 165). Philp and Tognini (2009) describe interactions as "the use of language for communicative purposes, with a primary focus on meaning rather than accuracy" (p. 246). Research on interaction has been informed by two main theoretical perspectives: cognitive and sociocultural.

\subsubsection{Cognitive and sociocultural perspectives}

\subsubsection{Cognitive perspective}

The cognitive perspective claims that interaction activates the cognitive processes important for language acquisition. According to Piaget (1970), young learners cannot be given information that they immediately understand and use; they construct knowledge from actively interacting with the physical environment in their developmental process. They learn through their actions and exploration and gradually develop their formal and logical thinking. For children, knowledge derives from action and children's language learning depends on what they experience. In interacting with their environment, learners learn a language via 
individual cognitive efforts. These conversational efforts facilitate language learning in three ways: (1) understanding input and negotiating the form or meaning provided in the input (Long, 1983), (2) producing output to express their meaning in the target language (Swain, 1985), and (3) noticing the difference between the produced interlanguage forms and the target language form (Schmidt, 1990).

Taking these in turn, cognitive effort occurs when learners negotiate meaning to resolve a communication problem triggered by communication difficulties and to achieve mutual comprehension. Learners benefit when input is interactionally modified through clarification and confirmation checks (Long, 1983). According to Long (1996), negotiation can prompt interactional amendment and adjustment between interlocutors and accelerate language acquisition since "negotiation of meaning ...facilitates acquisition because it connects input, internal learner capacity, particularly selective attention, and output in productive ways" (p. 451-452).

Cognitive effort is also required to produce language. Interactions provide opportunities for output. In interactions, through written or spoken language production, learners realize a gap in their linguistic knowledge and try to modify their output in interactions in order to learn something new about the language (Boutorwick, 2017; Swain, 1995). The need to communicate encourages learners to co-construct knowledge and put their thoughts into words to explain, reflect and describe language problems. This process is important for language development (Swain, 2010).

Interactions also promote noticing as they help to draw learners' attention to language forms, to notice meaning-form connections and to notice the gap between their inaccurate productions and the accurate target language element. Through interactions with input, learners to make a comparison with their initial (imperfect) output and the target-like language produced by their conversational partner, which subsequently lead to restructuring and modification of their existing knowledge (Schmidt, 1990). In doing so, learners are able to consciously reinforce their previous knowledge and acquire new language features. As they face difficulties in comprehension and production, learners receive feedback from their interlocutors, which plays a major role in this reinforcement.

The cognitive perspective on interaction has emphasized individual cognition, cognitive processing, and information processing. However, it has been criticized for focusing on learning outcomes, and on the cognitive processes learners use to achieve knowledge but neglecting the factors that influence the performance (Platt \& Brooks, 1994), the children's 
social life (Cameron, 2001) or what actually happens in the language classroom (Bygate, 2016). Research on the cognitive perspective has also been criticized for ignoring relationships within group work (Storch, 2002) and failing to take into account of the sensemaking of activities and experience when learning a language (Lantolf, 2000). How social factors influence learners' development is explained in the sociocultural approach, elaborated in the following section.

\subsubsection{Sociocultural perspective}

Interaction is a central aspect in sociocultural theory, which emphasizes the interdependence of social and individual processes in the co-construction of knowledge (Vygotsky, 1978). Sociocultural theory argues that interaction is an opportunity to learn as well as serving as the actual site where learning occurs (Lantolf, 2006). In the sociocultural perspective, children internalize language through doing things in social contexts (Vygotsky, 1962). In other words, children learn through social interactions and can construct knowledge through interaction with peers or adults. Social interaction is an essential process during which individuals cognitively and socially develop. Interactions provide opportunities for gaining knowledge of how to learn, as learners notice the processes and practices within a pair or a group (Putney, Green, Dixon, Duran, \& Yeager, 2000). Learning is the result of social interaction and language is the most important tool for interaction.

Language is an essential tool as it mediates social interactions. Learners use language while working together to complete a language task; their peer collaborative dialogues mediate construction of linguistic knowledge and this process of joint construction contributes to language development (Swain, 2010). As learners attempt to solve a linguistic problem, they construct and analyse the new linguistic forms, which enable them to learn new language or knowledge about language, thus improving their language use.

In the classroom, learners internalize information by linking the new concepts with what they previously learned as results of talking and discussing in a given academic activity or task. In social interactions, internalization happens often through the use of language between the learners and a more capable peer. In this kind of interaction, there is a distance to which new skills can extend from the instrumental sphere, which marks the potential capability for learning. The distance between what learners can achieve by themselves and what they can achieve with assistance from others is conceptualized as the zone of proximal development. 


\subsection{Zone of proximal development}

Vygotsky's zone of proximal development (ZPD) describes how cognitive growth occurs in children. According to Vygotsky (1978), in order to learn, learners must participate in activities that are just out of reach of their present ability; activities that are too simple or within our present ability do not promote learning; activities that are too complex become frustrating and no learning occurs. In Vygotsky's opinion, when a learner is in the zone of proximal development for a particular task, if the appropriate assistance is provided, he/she will achieve the task because this learning condition "awakens a variety of developmental processes that are able to operate only when the child is interacting with people in his environment and in cooperation with his peers" (Vygotsky, 1978, p. 90).

\subsection{Scaffolding}

Scaffolding, one of the components in ZPD, is defined as a temporary intellectual support and as an interplay of conscious and control (Bruner, 1985). The process of scaffolding enables children to advance their cognition in the presence of more knowledgeable people. In an activity, the more competent person would offer a degree of support but would gradually withdraw the support until the child can perform the tasks independently. Scaffolding is considered to bridge the gap between what a person can accomplish independently and what the person can do with support from others. In language learning, scaffolding is "the dialogic process by which one speaker assists another in performing a function that he or she cannot perform alone" (Ellis, 2003, p.180). It is a kind of supportive dialogue (Aljaafreh \& Lantolf, 1994).

The concept of scaffolding children in learning has become a common way of describing learning relationships in the classroom. What makes scaffolding so effective is that it enables a teacher to keep a task as a whole while students learn to understand and manage the parts of the task. In other words, students become active in their learning. Children learn through scaffolding interaction with the teacher as well as with peers (Ellis, 2003). Teachers' scaffolding can be either vertical or sequential (Foley, 1994). Vertical scaffolding involves the teachers extending the young learners' current language level by asking further questions. Sequential scaffolding is used to develop the young learners' vocabulary or introduce new ideas by organizing games or tasks that have a sequence of activities. Scaffolding among learners has been named 'collective scaffolding' (Donato, 1994) and 'collaborative dialogue' (Swain, 2000; Swain \& Lapkin, 2001; Watanabe \& Swain, 2007) 
Studies have shown that students can effectively scaffold one another. Ohta (2001) explains that students can help their peers because each student has different strengths and weaknesses and they can give vertical scaffolding in pair or group work. Donato (1994) reports evidence that students can provide support to their peers in the same ways as experts, such as parents or teachers. In interactional scaffolding, not only can less proficient learners benefit, but more capable learners can learn as well (Watanabe \& Swain, 2007). Through explaining problems to a less proficient learner, a more capable learner must clarify using suitable language, thus improving their language ability. Similarly, Van Lier (2013) claims that more advanced learners can benefit from collaboration with less proficient students by teaching them. Empirical evidence also shows that less proficient learners can support more proficient learners (Samana, 2013; Seo \& Kim, 2011; Storch \& Aldosari, 2013). Samana (2013) found that students with a low level of English proficiency can also scaffold their peers to complete tasks. They found that students have different roles during an interaction: while one is speaking, the others are listening; they can notice their peers' encountering problems and provide solutions. In an EFL environment, even young learners can scaffold their peers. However, taking advantage of young learners' ability to scaffold each other is rare in EFL classrooms and in primary school classrooms in Vietnam. Studies in Vietnam (Bui, 2019; Grassick, 2016; Vi, 2018) found that the teachers scaffold children by offering mechanical practice on target language items or group work practice in which interactions between peers do not genuinely happen, offering little room for peer assistance to take place.

In summary, children learn language through classroom interactions. Students' participation in interactions can help them enrich their linguistic resources and build their confidence in communicating with others in English. The importance of interactions for cognitive and social development has been acknowledged in cognitive and sociocultural theories of learning although the role of interaction is conceptualized quite differently in each theoretical tradition. The cognitive perspective focuses on the individual and how the individual constructs knowledge, while the social-cultural perspective explores how learners co-construct meaning while joining in interaction. The cognitive perspective claims that interaction activates the cognitive processes important for acquisition, and the social perspective emphasizes the interdependence of social and individual processes in the co-construction of knowledge. In interactions, learners construct their own meaning. They are active participants in learning situations, controlling and shaping their own learning process. They can construct knowledge in meaningful and useful situations and language acquisition happens in interactions. Interaction has been recognized as an effective strategy to enhance young learners' learning 
and development in educational settings. Students can be assisted by their teachers or peers in their activities until the language has become internalized. When internalization happens, young learners can use the language with a clear mental image; they no longer need scaffolding and can move a higher-level activity. However, foreign language development for young learners resulting from this support rarely occurs due to the lack of social interactions in the target language classroom.

\subsection{Considerations for teaching young learners}

\subsubsection{Characteristics of young learners and how they learn}

Young learners have characteristics that differentiate them from other groups. As Cameron (2001) has noted: “Knowledge about children's learning is seen as central to effective teaching" (p. 1); it is crucial for teachers to be well-informed about learners. Teachers who specialize in the area of adult learners need time and experience to make their way toward children in young learners' groups (Stelma \& Onat-Stelma, 2010). For the successful teaching of English in primary school, teachers need to understand young learners' characteristics in order to build a lesson and make sure that learners are fully involved in the learning process.

Although children are in a period of their lives in which they go through constant cognitive and psychological change and every child is different, they still have a lot of characteristics in common (Mc Donough, 2013; Shin \& Crandall, 2014; Ur, 2012). The following sections present young learners' characteristics in light of intellectual development, cognition, language perception, imagination and creativity, and their psychology.

\subsubsection{Intellectual development}

Unlike adult learners who have already firmly developed their first language, young learners can communicate verbally but they are still developing their communicative skills, especially in reading and writing (Pinter, 2017), and their social skills (Butler, 2019). In general, by age 12 , they can already "develop their social-cognitive interactive abilities, ... collaborate with others in tasks and take turns in communicative exchanges .... read for information ... and they are gradually able to sustain abstract topics in conversation" (Butler, 2019, p. 14). Young learners are in the process of developing social competence such as collaboration, considered necessary for effective group work, in their first language (Fisher, 2005) and in second and foreign languages (Donato, 2004).

According to Piaget, as mentioned in Brown (2007), children are in the stage of "concrete operations" (p. 88), meaning that young learners learn only from what they can sense using 
the five sensing organs. In this learning age, explaining something abstract or using abstract language very often causes misunderstanding on the part of the children. Children can understand better when they interact, touch, hear and see, as their senses are stimulated (Tragant \& Vallbona, 2018; Warrington, Younger, \& Bearne, 2006).

Information from brain research supports their intellectual and cognitive development through multiple senses. The brain relies on both sides to function well and the information is not processed by one part; rather the sensory parts of the brain work together to transfer information (Dekker, Lee, Howard-Jones, \& Jolles, 2012). Kennedy (2006) identifies several implications from brain research for language teaching, highlighting the importance of engaging many senses and an enriched environment: "Repetition is necessary but it requires novelty with regard to instructional design which should incorporate all five language processes - observation, listening, speaking, reading, and writing - and utilize a variety of methods and approaches" (p. 479). This implies that young learners learn well in an integrated skills approach, which assimilates opportunities for reading, writing, speaking and listening (Warrington et al., 2006). Integrated teaching is suitable for the way children learn naturally (Cameron, 2003).

\subsubsection{Cognition}

Concentration span is considered to be the amount of time during which children are able to concentrate on a certain topic. According to Harmer (2003) and Scott and Ytreberg (1990), young learners have a limited attention span; unless activities are extremely engaging, they can easily get bored, losing interest after about 10 minutes. However, that children have a short attention span is "a sweeping claim" (Brown, 2007, p. 88), as that they can concentrate well on things that interest them. Young learners' attention span depends on learning materials and activities. They find it difficult to concentrate if they have to deal with material that is boring or too difficult or too easy and they will attend well on activities that are designed to capture their immediate interest and that are meaningful to them (Brown, 2007). Therefore, meaningfulness in learning for young learners is essential.

Language that is meaningful to the learner supports the learning process (Richards \& Rodgers, 2014). Meaningfulness means that the content leads to some emotions. As Wright, Betteridge, and Buckby (2005) put it "A useful interpretation of 'meaningfulness' is that the learners respond to the content in a definite way. If they are amused, angered, intrigued or surprised the content is clearly meaningful to them. Thus, the meaning of the language they listen to, read, speak and write will be more vividly experienced and, therefore, better 
remembered" (p. 1). Similarly, Curtain and Dahlberg (2010) state that young learners eagerly take part in communication when they have a desire to communicate something in meaningful contexts and with emotional content. In meaningful language learning, mindless repetition, imitation and other rote practices in the language classroom have no place (Cameron, 2001). Therefore, teachers may facilitate the development of language acquisition by providing children with classroom experiences that have meaningful contexts in which the content is understandable and emotional. In these contexts, familiar language becomes more memorable and useful, and children can identify new language, and make connections, linking new information to existing knowledge for effective knowledge and recall.

\subsubsection{Language perception}

Children understand the meaning of the message as a whole and they engage with messages better if they are presented in natural chunks (Brown, 2007). Focusing on discrete language features is much less relevant for children because they are more accepting and tend not to analyse. As Cameron (2003) writes: “children see the foreign language 'from the inside' and try to find meaning in how the language is used in action, in interaction, rather than 'from the outside' as a system and form" (p. 107). It is suggested that in order to develop young learners' proficiency, vocabulary should be taught in context and communication should be created in the classroom (Brown, 2007). Grammatical explanation is not an effective strategy for teaching young learners for developmental reasons. To optimize young learners' learning, teachers should avoid using grammatical terms and rules that young learners will not understand and help learners 'notice' the grammar by repeating and recycling new language (Cameron, 2001; Shin \& Crandall, 2014).

Taking into consideration how children perceive language, it would seem that a holistic approach would be appropriate for teaching a foreign language to young learners (Cameron, 2001; Kirsch, 2008). A holistic approach treats what is to be learned as a whole, and the skills of languages are not presented in isolation but are integrated (Kirsch, 2008). Language, specifically a text, is not broken into small units, such as teaching vocabulary and structural patterns separately; rather the input is presented in all its complexity, which enables learners to acquire the real meaning and the language rules. Young learners should be focused on all the meaning of the content rather than on forms. As Cameron (2001) puts it: "Meaning must come first: if children do not understand the spoken language they cannot learn it" (p. 36). Ellis (2005) also emphasized the significance of meaning and notes that activities focused on creating meaning are intrinsically motivating for learners. 
Focus on meaning in learning is the way the brain works (Curtain \& Dahlberg, 2010). The brain always searches for meaning through patterning in the information and experience that people encounter. Caine and Caine (1997) point out that the search for meaning is innate and state that meaningful information is stored in a memory that can be recalled effortlessly as a complete experience. The brain looks for patterns as it organizes information according to schematic maps and categories; therefore, facts and skills that are presented in isolation need more practice and rehearsal to be stored (Curtain \& Dahlberg, 2010). As young learners in language classes search for meaning in the experience the teacher provides them, the experiences need to be meaningful so that young learners construct their own patterns of understanding.

There is a strong link between focusing on meaning and activating prior knowledge. Focus on meaning occurs only when learners are engaged in decoding and encoding messages in the context of actual acts of communications created for acquisition to take place (Ellis, 2005). Learning occurs when learners willingly relate new to existing knowledge, and learners can evoke their prior knowledge with ease and relate other new information from it. Activating the students' prior knowledge can enhance meaningful learning (Willis, 2010). Classroom instructions need to provide activities, especially interactions, for students to use information, to transfer information from its original context to other uses so they can take in more associated information and make better prediction of correct responses to the new information. This is the path for long-term memory (Willis, 2010). New learning is constructed on prior knowledge. Students' prior knowledge is the factor that makes the most important difference in student learning (Clark, 2015; Riener \& Willingham, 2010). As teachers cannot scaffold all the learners in their practice, especially in large classes, peer scaffolding is known to be effective in promoting student learning and takes into account students' prior knowledge.

\subsubsection{Imagination and creativity}

Children learn and develop their creativity via their imagination when taking part in classroom activities. Young learners generally live in "a world of fantasy and make-believe" (Bourke, 2006, p. 280). They can learn well when they use their imagination and they love activities that encourage them to use their imagination (Shin \& Crandall, 2014). Egan (1986) has long argued that children's imaginations "are the most powerful and energetic learning tools" (p. 2). Young learners have vivid imaginations and can be creative with their limited sources (Halliwell, 1992). When children are about seven or eight, they start distinguishing 
between fantasy and reality (Shin \& Crandall, 2014). Imagination is fundamental to the process of learning and relevant across subject disciplines (Egan \& Nadaner, 1988). Creativity can be eminent as exhibited by great artists or scientists or be at expert level as shown by professional creators (Kaufman \& Beghetto, 2009). In learning, creativity does not need be that significant. Beghetto and Kaufman (2007) define creativity as "the novel and personally meaningful interpretation of experiences, actions, and events" (p. 73). In this definition, the novelty and meaningfulness of these interpretations need not be original nor even meaningful to others.

Creating a learning environment to support young learners' creativity is very important (Richardson \& Mishra, 2018; Soh, 2017). Some common features of classroom practice that support creativity development (Richardson, 2018) are: (1) the physical environment has multiple spaces in which the students can work together; (2) the learning climate emphasizes cooperation and positive relationships between students and the teacher; and (3) activities emphasize the learning process, not the products. However, in an EFL environment, using and developing children's creativity has not been exploited. Although some teachers value creativity for learning, others have limited conceptions and are uncertain about creativity and foreign language teaching (Wang \& Kokotsaki, 2018). The way the teacher perceives creativity has an impact on how they nurture it in their classroom (Nedjah \& Hamada, 2017). That is the reason why common activities that offer young learners opportunities to experiment creatively with language and to go beyond fixed dialogues are rare in EFL classrooms (Becker \& Roos, 2016). To effectively improve language learning for EFL young learners, their creativity should be developed.

\subsubsection{Psychology}

In addition to these prominent characteristics relating to children's intellectual, cognitive and imaginative development, children display many other characteristics. They are spontaneous and not afraid of speaking or participating, curious and receptive to new ideas (Shin \& Crandal, 2014). Young learners are willing to use the language even with limited proficiency (Lightbown \& Spada, 2013). Group work is supposed to be effective for young learners to exploit their willingness to use the language, and to encourage interaction and participation among learners (Kutnick \& Blatchford, 2014; Lightbown \& Spada, 2013).

\subsubsection{Group work}

Group work provides the conditions in which learners are most willing to use spoken language particularly with friends. As Kramsch (1987) put it: "It is through the interaction 
with this social group that language is used and learned. In turn, it is through the use of the language that the group is given a social identity and social reality" ( $\mathrm{p}$ 17). Children who work in small groups will be more focused on their learning activities, have opportunities to help one another on similar tasks and will be less dependent on the teacher for support and direction of their learning (Kutnick \& Blatchford, 2014).

Providing learners with opportunities to build knowledge together is a fundamental principle in teaching young learners (Jolliffe, 2015). Small groups maximize the students' own and each other's learning (Johnson, Johnson, \& Holubec, 1994) and can enhance both academic and social skills (Brown \& Thomson, 2000). Making learners active in their learning, especially group work, is brain compatible (Willis, 2007b). Brain research implies that cooperative learning activities allow students to use both sides of the brain (Willis, 2007a, 2007b). In addition, brains are more effective in interactions with others than when interacting alone (Carter, 2010). In cooperative learning, students work together for the group's outcomes. They have to use language to express their opinions and to discuss with peers. As a result, they develop their language skills as well as social skills.

Research in EFL has shown children's ability to engage in social skills in pair work and group work (Azkarai \& Imaz Agirre, 2016; Bui, 2019; Garcia Mayo \& Imaz Agirre, 2019; Garcia Mayo \& Lazaro Ibarrola, 2015). They were able to use verbal interactional strategies to complete their tasks such as co-construction, self- and peer-correction, negotiation for meaning and L1 use as a scaffold (Bui, 2019). They used conversational adjustments for meaning such as clarification requests, confirmation checks and repetitions (Garcia Mayo \& Lazaro Ibarrola, 2015), but they seemed to have more off-task behaviours if they were in a self-selected group than proficiency paired and teacher-assigned groups who were more on task (Garcia Mayo \& Imaz Agirre, 2019). Older learners seemed to use their first language more than the young groups (Garcia Mayo \& Lazaro Ibarrola, 2015). These authors claim the younger learners were collaborative in most of the tasks and they used and developed their social skills in peer-inetractions in group work activities.

Putting students in groups does not always garantee they interact and communicate with one another. Various factors can affect their interaction to make group work successful. According to Brown (2001), group work "is a generic term covering a multiplicity of techniques in which two or more students are assigned a task involves collaboration and selfinitiated language" (p.176). In this definition, three important aspects are highlighted. The first is real cooperation in which students have to work together for the completion of a task 
and everyone is aware of his/her responsibility. The second aspect is self-initiated language. Students use what they know and learn to communicate with others in the group. The third aspect relates to the group size. In order for real cooperation and self-initiated language use, the group has to be small as Brown (2001) suggests.

In interaction, young learners have to rely on their existing repertoire to work naturally with rules and patterns to create utterances; therefore, making errors is common in their discourse. However, if the teacher keeps correcting mistakes directly, it may lead to the students' fear of making mistakes or feeling anxious, and therefore lead to avoiding speaking a foreign language in public. As Brown (2001) points out, errors are a necessary manifestation of interlanguage development and constant correction from the teacher makes the students obsessed; instead, "Well-managed group work can encourage spontaneous peer feedback on errors within the small group itself" (p. 181). Studies (Mackey, Oliver, \& Leeman, 2003; Mackey \& Silver, 2005) have provided clear evidence that young learners were able to give positive feedback on their language learning. During the interactional process, young learners strived not only to resolve communicative difficulties, but also to correct each other and make use of their peer assistance; as a result, they improved their language production.

Students all speaking at once trying to accomplish their activity can cause noise, especially in large classes. One cause of noise comes from using the first language in EFL learning interactions. Use of L1 has been reported in many studies where the teachers and learners shared the same L1. Studies have stated that students' noise benefits their learning. Noise “created by group work is considered as 'good' noise since they are using English and are engaged in a learning task" (Dolff, 1988, p. 141). L1 use while learning is normal and beneficial as L1 use functions as a scaffolding mechanism that facilitates interaction. The use of the mother tongue in the EFL class could become a tool to understand the target language more accurately and to accomplish their work (Storch \& Aldosari, 2010; Yaghobian, Samuel, \& Mahmoudi, 2017). Recent studies with EFL young learners suggest L1 use occurs to resolve difficulties in interactions such as limited target language proficiency. Azkarai and Garcia Mayo (2017), Garcia Mayo and Hidalgo (2017) and Tognini and Oliver (2012) have reported that young students use L1 for three main purposes: moving the tasks along, focusing attention and interpersonal interaction. In a Spanish setting (Azkarai \& Garcia Mayo, 2017; Garcia Mayo \& Hidalgo, 2017), EFL young learners employed L1 more frequent than EFL adult learners within task-based interaction but they did not use L1 excessively. Their L1 use significantly decreased when they became familiar with their tasks. Like adults, the Spanish young learners used L1 mostly to ask for words they did not know in English. They also used 
L1 for metacognitive talk and emotional small talk. All these functions of L1 use were for the fulfilment of the task, to avoid communication breakdown and to make their interactions move along without abrupt interruption.

Besides on-task noise from using L1, off-task noise can occur in some circumstances (Carless, 2002). First, when students are not clear what to do, arguments in L1 may start. Second, when the tasks are too easy or too difficult, students go off-task due to finishing too quickly, not knowing what to do, or becoming frustrated with the difficulty. Third, the activity itself may provoke excessive noise. For example, certain role-plays may breed overexcitement or require students to make sounds of animals or machines and they may make use of these to make undisciplined sounds. To minimize the noise, rationale for group work activities needs to be indicated clearly to the students and students are informed clearly of their roles in groups so that they are aware of what is expected of them (Carless, 2002). In brief, group work can promote EFL language learning as it can make use of the children's willingness to use language. Knowledge of group work, particularly of errors, L1 use and noise, helps teachers to design effective group work activities and to provide young learners with successful learning in interactions with peers.

\subsubsection{Attitudes and Motivation}

Attitude and motivation are often considered to be interlinked (Djigunovic, 2006, 2012; Lightbown \& Spada, 2013). As one of the affective variables that can influence language learning, attitude and motivation appears as predictors of performance in a foreign language. Attitudes refers to "a disposition to respond favorably or unfavorably to an object, person, institution or event" (Ajzen, 2005, p. 3). Language attitude is known as a positive or a negative feeling toward language learning and what learners may associate with that language (Gardner \& MacIntyre, 1993). Learners' attitude may be formed partly by socio-affective factors such as parents' and siblings' opinions, relationships with peers and teachers or their personalities. Motivation is referred to as the desire to learn a language, combined with positive attitudes to learning the language and with the effort invested in learning (Gardner, 1985, 2010).

Deci and Ryan (1985) introduce the self-determination theory, a widely used distinction within L2 motivation research, which differentiates extrinsic motivation from intrinsic motivation. Extrinsic motivation occurs when the learner "performs to receive some extrinsic 
rewards (e.g. good grades) or to avoid punishment" (Dornyei, 1994, p. 275). Adults' and young learners' grounds for extrinsic motiviation are likely different. Adults have more reasons to be learning an L2 for career purposes, travell or business. Young learners, in contrast, are likely to learn a language to satisy their parents' demand. Extrinsic motivation is based on external reasons, whereas intrinsic motivation is based on enjoying doing something for its own sake. Intrinsic motivation is evident "whenever students' natural curiosity and interest energize their studies" (Deci \& Ryan, 1985, p. 245). In other words, intrinsic motivation happens when learners want to participate in an activity, solely for the enjoyment of doing the activity itself (Schunk, 2012). In foreign language classes, young learners' intrinsic motivation is also determined by the interest, joy and curiosity they experience during their learning activities (Brewster, Ellis, \& Girard, 2002), by successfully learning English (Lightbown \& Spada, 2013), by providing learners with choices and a sense of control over their learning outcome, and by involving learners in fantasy (Schunk, Meece, \& Pintrich, 2014).

With time, children's motivation in foreign language learning may decline (Carreira, 2011; Djigunovic \& Lopriore, 2011). Many causes for students' demotivation have been detected, such as boring teaching methods, lack of opportunities to practice the language both inside and outside the classroom and poor teacher-student relations (Lamb, 2016). English teachers may decrease students' motivation by their teaching practices due to incongruence with students' needs, teachers' impatience and disinterest in teaching (Kim \& Seo, 2012). Lowproficiency students tend to have more strongly reduced motivation, interest and attitudes toward foreign language learning (Lee \& Lee 2011). However, Cenoz (2003) suggests that a high level of motivation can be sustained but requires good conditions. To maintain young learners' motivation, classroom activities should contain the sources of intrinsic motivation as mentioned in the previous paragraph. The teacher's intruction needs to create curiosity and enjoyment in student's learning (Carreira, 2011), providing an engaged classroom experience and appropriate support, structuring their foreign language lessons to help students engage. In short, students' intrinsic motivation drives activities in learning processes and information is best learned and retained if it is made meaningful to students.

\subsubsection{Inter-personal relationships}

Young learners need to interact and relate positively with one another for development to take place. The quality of interaction may also depend on interpersonal relationship. Research has shown that positive relationships between teachers and students is essential for effective 
teaching and learning to take place (Corrie, 2002). Another factor that facilitates effective collaborative work is how well the learners know each other.

Peer relations have a particular value for social and even cognitive development (Blatchford \& Baines, 2010). Peer relations differ from child-adult relations by showing equality, cooperation, reciprocity and mutuality, all of which contribute to social development (Kutnick \& Blatchford, 2014). An understanding of peer relations is important when considering the classroom as a context for learning. Friendship groups may be good for children's learning, although grouping friends together might lead to more off-task behaviours, such as L1 use. Studies suggest that positive relationships improve intrinsic motivation. A sense of competence and relatedness with teachers and peers enhances students' engagement in learning (Li, Han, \& Gao, 2018). A series of studies in Japan (Carreira, 2011; Oga-Baldwin \& Nakata, 2017) have shown that the teacher's instructions can enhance students' learning motivation by providing them with opportunities to critically recall their English learning and link it to their personal life. As a result, students feel connected with peers, capable of the tasks and personally invest in their learning (Oga-Baldwin \& Nakata, 2017).

A characteristic of a classroom is that relationships are formed over a period of time (Gieve \& Miller, 2006). In primary schools in Vietnam, learners stay with the same class throughout the primary period and have one class teacher teaching most of the subjects. This familiarity potentially creates a positive socio-affective context in which communitive competence can be developed, as long learners have an interactive task and are motivated to communicate.

\subsubsection{Summary}

The literature on young language learners' characteristics emphasizes the explicit link between cooperation, meaningfulness, motivation and creativity. Young learners need a way of learning that can help them use five senses, that is meaningful to help them want and need to use English and to prolong their attention, to help them learn via their creativity and at the same time develop their creativity. They need to be active in building knowledge together with their friends. In general, they need a holistic approach that is compatible with their perception of language. It is suggested that storytelling is a good choice of pedagogical approach for young learners. The next part will present, and discuss literature related to stories and storytelling. 


\subsection{Stories and storytelling}

\subsubsection{Stories}

Stories can be heard everywhere from news reports, books, movies, television, dramas, songs, the Bible and people's casual conservations. Stories include myths, legends, fairy stories and fables, personal anecdotes, descriptions of the development of a firm or a nation, and the news in both oral and written forms. Historically, 'story' is probably one of the most frequently employed words in relation to children's literature.

Some scholars define stories on the basis of story structure or story grammar (Gordon, 1989; Graesser, Golding, \& Long, 1991; Morrow, 1989; Paris \& Paris, 2008; Pressley, Johnson, Symons, McGoldrick, \& Kurita, 1989; Tompkins \& McGee, 1989). Story structure refers to the organization found in common children's stories. A story has three prototypical features (Garvie, 1990), including:

Setting: where and when the story takes place.

Characters: the people in a story the audience can identify with and relate to; they represent helpers or hinderers, friends or enemies and most importantly, themselves, and the various aspects of nature that conspire to propel their story onward.

Plot: a sequence of events logically connected through the chain of cause and effect. The plot explains what happens in the story. The plot has a beginning, a middle and an end. The beginning introduces the setting and the characters. The middle is the main part of the story. There is usually a conflict which is a problem or meeting between characters that results in challenge and opposition. Conflict makes the story more engaging, as the audience is able to observe a personally confronting or challenging experience from a safe distance. The end of a story is when the problem is sorted out, either with a happy or unhappy ending.

Stories have become invaluable language resources in education. Stories can provide a great deal of comprehensible input to learners (Hendrickson, 1992; Krashen, 2009; McQuillan \& Tse, 1998), which is a necessary condition for language acquisition. Stories "introduce children to language items and sentence constructions ...” (Wright, 1995, p. 7). Stories and the re-enactment of stories are "valuable strategies for the development of spoken language and literacy within early years and elementary classroom" (Cremin, Flewitt, Mardell, \& Swann, 2017, p. 1). Teachers have used stories in their teaching for a long time and storytelling has become one of the methodologies commonly used in language learning. 


\subsubsection{Storytelling}

In education, stories and storytelling have been recognized as powerful tools in the development of language skills in first and also foreign or second language learning, regardless of the learners' age or background (Cameron, 2001; Isbell, Sobol, Lindauer, \& Lowrance, 2004). Storytelling is a methodological approach in which learning is structured around a story as means of sense making. Storytelling can effectively facilitate the acquisition of English as it is "a useful strategy in order to prompt and implement the acquisition of English while following the main stages of English acquisition as an L1, and at the same time adapting them to the specific context of second language learning and teaching" (Costenaro, 2008, p. 66). Storytelling is, in fact, "an encompassing method" (Kim, 2013, p. 54) and it gains support from several theoretical frameworks and perspectives. First, I will review the storytelling frameworks and perspectives; next I will discuss the common characteristics of the storytelling frameworks and the explanations for this 'encompassing method'; and then I will present the benefits of storytelling on the basis of research in EFL environments.

\subsubsection{Storytelling frameworks}

Research on storytelling has been informed by various theoretical perspectives.

The natural approach embraces stories as a key source of input (Krashen \& Terrell, 1995); Don Foldaway (Park, 1982) developed this theory with the employment of stories into the Natural Learning Model. This model is based on the belief that children can learn how to read by experiencing the texts in storybooks over and over and, through these experiences, acquire the language. Don Foldaway created a storytelling approach called shared book reading which involves a teacher, also referred to as a reader, reading a selected picture book aloud to a group of children in close proximity so that the pictures are visible. This approach was applied in the Book Flood experiment (Elley, 2000). In its teaching application, the lesson procedure of the shared book experience method consists of three stages (Elley, 2000; Elley \& Mangubhai, 1983). In the first stage, the children discuss the pictures, the likely content and a few new words. The second stage consists of teacher reading, student reading and discussion. First, the teacher using big books reads all the story to the class and then children join in the reading and discuss the content of the story. Second, children read in the class group, in small groups, in pairs or as individuals. In the third stage, children do some follow-up activities such as roleplaying, word study, artwork or writing activities.

Similar to the Natural Learning Model, the Hook Book Look Took lesson framework employs reading storybooks to young learners. It was first introduced to teach Bible stories. Later, the 
four-step lesson was adapted to teach English, as described in Tedjaatmadja and Renandya (2012): (1) introducing and preparing the children for the lesson through various fun activities (the Hook); (2) focusing the children's attention on the content of a story (the Book) including listening to the story told by the teacher, and follow-up reading-aloud techniques; (3) guiding children to look more closely at the language features of the story (the Look); and (4) finishing the lesson with a concrete takeaway (the Took) which is what the teacher wants students to remember most from the lesson.

Storytelling also matches the Communicative Language Teaching (Ellis \& Brewster, 2014; Pinto, 2012) because the main focus of storytelling is to set up life-like situations in which students communicate meaningfully and the primary focus of storytelling is on the meaning and the construction of stories. Due to the familiarity and universality of stories, storytelling can be defined "as a broader version of the communicative approach" (Ellis, 1995, p. 89). Ellis and Brewster (2014), Shin and Crandall (2014) and (Wright, 1995) introduce three stages: pre-storytelling, during-storytelling and post-storytelling activities.

At the pre-story stage, appropriate activities are used to warm up, to introduce the story and get students ready for listening to the story; in other words, they aim to attract the students' attention, or to arouse their curiosity, to activate students' background knowledge, to connect to prior knowledge and experiences and to review language already learned. A variety of activities are employed, such as games, pre-teaching new vocabulary or expressions, asking students to predict what will happen in the story or giving students a purpose for listening/reading the story. Some scholars criticize the introduction of new vocabulary contained in the story, arguing that vocabulary can never be taken out of the text and taught first. Some scholars support teaching vocabulary before listening to the story, arguing that students do not have the same vocabulary basis and whenever they do not understand any vocabulary, they have nothing to relate to when listening, resulting in total frustration, misunderstanding and boring learning.

At the during-story stage, contextualized storytelling techniques are used to help students comprehend the story and add fun to learning. In this activity, the story can be presented or acted out in various ways to provide meaningful and comprehensible input, to activate prior knowledge and draw young learners' attention to new knowledge and to practise the new language target items. As a key source of input, stories can contribute considerably to successful language learning because they provide interesting and enjoyable content and memorable contexts for language practice. Children are encouraged to engage with the story 
through prediction, hypothesizing and using their imaginations. Through these activities, young learners' cognition is activated, and it is easy for them to acquire the language elements from the data provided by the stories (Wright, 1995).

At the post-story stage, a variety of follow-up activities used to develop the pupils' thinking skills, reinforce learning, and stimulate their creativity. Comprehension check, group retelling, acting the story out or writing a dialogue script for a story are among the proposed activities. Storytelling also features in a teaching method of its own called TPRS which initially stood for Total Physical Response Storytelling. Unlike storytelling in the CLT teaching approach which provides classes with real-life communication activities and generally requires students to make early language production, storytelling in TPRS lets the learners receive the language with a silent period in which spoken language was delayed. This reflects the perspective of Ray Blaines, the founder of TPRS, and James Asher, TPRS developer, based on principles by which children acquire their first language (Spangler, 2009). According to Curtain and Dahlberg (2010), Total Physical Response Storytelling is an approach to combining language with actions and stories. TPRS embeds new vocabulary and structures as functional chunks and provides extensive listening practice before students are expected to speak. The procedure has seven steps which, align with the three phases of pre-while-post activities presented in storytelling in CLT above. A difference can be found in the while-storytelling stage and the post-storytelling stage. The while stage consists of a sequence of activities: the teacher tells the story and students act out the story; the teacher re-tells the story, students retell the story. In the post-stage, the teacher retells the story from a different perspective such as changing characters or settings and students retell the story from that new perspective. The activities enable learners to hear comprehensible input from the teacher and students are not required to produce any outputs until they have been exposed long enough to the input messages.

Storytelling also fits with the task-based approach as "[t]asks provide a framework for storytelling which can be manipulated by the task designer or teacher to both support and challenge the learner" (Kiernan, 2005, p. 59). Storytelling in the framework of pre-duringpost tasks can be found in many studies such as Essig (2005), Kiernan (2005), Saucedo (2005), Li and Seedhouse (2010), and Hamamorad (2018). There are two perspectives of taskbased storytelling: one considers that students' interactively listening to and joining the teacher telling the story is the main task and one considers students' telling the story to be the main task. 
The first perspective of task-based storytelling is quite similar to storytelling in the CLT approach. In this framework, the input task - listening to the story told by the teacher - was the core task, and the other activities were pre- and post-tasks. Student retelling the story is one of many post-task activities. Li and Seedhouse (2010, p. 291) diagrammatized the structures of the story-based lesson based on the task framework (Cameron, 2001) for young learners as shown in Figure 3.1 below:

Figure 3.1 The framework of a task-based storytelling lesson

\begin{tabular}{|c|c|c|c|}
\hline Preparation Stage & Core Activity Stage & \multicolumn{2}{|c|}{ Follow-up Stage } \\
\hline \multicolumn{4}{|l|}{ Lesson one } \\
\hline \multirow{3}{*}{$\begin{array}{l}\text { - Use visual aids } \\
\text { (e.g., puppets, realia } \\
\text { and pictures) to } \\
\text { attract the pupils' } \\
\text { attention or arouse } \\
\text { their curiosity. } \\
\text { - Introduce key } \\
\text { vocabulary. } \\
\text { - Activate pupils' } \\
\text { background } \\
\text { knowledge. }\end{array}$} & \multirow{3}{*}{$\begin{array}{l}\text { Teacher reads or tells } \\
\text { the story and pupils } \\
\text { listen to the story. } \\
\text { - Teacher helps pupils } \\
\text { to comprehend the } \\
\text { story by means of } \\
\text { gestures, tone of } \\
\text { voice, facial } \\
\text { expressions, sound } \\
\text { effects and mime. } \\
\text { Teacher gets pupils } \\
\text { involved during the } \\
\text { process. }\end{array}$} & \multicolumn{2}{|c|}{$\begin{array}{l}\text { - Post-story discussion } \\
\text { - TPR } \\
\text { - Games } \\
\text { - Comprehension-check } \\
\text { quiz }\end{array}$} \\
\hline & & Lesson two & \\
\hline & & $\begin{array}{l}\text { - Review v } \\
\text { sentences } \\
\text { - Act out th } \\
\text { - Make a st } \\
\text { - Draw a pi } \\
\text { - Retell the }\end{array}$ & $\begin{array}{l}\text { bulary, } \\
\text { the story } \\
\text { tory } \\
\text { book } \\
\text { re } \\
\text { ry }\end{array}$ \\
\hline
\end{tabular}

The second perspective of task-based storytelling is found in Kiernan (2005), Essig (2005) and Saucedo (2005) who did not consider the input task (listening to the teacher telling a story) to be the core task. In their framework, students' retelling the story is the during-task phase and the other activities were pre- and post-tasks. For example, Saucedo's method (2005) worked in a pre-school classroom in an English-as-a-second-language context in the UK. In the pre-task, children listen to the story; in the during-task, children retell the story; and in the post-task phase, children draw pictures from a story and describe their work while/after drawing and children are asked to make changes to the characters, setting, and ending in the story.

\section{Storytelling — an encompassing method}

Storytelling is composed of not only pre-while-post activities but also includes content-based activities, projects or an extended programme by the linking of other programmes or subjects (Kim, 2013). A wide range of content-based activities are recommended (as suggested in (Shin \& Crandall, 2014)) such as group retellings, storyboarding (students make simple drawings of the plot of the story on boxes and writes the characters' thoughts in bubbles) 
mini-books (students create their own stories and write them in their own books), parallel story (students write a similar story to the one in the storytelling but with details drawn from their own experience or imagination) and drama activities. In projects, students can work together in small groups to show their comprehension of the story, to improve their skills such as creating a story with a story map and expand their knowledge such as researching the author. Storytelling can also be combined with extensive reading. Macalister (2014) presents an approach incorporating extensive reading into the classroom using stories and the say-it activity for teaching and learning English in resource-poor contexts.

\section{Common characteristics of storytelling frameworks}

The discussion above has shown that storytelling has found support from different learning theories and perspectives, and various frameworks for constructing a storytelling lesson have been proposed. In fact, the frameworks from different learning theories have two main characteristics in common: the story and the procedure. In other words, the proposed frameworks are characterized by the fact that activities are contextualized in the framework of a story and are typically arranged in a three-phase sequence.

The story provides a meaningful context making links to all the activities. The story acts as a common thread in introducing various activities to provide learners with opportunities to engage them in using a variety of language skills in relation to the content of the story and bring learners together to create a dynamic learning atmosphere. Most of the activities are cooperative to offer opportunities for interactions, involving the use of language and for learning.

The common three-phase pedagogical sequence is comprised of pre-storytelling, duringstorytelling, and post-storytelling. The pre-storytelling phase is to introduce the story and to make the student aware of the context and the purpose of their tasks. In the during-storytelling phase, the story is read or told, and the post-storytelling phase is to extend and to consolidate the language presented through the story and to allow personalized work.

All of the aforementioned frameworks employ a holistic approach to teaching and learning and create classroom conditions in which the learners are involved "in dealing with different aspects of the language in the way language is normally used" (Samuda \& Bygate, 2008, p. 7). The approach focuses on meaning, not correction, on the outcome of the activity, not on the language or discrete language items, on collaboration and social development (Peck, 2001). The approach integrates the four skills and provides the learner with the linguistic and intellectual immersion necessary for language acquisition and cognitive development to take 
place. The approach is consistent with the cognitive, linguistic, social and emotional development of children.

In short, all of the activities in storytelling lessons are for meaningful language development and enjoyment and to develop children's intrinsic motivation, which is determined by the interest and the pleasure they experience during the activities in the foreign language classes (Brewster et al., 2002). The primary focus of the storytelling approach is on the construction of meaning. It sees language as a whole in a meaningful way for teaching and learning. Storytelling resonates the principles that deploy the holistic approach (Peck, 2001). The sequence of the activities around a story aims to create dynamic, meaningful activities with an emotional component in classrooms and to build a natural language learning and teaching environment so that students may implicitly acquire target language items.

\subsubsection{Benefits of stories and storytelling}

The benefits of storytelling have been validated by a considerable number of studies that investigate the effects of storytelling on the development of linguistics skills for young learners in EFL environments. Studies will be presented in three categories: motivation and engagement, language knowledge development and language skill development through interactions. In addition to positive claims, some studies with modest and negative findings were also analysed. The review of empirical studies shows two research gaps which will be presented in the summary section.

\subsection{Motivation and attitudes}

Storytelling is considered to be a powerful instrument to boost learners' motivation to learn languages and increase active participation in the language learning process (Ellis \& Brewster, 2014). The content and meaning of stories and the teacher's appropriate techniques create learners' interests in listening to and reading stories and engage learners in the learning process (Wright, 1995). Activities with stories make students' participation meaningful and improve their engagement.

This issue was examined in Gonzalez (2010), documenting an action research project conducted by eight trainee teachers who created and implemented their use of story reading and storytelling as a teaching tool for teaching English in elementary schools in Colombia. Based on the needs analysis, including direct observation, a survey and a diagnostic test, they created the syllabus and stories according to the children's interests and likes, planned the lessons, and collected and analysed data. Their lessons followed a pre-reading stage, a while- 
reading stage, and a post-reading stage. During the pre-story reading stage, large posters were used to create a good environment to introduce the story; some vocabulary work was done through games, songs, poems and matching activities; in the during-story reading stage, the story was read with body language and pictures to help students understand better. The students' prior knowledge was activated by making connections between the story and their lives, making predictions and answering questions. Follow-up activities in the post-reading stage included making little books with guided writing. The researcher stated that not only were young learners' attitudes, motivation, and participation found to have improved but their also comprehension ability and vocabulary acquisition.

In another qualitative study, Elk1lic and Akca (2008) researched the motivation and attitudes to learning English through storytelling of 21 Turkish Grade 4 elementary students. Using textbook units based on an adventure story about children, the intrinsic and extrinsic motivation of the young students was investigated using open-ended questions in a questionnaire. Most participants reported enjoying storytelling activities and perceived it as an important motivational tool. However, what learners perceive may not reflect how learners actually react or respond in the classroom. In addition, this study did not provide information about the students' actual performance in the classroom.

A caution was found in Safdarian and Ghyasi (2013) and Yang (2009) when applying the storytelling approach. The researchers warn that, although storytelling could boost students' reading skills and vocabulary knowledge, it was ineffective in motivating learners in foreign language learning if they did not fit with learners' age, interests, and language proficiency. Safdarian and Ghyas (2013) investigated the influence of storytelling on elementary-level foreign language learners' motivation and school achievement. The participants were 110 first grade secondary school learners who were 12 to 13 years old. Storybooks were selected at the students' level and the themes of the stories were similar to those of the chapters of the course book. Stories were read by the teacher and the meaning of new vocabulary was taught through gestures or actions. Data were collected using different tools: two parallel achievement tests, a motivation questionnaire and a semi-structured interview conducted among the intervention group. The study found that storytelling increased the students' school achievement, but that stories must be chosen carefully to suit the learners' age, interests, and language proficiency, otherwise, storytelling will not be a good measure for learning development. Similarly, Yang (2009) conducted a case study with 20 students aged from 12 to 14 years old to investigate the effects of short stories on students' attitudes, especially their interest and confidence in English. He found that "using short stories will not automatically make students more 
interested in English unless the stories are interesting, and the language used meets the level of the students" (p. 35).

Taken together, the studies seem to support claims about the effectiveness of storytelling in motivating learners in meaningful and engaging activities. Stories must be chosen carefully to suit young learners' characteristics.

\subsection{Storytelling and development of language knowledge}

Storytelling is also a way to improve students' vocabulary (Gomez, 2010), grammar (Garcia, 2017; Kalantari \& Hashemian, 2016; Kirsch, 2016; Soe, 2016) and pronunciation (Lucarevschi, 2018) in the meaningful contexts provided with the story. As an example, Kalantari and Hashemian's (2016) performed an experimental study on the effectiveness of storytelling on Iranian young learners' vocabulary and attitudes. They compared a regular class with lessons based on the Backpack textbook and an experimental class with storytelling lessons based on the textbook prepared by the teachers and the researcher. The teachers used storytelling with pre-, while- and post- activities. Before reading the stories, the participants received interesting and comprehensible input through the teacher's talk, games, reading and listening activities which familiarized them with the new language and vocabulary. While reading the story, the teacher directed the participants' attention to the PowerPoint presentation which included the visual representation of the story to facilitate comprehension. In the post-storytelling stage, the teacher played vocabulary games with the participants and asked them to role-play the story by memorizing the dialogue. To assess the students' improvement, a vocabulary pre- and post-test was conducted. The results showed that the experimental group of students experienced a significant increase in their vocabulary knowledge, compared to the control group. In addition, they become more motivated in learning with storytelling.

\subsection{Storytelling and development of language skills through interactions}

Some empirical studies report that storytelling can develop specific sets of skills, such as reading comprehension skills, critical reading skills (Belet \& Dala, 2010), listening (Oduolowu \& Oluwakemi, 2014), speaking (Fikriah, 2016) and writing (Alkaaf \& AlBulushi, 2017). Gupta (2009) report that storytelling plays an important role in the development of language skills by promoting social interaction and mutual collaboration. They claim that storytelling encourages learners to interact with the teachers and their classmates by listening and telling stories to each other, thus providing opportunities to receive support from their teachers and their classmates. 
Kim (2013) used classroom observations and teacher interviews to compare Korean elementary students' interactions in task-based lessons and storytelling-based lessons. The data included eight video lessons employed the task-based approach and eight lessons employing the storytelling approach. The findings indicate that different interaction patterns for task-based lessons and storytelling-based lessons were different. In task-based lessons, some pitfalls were found such as spending time explaining how to perform a task, mainly using low-level lessons, and frequent use of native language. The researcher suggests that task-based lessons may be most effective for learners who need to enhance a specific communicative activity. The frequency of students' interaction was significantly higher in the storytelling classrooms. The overall process of the storytelling lessons provided students with opportunities for dynamic interactions in the classroom, while in the task-based lessons, the teacher and students talked more in their native language. Kim (2013) also suggests that the storytelling approach was more efficient in developing vocabulary, background knowledge and skills due to the enjoyment created in story-based lessons.

Li and Seedhouse (2010) investigated the role of storytelling in the development of oral interaction in primary Taiwanese EFL classes. They compared learners' interactions in standard classes with textbook support (including choral drills, task-based activities and playing games) and storytelling classes (including talking about characters, prediction, storytelling, story discussion and pupils retelling the story). The researchers found there was an increase in oral interactions, vocabulary and expressions of different language functions among students in storytelling lessons as the story-based approach created an entertaining environment, causing a higher level of motivation and engagement from students. Li and Seedhouse (2010) suggest that storytelling is an effective tool for promoting social interactions and different language areas. Results of the studies by Kim (2013) and Li and Seedhouse (2010) suggest that storytelling helps learners improve their language skills through interacting in activities about the story.

However, Chwo and Chen's (2015) found that storytelling was not very effective. This study had a large population of 40 classes including 1036 primary school learners, from 10 schools, lasting 34 weeks. In the experimental group, the students, in addition to their normal English classes, had a daily 10-15 minute storytelling session led by the general class teacher who played a CD of an English story being read aloud, with no attendant preparation or associated activities. Occasionally, foreign English teachers told a story in person in a 40-minute session with pre-, while- and post- activities. Student also read and listened to stories from magazines. The control group had normal reading and listening input and they could borrow magazines to 
read and listen to outside the classroom. Results showed many favourable attitudes, together with considerable gains between pre- and post-tests of reading and listening, but interestingly no overall significant difference between the score improvements in the storytelling classes and those in the control classes.

In Chwo and Chen (2015), the unsuccessful storytelling may be due to two reasons. The first is that it was not clear whether the students listened to the stories during the daily 10-15 minutes storytelling sessions conducted by the general teachers. They did not have any reasons for listening to the stories and it was not clear how the students interacted with the story. The second reason was that they did not have any interactions after listening to the story to use what they had learned. The children had exposure to many stories, but they did not interact with the story or with friends to construct meaning and to use the language. McGee and Schickedanz (2007) suggest that just exposing children to stories is not enough to develop language and cognitive skills through storytelling. Storytelling should include activities planned around specific learning outcomes and the story serves as the reference point for teaching cognitive and linguistic skills.

\subsubsection{Summary}

There is a large range of literature addressing the impact of storytelling on EFL learners. Although the studies explore the effects of storytelling in different areas, a common feature across their findings is that storytelling positively influence motivation, language knowledge and language skills for young learners. Most studies report the positive effects on learners'motivation and interest in English classrooms. The use of stories is intrinsically motivating. They encourage learners to actively participate in the learning process by not only listening to stories but also discussing them and telling their own stories. The students enjoy the meaningfulness of the story and its creative activities. A significant finding from the empirical studies is that interaction plays an important role in storytelling lessons for language learning development.

The literature reveals two research gaps. First, in the studies, attention was paid to teachers telling the story and teacher-learner interaction when the teacher is telling the story. Learnerlearner interactions in storytelling lessons seems to be under-researched. Second, it was found in these above-mentioned studies that the storytelling approach is popularly conducted in countries where the curriculum is less restrictive and where teachers are allowed to choose their own materials and teaching method or where their textbooks were designed with stories and interactive storytelling. The researchers or participant teachers had freedom in choosing 
storybooks and creating stories that were suitable for the students' interests, proficiency levels, and age or they were supported with storybooks and by the authorities. There is a gap for more empirical research on the storytelling approach in a resource poor EFL environment where teaching is strictly regulated, and textbooks are considered to be the curriculum.

\subsection{Student engagement}

The main aim of storytelling in the classroom is develop learning. Student engagement is generally considered to be the best predictor of learning (Skinner \& Pitzer, 2012).

\subsubsection{Definition and indicators of student engagement}

Student engagement is used in education to refer to the degree of students' interest, participation and commitment in learning activities (Guthrie, 2010). It is defined as levels of effort in learning. As Lewis, Huebner, Malone and Valois (2011) put it: "Student engagement refers to a student's degree of active involvement in school through his or her thoughts, feelings and actions" (p. 251). In foreign or second language settings, student engagement refers to language use or development in activities that involve a primary focus on meaning and that require the use of the participant's own linguistic recourses such as their own language and their own ideas (Philp \& Duchesne, 2016). Student engagement shows how learning is happening; simultaneously, it cultivates learning outcomes and academic achievement.

Student engagement is displayed through taking part in activities and it is manifested in cognitive engagement, emotional engagement, and behavioural engagement (Fredricks, Blumenfeld, \& Paris, 2004). These three dimensions are conceptually distinct but highly integrated.

\subsubsection{Cognitive engagement}

Cognitive engagement involves the students' mental efforts, sustained attention and willingness "to exert necessary effort for comprehension of complex ideas or mastery of difficult skills" (Fredricks et al., 2004, p. 60). Engaged students use various thinking skills and self-regulatory strategies in combination with prior knowledge to learn deeply and thoughtfully. All of these cognitive activities are critical for deep understanding and learning. In different teaching contexts, various indicators of cognitive engagement have been identified, such as active listening, completing peer utterances, exchanging ideas, giving direction, explanation, questioning, justifying and argument (Philp \& Duchesne, 2016). Cognitive engagement is dependent on the task at hand; therefore, to define student cognitive 
engagement, it is necessary to investigate the mental effort students invest in working on the task. Bloom's taxonomy is a popular tool used to describe student cognitive engagement. In Table 3.1, the six levels of Bloom's taxonomy (Anderson et al., 2001) have used indicators of the depth of engagement. Each level of the revised Bloom's revised taxonomy is briefly restated as follows.

Table 3.1 Indicators of cognitive engagement

Indicators of cognitive engagement

\section{Explanations}

Happens when learners exhibit memory of previously learned material by recalling or memorizing facts, terms, concepts and answers.

Understanding Happens when learners take part in activities such as describing, explaining, summarizing, translating and stating the main ideas.

Applying Happens when learners use or apply their knowledge and understanding in different contexts.

Analysing Happens when learners break down information into its component elements and searching for relationships.

Evaluating Involves making informed judgement about something through activities such as comparing, contrasting and prioritizing.

Creating Happens when learners are required to generate new ideas through activities such as reconstructing, designing and inventing.

Among these six indicators of cognitive engagement, remembering, understanding and applying are categorized as low-order thinking skills, and analysing, evaluating and creating are high-order thinking skills. These indicators of cognitive engagement do not occur in a sequence or hierarchy. They are types of cognitive effort students might do in an activity and reflect differences between students' efforts to simply do the work and students' efforts that are focused on understanding and mastery. Remembering and understanding can be achieved through active or passive learning but applying, analysing, evaluating and creating can only be achieved through active learning. Children do not need to master the lower-level skills before engaging in higher-order thinking (Resnick, 1987). 


\subsubsection{Emotional engagement}

Emotional engagement refers to students' feelings about their relationships with others in a school environment, a sense of belongingness in the classroom and an interest, curiosity or enthusiasm about specific topics or activities. Emotional engagement tends to influence the students' overall willingness to do the work (Finn, Folger, \& Cox, 1991; Fredricks \& McColskey, 2012). Enthusiasm, interest, enjoyment, purposefulness and autonomy are identified as key positive indicators of engagement (Baralt, Gurzynski-Weiss, \& Kim, 2016; Skinner \& Pitzer, 2012). Emotional engagement also includes students feeling connected with peers in the classroom, particularly with their learning partners, and connectedness to and interest in the academic content (Bundick, Quaglia, Corso, \& Haywood, 2014). Students are engaged when they find personal meaning and value in the tasks (Schlechty, 2011) and when they have a sense of belonging, acceptance respect and value from their classmates, (Willms, 2003). One way to engender a feeling of value and belonging is to choose content that meets the students' interest (Brophy, 2008).

Another way is to teach students to work productively in cooperative groups. Depending on group activities, in which students can have a feeling of positive interdependence and group accountability (Frey, Fisher, \& Everlove, 2009; Smith, Sheppard, Johnson, \& Johnson, 2005). Positive interdependence is a feeling that their individual success depends on the success of all members in the group; that is, group members must work as a team toward a shared goal and be truly cooperative, not in competition with each other. Low interdependence shows that members do not need to cooperate and take loose responsibility because they do not cooperatively work toward the group's outcome. High positive interdependence shows that members need to cooperate to complete the task. Group accountability refers to the feeling of being responsible for the success of the group and that group success depends on all members' contributions. Weak group accountability shows little commitment to each other's learning and strong accountability indicates strong commitment for high-quality work in which members promote each other's success, helping and supporting each other's effort to learn, and building the feeling of competence.

\subsubsection{Behavioural engagement}

Behavioural engagement covers the ideas of students' participation and involvement in academic activities. Research indicates that student behavioural engagement leads to greater academic achievement (Ladd, 2013). It can be measured by observing students' various 
learning actions, and their effort and persistence in activities (Finn et al., 1991; Fredricks et al., 2004). Indicators of behavioural engagement are attendance, punctuality (Willms, 2003), numbers of spoken words (Bygate \& Samuda, 2009), numbers of talking turns (Dornyei \& Kormos, 2000; Shintani, 2016), dealing with trouble occurring in interactive language use (Shintani, 2016), concentrating, taking initiatives, following rules, asking questions and positively interacting with teachers and peers (Ladd, 2013). According to Schlechty (1994), students exhibit their engagement in three observable behaviours: (1) they are "attracted to their work", (2) they "persist" in their work "despite challenges and obstacles", and (3) they take "visible delight in accomplishing their work" (p. 5). Young learners depend on their parents/guardians for their attendance and punctuality and on the teacher' task for their turntaking; therefore, the categories identified by Schlechty (1994) are used to analyse students' engagement in this study.

To summarise, student engagement mirrors students' learning in multiple dimensions, particularly those of cognition, emotion, and behaviours.

\subsubsection{Factors influencing student engagement}

In the classroom, levels of engagement differ because of the teachers' behaviours and instructional styles. Researchers (Jang, Reeve, \& Deci, 2010) indicate that teachers' instruction supports student engagement if it presents interesting and relevant learning activities, provides optimal challenges with opportunities for initiation, autonomy, and creativity, highlights meaningful learning goals and supports students. However, instruction that is teacher-directed and focuses on skill mastery and controlling were not found to produce high level engagement (Bock \& Erickson, 2015). In general, students are more engaged in pedagogical approaches that make learning meaningful and communicative (Gibbs $\&$ Poskitt, 2010) and in autonomy-supportive learning activities (Reyes, Brackett, Rivers, White, \& Salovey, 2012). In particular, classroom interaction has been shown to produce a considerable influence on student engagement. Reyes et al. (2012) and Guvenc (2015) indicate that student engagement and academic performance depend on how the teacher promotes the classroom emotional environment. Students who feel happy in learning activities and feel that their classroom is a safe and valuable place to be were enthusiastic about learning. In contrast, students who were ignored by the teachers were unhappy and disengaged in learning. Indicators of engagement were developed from interactions in the classrooms and they varied due to different types of tasks. Therefore, teachers' instruction plays the most important role in student engagement in the classroom. Indicators of 
engagement mostly depend on the teacher's instructions and are specified in different processes of teaching and learning in the classroom.

Shintani (2016) compared student engagement in PPP lessons and task-based lessons in the Japanese context. The study reveals a clear difference between the classroom engagements resulting from the two kinds of instruction. The participants in her study were six-year-old beginning learners. The researcher compared of the students' engagement in terms of turntaking and repair. With regard to turn-taking, she examined IRF exchanges, question types, control of turn-taking, turns in chorus, topic, and length and frequency of turns. The students in the task-based class engaged in longer sequences of IRF exchanges, more referential questions, took more control in turn-taking and made more initiations in developing the topic than the PPP class. The results also revealed that, in the PPP group, the learners frequently engaged in interactions from the presentation input and corrective feedback from the teacher, while the task-based group learners frequently engaged in interactions from the production output.

Huang, Liu, Wang, Tsai, and Lin (2017) examined student engagement through their interactions in a digital storytelling approach in Taiwan. In their study, the students were provided with 15 model stories in an e-book on iPads. The students were asked to listen to the stories and to cooperatively work in pairs to record their oral readings, create their picture books and retell their stories. The student engagement was measured in terms of the students' flow patterns (interest, curiosity, control, and attention), strategy use (memory, compensation, cognitive, affective and social) and pair performance (language productivity, drawing presentation and audio recordings) in relation to their English proficiency level. Findings were that the students' proficiency levels influenced their engagement. First, mid- and lowproficiency students' flow perception increased with time as they gained a sense of achievement, while that of high-proficiency students decreased throughout the activities. Second, mid-proficiency students engaged more in applying multiple learning strategies in collaborative storytelling activities than the other two groups. Third, pair performance depended on whether the pair included a high-proficiency student who was likely to lead the learning process.

In summary, facets of engagement in the classroom are expressed differently in different teaching contexts and teaching practices. Teachers influence opportunities for engagement through instructions and classroom practices. It is what the students are expected or allowed to do and with whom that provides opportunities for engagement. 


\subsubsection{Young learner engagement}

Like adult learners, primary school students are able to distinguish the value of activities, enjoyment of activities and feeling of competence in joining in activities (Rimm-Kaufman, Baroody, Larsen, Curby, \& Abry, 2015). Elementary school children may easily disengage from their learning work if they are not provided with lessons they find meaningful and valuable with an appropriate challenge to foster their learning development. However, it is not easy to recognize how primary school children feel at the beginning of the activity as " $t$ ] hey want to please the teacher rather than their peer group. They will have a go at an activity even when they don't quite understand why and how" (Cameron, 2001, p. 1). They tend to be more obedient to their teachers than older learners; therefore, they appear to have more emotional engagement (Wang, Bergin, \& Bergin, 2014) and show their enjoyment in all activities the teacher prepares for them (Phillips, 1993). It is even more difficult to observe children's engagement. In Vietnam, children tend to be respectful of each other, patient and well behaved when sitting in class and follow all the teacher's instructions (Behr, 2005). However, in some classes, students appear to work on the task but does not necessarily mean that they are learning (Pintrich, 2003). In some activities, students may be behaviourally engaged but not cognitively engaged, resulting in superficial learning (O'Donnell, 2006). It is important to examine their actual engagement based on what activities they are doing, the quality of activities offered and their language-related episodes in interactions.

As stated in 3.4.2, student engagement in a classroom strongly depends on the teacher's practical instruction. How teachers view, and experience language learning and teaching is worth understanding because it affects actions in teaching situations. The following section will discuss the teacher's thinking and implementation decisions in terms of language teacher cognition.

\subsection{Language teacher cognition}

In recent years, many studies have aimed to understand teachers' cognition and their classroom practice (Baker, 2014). Research on the connection between language teacher cognition and educational practice is well established (Borg, 2003). Language teacher cognition has been defined as "what the language teachers think, know, and believe and the relationships of these mental constructs to what teachers do in the language teaching classroom” (Borg, 2003, p. 81).

Language teacher cognition research is acknowledged as essential because it provides a nuanced understanding of what is happening in their classroom (Borg, 2006; Macalister, 
2012). Research into language teacher cognition helps to understand teachers' minds and emotions in reference to their personal, professional, social, cultural and historical contexts and the roles they play in the process of becoming, being and developing as a teacher (Borg, 2019). According to Lai (2015), researching teacher cognition is valuable for on-going dissemination of innovation in teaching. If research focuses on improving teacher effectiveness and teaching performance, it is necessary to understand what accounts for thinking processes underlining teacher decision-making in terms of planning, instructions and reflection (Woods, 1996).

Teachers' mental constructs are assumed to be resistant to change, even in positive ways (Borg, 2003). Teachers' practices and decisions may be difficult to change when they become subject to "impulse, intuition, or routine" (Richards, 1998, p. 21), which may further prevent professional growth. Therefore, understanding of teacher's thinking and beliefs informs what is further required to affect them so that the appropriate influence will result in positive classroom change.

The dynamic relationship between teachers' mental constructs and their actions in the classroom has been described in three models. Woods (1996) developed a cognitive model to study teacher's decision-making processes. The model has three elements: classroom actions, the planning that precedes these actions, and the interpretation that follows them. The three elements interact with each other forming a system of teacher cognition. According to Woods (1996), classroom actions are carried out to operationalize plans that depend on the teacher's belief system, background knowledge and relevant contexts such as curricula or syllabus and materials. What happens in the classroom adds to the teacher's interpretation. In addition, Woods' model proposes the construct of beliefs, assumptions and knowledge (BAK) to explain the teacher's thinking and behaviours. Woods views all the teacher actions in the classroom as determined and interpreted through an interrelated cognitive system of BAK. BAK resembles schemata in the sense that "knowledge, assumptions, and beliefs can be posited in terms of interrelated propositions, in which certain propositions presuppose others" (Woods, 1996, p. 196). In summary, Woods' concept of teacher cognition is composed of the teacher's belief system, which consists of BAK and how this system influences their teaching behaviours.

In Borg's (2003, p. 82) model (Figure 3.2, below), language teacher cognition is developed through its relationship with four main aspects: the teacher's prior language learning experience, teacher education, contextual aspects, and classroom practices. The teacher's 
concepts about teaching and learning are established early on in their schooling experience. These concepts continue to be influential throughout their professional lives, and later they may be affected by professional education and training. Some contextual elements such as curriculum and teaching culture also affect the teacher's teaching practices which may be more or less compatible with the teacher's beliefs. At the same time, the teacher's ongoing experience in the classroom may simultaneously shape their cognition unconsciously or consciously through reflection; among these aspects, contextual and classroom aspects are directly related to the work of in-service teachers. The four constructs, in turn, manifest themselves in the teacher's decisions about classroom practices and choice of materials. This model emphasizes the importance of experience and contexts in the development of language teacher cognition.

Figure 3.2 Elements and processes in language teacher cognition: Borg's (2003) model

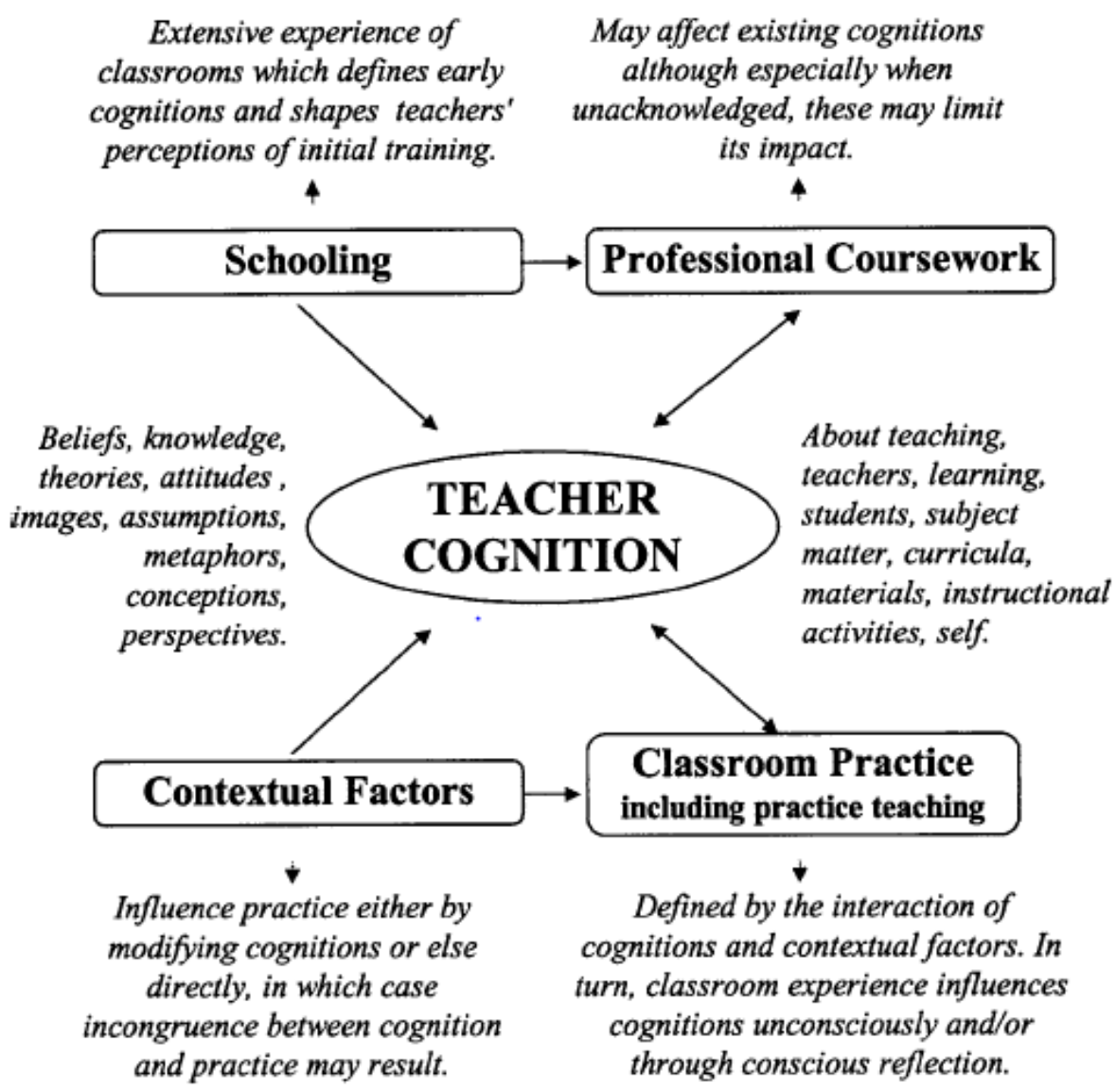

Macalister's (2010, p. 62) model (Figure 3.3, below) supports Borg (2006) with worthy innovations. Macalister (2010) emphasizes the interrelatedness between BAK and four aspects: the teacher's prior language learning experience, teacher education, contextual aspects, and classroom practices. BAK plays an important role in shaping the development of teacher cognition. In Macalister's model, BAK influences the development of language 
teacher cognition, and context affects both practice and cognition directly instead of affecting practice exclusively.

Figure 3.3 Elements and processes in language teacher cognition: Macalister's (2010) model

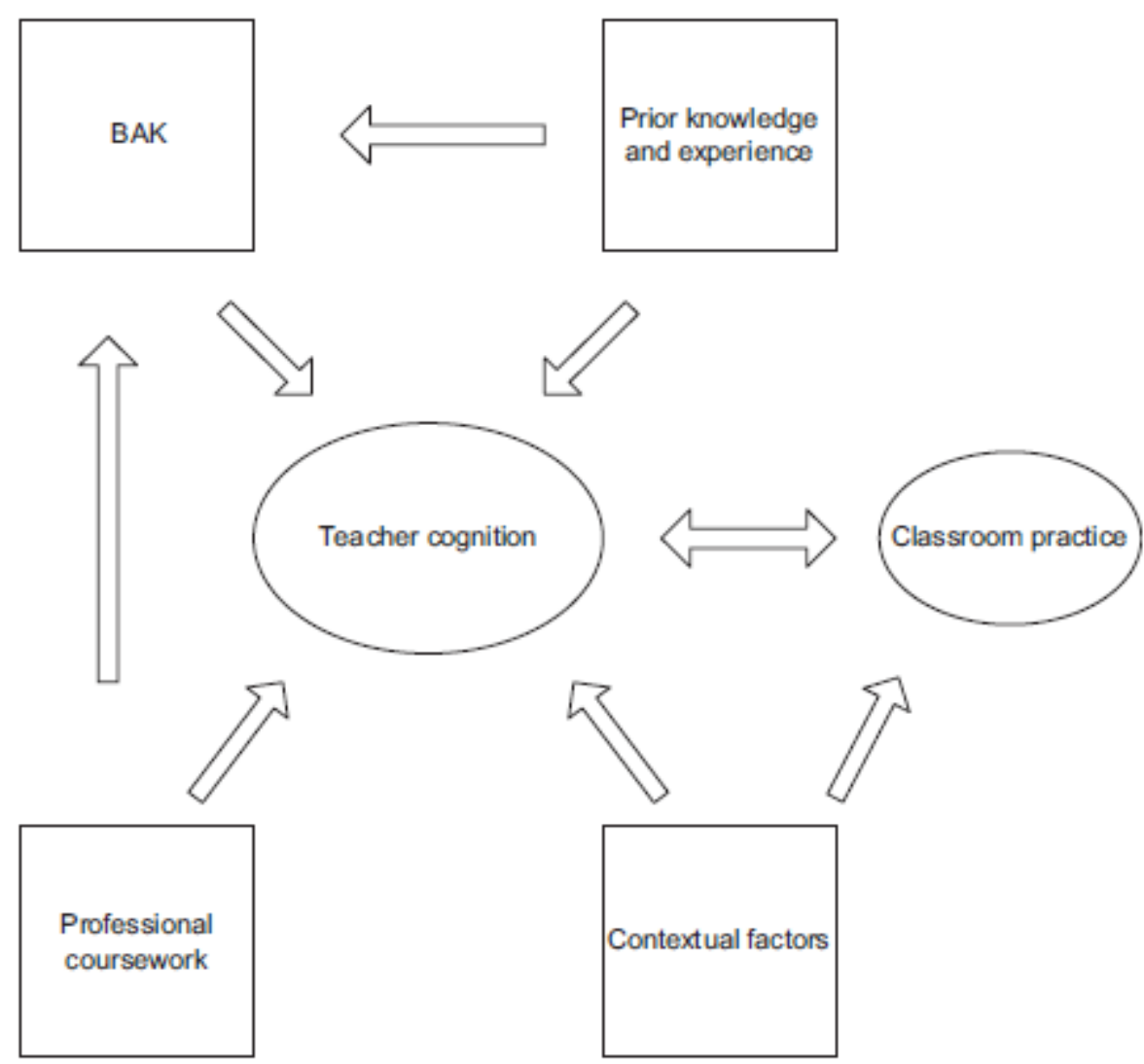

In Vietnam, research on teacher cognition has been mainly conducted at the secondary school level or higher and has mainly focused on task-based teaching and learning. It has been found that teachers' perceptions have been affected by many factors such as the status of the school, and the motivation and background of the teachers and students. However, teachers' beliefs and perceptions at the primary school level have recently been of concern.

Grassick (2016) investigated stakeholders' experience of primary English language curriculum change in a big city in Vietnam. Part of her study focuses on the teachers' perceptions of the curriculum change process and how their immediate implementation influenced the kind of pedagogical choices they make. The study consisted of seven primary school teachers as well as other participants. Using a qualitative research method, the researcher interviewed the teachers about their experience and perceptions of the curriculum change and observed the teachers' lessons. The findings showed that the teachers viewed the new curriculum and the Vietnamese National Foreign Language Project as a positive change, which benefited the students. However, no change was found in teaching practices. The need 
to complete the lesson in the textbook and to cover the set content for the end-of-term tests led to the teachers choosing to stick to old ways of teaching. What the teachers did in the classroom was much closer to an audio-lingual approach where the main aim of the lesson was to produce correct sentences. They expressed concerns about the constraints they faced which influenced what they did in the classroom. One of the constraints was teachers' professional selves - the teachers' own perceptions of the significance of their role in Project 2020. They felt they were viewed as inferior and less important than the core curriculum subject teachers. The teachers' own perception of their abilities, reinforced by other perceptions, led to little motivation to go beyond what was expected of them and did not foster an environment where the teacher was likely to take risks. Although the teachers perceived that communicative teaching would create opportunities for learners to be able to use English in real situations, they could rarely go beyond the mechanical practice designed in the textbooks. The teachers' understanding of communicativeness was based on their current teaching in which their lessons had a PPP structure and they described the students' language use as moving from controlled to less controlled practice. The curriculum changed, but the teaching context did not change. This resulted from teachers' lack of knowledge of TEYL, the management of teachers' teaching and students' learning basing on the textbook (the textbook was used as the curriculum) and limited professional development (they received little support from colleagues or from BOET and DOET).

Phan (2017) investigated primary school English language teachers' cognition of their professional learning in professional learning communities (PLC) in a large Vietnamese city. PLC refers to compulsory professional meetings for primary school teachers. One of the main jobs was to observe demonstration lessons and discussion activities in those lessons. A qualitative approach was employed to collect and analyse data. Results suggested that the teachers' perceptions of their learning in the PLC varied depending on their experience with PLC. For less experienced teachers, interschool meetings were valuable sites where they could learn from more experienced primary school English language teachers. Some primary English language teachers expressed their criticism of the over-rehearsed nature of the demonstration lessons as being too perfect and different from unobserved ones. For these teachers, what the demonstration teachers' perfect lessons offered them was irrelevant or inapplicable to their teaching situation. The results indicated that professional learning can both negatively and positively affect teachers' learning.

Part of Bui (2009) study explored teachers' perceptions of textbook speaking lessons and task-based lessons introduced as innovation in a two-phase study in a province in the south of 
Vietnam. Seven Grade 3 and 4 teachers participated in her research. In phase one, after observing nine speaking lessons, stimulated recall interviews were conducted with the teachers. The seven teachers all closely followed the PPP sequence of the speaking lesson. Three teachers had positive views about PPP lessons viewing the sequence of PPP as appropriate for lower-level classes. Three teachers were highly critical of this approach, viewing PPP lessons as mechanical, time-consuming and boring, and problematic for highlevel classes. One teacher had a neutral view. In phase two of her study; three teachers each taught two task-based lessons redesigned from the PPP textbook speaking lesson. They recognized the change of their students' behaviours in the classroom regarding their speaking opportunities, social development, and engagement. Although the teachers in Bui's (2009) study had positive opinions about the effects of the two task-based lessons, they worried that preparing tasks would take time and they would need to learn how to give clear task instructions. The researcher suggests that these practical concerns could be solved as teachers and learners became familiar with tasks.

Le (2019) explored how a primary school teacher in a big city developed her knowledge of teaching English to young learners via a single case study using narrative enquiry. The participant attended a four-year university degree in TEYL. Findings were that her expertise was from language learning and teaching rather than from TEYL coursework. Her professional coursework did not offer enough understanding of the underlying principles of teaching young learners. The teacher's lack of awareness of the needs and characteristics of young learners resulted in ineffective teaching practices. She was unaware that some of the teaching approaches in which she had been trained, such as those focusing on language such as grammar and vocabulary, were more appropriate for adults than young learners. She was one of the rare primary teachers who had a graduate education. Reflecting on what she did in her practicum, her lack of knowledge about the students made her rely on the textbook input without thinking about how the students learn. To deal with the problem of discipline, she reported talking too much in her classes. She had used the PPP model in her teaching ever since she started her teaching career. Although she wished to develop the children's basic skills in using English for communication, this was difficult because of pressure of preparing for language-focused examination, pressure from parents, professional isolation, heavy teaching overload, the need to teach private classes to compensate for her low salary and family responsibilities. These barriers prevented her from critically reflecting on her teaching for improvement or making professional change. The findings in this study were consistent with Richards (1998) finding that routine may prevent teachers' professional growth. 
The four studies discussed above demonstrate varied but inconclusive results of teachers' cognition in different contexts in Vietnam. Grassick (2016) is mainly concerned with the cognition related to the compatibility between the intended curriculum and the teachers' implementation of the curriculum; Phan (2017) is concerned more with the teachers' perception of professional learning activities. Le (2019) inquires how a primary school teacher made sense of her experience to develop her practical knowledge and Bui (2019) studied the teachers' cognition of the PPP lessons compared with the two task-based lessons. More research is needed in the current context where interschool meetings are becoming a monthly routine increasing the influence on teachers' learning from colleagues and leaders. Also, what is lacking is a more comprehensive picture of teachers' thinking and implementation decisions in a longitudinal study to trace teachers' cognitive development during a methodological change. Furthermore, research on teachers' perceptions in relation to storytelling has been limited. In the context of second and foreign language research, there have been no studies investigating the relationship between teacher cognition and storytelling.

\subsection{Summary and rationale for the study}

This chapter began by defining the importance of interactions in young learners' language learning. It then discussed the cognitive and sociocultural perspectives on interactions. Cognitive theory of learning views language acquisition as a conscious and reasoned thinking process, involving the use of mental efforts in processing information and learners as thinking beings and active processors of information. Sociocultural theory considers language learning as a social practice and students as active participants in the construction of learning processes. The two theories help understand the processes of social interactions, and their influence on young learners. The fact that young learners learn as they use language in interaction is affected by many factors such as learners' characteristics, social contexts and affective states. Therefore, research on language learning needs to focus on performance as well as social relationships in the context of which interactions take place.

The second section mainly presented young learners' characteristics and implications for TEYL. Young learners have distinctive features in regard to their intellectual development, cognition, language perceptions, imagination and creativity, and psychology. They have a strong desire to construct meaning via interactions with other people and they can use imagination as learning tools. They have social abilities that make them active in learning and they are able to give peer assistance. They need a holistic, integrated way of learning that involves them in meaning focus, interactions, cooperation and social development. 
The third section reviewed storytelling as an appropriate approach in TEYL in EFL contexts. Kirsch (2008) makes the point that the storytelling approach provides "a purposeful and communicative context [which] makes links to the real world" and it is "based on the pupils' prior knowledge experience and harness[es] their creativity and desire to learn" (p. 104). A review of studies on storytelling for young learners reveals a growing body of research. The results provided empirical evidence showing that storytelling benefits young learners in EFL contexts in terms of motivation, language knowledge and language skills. However, the review suggests that research into storytelling has two limitations. First, most research has focused on teachers-learner interactions and has emphasized students' involvement when the teacher is telling the story. Interactions in groups of learners in storytelling are underresearched. Second, studies reported successful implementation of storytelling with young learners designed by experts in quasi-experimental conditions or by teachers who have freedom in choosing their teaching materials. The review reveals no research into how EFL primary school teachers transform textbook dialogues into storytelling activities.

The fourth section reviews student engagement. Student engagement reflects how students invest their mental efforts, how they feel and how they participate in activities. Empirical studies have centred on one or two of the three dimensions of student engagement. There has not been any research into three dimensions of student engagement - cognition, emotion, and behaviours - especially with storytelling lessons.

The fifth section reviews teacher cognition. Teacher cognition reflects what the teacher thinks, knows and believes, and explains the teacher's actions in the classroom. Studies on primary school teacher cognition have provided an understanding of the popularity of PPP lessons, which are aimed at language features. As teachers are not well trained in TEYL, their teaching is mainly affected by their teaching contexts. The application of a new approach may influence the teachers' perceptions of their classroom routines. For these reasons, a longitudinal study is necessary to trace how EFL teachers perceive and reconstruct innovative activities they experience. Together with the analysis of student engagement, teacher perceptions would serve a clear explanation for the feasibility of an innovation.

The current study is an attempt to fill these gaps in the literature by exploring the effects of implementing storytelling lessons redesigned from the PPP textbook lessons in an authentic primary school classroom and by investigating student engagement in storytelling interactions and teacher cognition in the application of the storytelling innovation. The study seeks to 
examine factors that lead to success in order to introduce storytelling in a context where textbooks are the de facto curriculum, particularly in the primary school context in Vietnam. 


\section{CHAPTER 4 METHODOLOGY}

This chapter addresses the methodology used in the current study. It starts with an overview of the research design to present the rationales underpinning the methodological decisions. This is followed by the timeline of the research. Then, the methodologies of the first and the second phase of the study are described, including the research setting, data collection, data analysis, and ethical procedures. The methodology of the second phase also describes how story retelling tests were designed, piloted, and analysed, and how the intervention was created and piloted. The next section clarifies the strategies used to enhance the quality of the research project. The chapter ends with the role of the researcher.

\subsection{Research design}

This study adopted a mixed-method design for data collection, involving collecting qualitative data before and after an intervention; data interpretations were then made based on data integration. Mackey and Gass (2016) and Cohen, Manion, and Morrison (2018) point out that each type of qualitative and quantitative data collection has both strengths and weaknesses. Mixed methods combine the strengths to develop a stronger understanding of the research problem and minimize the weaknesses of each type of data to enhance validity and reliability of data and interpretations and to substantiate the findings.

In research on language teaching and learning, a mixed-method design has been a useful model as it helps collect both qualitative and quantitative data about the developmental processes in language acquisition, learner performance, learning outcomes and proficiency levels (Hashemi \& Babaii, 2013). In addition, the mixed-methods design allows researchers to generate multidimensional perspectives regarding the effects of teaching strategies and an understanding of learners' behaviours and reactions in a learning process and what happens in their minds and what factors allow learning (Ponce \& Pagán-Maldonado, 2015). My study employed exploratory sequential mixed-methods design (Creswell, 2014) which had two main phases. 
Phase 1 aims to seek answers to the research question: What is the current state of using stories and storytelling in teaching EFL in primary schools in Vietnam? Specifically, this phase focuses on answering the following sub-research questions:

1. What are the primary school EFL teachers' perceptions about stories and storytelling?

2. What is the primary school Vietnamese EFL learners' prior learning experience with stories and storytelling?

3. How do the primary school EFL teachers implement storytelling in their classroom practice?

4. What indicators are there of primary school EFL learners' engagement and participation with storytelling?

In Phase 1, qualitative methods (classroom observations, in-depth interviews and focus group interviews) were used to engender a better understanding of how stories and storytelling were used in teaching and learning in Vietnamese primary schools EFL context and to develop an intervention.

Phase 2 is aimed at determining the effectiveness of the storytelling innovation on teaching and learning EFL young learners' oral communicative competence, seeking answers for the questions below:

1. To what extent does the storytelling innovation improve primary school students' oral communicative competence?

2. What indicators are there of primary EFL students' engagement and participation?

3. What are the teachers' and students' perceptions of and reactions toward the storytelling innovation?

This phase employed an intervention referred as storytelling innovation and collected both quantitative and qualitative data to explore the effectiveness of storytelling innovation lessons. A quantitative method (story retelling tests) was used to find out whether the storytelling innovation could improve young learners' oral language production. Qualitative methods (classroom observations, in-depth interviews and focus group interviews) were employed during and after the intervention for a better understanding of the intervention results by incorporating and integrating teachers' and students' perspectives, behaviours and 
reactions. This mixed-method approach helped to collect rich data and develop contextualized descriptions and understanding of the storytelling innovation in Vietnam.

\subsection{Timeline of the research}

This section provides the timeline for the two phases of the study. Table 4.1 and Table 4.2, below, detail the main data collection procedures from the start to the completion of Phases 1 and 2. To prepare for the main data collection, some preliminary activities were conducted. The timeline for the preparatory activities is also detailed in the tables.

Table 4.1 Timeline for Phase 1

Research activities

1. Permission to conduct research

2. Piloting

3. Permission from BOET

4. Piloting in researched sites

5. Inviting participating schools

6. Inviting participants teachers and pupils

7. Classroom observations

8. Interviewing teachers and students
Time

June 2017

July-September 1017

October 2017

October 2017

October 2017

October 2017

October-December 2017

December 2017

Table 4.2 Timeline for Phase 2

\section{Research activities}

1. Story retelling piloting

2. Storytelling lesson piloting

3. Story retelling piloting researched sites

4. Permission to conduct research from BOET

5. Inviting participant schools

6. Inviting participant teachers and students

7. Meeting with the intervention group teacher

8. Pre-story retelling

9. Modelling teaching storytelling lesson

10. Classroom observations

11. Post-story retellings

12. Interviewing teachers and students

\section{Time}

July 2017

August 2017

November 2017

December 2017

December 2017

December 2017

December 2017

December 2017

January 2018

January-May 2018

May 2018

May 2018 


\subsection{Phase 1 Methodology}

\subsubsection{Research setting}

\subsubsection{Research sites}

The study took place in 18 state primary schools in three towns in a province in the Mekong Delta in the south of Vietnam.

As seen in Table 4.3, the number of the students in each class was high; observed classes in only 13 out of 21 primary schools met the standard of no more than 35 students set by MOET. Two schools were half-day schools while the other primary schools were full-day schools, five days a week.

At the time of data collection, the same mandatory textbooks were used in primary schools in these three towns except for the textbooks for teaching English. The two textbooks were Tieng Anh third edition and Family and Friends special edition (see section 5.1 for more information about the textbooks. In the researched site, there were three official English teaching programmes: (1) four periods per week with Tieng Anh textbooks, (2) two periods per week with Tieng Anh textbooks and (3) four periods per week with Family and Friends textbooks. Each period lasted 35 or 40 minutes.

Table 4.3 shows that 10 schools taught English for four periods per weeks and 11 schools taught English for two periods a week.

Table 4.3 Participants' demographics

\begin{tabular}{|c|c|c|c|c|c|c|c|c|}
\hline \multicolumn{6}{|c|}{ Schools and students } & \multicolumn{3}{|c|}{ Teachers } \\
\hline$\dot{0}$ & 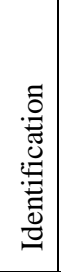 & 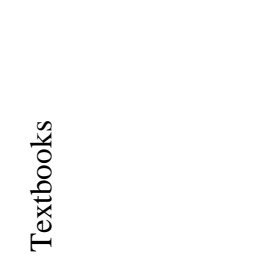 & 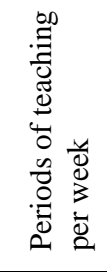 & 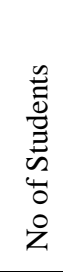 & 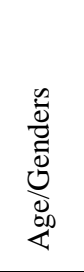 & 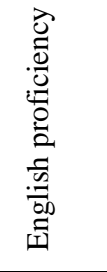 & 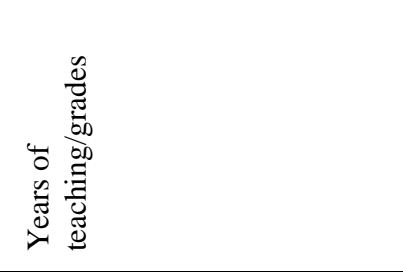 & 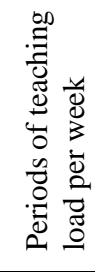 \\
\hline 1 & A & Family and Friends & 4 & 35 & $42 / \mathrm{M}$ & $\mathrm{B} 2 / \mathrm{W}$ & 22 (teaching grades $3,4,5$ ) & 19 \\
\hline 2 & B & Family and Friends & 4 & 35 & $33 / \mathrm{F}$ & B1 & 9 (teaching grades $3,4,5$ ) & 20 \\
\hline 3 & $\mathrm{C}$ & Family and Friends & 4 & 47 & $42 / \mathrm{F}$ & $\mathrm{B} 2 / \mathrm{W}$ & $\begin{array}{l}22 \text { ( } 4 \text { years teaching both } \\
\text { junior secondary schools, now } \\
\text { teaching grades } 3,4,5)\end{array}$ & 16 \\
\hline 4 & $\mathrm{D}$ & Family and Friends & 4 & 34 & $41 / \mathrm{F}$ & $\mathrm{B} 2 / \mathrm{W}$ & 21 (teaching grades $3,4,5$ ) & 16 \\
\hline 5 & $\mathrm{E}$ & Family and Friends & 4 & 32 & $42 / \mathrm{M}$ & $\mathrm{B} 2 / \mathrm{W}$ & 22 (teaching grades $3,4,5$ ) & 16 \\
\hline \multirow[t]{3}{*}{6} & \multirow[t]{3}{*}{$\mathrm{F}$} & \multirow[t]{3}{*}{ Tieng Anh } & \multirow[t]{3}{*}{4} & 46 & $44 / \mathrm{F}$ & $\mathrm{B} 2 / \mathrm{W}$ & 24 (teaching grades $3,4,5$ ) & 18 \\
\hline & & & & 46 & $44 / \mathrm{F}$ & $\mathrm{B} 2 / \mathrm{W}$ & 24 (teaching grades $3,4,5$ ) & \\
\hline & & & & 46 & $43 / \mathrm{F}$ & B2 & 20 (teaching grades $3,4,5$ ) & 18 \\
\hline
\end{tabular}




\begin{tabular}{|c|c|c|c|c|c|c|c|c|}
\hline 7 & G & Tieng Anh & 2 & 29 & $43 / \mathrm{F}$ & B2 & $\begin{array}{l}21 \text { ( } 3 \text { years teaching both } \\
\text { junior secondary \& primary } \\
\text { schools, teaching grades } 3,4 \text {, } \\
5 \text { since } 1999)\end{array}$ & 18 \\
\hline 8 & $\mathrm{H}$ & Tieng Anh & 2 & 35 & $42 / \mathrm{M}$ & $\mathrm{B} 2 / \mathrm{W}$ & 22 (teaching grades $3,4,5$ ) & 12 \\
\hline 9 & I & Tieng Anh & 2 & 28 & $39 / \mathrm{F}$ & B2 & 16 (teaching grades $3,4,5$ ) & 10 \\
\hline 10 & $\mathrm{~J}$ & Tieng Anh & 2 & 41 & $51 / \mathrm{F}$ & B2 & 24 (teaching grades $3,4,5$ ) & \\
\hline \multirow[t]{2}{*}{11} & \multirow{2}{*}{$\begin{array}{l}\mathrm{K} \\
*\end{array}$} & \multirow[t]{2}{*}{ Tieng Anh } & \multirow[t]{2}{*}{2} & 51 & $45 \mathrm{~F}$ & $\mathrm{~B} 2 / \mathrm{W}$ & 25 (teaching grades $3,4,5$ ) & 16 \\
\hline & & & & 29 & $36 / \mathrm{F}$ & B2 & $\begin{array}{l}14 \text { ( } 13 \text { teaching junior } \\
\text { secondary school, first year } \\
\text { teaching grade } 5)\end{array}$ & 2 \\
\hline 12 & $\mathrm{~L}$ & Tieng Anh & 2 & 23 & $51 / \mathrm{F}$ & B1 & $\begin{array}{l}24 \text { ( } 9 \text { years teaching junior } \\
\text { secondary school, } 15 \text { years } \\
\text { teaching grade } 3,4,5 \text { ) }\end{array}$ & $18 /$ \\
\hline 13 & M & Tieng Anh & 2 & 35 & 38/M & $\mathrm{B} 2 / \mathrm{W}$ & 17 (teaching grades $3,4,5$ ) & 29 \\
\hline 14 & $\mathrm{~N}$ & Tieng Anh & 2 & 35 & $\mathrm{~F}$ & B2 & 17 (teaching grades $3,4,5$ ) & 26 \\
\hline 15 & $\mathrm{O}$ & Family and Friends & 4 & 35 & $40 / \mathrm{F}$ & B2 & 19 (teaching grades $3,4,5$ ) & 20 \\
\hline 16 & $\begin{array}{l}\mathrm{P} \\
*\end{array}$ & Family and Friends & 4 & 40 & $42 / \mathrm{F}$ & B2 & 22 (teaching grades $3,4,5$ ) & 18 \\
\hline 17 & Q & Family and Friends & 4 & 41 & $42 / \mathrm{F}$ & $\mathrm{B} 2 / \mathrm{W}$ & 22 (teaching grades $3,4,5$ ) & 22 \\
\hline 18 & $\mathrm{R}$ & Family and Friends & 4 & 40 & $45 / \mathrm{F}$ & B2 & $\begin{array}{l}25 \text { ( } 3 \text { years teaching junior } \\
\text { secondary school, teaching } \\
\text { grades } 3,4,5)\end{array}$ & 24 \\
\hline
\end{tabular}

Note. $\mathrm{F}=$ Female, $\mathrm{M}=$ male, ${ }^{*}=$ half-day school, $\mathrm{W}=$ attended workshop on TEYL

\subsubsection{Participating teachers}

Twenty-one primary English teachers who were teaching Grade 5 participated in the current study. All the teachers studied at the same teacher training college. Nineteen of them graduated from a three-year course majoring in English teaching. Two of them first graduated from a three-year course majoring in Russian teaching. After graduation, they immediately attended a two-year course in teaching English. They majored in teaching junior secondary school students. In 2011, nine of the participating teachers attended 180-period workshops on TEYL. Table 4.3 showed that nearly all of them had some years of experience in teaching at primary schools except one of the teachers (in School K) who was teaching at primary school for the first year in her career after her teaching at a junior high school for 10 years.

Table 4.3 indicates that the teachers' teaching load was very different. The teachers who had lower teaching load reported that they had to do other jobs such as being the secretary of their school council of examination and organizing School Union activities. 


\subsubsection{Participant students}

Students in 21 Grade 5 classes joined the study. They started to learn English in Grade 3. They had similar educational backgrounds. When they started schools, they were randomly put in a Grade 1 class and they had remained in the same class for five years. The students' relationships had been formed over four years. This familiarity potentially creates a positive socio-affective context for language learning.

\subsubsection{School facilities}

The participant schools seemed well-equipped, but the quality of the equipment had problems. Among 18 schools taking part in the study, 12 schools had a special room for teaching English which was called Learning English Classroom. In this room, there was a computer, a projector, a smartboard, a visualizer, loudspeakers and other devices for playing multiplechoice tests or doing a survey and some pictures. However, only two Learning English Classrooms in two of the primary schools worked well. Some normal classrooms had a projector or a TV. In the normal classrooms and Learning English Classrooms, students sat in rows and it was difficult for them to move around. Normally, each school had tape players for teachers of English.

\subsubsection{Data collection methods}

Data in this phase were collected through multiple methods including analysis of materials, observation, field notes and interviews.

\subsubsection{Materials}

Analysis of the curriculum and textbooks allows the researcher to understand the rationale for the teachers' process in the classroom. Materials such as textbooks and their manuals provide the main contextual data for the research. Mackey and Gass (2016) and Kumaravadivelu (2006) point out that material analysis makes sense of how teachers planned their lessons and how they implemented what they planned.

These important documents served as a start for this current study's data analysis. In the current study, the 2010 and 2018 curricula, Tieng Anh for Grade 5 (Hoang et al., 2015a), Family and Friends Grade 5 (Thompson \& Simmons, 2016) and the teachers' manuals for Tieng Anh textbooks Grade 5 (Hoang et al., 2015b) and lesson plans of Family and Friends Grade 5 were analysed to understand how stories and storytelling were designed in a lesson and the principles behind them. 


\subsubsection{Classroom observation, audio-recording and field notes}

Classroom observation is a useful tool to collect "first-hand, 'live' data in situ from naturally occurring situations" (Cohen et al., 2018, p. 542). It is an effective way to gather information about second and foreign language teaching and learning in a classroom such as instructions, interaction, participation, engagement and language use (Mackey \& Gass, 2016). In teacher cognition research, observation is essential because it "provides evidence of what happens in classrooms" (Borg, 2006, p. 247).

The observational data were obtained from observing 42 lessons (see Table 4.4, below) (two lessons each teacher) on the teachers' normal schedules. The observations were supplemented with field notes and audio-recordings. Audio-recordings of the observed lessons were made during the classroom observation to avoid missing any important information.

Table 4.4 Lessons observed

\begin{tabular}{|c|c|c|c|}
\hline No. & Teachers & Textbook & Lessons \\
\hline \multirow[t]{2}{*}{1} & \multirow[t]{2}{*}{$\mathrm{T} 1$} & \multirow{2}{*}{$\begin{array}{l}\text { Family and Friends } \\
\text { Grade } 5\end{array}$} & Unit 5 Lesson 1 \\
\hline & & & Unit 5 Lesson 5 \\
\hline \multirow[t]{2}{*}{2} & \multirow[t]{2}{*}{$\mathrm{T} 2$} & \multirow{2}{*}{$\begin{array}{l}\text { Family and Friends } \\
\text { Grade } 5\end{array}$} & Unit 6 Lesson 1 \\
\hline & & & Extensive Reading \\
\hline \multirow[t]{2}{*}{3} & \multirow[t]{2}{*}{ T3 } & \multirow{2}{*}{$\begin{array}{l}\text { Family and Friends } \\
\text { Grade } 5\end{array}$} & Review 1 Part 1 \\
\hline & & & Unit 4 Lesson 1 \\
\hline \multirow[t]{2}{*}{4} & \multirow[t]{2}{*}{$\mathrm{T} 4$} & \multirow{2}{*}{$\begin{array}{l}\text { Family and Friends } \\
\text { Grade } 5\end{array}$} & Review 1 part 1 \\
\hline & & & Unit 4 Lesson 1 \\
\hline \multirow[t]{2}{*}{5} & \multirow[t]{2}{*}{ T5 } & \multirow{2}{*}{$\begin{array}{l}\text { Family and Friends } \\
\text { Grade } 5\end{array}$} & Review 1 Part 1 \\
\hline & & & Unit 5 Lesson 1 \\
\hline \multirow[t]{2}{*}{6} & \multirow[t]{2}{*}{ T6 } & \multirow[t]{2}{*}{ Tieng Anh 5 Volume 1} & Unit 6 Lesson 2 part 1 \\
\hline & & & Unit 6 Lesson 2 part 2 \\
\hline \multirow[t]{2}{*}{7} & \multirow[t]{2}{*}{$\mathrm{T} 7$} & \multirow[t]{2}{*}{ Tieng Anh Volume 1} & Unit 6 Lesson 1 Part 1 \\
\hline & & & Unit 6 Lesson 1 Part 2 \\
\hline \multirow[t]{2}{*}{8} & \multirow[t]{2}{*}{$\mathrm{T} 8$} & \multirow[t]{2}{*}{ Tieng Anh Volume 1} & Review 1 Short story \\
\hline & & & Unit 6 Lesson 1 \\
\hline \multirow[t]{2}{*}{9} & \multirow[t]{2}{*}{ T9 } & \multirow[t]{2}{*}{ Tieng Anh Volume 1} & Unit 6 Lesson 1 \\
\hline & & & Unit 6 Lesson 2 \\
\hline \multirow[t]{2}{*}{10} & \multirow[t]{2}{*}{ T10 } & \multirow[t]{2}{*}{ Tieng Anh Volume 1} & Review 1 Short story \\
\hline & & & Unit 6 Lesson 2 \\
\hline \multirow[t]{2}{*}{11} & \multirow[t]{2}{*}{$\mathrm{T} 11$} & Tieng Anh Volume 1 & Unit 6 Lesson 3 \\
\hline & & & Unit 7 Lesson 1 \\
\hline 12 & $\mathrm{~T} 12$ & Tieng Anh Volume 1 & Unit 8 Lesson 1 \\
\hline & & & Unit 8 Lesson 2 \\
\hline 13 & T13 & Tieng Anh Volume 1 & Unit 5 Lesson 3 \\
\hline & & & Unit 6 Lesson 2 \\
\hline 14 & T14 & Tieng Anh Volume 1 & Unit 6 Lesson 2 \\
\hline & & & Unit 7 Lesson 3 \\
\hline 15 & $\mathrm{~T} 15$ & Tieng Anh Volume 1 & Unit 4 Lesson 1 \\
\hline & & & Unit 5 Lesson 1 \\
\hline
\end{tabular}




\begin{tabular}{|c|c|c|c|}
\hline \multirow[t]{2}{*}{16} & \multirow[t]{2}{*}{ T16 } & \multirow[t]{2}{*}{ Tieng Anh Volume 1} & Unit 5 Lesson 1 \\
\hline & & & Review 1 Short story \\
\hline \multirow[t]{2}{*}{17} & \multirow[t]{2}{*}{ T17 } & \multirow[t]{2}{*}{ Tieng Anh Volume 1} & Unit 5 Lesson 2 \\
\hline & & & Review 1 Short story \\
\hline \multirow[t]{2}{*}{18} & \multirow[t]{2}{*}{ T18 } & \multirow{2}{*}{$\begin{array}{l}\text { Family and Fiends } \\
\text { Grade } 5\end{array}$} & Unit 5 Lesson 1 \\
\hline & & & Unit 5 Lesson 5 \\
\hline \multirow[t]{2}{*}{19} & \multirow[t]{2}{*}{ T19 } & \multirow{2}{*}{$\begin{array}{l}\text { Family and Fiends } \\
\text { Grade } 5\end{array}$} & Unit 3 Lesson 6 \\
\hline & & & Unit 4 Lesson 1 \\
\hline \multirow[t]{2}{*}{20} & \multirow[t]{2}{*}{$\mathrm{T} 20$} & \multirow[t]{2}{*}{$\begin{array}{l}\text { Family and Fiends } \\
\text { Grade } 5\end{array}$} & $\begin{array}{l}\text { Unit } 4 \text { Lesson } 3 \\
\text { (a song lesson) }\end{array}$ \\
\hline & & & Unit 5 Lesson 5 \\
\hline \multirow[t]{2}{*}{21} & \multirow[t]{2}{*}{$\mathrm{T} 21$} & \multirow{2}{*}{$\begin{array}{l}\text { Family and Fiends } \\
\text { Grade } 5\end{array}$} & Unit 3 Lesson 1 \\
\hline & & & Unit 5 Lesson 5 \\
\hline
\end{tabular}

During classroom observation, I took the role of a non-participant observer. Non-participant observation was employed as it allows the researcher "to catch the dynamic nature of events" (Cohen et al., 2018, p. 544). For each observation, I sat quietly at the back of the room, turned on the recorder and took notes. A few students paid attention to my presence in the classroom by occasionally looking at me. Most of them quickly ignored me when the lesson proceeded. In these cases, I gave them a friendly smile and signalled them to focus on their study. After the lesson, I thanked them for allowing my presence in their classroom.

\section{Field notes}

Field notes are significant for future recall of any particular details of a situation (Patton, 2015). Fieldnotes describe how the activities took place during the observed lessons and include the researcher's reflective comments on reactions and initial interpretations; therefore, these descriptive notes provide opportunities to look back at classroom observations for analysis (Merriam \& Tisdell, 2016). During the observations, I also took unstructured field notes to record the facts, reactions or perceptions I felt were relevant to the inquiry (Borg, 2001) without being constrained by predetermined categories (Nunan, 2011).

I took notes about the lesson sequence and events that happened in the teachers' lessons. I made brief notes of what happened, the time that each activity happened, and the student's reactions and I noted occasional comments. The field notes gave me a good sense of the structure of the lesson and they also allowed me to record easy-to-find details of the recordings if necessary. The purpose of my observations was to understand the reasons behind the activities in the teachers' lessons. Some points that needed clarifying were noted and were used to frame questions in the interviews. 


\subsubsection{Interviews}

Collecting data on teaching practices from observation is insufficient for examining teachers' thoughts and beliefs (Borg, 2006; Nunan \& Bailey, 2009). Other research methodologists (Creswell, 2005; Mackey \& Gass, 2016) suggest the use of interviews to explore what is not directly observed. Interviews can enter into the participants' perspectives, and discover the meaning they attach to their own experiences (Patton, 2015). The combined analysis of observation and interview data facilitate a deep understanding of the phenomenon being investigated (Merriam \& Tisdell, 2016).

Semi-structured interviews were used, in which topics and issues were specified in an outline form in advance (Cohen et al., 2018). A semi-structured format allowed researchers to 'probe for more information' when necessary. The order of the questions can be changed depending on the flow of the conversation. Follow-up questions can clarify unclear opinions. Therefore, semi-structured interviews help collect the same general area of information from each participant, but still allowed freedom and adaptability in gaining information (Cohen et al., 2018; Guthrie, 2010; Merriam, 2009). Second, semi-structured interviews allow for prior preparation based on what has emerged from the observed lessons. Third, the topics are prepared ahead of time; thereby allowing for comparisons of the rationales of individual teachers and students on their practices. Fourth, semi-structured interviews are fairly conversational and informal, which helps establish comfort for interviewees, especially for children (Flewitt, 2014).

One weak point of interviews according to Creswell (2005) and Borg (2006) is that interview data may be deceptive; that is, teachers might talk about what might not be true for them. To deal with this concern, I met each individual teacher twice to seek the teachers' rationales for their teaching practices, especially on their perceptions and theories about stories and storytelling. The second interview assisted in avoiding relying on one source of data and provided a rich foundation for triangulation to enhance the quality of the findings.

Each interview followed up an observation. The meetings were set by making an appointment at the teachers' convenience. All the participant teachers chose to be interviewed in Vietnamese, which made them feel relaxed and confident. Each interview lasted around 20 to 30 minutes. The questions for the teachers' interviews centred on 10 main areas. They included personal teaching experience, English school environment, English class environment, the new curriculum and the new textbook, the lesson observed, learning goals and activities, indicators of students' engagement and participation, recollections of using 
stories and storytelling, perceptions of stories and storytelling, stories the students like and out-of-school storytelling experience.

To get data from the participant students, focus group interviews (see Appendix 1) were employed. Focus group interview refers to a number of people forming a group who are asked to reflect on questions asked by the interviewer (Kitzinger, 1995; Krueger \& Casey, 2009; Patton, 2015). This means that it does not involve the researcher asking each participant to response to a question. Also, participants could change their responses or make additional responses after hearing what other members say. Focus group interview focusses on encouraging participants to interact, talk and share ideas with each other about the questions in order to generate data "in a social context where people can consider their own views in the contexts of the views of other" (Patton, 1987, p. 135). Members of a group do not need to reach an agreement or have complete opposite opinions.

Group interviews are appropriate when working with children, especially children who have been studying together for some time (Watts \& Ebbutt, 1987). Cohen et al. (2018) note that group interviews can establish a friendly, trusting and confident atmosphere. Second, they can also be less intimidating for students than an individual interview. Third, a group interview is economical in terms of time and cost.

A group of six students from each class (one group had eight students because two uninvited students insisting on joining the interview) was invited. Each group was interviewed once after I observed two lessons in their class. The students wanted to talk in Vietnamese. Due to time constraints and a busy class schedule, the length of each interview varied from 15 to 20 minutes. Interviews with the students were conducted in the staff room in the break time, without any presence of staff or their teachers. These interviews were supported by the form teachers who allowed the students to be absent for a while for the interview. The questions for the students' group interviews centred on learning topics equivalent to those mentioned above for teachers.

From the experience of interview piloting (mentioned below), I followed a friendly interview process: (1) start informally by saying hello and expressing appreciation for their attendance; (2) address the reason and goal of interview and determine the duration; (3) increase the interviewee's confidence by emphasizing that there were no right or wrong answers and that their participation would be anonymous; (4) allow the interviewees to ask questions before the interview started (5) begin with easy questions and continue with open questions, and take 
notes to facilitate follow-up or elaboration questions or to request examples to get deeper information; and (6) summarise their opinions and express appreciation again.

For the students, I tried to be friendly to them at the first appearance and did some friendly body language gestures such as the give-me-five action or thumbs-up when they were trying to give their ideas. I took the role of a moderator to facilitate the students' talk. To avoid hurting their feelings, for each question, I neither pressed for the answers nor forced students to give the answers, nor made any comments. The students understood that they did not have to agree with their friends and that they were free to tell what they experienced and perceived. In the interviews. I probed for opinions from all the pupils in the group and used open-ended questions to generate discussion between interviewees in a group. I sometimes used closed questions to make them feel at ease before asking them open questions.

Being aware of the possibility that some higher proficiency students or students with a strong personality might dominate the interview, I encouraged each student to speak. I tried to develop good rapport necessary for group interview, as Flewitt (2014) puts it: "interview data depends upon how researchers manage the interview process and the relationship between themselves and the participants, and also between the participants in group interviews" (p. 142). My friendly attitudes helped the students feel relaxed and confident during the interviews.

\section{Interview piloting}

Although a piloting study cannot detect all the systematic errors or all unexpected problems, it can partly help to test the research process and the efficacy of research instruments and to make necessary adjustments (Walliman, 2011). The purpose of piloting is also to familiarize researchers with the data collection instruments, to test the quality of recordings, to modify the interview questions and to learn how to probe appropriately and effectively during the interviews (Patton, 2015).

The piloting in the current research was carried out in New Zealand and in Vietnam before the formal data collection. In New Zealand, two in-depth interviews were piloted; one was with my three PhD friends and the other was with my supervisor. In Vietnam, semi-structured interviews and group interviews were tested with two teachers and two groups of six Grade 5 students in two different schools that were officially participating in my study.

A good interview is a co-constructed conversation between the interviewer and the interviewees, allowing the interviewee to talk about what they want to talk about (Merriam \& 
Tisdell, 2016). My pilot interviews seemed not to achieve this fully. I was quite hurried in my way of inquiry. I should have given the interviewees enough time to think and to talk about their opinions, even although what they were talking was off-track. During the interviews, I lacked eye contact because I was busy taking notes; as a result, the teachers were put off while they were talking. In addition, I noticed that could not take notes fast enough. Therefore, I decided to take notes of some points that I need to make clear. In this way, I was able to make more eye contact with the interviewees instead of focusing on writing. The main task I could do well in the interviews was to listen actively and respond to what the participants said. I was also able to develop my interview techniques by listening to the recordings and noting when I seemed to be leading the participants and where I needed to encourage them to expand on their responses.

The Vietnamese primary school teachers and students had hardly ever joined any research or been interviewed before; hence, they felt nervous when being interviewed and recorded. The teachers easily felt ashamed when they could not answer, and sometimes appeared to think that their answers were wrong; therefore, I kept informing them about the values of their opinions, about confidentiality and anonymity in presenting the data.

All these piloting experiences improved my interview skills and help me to conduct a friendly process of interviews as mentioned in the previous section.

\subsubsection{Data analysis}

\subsubsection{Textbook analysis}

The aim of textbook analysis is not to evaluate the whole textbook, but to discover the methodology suggested to be used with the stories in the textbooks. The analysis of the stories in the textbook was based on the definition of a story mentioned in the literature chapter. The analysis of the qualities of activities was in light of the conditions of meaning-focused input, output and language-focus learning (Nation, 2007). These conditions are presented together with the results of the analysis of the textbook activities in Chapter 5.

\subsubsection{Observation data analysis}

The observations aimed to discover what is happening in the classroom. As Alexander (2001) points out, if an aspect of teaching and learning is to be fully understood it has to be integrated into the context of teaching and learning before and after it. Therefore, the analysis of the observation takes a whole lesson perspective. To do this, I consciously used my field notes (and the audio-recordings when necessary) transforming them into narratives that 
described what the teachers and students were doing at each stage of the lesson. I transcribed the classroom episodes that typically illustrated kinds of student engagement in the lessons. I briefly made comments in the margins. I conducted initial coding and noted the frequency of certain practices to find patterns for each teacher and all the teachers as a group. The process of writing up the notes facilitate my familiarity with the data. I then searched for statements of rationales in the interview transcripts. This process helped identify themes related to actions in the classroom, the teachers' explanations and students' opinions. Themes emerged, which were reviewed and refined across other observations and with the interview data.

\subsubsection{Interview data analysis}

Content analysis (Creswell \& Plano Clark, 2007) was used with the interviews to identify the patterns and themes. My analysis of the data was a recursive process. First, I transcribed all the teachers' and students' interviews verbatim (I transcribed all the data in both Phase 1 and Phase 2, including interview data and students' retold stories in pre-and post-test to deeply immerse myself in the data). Next, I adapted Ellis and Barkhuizen's (2005) approach, grounded in content analysis, to analyse data. Ellis and Barkhuizen's original sequence has four stages, which I outline below; I adopted the first three stages to address my research questions; the fourth stage related to the ways this study contributed to a theoretical understanding of learning with stories and storytelling will be presented in Chapter 9 .

In Stage 1, I inductively made notes within each interview transcript regarding topics discussed in the interviews and I reread the transcripts to make open-notes and create new topics. When searching for themes, I double-checked them in each participant's interview transcripts. In Stage 2, I identified the relationship between themes; this involves searching for links like "repeated themes or key words", "parallel or connected comments" or "metaphoric use of language" (Nunan \& Bailey, 2009, 416-417). In Stage 3, I analysed the themes in light of the research questions to make interpretations and to reach conclusions. After I had decided on what quotes to be included in the report findings, I translated them into English. The translations were double-checked by a Vietnamese EFL teacher.

\subsubsection{Ethics}

Since this study involves primary school teachers and primary school children as participants, I gave ethics priority in conducting research and throughout the research process. I kept in mind the need to respect participants' rights and to honour research sites (Brooks, Te Riele, \& Maguire, 2014; Creswell, 2014). When researching with children, I gave more care to ethics as they "are frequently positioned as 'vulnerable' and relatively powerless to their social 
status and positioning in society" (Brooks et al., 2014, p. 102). No fieldwork, including contacting potential participants and piloting activities was conducted before my human ethics application was reviewed and approved, including information sheets, consent forms and translated versions.

When I obtained ethics approval from the Human Ethics Committee No. 24403 (see Appendix 2), I recruited participants for pilot studies in New Zealand. For fieldwork to collect data in Vietnam, I sought official permission from the leaders of BOET for access to state primary schools (see Appendix 3). Second, I sought approval from the principals of primary schools. Third, I met teachers and invited them to join my study. Most of invited teachers refused to join my research because they felt uncomfortable for being video recorded. They then agreed to join my study only if I used audio-recording instead of video recording. The participants' feelings of ease and comfort are very important (Johnson \& Christensen, 2014), so I agreed with this condition.

After recruiting the teachers for my study, I sent information sheets to the parents of the students to ask permission for their children's participation. The parents or guardians who signed the consent forms to allow their children's participation were also informed about the confidentiality and anonymity of their children's interactions in the classroom and views. The students knew their participation was voluntary and they expressed their agreement by colouring a happy face on the consent forms. All the participants were reassured that their identities would not be revealed in any reports of the research findings, and they were entitled to withdraw from my research if they wanted to before the date in the information sheet and consent form. They also knew that their knowledge, experience, attitudes and feelings were important for my research. I encouraged the teacher and the students to behave normally as they did in their daily lessons.

\subsection{Phase 2 Methodology}

\subsubsection{Research setting}

\subsubsection{Research site}

School F (Table 4.1) joined the second phase of the study. It was located near the centre of town. It had a four-period-a-week English programme with the Tieng Anh textbook. This school had six Grade 5 classes as well as other grades.

\subsubsection{Participant students}

Two Grade 5 classes, each with 46 students, joined Phase 2. 


\subsubsection{Participant teachers}

The comparison group teacher and the intervention group teacher had homogeneous educational backgrounds. They attended the same three-year course at college. Since graduation, they had been teaching at primary schools. They had worked together in the same school for over four years. Their qualifications met the requirement set by MOET: they achieved the B2 certificate of English proficiency and attended a 180-hour workshop on TEYL and textbook training workshops held by DOET. They were in the same professional learning group. Together with teaching normal classes, both had been working as teaching assistants for foreign teachers.

\subsubsection{Classrooms}

There was no English Learning Classroom in this school. They studied English in their normal classrooms. Their rooms had big windows and were not noise insulated. There was a large magnetic board on the wall. In the intervention group classroom, there were two lines of 16 old desks and benches, and four students sat at each desk. There was a television with a system to move it up and down, but the system had stopped working. The board was partly covered by the television. In the comparison group classroom, there was a television over the magnetic board and four lines of 24 newer and smaller desks and chairs. All the desks and chairs were heavy and unmovable. The rooms looked crowded for the high number of students and the space for each student for moving around was extremely small.

\subsubsection{Data collection methods and data analysis}

Data for this phase were collected through a quantitative approach including pre-and poststory retelling tests and a qualitative approach consisting of observations, field notes and interviews.

\subsubsection{Quantitative approach}

\subsection{How story retelling tests were designed}

One of the effective ways to know the state of individuals' proficiency is to get them to do what they usually do with language to let them talk freely. According to Schmid (2011), talking freely was "the only linguistic task which requires a speaker to activate all of the subcomponents of language knowledge at the same time" (p. 187). Researchers used two main ways to encourage the speaker's free speech: (1) initiate a natural conversation by using semi-structured interviews, and (2) give the speakers a descriptive task such as watching a film and asking them to retell it or look at a series of pictures of a story and talk about it in 
English. The latter was chosen for two main reasons: to make the students feel that they were not being tested and secondly because children are generally easily engaged by images.

Watching a cartoon (film) and talking about it in English or looking at a series of pictures of a story can be challenging for EFL students. In a cartoon, there are a lot of events and young students may be worried that they cannot remember the events in the stories, or that they do not have enough English to describe the events. Looking at the pictures may be too simple to understand, or the students might be unable to generate ideas from the pictures. Therefore, piloting was conducted to choose the more suitable medium for young learners.

\subsection{Piloting}

\section{Piloting 1}

Four criteria were established before choosing stories: age appropriateness, cultural appropriateness, familiar content, and whether the stories were available in film. Little Red Riding Hood (LRRH), the Hare and the Tortoise (H\&T), and Tom and Jerry (T\&J) were chosen because they met these criteria, are similar to Vietnamese folktales and are popular with children. Three series of pictures of the three stories were also prepared.

With the help of the Vietnamese Community in Wellington, six children participated in the piloting. Four of them (one six years old, two eight years old, one ten years old) were born and had grown up in New Zealand, and two of them (one six years old and one eight years old) had been in New Zealand for one year. They were put in two groups as shown in Table 4.5, below.

Table 4.5 Groups of story retelling piloting

\begin{tabular}{ll} 
Group 1 & Group 2 \\
\hline A & C \\
LRRH cartoon & H\&T cartoon \\
B & D \\
H\&T pictures & LRRH pictures
\end{tabular}

Group 1 watched the LRRH cartoon and retold it; then they looked a series of the H\&T pictures and retold the story. Group 2 watched the H\&T cartoon and retold it; then they looked a series of the LRRH pictures and retold the story. I compared the language outputs of Group 1 and Group 2. Their stories were transcribed; then, tokens and types were counted and compared. The preliminary result showed that more tokens and types were produced after watching the cartoons than looking at the pictures. Although the piloting drew a general picture of what helped the students produce more language, it was noticeable that the piloting 
students were not representative of EFL Grade 5 students. Their age and proficiency were not similar to those of my target EFL participants. This piloting was not informative enough to decide which kind of story-retelling was better. Therefore, the second piloting was conducted.

\section{Piloting 2}

Five Grade 5 students a primary school took part in the piloting. They were from classes which did not participate in the study. I got permission from their parents and school staff for the piloting. The piloting took place in the staff room.

Two of them watched the LRRH cartoon and looked at the H\&T pictures, three of them watched the H \& $\mathrm{T}$ cartoon and looked at the LRRH pictures. All five students also watched the T\&J cartoon. Unlike piloting 1, the students in this pilot also watched the Tom and Jerry film. The aim was to check whether there was a difference in students' language production after watching a cartoon with verbal words (LRRH) and a cartoon with no dialogue (T\&J). Unlike the retold stories of the students in piloting 1, which were all in English, the retold stories of the students in pilot 2 were in English and Vietnamese.

After transcribing and counting tokens and idea units, there were two important findings. First, the students produced more tokens, and idea units in the students' retold stories. The students seemed to produce more language with LRRH and T\&J. This was a similar finding to that of piloting 1. Second, the students also produced more language with LRRH and T\&J than with H\&T. The students seemed to be confident in retelling T\&J. Their T\&J stories were much longer than their H\&T stories. Based on the result of the pilots, watching a cartoon and retelling its story was finally chosen as the pre- and post-test to analyse learners' language proficiency.

Both the LRRH cartoon and the T\&J cartoon were chosen. This would help to check the reliability of the measure (whether the students' language outcomes were stable and consistent), that is, their language production was not affected by watching the same cartoons or a different cartoon in post-test. The participant students were put into four groups, and each group had a different pre- and post- combination (see Section 7.1 for how the students were grouped).

\subsection{Story retelling test procedure}

The implementation of the tests was supported by the form teachers and other staff who allowed the students to participate in the study. Pre- and post-storytelling tests were conducted in the staff room and the corridor in front of the staff room where it was quiet. One 
of my colleagues at the university managed the cartoon watching. She explained what the students would do, did a short modelling demonstration, and invited them to watch a cartoon. The participants needed to understand their task and practice it. The cartoon Three Little Pigs and a series of pictures from it were used in modelling. Two watched a cartoon together which help increase the students' enjoyment of watching a cartoon. They had time to prepare their retold story individually. Each of them took turns to retell their stories to me. I listened to their retold stories and audio-recorded them. The story retelling task was not timed, and the participant students were free to retell the story in as much detail as possible. They were also encouraged to use English as much as possible. No comments on the children's story retellings were revealed to the children or their teachers and parents to minimize external threat.

\subsection{Story retelling data analysis}

Lexical richness and idea units were used to analyse the participants' language. Lexical richness is about the quality of vocabulary in a language text, and it is popularly employed to measure the proficiency level of a student. Educators (Laufer \& Nation, 1995; Read, 2000) have suggested different models to measure lexical richness. The oldest and the most frequently used measure of lexical richness is based on their principle of the type-token ratio, which is generally concerned with counting how many different tokens there are for each type in a text (Van Hout \& Vermeer, 2007). However, in the current study, the students' English proficiency in their story retellings was at a low level. Most of the students were less proficient English speakers, so they spoke in English and Vietnamese in story retellings. Only a few proficient students spoke completely in English. In this study, tokens and types were counted but no ratio was taken.

In addition to counting tokens and types, idea units were also counted to measure the amount of ideas in a text. Idea units have been shown as a useful measure of oral speech, especially narratives (Brenes, 2005; Gee, 1991, 2018). Idea units provide communicative value, emphasizing the transition of meaning (Chafe, 1985; Gee, 2018). Each idea unit is weighed according to its importance to the ideas in the whole passage. More discussions of the analysis will be provided in Chapter 7; for example, detailed explanations of tokens, types and idea units and how to count these language units are given in Section 7.1. 


\subsubsection{Classroom intervention}

\subsection{Story adaptation and storytelling innovation structure}

Phase 1 preliminary result indicates that the teacher had to use the textbook, but the quality of the texts was found to be not interesting enough (see Sections 5.1.3 and 6.1); the stories were not employed to provide effective learning opportunities for young learners (see Sections 5.2, 6.2 and 6.3); and student engagement was low (see Sections 6.4). Therefore, adopting and adapting the materials suggested by Macalister (2016) was used to create the storytelling innovation. The textbook speaking lessons were redesigned into storytelling lessons to offer interactive opportunities for young learners to use language.

Based on literature on the interactions, young learners' characteristics, and stories and storytelling reviewed in Chapter 3, two main changes were made to create the storytelling innovation.

The first was a change to the format and presentation of the story. A story in the textbook becomes clearer by adding some short sentences to provide the setting and the characters. Instead of asking student to 'Look, listen and repeat' as instructed in the textbook, the teacher tells the story, using the pictures without showing the words (see Appendix 4 for an example of an adapted story). 
The second was a change to the format and presentation of the lesson. The textbook lessons 1 and 2 in each unit that have a PPP structure (the first three activities) and the short stories of the review lessons (see Table 5.1) were redesigned into the storytelling innovation lesson. Table 4.6, below, presents the structure of a storytelling innovation lesson.

Table 4.6 Structure of a storytelling innovation lesson

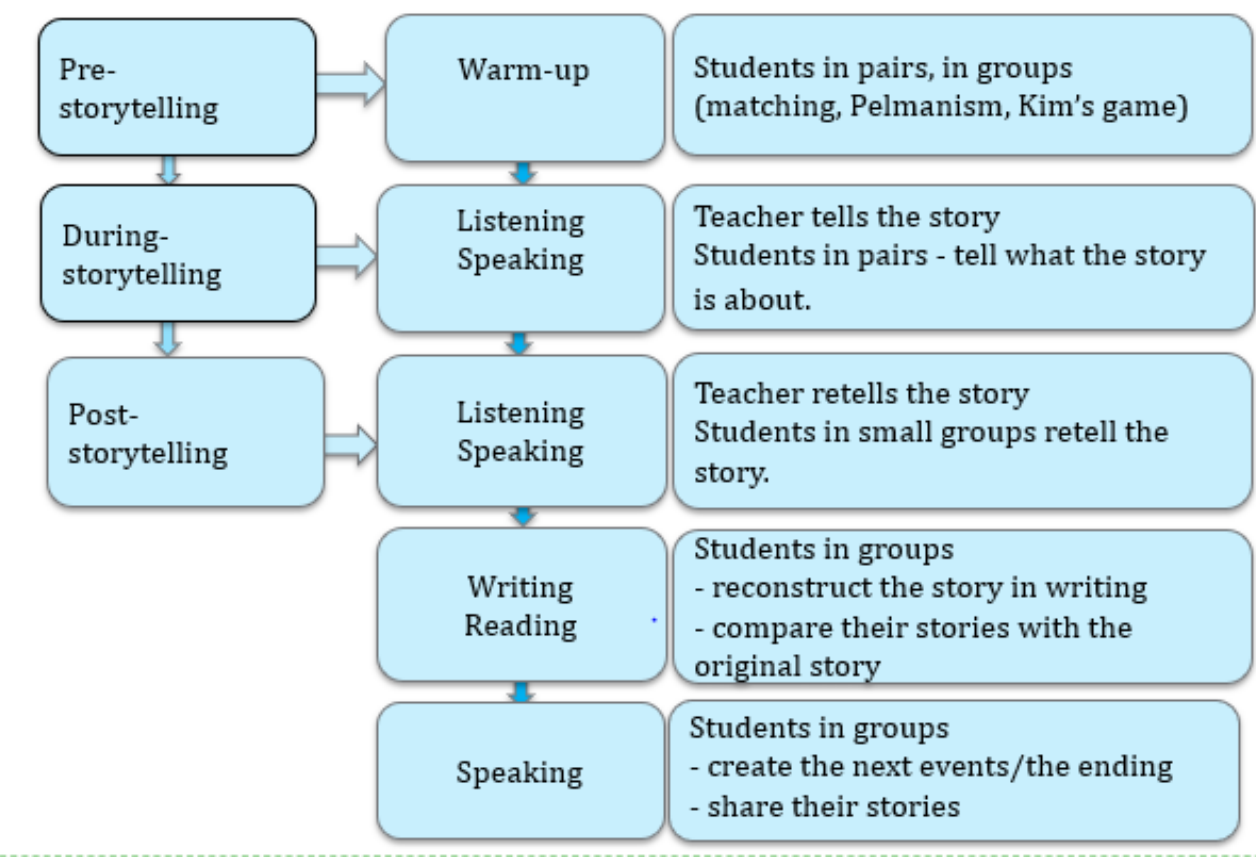

A storytelling innovation lesson has a structure consisting of three phases: pre-, during- and post activities. It is an integrated skills lesson with a focus on speaking and it has five main activities. In the first activity, students in groups or pairs join in a fun and engaging game. In the second activity, the teacher tells the story, pointing to the pictures (without showing the text), or using body language. Students are asked to work in pairs to tell what the story is about. In the third activity, the teacher retells the story (similar to Activity 1). Students retell the story in small groups. In the fourth activity, students retell the story in writing and compare their group's story with the original. In the fifth activity, students are required to make the next events of the story (the ending of the story) and retell the story with their own endings (see Appendix 4 for an example of the storytelling innovation lesson plan).

\subsection{Storytelling lessons piloting}

Due to availability issues, the lessons were not piloted in real classes. In New Zealand, I did the piloting twice. I invited three children to be my students. One was my eight-year-old daughter who had been in New Zealand for one year, and the other was my Vietnamese friends' six-year-old daughter and seven-year-old boy who were born and grew up in New Zealand. I invited an EFL Vietnamese teacher who was doing a PhD course at VUW to 
observe my second lesson with the two students. In Vietnam, I conducted a teaching trial with a group of six Grade 5 children who were having private tutorials with one of my friends. The aims of the teaching trial were (1) familiarise myself with the new way of teaching, (2) to see whether the new lessons engage students more than the normal lessons and (3) to modify the lesson structures or instructions in the lessons.

Besides achieving these aims, piloting informed me of what to prepare for the teachers. First, the piloting in Vietnam showed that Vietnamese students were not familiar with cooperation in group work, the teacher needed to learn to give new instructions for activities and it was important to make sure the instructions were given clearly (ideally in Vietnamese in one or two first lessons). This would take classroom time in these lessons. Second, the teacher needed to practise telling the story, practising using pictures and body language when telling it, to interest learners and highlight new language items.

\subsection{Briefing the teacher}

After getting the participants' consent and prior to the implementation of the storytelling innovation, I made an appointment with the intervention group teacher to further discuss the lesson plans. At the briefing, I talked through the lesson plans with the teacher. I taught one model lesson with the teacher as a student and one model teaching with one of the intervention group teacher's classes to provide a general picture and understanding of what a storytelling innovation was. The teacher's perceptions of the modelling lessons are presented in Section 7.3. After the principles behind the design of the storytelling lessons were made clear to the teacher, we rehearsed the first lesson with me as a student. The rehearsal aimed to familiarize the teacher with telling the story and using gestures when telling the story and giving instructions. The drawback of the rehearsal was that some classroom issues such as L1 use and target language production, and noise from group work could not be experienced. Therefore, I also disused those issues with the teacher.

\subsection{Number of storytelling innovation lessons in the study}

Twenty two out of 64 normal lessons in Tieng Anh textbook volume II were changed into storytelling lessons. See Table 5.1 in Section 5.1.1 for which lessons employed the storytelling innovation approach. The students had 4 English lessons per week. Thus, every two weeks, they had two storytelling lessons and two normal lessons in the first week, one storytelling lesson and three normal lessons in the second week. This pattern lasted for fifteen weeks. 


\subsubsection{Qualitative approach}

\subsection{Data collection methods}

As in Phase 1, classroom observation, field notes, in-depth interviews with teachers and group interviews with students were also employed to collect data in this phase.

The two teachers agreed to have their lessons video recorded. Video recording allowed me to repeatedly view the lessons when necessary. I was offered a seat in the back by the back door of the room to be minimally intrusive. I used my iPhone to video record the lessons. The students were familiar with me from Phase 1; therefore, my video recording attracted some students' attention initially but was quickly ignored when the teacher entered the classroom and the lesson proceeded. When the students joined the storytelling activities in the lesson, the classroom became noisy. My iPhone could only record the group that sat next to me. Therefore, apart from observing the classroom lesson as a whole, I also audio recorded the students' interactions. Recoding naturalistic classroom interactions requires strategies to minimize distraction. Care was taken to limit the distraction before and during the recording of students' interactions in groups. I used two high quality digital recorders. They were put in the groups who were sitting at the side of the desk rows to minimize distraction across groups and the possibility of picking up talk from other groups. The teachers and students were informed about the presence of the recorders, which were placed on the students' desks. The students were familiar with my presence from the first phase and I had built a good relationship with the students during the pre-story retelling test; hence, they all welcomed the recorders.

During the observation, I took field notes. I took observational notes as I had done in Phase 1. I also took field notes when I met the intervention group teacher after each lesson so that the teacher could reflect on the lesson with me. This was done to help ease the teacher's recollection of their thought processes (Nunan \& Bailey, 2009) and enhance the reliability of the data.

After the intervention, the two teachers and the students were invited to be interviewed about their perceptions of the lessons. All the interviews were audio-recorded. Each interview with the teachers was approximately 60 minutes long. The interviews with the teacher of the comparison group and the intervention group centred on the five topic areas: recollections of teaching and teaching with stories and storytelling, indicators of students' engagement and participation, students' English proficiency, perceptions of stories and storytelling, and suggestions for better teaching. 
Each student group interviews lasted about 20 minutes, covering the four topic areas: recollections of learning and learning stories and storytelling, students' engagement and participation, students' English proficiency and suggestions for more effective English learning. My presence in the classrooms for the whole semester made the students feel at ease and eager to join the interviews. Most of them contributed several insights about their learning English in general and storytelling lessons in particular.

\subsection{Data analysis}

The analysis of observation and interview data followed the same approach for analysing the teacher interview data in Phase 1 (see Section 4.3.3).

\subsubsection{Ethics}

After seeking BOET's permission for the second phase of my study, I started the recruitment of participants. In selecting schools and teachers, I made a priority list. The first priority was teachers who were conducting the English education programme of four periods per week (it was based on the requirement of the 2020 project that $100 \%$ of primary school students would receive four English classes per week). The second priority was on the textbooks designed by MOET. School F in Table 4.3 became the number one choice because it met the three requirements. I met the three teachers in School $\mathrm{F}$ and invited them to participate in the second phase of my research. I gave them verbal information about the research and read the information sheet; two of them were willing to join and signed the consent forms. Then, I met the school leaders again to ask for their permission for the second phase of my study (see Appendix 5).

Each of the two participant teachers was teaching two Grade 5 classes at that time. It was the teachers who chose one of their Grade 5 classes to join the research. Their choice was not on the students' better English proficiency, but on the form teachers and the Class Parents Council, who were helpful, cooperative and understanding.

With the help of the form teachers, I could meet the students' parents/guardians at their endof-semester-one meetings. At the meetings, I introduced my research and read the information form to the parents. The form teachers also helped send the information sheets and consent forms to the students' parents/guardians who were absent from the meetings. As in Phase 1, before the interviews and story retellings tests, I tried to ensure that the students knew about their voluntary participation, confidentiality, and withdrawal if they wanted. 


\subsection{Trustworthiness}

This section discusses trustworthiness with reference to the validity and reliability of the research. Validity and reliability are two main quality criteria of a study (Dornyei, 2007). These criteria adhere to the research process in order to present "insights and conclusions that ring true to readers, practitioners and other researchers" (Merriam, 2009, p. 210). Validity refers to whether the data collected has been carefully analysed and presented in a "fair and unbiased manner" (McKay, 2006, p. 13). Ensuring the validity of the study means giving readers confidence that the insights have emerged from the data itself and not from the researchers' own biases and assumptions. Reliability refers to the consistency of the findings. A study needs to show that the findings are consistent with the data gathered, the findings integrated, and the results reported (Merriam \& Tisdell, 2016).

To ensure the validity and reliability of the study, six main strategies were employed. They were triangulation of methods, adequate engagement, double-coding, peer-debriefing, member checking and inter-coder checking.

Triangulation was one strong indicator of validity in the study. The interviews coupled with observations and relevant documents helped to gather multiple sources in order to identify: (1) how the teachers used and implemented stories and storytelling (observations, field notes, and textbooks); (2) how learners engaged and participated in story lessons (classroom observations, field notes, and interviews); and (3) the teachers' rationales and students' perceptions (students and teachers' interviews). The data were collected from quite a range of participants, which facilitate comparison of participant's perceptions and understandings, and identification of emerging themes within the data. This helped me look at connections within a social setting to gain greater depth of meanings of a particular activity or perception (Holliday, 2007).

Adequate engagement was another strong indicator of validity in the study. According to Merriam and Tisdell (2016), being present long enough in the site where the study is being done helps build trust with the participants, and lessens any effects of the presence of the researcher in the site. The eight months of data collection enabled collection of rich data of the current state of teaching and learning and of the effectiveness of the innovation. This afforded me opportunities to observe a large number of lessons. They helped me understand the teachers' two different teaching practices at a deep level. This also allowed me to reflect on the research process, which added to the validity of the findings (Lincoln \& Guba, 1985). 
To ensure the consistency of data analysis, I followed the process of double coding to identify and compare the results. When analysing the data, I maintained a persistent process of coding and developing the codes for and each data source. I read and reread the data, analysed them, and revised the coding categories. Peer-debriefing was employed to ensure the credibility of the emerging themes and interpretations. I discussed the coding process, interpretations, and conclusion with my $\mathrm{PhD}$ colleagues. For example, in analysing students' storytelling interaction data sources, we discussed the kinds of engagement the students were involved in. The discussions helped probe my thinking of the research process, and identify and solve problems such as misinterpretations, researchers' bias and unconvincing explanations.

In addition to scrutinizing the data, member checking and inter-coder checking were also applied. Member checking (Lincoln \& Guba, 1985) was an on-going process throughout the two phases of my research. I was careful to ask for clarification during the interviews to avoid making assumptions based on my own bias. At the end of the interviews, I summarized what I had understood from the conversations and checked what they had said or meant, so the participants could confirm whether I had understood their comments. In the second phase of the current study, after each lesson, the intervention group teacher and I had a reflection meeting, and notes were taken.

Inter-coder checking was carried out in coding of language units in students' story retellings to ensure the reliability of qualitative coding. Two Vietnamese teachers were trained to code tokens, types and idea units. A third of the data were randomly selected. This included 17 out of 50 stories from the comparison group and 20 out of 60 stories from the intervention group. Some differences in coding idea units were found. This was mostly due to the nature of the data which was complicated and required highly sensitive coding decisions. The idea units that were coded differently by me and the two inter-code checkers were resolved through follow-up discussions. Those items where the other coders and I could not reach agreement were excluded from the analysis.

\subsection{Role of the researcher}

The researcher-participant relationship and the role of the researcher during the data collection were important considerations. As an insider of Vietnamese culture, I was aware of the importance of close relationship building in this culture and how this was a necessary process in my research design. This was to gain the trust and confidence of my research participants and to lessen the threat that I might create. 
It was crucial to shorten the power distance with the teachers. I used to be a college mate of four participating teachers and a university instructor of the other teachers in Phase 1; the teachers participating in Phase 2 were two of my four college mates. The relationships brought me an advantage in that, as a university lecturer and a college mate, I did not have much difficulty in recruiting the teacher participants. However, the relationships also brought the challenge of a potential threat of power distance due to the hierarchical relationship between the instructor and their students in Vietnamese culture, as mentioned in Chapter 2. To reduce the power distance, I always behaved in a friendly manner, showed no power over them and maintain a neutral rapport with the teachers (Merriam \& Tisdell, 2016; Patton, 2015). I usually reminded them that they were my colleagues and my professional friends. I believe that my friendly behaviour went some way to minimise any a strong power-distance. Reducing the hierarchal relationship with the students was also important. I tried to have a happy friendly face. If their lesson started with a song, I sang and danced with them. If their lesson started with a game, I laughed with them. Some of the students in Phase 1 even ran after me when I left the room, expressing their happiness about my presence in the class and hoping to see me in the future. They gave me a warm welcome when they saw me again for my second classroom observation. By the time Phase 2 data were collected, they considered me a familiar member of their class. They appeared to be relaxed and seemed to behave naturally during the observation and to be eager to join the interviews. The students and I became comfortable with the process of interviews and story retelling tests. Reducing power distance in the researcher-participant relationship helped me build "a trusting relationship" necessary for "good quality research" (Pinter, 2018, p. 420).

My experience and knowledge of the local situation provided me with an insider perspective which helped to build and maintain rapport with the teachers. While they are a benefit in having the potential to provide insight into the context of primary English education in Vietnam thus assisting the description and analysis (Van Lier, 1990), they also mean I could be affected by my own perspectives and I could possibly put my voice in the analysis or overinterpret participant experience. This required me to be sensitive to its influences in order to help reduce any potential bias. I was mindful of my previous role as a teacher trainer, holding certain pre-conceptions of TEYL in general and PPP and storytelling in particular. During the interviews, I refrained from expressing personal opinions or evaluating the teacher's practices as I had done in my previous role as a teacher trainer. 
As the researcher, I was concerned about the 'Hawthorne' effect (Dornyei, 2007, p. 53), which refers to the possibility that the teachers and the pupils could have performed or behaved differently from how would have normally. Different behaviours was their normal response to a visitor being in their classrooms as they wanted to show a perfect lesson to visitors (Phan, 2017). To minimize this 'Hawthorne' effect, I kept encouraging them to teach normally and reassured the teachers and students that I was not making observations for assessment or inspection. In interviews, I was also sensitive to the issues of socially desired responses from the teachers and students with regard to their perceptions of the storytelling lesson. I tried to make them aware that authentic and honest responses were important for the integrity of my study, and that their experiences and comments were respected and valued and that their participation was important for my research and for their professional development. In addition, to ensure consistency of the teacher's response, field notes were used to keep track of the intervention group teacher's change in her perceptions.

In this chapter, I have outlined the research design and described the data collection, analysis and ethical processes. I have discussed the strategies used to ensure trustworthiness and my role in this research. The next three chapters will present an analysis of the data through the methodological process described and justified in this chapter. 


\section{CHAPTER 5 FINDINGS FROM TEXTBOOK ANALYSIS}

This chapter addresses the findings from the textbook analysis. The aim is not to evaluate the whole textbook, but to discover the methodology suggested to be used with the stories in the textbooks. The results of the findings in this chapter will be used as the foundation and justification for the analysis of the current state of using stories and storytelling in the first phase of the study (see Chapter 6) and the implementation of the storytelling innovation in the second phase (see Chapter 7). This chapter is divided into three sections. The first section begins with a brief general textbook description of the nature and qualities of the texts in the textbooks. The second section provides the analysis of the qualities of activities in light of the conditions of meaning-focused input and language-focused learning (Nation, 2007). The final section identifies the mismatch between the methodologies suggested in the textbooks, and in the curriculum and how young language learners learn.

\subsection{Textbook description}

\subsubsection{Textbooks}

The Tieng Anh series for Grades 3, 4 and 5 were designed by a group of Vietnamese educators and published by Vietnam Education Publishing House, which is believed to belong to MOET; therefore, Tieng Anh textbooks are commonly named MOET's textbooks. There are two books for each grade; each book is comprised of 10 units and two review units.

Table 5.1 shows that each unit in the Tieng Anh for Grade 5 has three lessons and each lesson has six sections (the word "section" is used in their teachers' guidebook); each lesson is supposed to be taught in two periods. After every five lessons, there is a review unit, also taught in two periods.

Table 5.1 Design of a textbook unit

\begin{tabular}{ccccccccc}
\hline $\begin{array}{c}\text { Textbook } \\
\text { lessons }\end{array}$ & \multicolumn{2}{c}{ Lesson 1 } & \multicolumn{2}{c}{ Lesson 2 } & \multicolumn{2}{c}{ Lesson 3 } & \multicolumn{2}{c}{ Review } \\
\hline $\begin{array}{c}\text { Teaching } \\
\text { period }\end{array}$ & $1 *$ & 1 & $1 *$ & 1 & 1 & 1 & 1 & $1^{*}$ \\
\hline & Sections & Sections & Sections & Sections & Sections & Sections & Sections & Sections \\
Sections & $1,2,3$ & $4,5,6$ & $1,2,3$ & $4,5,6$ & $1,2,3$ & $4,5,6$ & 1,2, & 1,2, \\
& & & & & & & $3,4,5$ & $3,4,5,6$
\end{tabular}

Notes: * lesson sections (in Book 2 for Grade 5) were changed into storytelling lessons in Phase 2 The title of each unit in the Tieng Anh textbooks is named after one of the target structural patterns in that unit. The Tieng Anh series has been used in the province since 2014 and they are popular in primary schools there. As mentioned in Section 3.3, instead of teaching each 
lesson in two periods, some schools taught each lesson in only one period. Their lesson plans showed that they chose to teach four sections, mainly from Section 1 to Section 4.

The Family and Friends grades 3, 4 and 5 were published by Oxford University Press with the advice and cooperation of Ho Chi Minh City Department of Education and Vietnam Education Publishing House. Each Family and Friends textbook has 12 units and four review units. Each unit is comprised of six lessons and is supposed to be taught in eight periods. Each unit of the textbooks is named after themes. They have been used since 2011 and since 2016 their special editions, which include some Vietnamese culture focus, specially designed for Vietnamese learners, have been used.

Although the appearance of the two textbook series looks a little different such as the number of lessons in each unit and how each unit is named, both Tieng Anh and Family and Friends series have some features in common. First, both have a similar layout. Each of the textbooks has a well-connected structure with others of their series, and colourful and child-appropriate illustrations. The books contain a variety of texts and tasks built around four themes: Me and my Friends, Me and My School, Me and My family and Me and My Community, which are the prescribed topics in the curriculum for English education at primary level (MOET, 2010a, 2018). Second, they have similar aims: each unit presents and engages learners in the practice of some target words and grammatical structures from easy to difficult and their tasks all focus on the target structural patterns in each unit. Third, both textbooks follow the same structure of teaching method, which is found in the Tieng Anh teacher's guidebook, and the Family and Friends teachers' notes. There are no Family and Friends teachers' guidebooks special editions for Vietnam, but there are suggested lesson plans available from the publisher's website (Oxford University Press).

The Tieng Anh teachers' guidebook states that the lessons follow "the sequence of presentation, practice, and production" (Hoang et al., 2015b). Each lesson aims to assist the students to learn and practise one or two structural patterns. The Tieng Anh teachers' guidebook states that Lesson 1 "present[s] the context in which the first language competence is introduced" (p. viii) and Lesson 2 "present[s] the context in which the second language competence is introduced" (p. ix). Lessons 3 "focus[es] on pronunciation, reading and writing skills" (p. x). In the Family and Friends textbook, Lessons 1, 2, 3 and 4 aim for language feature improvement. Although Lessons 5 and 6 are called skills lessons, the activities in these lessons provide practice for target language features. The suggested lesson plans for lessons in the Family and Friends textbook present a sequence of presentation, development 
and consolidation. Although the terms used to name stages in a lesson in the Family and Friends and in the Tieng Anh textbook are different, they have similarities. In a unit lesson in both textbooks, a lesson starts with one activity for contextual presentation of new language features (lexical or grammatical); next practice activities based on the target structural patterns or vocabulary are provided; most of them are in the forms of gap-fill, drills and language reproduction. There are a few activities for free production. In the Family and Friends textbook, the controlled activities and less controlled activities are in the development stage and activities for the reinforcement stage are not in the textbook; they are suggested activities only in the teachers' notes.

In both textbooks, a wide range of texts are composed to contextualize the presentation of language features. Section 5.1.2 will identify the nature and quality of texts used in the textbooks.

\subsubsection{Nature of texts in the textbooks}

There are four main kinds of stories in the textbooks and they are named for the convenience of easy recognition in this analysis.

(1) human-dialogue texts in captioned-pictures in every lesson 1, part 1, and lesson 2, part 1, in the Tieng Anh textbook (Figure 5.1) and in every Lesson 1 in Family and Friends textbook (figure 5.2).

Figure 5.1 A human-dialogue text in the Tieng Anh textbook

(Unit 12, Lesson 1 p. 12)

The image has been removed by the author of this thesis for copyright reasons. 
Figure 5. 2 A human-dialogue text in the Family and Friends textbook (Unit 3, Lesson 1, p. 20)

The image has been removed by the author of this thesis for copyright reasons. 
(2) animal-dialogue texts in review lessons in the Tieng Anh textbook (Figure 5.3). There are no animal-dialogue texts in the Family and Friends textbook.

Figure 5.3 An animal-dialogue text in the Tieng Anh textbook

(Review 2, p. 72)

The image has been removed by the author of this thesis

for copyright reasons. 
(3) Folktales and fables in three reading lessons in Unit 14 in the Tieng Anh textbook (Figure 5.4) and Family and Friends textbook (Figure 5.5).

Figure 5.4 A fable story in the Tieng Anh textbook

(Unit 14, Lesson 3, p. 28)

The image has been removed by the author of this thesis for copyright reasons.

Figure 5.5 A fable story in the Family and Friends textbook

(Unit 5, Lesson 5, p. 40)

The image has been removed by the author of this thesis for copyright reasons. 
(4) Narrative texts in Lesson 3 (figure 5.6) and in other lessons in the Tieng Anh textbook such as activity 3 of Lesson 3 in review units and in Lessons 5 and in review lessons in the Family and Friends textbook (Figure 5.7).

Figure 5.6 A narrative text in the Tieng Anh textbook

(Unit 2, Lesson 3 p. 17)

The image has been removed by the author of this thesis for copyright reasons.

Figure 5.7 A narrative text in the Family and Friends textbook (Unit 1, Lesson 5, p. 12)

The image has been removed by the author of this thesis for copyright reasons. 
In short, there are four main kinds of texts in the two textbooks and they are called stories in the Tieng Anh teachers' guidebook and in the Family and Friends teachers' notes. This reflects the textbook designers' plan to introduce stories in teaching and learning. Except for folktales and fables, which are recognized stories, the other texts were invented by the textbook designers; therefore, it is necessary to examine their qualities and the activities associated with them.

\subsubsection{Qualities of texts}

Texts, whether they are stories or not, are good for learning if they engage the emotions of learners. As Tomlinson and Masuhara (2004) put it: "Laughter, joy, excitement, sorrow and anger can promote learning. Neutrality ... cannot” (p. 18). Stories are widely viewed as offering effective engagement for young learners (Tomlinson, 2015). Most of the texts in the textbooks are called stories; therefore, they will be examined in light of the structure of a good story to find the involvement factors in these texts.

As mentioned in the literature review, a good story has a structure that consists of a setting of place and time, characters, a sequence of events, a problem and a resolution or a conclusion. The lack of one of these elements will reduce the meaning of a story, which will adversely impact on the students' interest in the story and, as a result, they might not create good learning opportunities for learners (Curtain \& Dahlberg, 2010). A good story with enough elements will serve as good input for EFL learning, as it can create curiosity and interest for the learners. Research (Elley, 1989) shows that the students learned better, especially in vocabulary acquisition, with stories that have elements of interests like humour, novelty and conflict; they learned less with stories with a "lack of involvement" (p. 185). The lack of key features may make stories sound like neutral texts, and neutrality makes the texts less interesting, which might negatively affect the students' attention to the meaning of the story and affective motivation in learning (Nation, 2013; Tomlinson \& Masuhara, 2004). Stories should be exploited as sources of memorable content and language through children's life (Ahlquist \& Lugossy, 2015).

In the current Tieng Anh textbooks, most of the texts are deficient in one or two key elements of a good story. Human-dialogue texts in speaking lessons do not have a clear stated setting. Although the pictures can provide a little information about the characters and the setting in the story, this is not as interesting as having a clear beginning. Furthermore, these texts just have a sequence of events without an obvious problem to attract young learners. For example, in Lesson 2 of Unit 12 in Tieng Anh Volume 2, p. 14 (Figure 5.1), the pictures indicate the 
characters and the place: a woman teacher Miss Hien, a girl Mai and a boy Nam (the students are familiar with these characters because they are in the previous stories). The pictures also help the students know that the characters are in a classroom. The sequence of events is the exchange between a teacher and two students. The story lacks a key engaging element of stories as Bruner (2002) writes: "for there to be a story, something unforeseen must happen" (p.15). This story is, in fact, a "situational sequence" rather than a well-constructed story (Read, 2015, p. xii). This corresponds to Cameron's (2001) criticism of the texts in many textbooks that are labelled 'stories' when they do not have some of the typical features: "Most often they lack a plot; instead of setting up a problem and working toward its resolution, the characters just move through a sequence of activities. Teachers should not assume that such non-stories will capture children's imagination in the same way that stories can do" (p. 162). Narrative texts in the Tieng Anh textbook had the same problem. Take the text in Figure 5.6 as an example. It just has a sequence of daily life events to describe what a girl named Hoa does every day.

The reason for such designed texts might be due to the textbook composers' intention: language feature introduction and practice. The priority for language introduction rather than meaning makes the story a neutral text which may not be of interest and involvement to young learners.

The texts in the Family and Friends textbook seem to have more interesting content with a problem and a solution. For example, the text in Lesson 1 of Unit 3 (Figure 5.2) has very clear characters: Leo, Army, Max and Holly. The pictures show that they may be in a living room. In regard to the problem, some characters think that reading books is boring, and through the sequence of exchanges related to the school project and the computer failure; they recognize that Max's book is useful for their schoolwork. Narrative texts have an engagement element, such as an underlying comparison between places, people's lifestyles and the like, which makes them interesting. For instance, the stories Figure 5.7 compare the seasons in Giang and Long's hometowns. The comparison of the two towns is "something unforeseen" (Bruner, 2002, p. 15) in the text, which interests the readers and listeners. The goal of the stories in the Family and Friends textbook is to provide context for just-learned vocabulary in Lessons 1 and to introduce new structural patterns in Lessons 2.

In summary, there are three findings from the analysis of texts in the textbook: (1) a wide range of texts are found in the textbook, (2) the texts in the Tieng Anh textbook lack key elements of good stories which make them meaningful to learners, while those in Family and 
Friends are likely to be more interesting with involvement factors like a problem and solution or a comparison in the texts, and (3) the main aim of the texts is for introduction to and practice of language features.

\subsection{Quality of the activities}

This part examines the quality of activities in the textbooks, following their lessons' sequence of presentation, practice and production (see Section 5.1.1).

\subsubsection{Presentation activities}

In a lesson of presentation, practice and production, the presentation stage consists of input activities which contextually present the target linguistic items. In the textbooks, three main input activities are introduced: listening to and reading to a story and repeating it. The quality of these input activities will be analysed according to the conditions of meaning-focused input (Nation, 2007). According to Nation, the activities should: (1) have new learning, containing a few new language items that are easily understandable through background knowledge and context clues; (2) interest the learners, so the learners want to read or listen to the materials; (3) focus on meaning, in which learners' attention should be focused on the message of the materials they are listening to or reading; (4) be understandable, so the texts and the tasks must help understanding and (5) stress-free, to help learners enjoy learning.

\subsubsection{Read- and-listen-to-a-story activities}

With regard to new learning, these activities meet this condition as they present certain target language features in the context of a story. For example, the human dialogue text in Figure 5.8 aims to present the structures Why shouldn't I ? and because you may . The

human dialogue text in Figure 5. 9 aims to present language items "your, our, their" and structural pattern Can I ? Yes, you can. Students are given the sample structures and/or vocabulary contextualized in a story to assist them to deduce the underlining rules or meanings. 
Figure 5.8 A lesson in the Tieng Anh textbook

(Unit 12, Lesson 2, p. 14)

The image has been removed by the author of this thesis

for copyright reasons. 
Figure 5.9 A lesson in the Family and Friends textbook

(Unit 3, Lessons 1 and 2, p. 20-21)

The image has been removed by the author of this thesis

for copyright reasons.

The activities meet the condition of interest in terms of the appearance of the texts. The layout of the stories attracts students with colourful and eye-catching pictures. Human-dialogue texts and other kinds of story have child-friendly pictures and photos. The Vietnamese and foreign characters look friendly and age appropriate. The familiar topics with characters of their age invoke a sense of familiarity for young learners. The appearance of the stories is likely to make the stories interesting input for teaching and learning practices.

The activities appear to be interesting. Reading and listening to stories are real-life activities, which intrigues young learners (Nation \& Newton, 2009; Pinter, 2017; Shin \& Crandall, 2014). Children read or listen to stories to satisfy their curiosity, to entertain or enter their imaginative worlds and to simultaneously develop their language (Cameron, 2001; Pinter, 2017; Shin \& Crandall, 2014), which means that when they read a story, their attention focuses on the meaning of the stories. Through reading and listening, stories become sources of memorable content and language in the children's lives, which is the power of stories (Ahlquist \& Lugossy, 2015). The tasks in the textbooks require the students to use different senses to learn. By involving both visual and auditory input in reading and listening, learners 
are given contextual clues to construct and infer the meaning of a text before and during reading and listening. Chapter 3 (Section 3.2.2.1) showed that multi-sensory learning enhances young learners' learning and engagement.

The appearance and layout of the stories and activities with the stories in the Tieng Anh textbook and Family and Friends text are likely to meet the condition of interest but the contents of the stories in the Tieng Anh textbook seem to be against it. As found in the previous section, the contents of the human-dialogue texts in the Tieng Anh textbook are not interesting enough to involve the young learners. In addition, in the recordings, even the letters to name each picture of the stories are read (Picture a... Picture b...), which indicates the recordings are mainly for familiarizing children with the sounds rather than for meaning. As a result, neutral content will affect the quality of the tasks and listening and reading to a story is just a normal learning task to finish. Texts in the Family and Friends seem not to have this problem because they have key elements that make them good stories.

The conditions of meaning and understanding will be analysed together as they have particular relevance to the use of comprehension questions. Superficially, a focus on meaning seems to be achieved by invoking learners' curiosity in the story of the lesson: "Tell the class that they are going to read a story. Have them look at the pictures and guess what the story is about". To guide the students' attention to the understanding of the story, teachers are encouraged to use comprehension questions in the teacher's guidebooks (Extracts 1 and 2, below).

Extract 1 A part in the Tieng Anh teachers' guidebook (Unit 12, Lesson 1, p. 14T) (see Figure 5.8 for the textbook story)

The image has been removed by the author of this thesis for copyright reasons. 
According to Macalister (2011), comprehension questions have two main functions. The first function is "goal-related" (p. 164): for language development (new vocabulary, a grammatical structure, pronunciation), ideas (content that needs to be learned or is required for other activities), skills (for literal understanding or meaning inference) or text structures (genre structures, cohesion, and coherence). The second function of comprehension questions is "to monitor the extent to which learners have made meaning from and understood the text" (Macalister, 2011, p. 164). The questions help the students to interact with the texts, using their own linguistic resources in conjunction with contextual information to comprehend the meaning of the input, and the students also potentially pay attention to linguistic forms when it is required in order to comprehend the text. Comprehension questions also require learners to demonstrate that they interact with and comprehend the texts.

The goal of Lessons 1 in the Tieng Anh textbook is language focus; therefore, comprehension questions help students focus on the target structural patterns: What are these children doing? What's the boy doing? Should he do that? Why shouldn't he climb the tree? (Extract 1) The suggested questions in the guidebook can be answered directly and explicitly from the text. There is a chance for the students to focus on the meaning and understanding of the structures in the story but not on the meaning of the story.

In the Family and Friends textbook, the activities have two language feature goals: for practising just-learned vocabulary and presenting one or two grammar points. The text and the questions offer opportunities for retrieving the learned vocabulary and presenting a grammar point in the contexts. The questions (as in Extract 2) work well in assisting the students to focus on literal comprehension and support the understanding of the stories.

Extract 2 Family and Friends teachers' notes (lesson plan Unit 3, Lesson 1, p. 2-3) (see Figure 5.9 for the textbook story)

The image has been removed by the author of this thesis for copyright reasons.

Creating curiosity to lead student's attention to the content of the story is beneficial and the questions assist learners in focusing on the language items. However, in the input tasks, there is no real communicative purpose because learners know they have to read and answer the teachers' questions to finish a given task and they do not have a chance to respond to the story 
or to express their emotions and views about the story. Profoundly, the activities of reading and listening to stories do not completely meet the condition of meaning.

\subsubsection{Repeat activities}

'Repeat' is an activity designed after reading and listening to the story. In this task, the learners are asked to repeat all the utterances of story dialogues. Young learners love and are actively involved in repetition and drilling if done quickly and in a lively way in enjoyable activities like chants and songs. This kind of choral drill, if done appropriately, is an activity that may help with pronunciation, intonation and rhythm of language but it may take the learners' attention away from processing meaning (Thornbury, 1999) and simple repetition without much though may come to nothing (Harmer, 2015). Repetition is helpful when the students need help with difficult sounds and when the teachers want to emphasize keywords or phrases. However, the repeat task in the textbook asking the students to repeat sentence after sentence for all the dialogues is boring, non-communicative and meaningless. Meaningless activities without cognitive engagement have very little impact on language learning (Tomlinson, 2015). As an input activity, it violates the condition of meaning, interest and new learning. The repeat task cannot create good learning opportunities as it cannot meet all the conditions of meaning-focused input.

At first glance, the activities in the textbooks are stress-free activities because reading and listening to a story naturally and enjoying activity and repeat is a easy kind of task. In fact, the texts are not true stories (as analysed in 5.1.3), making the tasks less intriguing. The students all know that what they are doing is to find the grammar points that need to be practised in the next activities. Learners may know that the next activity is to act out the dialogue. This kind of dramatized role-play can be fun, but learners have to learn by heart the utterances of the story. Memorization may increase stress for many young learners.

In sum, the input activities of reading and listening to a story and repeating in the Tieng Anh textbook focus on presenting language features; therefore, they unlikely meet all the conditions of meaning-focused input, specifically in terms of meaning.

\subsubsection{Practice and production activities}

When a story is used in a lesson, it is expected that the story will be the framework for other activities in a lesson. But the practice and production activities in both textbooks are designed in other contexts rather than the context of a story in the presentation stage and all the activities help to practise and use the target structures because they are the focus of the 
lessons. Therefore, no framework of a story lesson will be used to analyse them. Instead, their quality will be identified in the main conditions of language-focused learning (Nation, 2007) to discover whether they could offer opportunities for: (1) noticing the target form; (2) receptive retrieval, seeing the new form used in input material; (3) productive retrieval, using the language form in output material to express meaning; (4) meaning, focused on how meaning is conveyed; and (5) learner-centeredness, so learners learn what they need to learn.

\section{Activities in the practice stage}

There are a variety of practice activities for retrieving the target language features, helping teachers to check their students' correct understanding of the items presented in the first phase and to achieve accuracy of forms. Frequent activities in the textbook are 'Listen and complete/tick/match/ number/circle/write (answering questions), Read/look and complete/match/ write (answering questions), Let's sing, chant'. However, there is a problem with most common activities. Take the point and say activity in Lesson 2, Unit 12, p.14 (Figure 5.8) as an example. I this activity, the students are asked to practice these structures Why shouldn't I...? Because you may... using pictures and word cues; in fact, it is a kind of substitution drills with prompts to memorize a piece of grammar (Thornbury, 1999). Learners can easily do this activity by putting the blanks with the words in the pictures without retrieving the meaning of the words. This easy practice activity has little impact on language acquisition (Tomlinson, 2015).

In the Family and Friends textbook, there are some gap-fill activities for language retrieval. For example, the two 'Write' activities in Unit 3, Lesson 2, p.21 (Figure 5.9) offer good opportunities to read and think of the meanings of the target language items your, our, their and Can I__ ? Can We___ ?

\section{Activities in production stage}

There are many activities offering opportunities for productive retrieval in both textbooks. Take the 'Let's talk' activity in the Tieng Anh textbook in Lesson 2, Unit 12, p.14 (Figure 5.8) as an example. The activity requires children to practise What's he/she doing? He/she is . Why shouldn't he/she do Because he/she may This activity gives students a little freedom in what to talk about while they use the target patterns provided. Although it is based on repetition, if done well, this kind of activity may help promote automatization and be more engaging than other drills (Arnold, Dornyei, \& Pugliese, 2015). 
The practice and production activities offer opportunities for noticing, and receptive and productive retrieval, which is beneficial for learners.

However, two problems were found. First, ideas are not meaningful in how they are conveyed. Do students need these drills and gap-fill exercises in real life? Although some activities ask learners to say something about their own life, to connect learning in the classroom to their life outside the classroom, most of the contexts are unnatural and meaningless. Second, most of the activities are not learner-centred. The textbooks are designed with a set of structures from easy to difficult and the learners are expected to join in every activity in the textbook with little control of their learning process. They are forced to learn at the same pace and say similar things and the activities are unlikely to create opportunities for students to explore and discover things in learning, activate their thinking or convey their own messages.

In sum, in light of the conditions of language-focused learning, the activities in practice and production stages provide opportunities for receptive and productive retrieval but not in a meaningful and learner-centred way. It reflects a lack of meaning-focused output and fluency development; in other words, the textbooks present an imbalance of opportunities for language acquisition.

\subsection{The textbooks, the curriculum and how young learners learn}

This section contrasts the pedagogy in the textbooks with the suggested teaching approach in the curriculum and how young learners learn.

As mentioned in Chapter 2, the curriculum suggests that communicative language teaching should be used to teach English in primary school. First, the curriculum (MOET, 2010a, p. 14) highlights a desire for leaners to communicate. Activities must be communicative ${ }^{3}$, which can create a strong need for students to communicate what they think and feel. Second, the curriculum emphasizes the significance of meaningful contexts. The contexts should be diverse and rich to help students produce language. Activities in the forms of games, chants, songs and the like create meaningful contexts, which are likely to engage personal and cooperative interactions (individual, pair and group work). Third, it is expected in the curriculum that through communicative activities, learners can go beyond the mastery of language features (Language knowledge of vocabulary, phonology, and grammar is a vehicle for the development of language skills) to communicate and produce language with

\footnotetext{
${ }^{3}$ The italic words in this paragraph are translated words taken from the 2010 curriculum.
} 
confidence, which means that language forms are not the main target of learning activities. Fourth, less teachers' control is recommended. Rather than merely being the implementers of the textbook, it is intended that teachers will organize activities in which learners are offered independence in learning so that they can be active and creative in their learning process and be the subject of their learning. In short, the recommended teaching approach in the curriculum is the strong version of CLT (Holliday, 1994; Howatt, 1984; Littlewood, 1981), which focuses on learners' natural language production through active participation in meaningful situations.

The approach in the textbooks reflects some points in the curriculum. The textbooks have a variety of activities in different forms of interactions and in child-friendly contexts like stories, games, songs and chants, which are suitable for young primary school learners. However, the activities do not meet the requirements of the curriculum. First, they do not create a desire for communication for the students as the activities aim at language learning, not real communication. As discussed above, the input and output activities in the textbooks are exclusively language-focused, offering few opportunities for meaning-focused input, meaning-focused output and fluency development. Second, each textbook activity focuses on one grammar point, one structural pattern or a set of single-topic related vocabulary which is not the core of communication (Criado, 2013; Maftoon \& Sarem, 2015). Third, the activities adhere closely to the PPP structure, providing few opportunities for independent learning (Brown, 2007), as expected in the curriculum. It can be concluded that the approach in the textbook follows a communicative language teaching approach but it is a weak version, which suggests the integration of structural practices and focuses on learners' language reproduction (Holliday, 1994; Howatt, 1984; Littlewood, 1981). Therefore, the methodology suggested in the activity does not completely reflect the teaching approach in the curriculum. An adaption of Harmer's (2015, p. 70) communication continuum helps compare the communication in activities in the textbook and the ones the curriculum. The activities in the textbook seem to come very close to the non-communicative end while the curriculum requires them to come nearer to the right-hand side of the continuum, as seen in Table 5.2. 
Table 5.2 Communication continuum

Non-communicative activities

No communicative desire

No communicative purpose

Form not content

One language item only

Teacher intervention

Materials control

\section{Communicative activities}

A desire to communicate

A communicative purpose

Content not forms

Variety of language

Less teacher intervention

No materials control

The new textbook activities were inconsistent with how the children learn as well. In the Tieng Anh teachers' guidebook and Family and Friends teachers' notes, no evidence was given of conceptual support with the reasons why stories are designed in the framework of presentation, practice and production. Only procedural support is provided, as seen in Extracts 1 and 2, and steps of each activity as in 'Look, listen and repeat' or 'Listen and read' are described; there are no conceptual reasons why the activities should be conducted with young learners. Except for chants, songs and games, most activities such as gap-fills and substitutional drills are not commonly found in the children's real world. There are stories but they are associated with rote reading rather than being "a meaningful framework increasing the functionality of the separate activities" (Bogaert, Van Gorp, Bultynck, Lanssens, \& Depauw.V, 2006, p. 123). The PPP method is not well supported for teaching young learners. This method systematically introduces particular structures and functions in specific and short exercises, which will impact negatively on young learners' developing proficiency (Kirsch, 2008). This encourages an approach involving teaching language features separately, while children learn holistically (Halliwell, 1992; Pinter, 2017; C. Read, 2015; Shin \& Crandall, 2014). Shintani (2016) with her own experience with young learners in Japan, found that her students' communication abilities failed after many lessons with the PPP structure of. Lessons in the PPP framework cannot provide natural and communicative situations that help young learners' language acquisition. Newton and Bui (2017) addressed the deficiencies of communicativeness, meaningfulness and students' passive role in the textbook's PPP lessons. Like many Asian educational contexts, teachers closely follows what is designed in the textbooks (Grassick, 2016; Newton \& Bui, 2017; Vi, 2018) and heavy reliance on the textbook is also found in this study (see Chapter 6). Hayes (2014) warns about ineffectiveness if the methodology in the textbooks is not age appropriate: "Textbooks ..., in some instances, 
may themselves be a source of problems if they are not founded on a basis understanding of how children learn languages" (p. 26).

\subsection{Chapter summary}

Hutchinson and Torres (1994) view the textbook as an agent of change in curriculum reform and a framework of new methodologies, supporting the teachers with guidance, and creating a supportive environment and a sense of security in implementation of change in their classrooms. However, the findings in this chapter have shown that texts and tasks in the textbooks for English primary schools in Vietnam do not provide these kinds of support. The following summarises the main findings about the pedagogy in the textbooks.

- The textbooks are comprised of different kinds of texts. Texts in the Tieng Anh textbook that are called stories do not have enough of the elements of a good story.

- The stories are designed separately from other activities in a lesson; therefore, they cannot be fully exploited as a meaningful context for activities in a lesson.

- The overwhelming message from both textbooks is the language goals. Different skills get attention, but they are serving the purpose of language learning goals.

- A wide range of texts and activities are designed; they are colourfully and nicely presented and provide opportunities for interaction, but most of them are not meaningful and learner-centred.

- The textbooks' overwhelming goal is language-feature focused, and the goal of every activity in the lesson is primarily reinforcing the language goal of that lesson. The activities are exclusively language focused; as a result, output and fluency development activities are largely absent.

- There is a mismatch between the pedagogy in the textbook, which reflects the weak version of CLT, with the suggested teaching approach in the curriculum, which is the strong version of CLT.

- Lessons with a PPP structure have not been well-supported for teaching young learners.

The data in this chapter has shown the justification for improving the texts and activities in the textbooks. The textbook designers include stories as the main input in the lessons. It is crucial to explore how teachers and students experienced the story lessons, what they perceived about them, whether the texts and activities were improved and whether they applied storytelling. How PELT exploited the textbooks' texts and activities will be analysed in the following chapter. 


\section{CHAPTER 6 FINDINGS OF PHASE 1}

This chapter presents the qualitative findings to investigate the current phenomenon of using stories and storytelling in teaching EFL in primary schools in Vietnam. It consists of four main sections to answer the four sub-research questions about teachers' perceptions about stories and storytelling, learners' prior learning experience with stories and storytelling, lessons with stories and student engagement. The results of this phase will be used as the foundation and justification for the implementation of the storytelling innovation in the second phase of the study.

\subsection{Teachers' perceptions about stories and storytelling}

This section explores how the participating teachers make sense of stories and storytelling. To provide detailed and analytical description of the findings, the emerging themes will be presented: teachers' concepts of 'story', teachers' opinions on the roles of stories in their lessons and teachers' perceptions of and experiences with storytelling. The reasons for the teachers' perceptions were all found to be related to the five main factors that shape teachers' cognition: the teachers' prior knowledge and experience, professional coursework, contextual factors, classroom practice and teachers' beliefs, assumptions, and knowledge (Macalister, 2012). The teachers and the students had their own ways to define the stories in their textbook. Most of their definitions were related to human-dialogue texts because they were the most popular and they were used to present new target language items.

\subsubsection{Teachers concepts of 'story'}

It was found that not all the teachers had the same opinions as the textbook designers about what were considered stories and what were not.

Table 6.1 Teachers' perceptions of stories in the current textbooks

\begin{tabular}{|c|c|c|c|c|}
\hline & \multicolumn{2}{|c|}{ Tieng Anh teachers } & \multicolumn{2}{|c|}{ Family and Friends teachers } \\
\hline & $\ldots$ are stories & $\ldots$ are not stories & $\ldots$ are stories & $\ldots$ are not stories \\
\hline Fables \& Folklores & 12 & 0 & 9 & 0 \\
\hline Narrative texts & 4 & 8 & 4 & 5 \\
\hline Animal-dialogue texts & 11 & 1 & & \\
\hline Human-dialogue texts & 1 & 11 & 4 & 5 \\
\hline
\end{tabular}

As can be seen in Table 6.1, above, fables and folktales were the only kind of text that did not create different opinions from the teachers. Narrative texts were considered stories by eight of 
the teachers. The others that were usually considered stories were animal dialogue texts. On the other hand, a majority of teachers did not think that narrative texts or human-dialogue texts were stories. In this, they differed from textbook designers. To understand the teachers' responses, it is necessary to consider how they defined stories.

The participant teachers defined 'story' based on their prior experience with stories, especially with the stories they had read or worked with:

Dù các bài này có hình ảnh và nhân vật, các nhân vật chỉ nói chuyện với nhau, nên chúng chỉ là bài hội thoại. (Although the texts have pictures and characters, they are just people talking together. These are dialogues between people, not stories.)

[Participant T3].

Câu truyện là nói về kinh nghiện sống, các sự kiện xảy ra hằng ngày, câu chuyện phải có một bài học về cuộc sống (A story is about life experience, about events happening in daily life; a story always has a life lesson) [participant T1].

Câu truyện là nói về kinh nghiện cuộc sống để chúng ta học và thư giản, giống như truyện cổ tích vậy (A story is about life experience for people to learn and to relax, like folktales) [participant T16].

Cái sách trước đây có một vài truyện dân giang và ngụ ngôn, sách này không có (The old textbook had a few folklores and fables. This new book does not) said participant T13.

One teacher (Participant T10) defined 'story' as the need to evoke the learners' feelings: Không câu truyện nào trong quyển sách cả, ngay cả câu truyện ngắn này cũng không phải là câu truyện, chúng nó là bài hội thoại giữa các nhân vật. Câu truyện phải có bắt đầu, nhân vật nói chuyện với nhau tạo cảm xúc cho người học. (There were not any stories in the textbook, even these short stories in the review lessons are not stories because they are dialogues. A story must have a beginning, characters speaking together and inspire some feelings for the learners).

Nine teachers out of the 16 who said that the human-dialogue texts were not stories had conflicting opinions. They stated that the human-dialogue texts were not stories but when talking about practising, they asked the students to retell (as in the extract below from the interview with Participant T8). Although they did not say the word 'story' after 'retell', the use of the verb 'retell' may include 'story' in their opinion. 
Extract from the interview with T8

\begin{tabular}{cll}
\hline $\begin{array}{c}\text { Interviewer/ } \\
\text { Participant }\end{array}$ & \multicolumn{1}{c}{ Interaction } & \multicolumn{1}{c}{ Translation } \\
\hline I & $\begin{array}{l}\text { Sau khi luyện tập bài hội thoại } \\
\text { theo nhón, thì em cho học sinh kể }\end{array}$ & $\begin{array}{l}\text { After practising the dialogue } \\
\text { in groups, I ask the students } \\
\text { to retell. }\end{array}$ \\
lại. & How do the students retell? \\
T8 & Kể như thế nào em? & I ask them to roleplay.
\end{tabular}

Eight teachers said the narrative texts were not stories and they compared the texts with what they had seen. An example of this opinion is from T8:

Trong bài 3 không có truyện, chỉ có một bài short text để dạy đọc hiểu. Mấy bài này giống như nhật ký hay là thư nói về bản thân. (There is not a story in Lesson 3. It has a short text for reading comprehension. This is like a diary or a letter, talking about oneself).

In short, about two-thirds of the teachers did not consider human-dialogue texts to be stories and nearly half of them perceived narrative texts as stories. They defined stories on the basis of their prior experience with stories. From the teacher's opinions, it can be assumed that stories designed in the textbooks have a problem. The problem was identified in Section 5.1.2: the stories do not have engagement elements or a clear structure that makes the meaning of the stories interesting.

Whether or not the teachers perceived the texts as stories, their teaching practices did not differ. The textbooks' texts were used similarly in their lessons as they had the same roles as found in the following sections.

\subsubsection{Teachers' opinions on the roles of stories in their lessons}

In the teachers' opinions, stories in their lessons have three roles:

(1) to introduce the new structures to be learned in a lesson

All the teachers reported that the human-dialogue texts in Lessons 1 and 2 in the Tieng Anh textbook and lessons 1 in the Family and Friends textbook were for introducing the sentence patterns to make students familiar with the new structures before they learned how to use them and practised using them. Lessons 1 and 2 aim to help learners to learn the new structures. Twelve Family and Friends teachers said that in addition to introducing the new sentence patterns, the human- 
dialogue texts were used as the context for just-learned vocabulary in the same lesson and to improve speaking and listening.

(2) to review structures

Twelve Tieng Anh teachers said that the animal-dialogue texts in all review lessons were for reviewing the structures they had learned in previous lessons.

(3) to improve students' reading skills

Both Tieng Anh and Family and Friends teachers mentioned this third role. They reported that whether the texts were in different forms of advertisements, letters, or stories, they aim to improve reading skills.

In fact, the teachers did not pay attention to whether or not texts were stories because the texts were not the core of the lesson. It was the target structural patterns that were the centrepiece of the lesson, as Participant T9 pointed out:

Bài này để giới thiệu mẫu câu, trọng tâm của bài là các em hiểu và nói được mấy mẫu câu này (Chỉ vào mẫu câu trong phần Activity 2) (This is used to introduce structural patterns, the most important part of the lesson is that the students can understand and use them (Point to the patterns to Activity 2).

In short, what the teachers said about the roles of the stories did not differ from the intention of the textbook designers, as found in Chapter 5. Stories were not used as the main focus of the lessons and they did not play an important role in the teachers' lessons. They served as a steppingstone for another more important teaching in the lesson: teaching structural patterns.

\subsubsection{The teacher's perceptions and experiences of storytelling}

Most of the teachers seemed to perceive storytelling as a concrete exercise or an output activity in which students were asked to retell the learned story in the lesson or to role-play the dialogue of the story. This perception may be formed from the teachers' teaching contexts, teaching experience and their prior education.

The first factor for this perception was related to the textbook they were using. Tieng Anh teachers reported that storytelling was only one of the many activities in their textbook, as in Lesson 2 in Unit 14, in the 'Let's play' section (Table 6.2). This activity was not found in other lessons. 
Table 6.2 Storytelling section

(Unit 14, Lesson 2, p. 27)

The image has been removed by the author of this thesis

for copyright reasons.

The second factor may be due to teaching experiences. Nine of the participating teachers reported that they had attended a workshop on TEYL in 2011. In this workshop, besides learning about children's characteristics, multiple intelligences, classroom management and using songs and chants, these teachers studied how to use stories and storytelling in TEYL. However, their teaching contexts such as large classes and fixed furniture arrangements prevented them from applying storytelling; therefore, they could remember just a little about storytelling from the model lessons in that workshop. As Participant T1 recalled:

Giáo viên dời bàn ghế và cho học sinh ngồi trên sàn xung quanh giáo viên. Giáo viên kể truyên và yêu câu học sinh làm một số hành đông như nhân vật trong truyện. Sau đó học sinh kề lại câu truyện theo nhóm hoặc đóng kịch. Em nhớ bài kể chuyên nhìn 
hay và vui nhưng thưc tế em làm không được. Cô nhìn xem lớp thì đông, bàn ghế như vậy sao mà di chuyển được (The teacher moved all the tables and chairs and allowed the students to sit on the floor around her. She told a story and asked students to do something like the characters did in the story; then, the students retold the story in groups or made a drama of the story in groups. I remember that the storytelling lesson was interesting and fun, but I can't apply it in my teaching. Just have a look, you see, the class is crowded, and I cannot move all of these heavy desks).

Gradually, how they had been teaching formed their perception: the students' retelling a story was storytelling:

Mấy bài dạy đọc này, sau khi tui nó trả lời câu hỏi xong, này nếu có thời gian em kêu mấy đứa học giỏi kể lại (In these reading lessons, after they finish answering the questions, I invite some good students to retell the story).

Teachers who did not attend any TEYL workshops or courses may also form their perceptions based on their classroom practices. In Family and Friends teachers' opinions, storytelling was an activity in a cycle of activities in the teachers' lessons. As Participant T2 said "Theo em dạy bài kể truyện theo ba bước pre-while post, bước Post là yêu cầu các em kể chuyên (For me, a storytelling lesson has three steps, Pre-While-Post, the post- step is requesting students to retell the story)."

The third factor concerned the teachers' prior education. Participant T5 compared a storytelling lesson with what they used to learn and teach.

Hồi trước, bài kể chuyện có 4 bước: dạy từ vựng, mời 2 hoặc ba em đọc to câu truyện và dịch câu truyện, hỏi và trả lời về nội dung và bài học rút ra từ câu truyện. Hồi đó thầy cô của mình dạy cũng vậy, hồi em dạy cho mấy đứa cấp 2 cũng dạy vậy. Nếu bây giờ dạy em nghĩ cũng vậy (A storytelling lesson generally had four steps: teaching vocabulary, inviting two or three students to read the story aloud; doing translation; answering the teacher's questions about the content of the story and talking about a lesson they could learn from the story; and two or three students (good ones) were invited to retell the story. Our teachers taught us that way and I used to have such a storytelling lesson with my junior high school students. Now I teach similarly with less translation).

Even with this perception that storytelling was a concrete output activity, the teachers stated that they rarely conducted this activity in their lessons. 


\section{Infrequent implementation of storytelling}

The infrequent implementation of storytelling was found to have a link with the teachers' teaching contexts, their prior knowledge, experiences and beliefs.

Five contextual factors affected the practice of storytelling. The first factor was related to administration and time constraints. In the teachers' opinions, their teaching practices were under strict supervision. An example of this was a quote from Participant 19:

Mỗi tuần em phải nộp lịch báo giảng, trong đó có lớp dạy, ngày dạy, dạy bài gì, dạy nội dung gì. Nhưng phải dự vào phân phối chương trình do nhà xuất bàn và phòng giáo dục đưa xuống (Every week, I have to submit my teaching plan in which I write the classes, the date, the lesson and the contents of each lesson. In fact, all teaching plans must be based on the teaching and learning content allocation [see Table 6.3, below] in each period provided by the book designers and local DOET).

Table 6.3 Teaching and learning content allocation plan for Grade 5

\begin{tabular}{|c|c|c|c|}
\hline \multicolumn{4}{|c|}{ 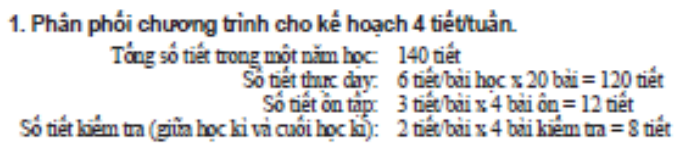 } \\
\hline \multicolumn{4}{|c|}{1.1 Học là I } \\
\hline Thết & $\begin{array}{l}\text { Đonn vi } \\
\text { bải bọc }\end{array}$ & Nội dung dạy học & Ghi chú \\
\hline & \multicolumn{2}{|c|}{ UNIT 1: WHAT'S YOUR ADDRESS? } & \\
\hline 1 & Lesson 1 & $\begin{array}{l}\text { 1. Look, listen and repeat. } \\
\text { 2. Point and say. } \\
\text { 3. Let's talk. }\end{array}$ & \\
\hline 2 & & $\begin{array}{l}\text { 4. Listen and couplete. } \\
\text { 5. Read and couplete. } \\
6 . \text { Let's sing }\end{array}$ & \\
\hline 3 & Lesson 2 & $\begin{array}{l}\text { 1. Look, listen and repeat. } \\
\text { 2. Point and say. } \\
\text { 3. Let's talk. }\end{array}$ & \\
\hline 4 & & $\begin{array}{l}\text { 4. Listen and circle } a \text { or } b \text {. } \\
\text { 5. Wite about you. } \\
\text { 6. Let's play. }\end{array}$ & \\
\hline 5 & Lesson.3 & $\begin{array}{l}\text { 1. Listen and repeat } \\
\text { 2. Listen and circle } a \text { or } b \text {. Then say the } \\
\text { sentences aloud. } \\
\text { 3. Let's chant. }\end{array}$ & \\
\hline 6 & & $\begin{array}{l}\text { 4. Read and tick Yes or No. } \\
\text { 5. Write about your friend. } \\
\text { 6. Project. } \\
\text { 7. Colour the stars. }\end{array}$ & \\
\hline
\end{tabular}

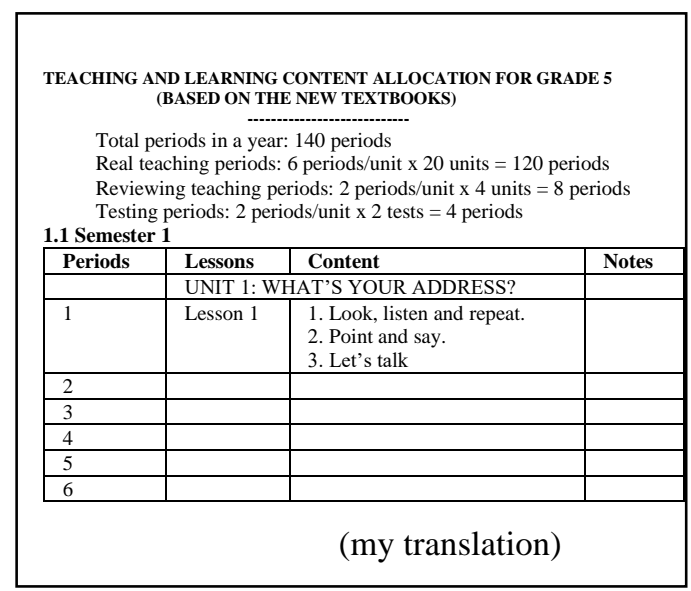

The teachers had to teach everything in the textbook for administrative reasons; therefore, they only asked the children to do storytelling when the lesson had the activity. Fifteen teachers said that what they did in the classroom was compatible with the instructions in their textbook. For example, referring to Lesson 2, p. 72 in the Tieng Anh textbook (Figure 5.3), Participant T13 said: "Cái bài này chỉ đọc và nghe câu truyên thôi, đâu có yêu câu mình kể 
(This instruction is to read and to listen to the story, it does not require to retell the story)." The second contextual factor was time constraint. Eight Tieng Anh teachers mentioned the short time of their English programme, which was two periods per week, compared to other teachers who were in the four-period-a-week English teaching programme. Therefore, time pressure made them rush through the textbook without spending time on storytelling. The third factor was end-of-term tests. The teachers indicated that it was not necessary to have storytelling lessons because the end-of-term speaking test did not require the students to retell a story. Parental expectation was the fourth factor. Some parents regularly and carefully checked what the teacher taught in the class. They hoped the teachers would teach everything in the textbook as the best solution for their children's preparation for end-of-term tests. The fifth factor linked students' English proficiency. Eight of the 11 teachers said that storytelling might be difficult for their students as their students' English level was very low.

Furthermore, it was difficult for the students to memorize the story and retell that story in English.

The teacher's prior knowledge and experience possibly impacted the application of storytelling. Nine teachers who had attended the TEYL workshop reported that they were advised to use stories from different materials beyond the textbook. In the teachers' opinion, designing a lesson outside the textbook was a time-consuming task as they had to prepare the storytelling lesson from scratch. Choosing a story suitable to the themes of the lessons and the student's English proficiency, finding ways to teach vocabulary and to tell the story and creating activities for the students so that they could actively participate in the lesson were all challenging. In addition, they had to prove that the new lesson they designed was better than the well-established lesson in the textbook. The teachers also reported that the workshop instructor had used a lot of puppets, pictures, headbands, and realia to help the students understand and retell the story. These teaching materials cost a lot of money, while they received no financial support, not even for photocopying.

The teachers' belief that human-dialogue texts in the textbook were not stories, as mentioned earlier, could affect their willingness to have storytelling lessons.

Overall, the teachers perceived the designed stories a little differently from the book designers. In particular, about two-thirds of them did not think that human-dialogue texts were stories. Due to their own beliefs, prior knowledge, contextual factors, teaching practices and experience, the teachers had their own definitions of stories; they thought that storytelling 
was an exercise, or an output activity and they rarely conducted the activity of storytelling in their lessons.

\subsection{Learners' prior learning experience with stories and storytelling}

\subsubsection{Students' concepts of 'story'}

Most of the students reported having studied with stories and they opened their books and showed me where the stories were. They even pointed to the stories they had not studied. When asked whether they understood the stories they had not studied yet, Tieng Anh students said that the texts had similar forms; therefore, they could guess what they were about from the pictures. Family and Friends students had the same ideas as Tieng Anh students about picture stories and added that they had studied the fables and folklores in Vietnamese.

It was found that not all the students had the same opinions as the textbook designers about what were considered stories, but they were more aligned than the teachers were.

Table 6.4 Students' perceptions of stories in the current textbooks

\begin{tabular}{lcc|cc} 
& \multicolumn{2}{c|}{ Tieng Anh groups } & \multicolumn{2}{c}{ Family and Friends groups } \\
\cline { 2 - 5 } & ... are stories & ... are not stories & .. are stories & ... are not stories \\
\hline Fables \& Folklores & 12 & 0 & 9 & 0 \\
Narrative texts & 0 & 12 & 3 & 6 \\
Animal-dialogue texts & 12 & 0 & 6 & 3 \\
Human-dialogue texts & 7 & 5 &
\end{tabular}

As can be seen in Table 6.4, fables and folktales were the only kind of text that did not create different opinions from the students, which is similar to the teachers' opinions in Table 6.1. Narrative texts were not considered stories by 18 students. The number of students who did not think of human dialogue texts as stories was lower than that of the teachers. Only a third of the students (five from the Tieng Anh textbook and three from the Family and Friends textbook) said that human dialogue texts were stories. To understand the students' responses, it is necessary to consider how they defined stories.

Unlike the teachers' opinions, only a third of students had a different opinion on humandialogue texts from the textbook designers. Three Family and Friends groups and five Tieng Anh groups said that human-dialogue texts are not stories. Students defined 'story' on the basis of their personal and school experience with stories, on the contents of or humanization 
in stories, or something like folktales as reflected in the following extracts from different groups of students:

Mấy cái này có nhân vật, có hình, giống câu truyện mình đọc (These have characters, pictures like stories we have read).

Câu truyện là một đoạn văn để kể lại một đều gì đó (A story is a passage to tell something).

Cái này người nói không, không phải truyện. Cái này có con vật nói chuyện mới là truyện (This has people talking, so it is not a story. This has an animal talking, so it is a story).

Mấy cái này là hội thoại thôi cô ơi (These are just dialogues).

Câu truyện phải là cái gì đó cổ cổ (Stories are about something rather old).

Câu truyện nói về người tốt, các anh hùng như trong sách Tiếng Việt mình học (Stories are about good people or about heroes like the one in the Vietnamese textbook).

Câu truyện là phải có ngày xửa ngày xưa (Stories start with once upon a time).

Mấy các bài này đâu có nhân cách hóa đâu cô (These do not have humanization).

The students defined the stories in the textbook on their appearance or story-like features. Not all of them thought that human-dialogue texts were stories; arguably, these texts seem to lack elements that interest them as, discussed in Section 5.1.2.

\subsubsection{Prior learning experience with stories}

\subsubsection{The students' opinions}

The ways the students experienced the story did not differ although they learned with two different textbooks. Listening to the tape, answering some questions, repeating, reading aloud in pairs and role-play (by good students) were what the students experienced with stories. Tieng Anh groups learned with a story in one lesson that had a framework: starting with a game, learning vocabulary, listening and reading to a text, learning new structures and practising structure. Family and Friends groups learned with a story in one lesson and learning structures and practising structures were done in other lessons. The following extract from Group 7 showed interesting information about the students' learning experience with human-dialogue stories in the Tieng Anh textbook. 
Extract from Group 7 (translated into English)

34 I What activity do you like in this lesson?

35 Ss This part [pointing to the human dialogue text].

36 I Why do you like learning this part.

37 Ss Because I have a chance to talk.

38 I When do you talk?

39 Ss When practising with friends and retelling the story.

40 I How do you retell the story?

41 Ss Roleplaying.

42 I Do you look at the book when practising?

43 Ss Yes, when practicing with friends, but not when doing roleplay.

44 Ss I have the same opinion. I also like playing games.

45 I When do you play games?

46 Ss Before learning the lesson and after learning vocabulary.

47 Ss I like speaking using the structures. This part.

48 I Why do you like this part?

49 Ss I can speak about pictures.

50 Ss I also like it because it is easy.

$51 \quad$ Ss I like this part [S points to Section 3] because I am allowed to answer with my own opinions.

52 I Do you have any opinions?

53 Ss I like listening because they help me pronounce words correctly.

54 I How do you learn this lesson?

55 Ss You speak.

56 Ss You speak.

Ss $\quad$ First, we play a game; next, the teacher teaches vocabulary; next she asks us to listen to the text. After listening, we repeat after the speakers; next we read in pairs and in front of the class. Sometimes we play roles. Then, we find the new patterns and learn them.

57 Ss That's not all.

58 Ss We study these pictures and talk about ourselves.

Notes: I=interviewer, Ss: students

First, the students seemed to be content with all the activities in their lessons (the whole extract); it may be partly because they had not experienced other ways of learning English. Second, in the students' opinions, learning a dialogue by heart and presenting the dialogue again in role-play was storytelling (see lines 39-41of the extract). Third, some students confused speaking with reading aloud (see lines 34-41). It may be because when the teachers 
asked them to do the task, the teachers said: "Practise speaking with friends" instead of saying "Practise reading with friends". Fourth, when they said they pointed to their book, it reflects that what they learned was mainly from the textbook (see Section 6.4).

Only one group of students referred to translation: "Sau khi nghe xong câu truyện cô kêu tụi con dịch rồi cô sửa (After listening to the story, the teacher asked us to translate each utterance and she did help us to correct them)." Translation was not a popular technique with human-dialogue stories, but it was a little more popular with reading lessons as found in the extract below from Group 1.

Extract from Group 1 (translated into English)

137 I How do you learn the reading lesson?

138 Ss We learn vocabulary first, then answer the questions.

139 Ss No. We read the questions and translate the questions. Then, we answer the questions.

140 I How do we read?

141 Ss We read aloud the questions.

142 Ss Then, we translate the questions.

143 Ss Then we write the answers in the book.

144 Ss That's it.

145 Ss We read aloud.

146 Ss Sometimes she asks us to translate the text.

In sum, the story was learned separately from other activities in a lesson. Listening to the tape, answering some questions, repetition, reading aloud in pairs and role-play were the main tasks conducted with the story in a lesson.

\subsubsection{Teachers' opinions}

The teachers reported that they used two cycles of activities, which were instructed in the annual workshops by the book designers and DOET and in monthly inter-school meetings for professional development. The first cycle was for Lessons 1 and 2 in the Tieng Anh textbook and Lessons 2 in the Family and Friends textbook. It was a five-part cycle of activities and the story appeared as a small part in a lesson solely for introducing the new structure and the vocabulary they just learned in the same lesson. As Participant T7 stated:

Em dạy mấy cái bài này giống như em dạy cho cho cô coi vậy đó. Em cho tui nó chọn một trò chơi để ôn bài học trước; kết tiếp em dạy từ vựng mới trong hoạt động 1 và hoạt động 2 , kế tiếp, em dạy bài hội thoại [chỉ vô bài phần 1]; kế tiếp em yêu cầu học trò tìm cấu trúc mới trong bài; kế tiếp em dạy cấu trúc;, em cho học sinh luyên cấu 
trúc với các bức tranh này [chỉ vào phần 2]; sau đó em chuyển qua phần 3 [chỉ vô bài phần 3]; để cho học sinh luyện tập mấy cái mà nó mới học (I teach these lessons like the one you observed. I give the students a game to review what they have learned in previous lessons; next, I teach new words from the sections 1 and 2; next, I teach this dialogue [points to Sections 1]; next, I ask the student to find the new structure in the text; next, I teach the new structures; next they practice the new structure with these pictures [points to Section 2]; then, I move to Section 3 [points to Sections 3] to ask students to practice using what they have just learned to talk about their real life).

In this cycle, except for the warm-up and reinforcement stages, every activity matched well with the sections designed in textbooks. The teachers' cycle of activities followed the same procedure as stated by the Tieng Anh teachers' guidebook and the Family and Friends teachers' notes. The table 6.5 shows the teachers' first cycle of activities done in the classroom with the sequence of stages mentioned in the teachers' guidebook and the teachers' notes.

Table 6.5 Teachers' first cycle of activities

\section{Cycle of activities reported by the teachers}

Sequence of teaching stages in teacher guidebook/teacher's notes

Presentation

Teaching new words

Listening to and reading the text

\section{(A story was used in this part of the lesson)}

Teaching new structures

Practice/development

Practise the new structures and new words that have been learned with picture cues in pair works and/ or group work

Practising using the new structures and new words that have been learned for their real life by using given situations
Production/reinforcement

Similar to what was found in Newton and Bui (2017) the teacher's lessons followed closely the sequence of presentation, practice, and production, but the difference is that no teachers used the terms 'presentation, practice and production' or PPP or 'practice, development, reinforcement' to talk about their cycle of activities. There may be two main reasons for not using the terms. First, they had learned about the sequence a long time ago (as no teachers had less than 10 years of teaching experience); therefore, they forgot the terms and, in their professional development meetings and workshops, these terms were not used in their 
discussions. Second, they rarely read the teachers' guidebook (three teachers even reported they had never seen the teachers' guidebook, which could be downloaded free of charge from the Internet).

The second cycle of activities (table 6.6) was reported to be used for Lessons 1 with humandialogue stories, for reading lessons with other kinds of stories by Family and Friends teachers and for the reading section in Lesson 3 by Tieng Anh teachers. This cycle of activities consisted of four main stages as in the following:

Table 6.6 Teachers' second cycle of activities

\section{Cycle of activities reported by the teacher}
Warm up: A game
Pre-activities: teaching new words and a guessing activity
While-activities: Answering the questions and read aloud
Post-activities: Retelling the stories (doing a role-play)

However, although the teachers reported that they were instructed to use pre-while-post activities, Tieng Anh teachers could not conduct all the stages due to the students' abilities and time constraint. They admitted that they had enough time for quick vocabulary teaching or reviewing and a while-activity because the lesson also had a writing section and a speaking section.

Phần đọc chỉ là một trong ba phần phải thực hiện trong 35 phút. Em không thể thêm hoạt động khác được. Em dạy từ hoặc ôn từ, rồi em yêu cầu học sinh đọc rồi viết [trả lời cho các câu hỏi], rồi em kiểm tra câu trả lời, Chỉ khi bị dự giờ thì em sẽ cố gắng làm phần post (The reading section is one of three sections in a 35-minute lesson. I cannot add other activities. With this reading section, I teach or review the vocabulary and then I ask the students to do as requested in the book: read and write [the answers for the question]. Then, I check their answers. When there is a visitor in my class, I will try to do post activities.)

Family and Friends teachers reported that good students who were able to remember the story or the characters' utterances could do the post-activities like retelling the stories or performing a drama. It is supported by Family and Friends students: "Sau khi nghe câu truyện và trả lời các câu hỏi. Bạn nào thuộc được thì lên kể cho cả lớp nghe (After listening to the story and answering some questions, we take turns to read aloud in front of the class. The students who can learn the story by heart will be called to retell it)." 


\subsubsection{Textbook-based teaching and learning}

According to the students, the teachers followed every section in the textbook. Students in the four-period-a-week English teaching programme reported that the teachers taught everything in the textbook: "Cô dạy hết trơn trong sách, không bỏ phần nào (She teaches everything in the book, not skipping any sections)." Students in the two-period-a-week English teaching programme omitted some parts but still followed the textbook: "Cô không có dạy hết, dạy phân này, phần này, phần này, phần này trong mỗi bài [chỉ vào từng phần] (She does not teach everything. She teaches this part this part, this part this part and this part) [points to the first four sections in a lesson]).” Six reasons were found for this kind of teaching practice.

The first reason is administrative. They followed the instruction on what to teach in each lesson, which was called "teaching and learning content allocation for Grade 5" (Table 6.2), provided by the textbook designers and officials from the local DOET.

The second reason is related to the teacher's beliefs. The teachers thought that the lesson was well-designed. As Participant T21 said: "Người ta thiết kế chặt chẻ hợp lý rồi, mình thêm hay bớt đều không hay (The lesson was logically designed; hence we should not cut and add anything that is not)." For them, textbooks provided a good framework on how a lesson can be delivered. The teacher reported that textbook-based teaching was considered a criterion of a good lesson.

Dạy thường có khi em có thay đổi chút, ví dụ như em thấy mẩu câu học sinh đã học qua rồi thì em nhắc qua rồi em không dạy phần này nữa (chỉ vào phần 2). Nhưng khi em dạy dự giờ là phải day đủ các bước trong sách. Nếu dạy sai một chút là bị nhận xét liền cô ơi mặc dù ai cũng nói không cần theo sách (In teaching, I have changed the activities a little bit once or two times. For example, once in a lesson, I noticed that the structures were not new to the students, so I reviewed it quickly and I did not teach them. I skipped this part [point to Activity 2]. When there were visitors, I have conducted a full lesson. If I did a little differently, I would receive a lot of criticism although it is said that teachers do not need to follow the textbook) [Participant T9\}.

Teachers' opinions reflect common practice in teaching English at primary level in Asia. Textbook-based teaching is a way to avoid being poorly-evaluated as Saito, Tsukui, and Tanaka (2008) point out; teachers often: “... systematically follow the textbooks in order to avoid any criticism from colleagues and authorities" (p.98). 
The third reason is related to parents' expectations. The students' parents hoped the teachers followed everything in the textbook as a good way for their children's end-of-term test preparation and it made it easy for them to keep track of their children's learning. If the teacher skipped an activity or used a text outside the textbook, some parents might think the teachers were making trouble for their students. For instance, Participant T4 reported: "Phụ huyng đến gặp em rồi hỏi tại sao cô bỏ phần này phần kia. Nếu kiểm tra rơi vô phần đó thì con tui phải làm sao? Sao cô dạy không giống trong sách? (The students' parents met me and asked why I skipped this or that part. "If this part were the end-of-term test, what would my kid do? Why was what you taught not from the textbook?)".

The fourth reason is related to end-of-term tests that were textbook-based, mainly focused on rote learning and memory recall. For instance, Participant T12 pointed to Section 2 of Lesson 1 and Lesson 2, and Section 5 of Lesson 3 and said: "Nếu mình không dạy mấy cái tranh này, mai mốt tới kiểm tra nó không biết tranh nói gì. Mấy cái chủ đề nói này là cho thi đó cô, nên mình không được bỏ (If we do not teach these pictures [in Section 2], they will not know what these pictures mean in tests later. These topics [in Section 3, Lesson 3] will be for tests, we cannot skip them)."

The fifth reason was due to the teachers' time constraints. During my observation during data collection at the research site and from the interviews, it was obvious that the teachers had other duties besides teaching. Because of this, following the textbook's designed sections seemed to help them a lot in terms of time and effort.

The sixth reason is the teachers' perception of the curriculum and CLT (discussed below).

\section{The teachers' perception of the curriculum}

In contrast with a recent study (Grassick, 2016), the teachers in this study seemed to know little about the curriculum. When asked about the curriculum, all the teachers associated it with their current textbooks or their teaching time: four periods or two periods per week as illustrated in the extracts from T1 and T5's interviews. The interviews were conducted in Vietnamese. I added the key concepts in English to avoid misunderstanding, as the translated words for 'curriculum' and 'programme' are nearly similar in Vietnamese. 


\begin{tabular}{|c|c|c|}
\hline $\begin{array}{c}\text { Interviewer/ } \\
\text { Participant }\end{array}$ & Interaction & Translation \\
\hline \multicolumn{3}{|c|}{ Extract from participant $\mathrm{T} 1$} \\
\hline $\mathrm{I}$ & $\begin{array}{l}\text { Em nói cho chi biết về chương trình } \\
\text { tiếng Anh tiểu học - primary English } \\
\text { education curriculum? }\end{array}$ & $\begin{array}{l}\text { Could you please talk about the } \\
\text { primary English education } \\
\text { curriculum? }\end{array}$ \\
\hline $\mathrm{T} 1$ & $\begin{array}{l}\text { Ở đây, tại tỉnh mình, là có hai chương } \\
\text { trình: chương trình Family and } \\
\text { Friends và chương trình sách tiếng } \\
\underline{\text { Anh } 3,4,5 \text { của Bộ. }}\end{array}$ & $\begin{array}{l}\text { Here, in our province, there are two } \\
\text { curricula: Family and Friends and } \\
\text { MOET's Tieng Anh 3, 4, } 5 \text {. }\end{array}$ \\
\hline \multicolumn{3}{|c|}{ Extract from participant $\mathrm{T} 5$} \\
\hline $\mathrm{T} 5$ & $\begin{array}{l}\text { Mình có hai chương trình: chương } \\
\text { trình hai tiết trên tuần và chương } \\
\text { trình fou tiết trên tuần, dạy theo hai } \\
\text { quyển sách: Family and Friends và } \\
\text { Tieng Anh. }\end{array}$ & $\begin{array}{l}\text { We have two curricula: teaching } \\
\text { four periods a week and teaching } \\
\text { two periods a week with Family } \\
\text { and Friends and Tieng Anh. }\end{array}$ \\
\hline \multirow{2}{*}{\multicolumn{3}{|c|}{$\begin{array}{l}\text { I then specified my question to remind the teachers of the main points in the document. } \\
\text { Fourteen teachers said that they had not seen or read it and six teachers said that they seemed } \\
\text { to have heard about it from a workshop. One teacher said that she had it in her computer, but } \\
\text { she had not read it for a long time. One of the teachers (T11) even questioned me about the } \\
\text { legitimacy of the document. }\end{array}$}} \\
\hline & & \\
\hline $\begin{array}{l}\text { Interviewer/ } \\
\text { Participant }\end{array}$ & Interaction & Translation \\
\hline \multicolumn{3}{|c|}{ Extract from Participant T5 } \\
\hline I & $\begin{array}{l}\text { Mình biết hay đã đọc qua về một tài } \\
\text { liệu trong đó nói về mục tiêu giảng } \\
\text { dạy tiếng Anh tiểu học, nội dung } \\
\text { giảng dạy, phương pháp giảng dạy, } \\
\text { kiểm tra đánh giá như thể nào } \\
\text { không?”. }\end{array}$ & $\begin{array}{l}\text { Had you read or heard about a } \\
\text { document on teaching English at } \\
\text { the primary level, consisting of the } \\
\text { aims, the contents, methodology } \\
\text { and assessment? }\end{array}$ \\
\hline $\mathrm{T} 5$ & $\begin{array}{l}\text { Chắc có lẽ là em có nghe qua mà em } \\
\text { tổng thể thì em không có nhận được } \\
\text { và chưa có đọc qua. Không biết hình } \\
\text { như mấy lần tập huấn người ta chỉ } \\
\text { nói chung chung, chứ đề giao về cho } \\
\text { trường phải như vậy như vậy thì em } \\
\text { nghĩ chắc chưa có }\end{array}$ & $\begin{array}{l}\text { I perhaps have heard about it, but I } \\
\text { have not had and read it. Maybe it } \\
\text { was referred to in some workshops. } \\
\text { If it had been sent to my school, I } \\
\text { would have had it. }\end{array}$ \\
\hline
\end{tabular}




\begin{tabular}{ccl}
\hline Extract from Participant T6 & \\
\hline T6 & $\begin{array}{l}\text { Em không để ý nhiều đến nó. Tức là } \\
\text { em cứ theo cuốn sách. Em dạy đúng } \\
\text { theo phân phối chương trình của } \\
\text { quyển sách đó. }\end{array}$ & $\begin{array}{l}\text { I do not pay attention to it. I teach } \\
\text { what is designed in the textbook. I } \\
\text { exactly follow the teaching and } \\
\text { learning content allocation for the } \\
\text { textbook. }\end{array}$ \\
\hline Extract from Participant T11 & $\begin{array}{l}\text { Chương trình tiếng Anh tiểu học là } \\
\text { do ai soạn hay là chỉ đạo hay là sao? }\end{array}$ & $\begin{array}{l}\text { Who designed the primary English } \\
\text { education curriculum? Who directed } \\
\text { it? }\end{array}$
\end{tabular}

In short, the curriculum was found to be not a popular document among the teachers. The teachers remembered little about the curriculum, which led to the question of how the teachers perceived the suggested methodology in the curriculum: the communicative language teaching approach. The teachers' perceptions of the communicative approach will be discussed in the next part.

\section{The teachers' perceptions of the communicative language teaching approach}

The majority of the teachers thought that the communicative language teaching approach was a method or a teaching technique. Eight teachers associated the communicative approach with teaching speaking skills, or both speaking skills and listening skills (as in T21 and T1's opinions). Twelve teachers (as in T5's opinion) thought that the communicative approach was one of the teaching techniques to develop speaking skills. Only one teacher (T7) highlighted the use of new language items in real-life situations. However, what she described was like a fairly standard Presentation, Practice and Production lesson moving from controlled to freer control practice. From the teachers' opinions, they seemed not to be aware of the importance of the development of learners' communicative competence.

\begin{tabular}{ccl}
\hline $\begin{array}{l}\text { Interviewer/ } \\
\text { Participant }\end{array}$ & \multicolumn{1}{c}{ Interaction } & \multicolumn{1}{c}{ Translation } \\
\hline Extract from Participant T21 & \\
\hline I & $\begin{array}{l}\text { Em có dạy theo đường hướng giao } \\
\text { tiếp hay phương pháp giao tiếp tiếng }\end{array}$ & $\begin{array}{l}\text { Have you applied the } \\
\text { communicative language teaching } \\
\text { approach in your teaching? }\end{array}$ \\
& $\begin{array}{l}\text { Anh là communicative approach } \\
\text { không? }\end{array}$ & $\begin{array}{l}\text { Yes, I focus my teaching on } \\
\text { T21 } \\
\text { Có dạy có chị, em dạy chủ yếu phát } \\
\text { triển kỹ năng nói cho học sinh. }\end{array}$ \\
\end{tabular}


T1 Bây giờ em dạy theo hướng communicative là giao tiếp nhiều hơn. Communicative approach là chủ yếu là chú trọng vô nghe nói nhiều. Mục đích sau cùng để học tiếng Anh là để nghe và nói để giao tiếp thôi.
At present, what I teach is more

communicative. The communicative approach mainly focuses on speaking and listening. The ultimate aim of learning English is just to speak, to communicate.

\begin{tabular}{|c|c|}
\hline \multicolumn{2}{|c|}{ Extract from Participant T7 } \\
\hline $\mathrm{T} 7$ & $\begin{array}{l}\text { Em dạy học sinh theo đinh hướng là } \\
\text { giao tiếp. Đối với tiểu học là không đặt } \\
\text { nặng về ngữ pháp lắm. Chủ yếu là tập } \\
\text { cho các em tập nói những cái mẫu câu, } \\
\text { vận dụng là trong mỗi bài học đều có } \\
\text { liên hệ thực tế để làm sao cho các em } \\
\text { đem được tiếng Anh vào thực tế sử } \\
\text { dụng cùa các em, chứ không phải là chỉ } \\
\text { trên sách vở, thì cũng theo đường } \\
\text { hướng là giao tiếp. }\end{array}$ \\
\hline
\end{tabular}

My teaching follows the communicative approach. Grammar is not the main focus for primary school students. The focus is to help students to practise structural patterns, and to use them in real situations which were beyond the prescribed situations in the textbooks. That's communicative teaching.

Extract from Participant T5

T5 Chưa nghe nó, mà có mấy lần đi hội thảo đầu năm thì mấy giáo viên người nước ngoài người ta cũng nói qua thôi hà. Nhiều phương pháp quá em không nhớ. Mình dạy phải đủ bốn kỹ năng nghe nói đọc viết chứ không có dạy nói không.

I haven't heard of it. I attended some workshop and foreign trainers talked briefly about it. There are too many techniques, therefore, I did not remember it. I teach four skills, not just speaking.

There were two main reasons that the teachers did not know about the national curriculum, the communicative approach, and associated the curriculum with the textbook.

First, the teachers had little expertise support. It may be because at the beginning of the curriculum reform, the textbooks and their teaching and learning content allocation plans were the only two documents the teachers received and they must have believed that, armed with the textbook and the methods of teaching instructed by the textbook designers and DOET experts in the workshops, teachers would be able to improve their teaching practices.

Tài liệu cần có quan trọng nhất là phân phối chương trình. Dự vào phân phối chương trình. Dự vào chương trình và sách, tụi em dạy bài theo cách dạy mới theo tập huấn của sở (The most important document is teaching and learning content allocation plan [see Table 6.2]. With that plan and the textbook, I teach lessons in the new way which was instructed in DOET workshops) [Participant T19]. 
Second, textbook-based teaching was considered a criterion of a good lesson, as mentioned earlier. In meetings for professional learning, their school leaders, their colleagues (in schools or from different schools) and DOET experts expected them to follow everything designed in the textbooks.

In short, there were six main reasons for the teachers' textbook-based teaching:

administration, teachers' beliefs, parental expectations, end-of-term tests, time constraints and their perceptions of the curriculum and CLT. Although textbook-dependent teaching is a safe and beneficial approach for the teachers, this indicates that the teachers focused their teaching on finishing the book rather than on the students' communicative competences as required in the curriculum (see Section 2.3). For them, all the sections in the textbooks were necessary and the story section was just a section like other parts in the lesson. Again, it reflects that they accepted the suggested methodology without any adaptations. With heavy reliance on the textbooks, the teachers may gradually regard the textbook as the curriculum, as found in previous studies as mentioned in Section 2.5.1.

The following parts will give detailed descriptions of what the teachers did with stories in their lessons in the classrooms to investigate the learners' engagement and participation.

\subsection{Lessons with stories}

This part presents how the teachers implemented their lessons with stories. Although the teachers used two different textbooks and had different teaching periods per week, the general steps and procedures in English classrooms were similar and some common features were found. The findings are arranged under the following headings: detailed description of lesson activities, mechanical practice, vocabulary and structure focus, competition focus, writing and copying from the board and child-friendly features.

\subsubsection{Detailed description of lesson activities}

Prior to the description of the lessons, two main concerns related to the validity of the data will be raised.

The first concern related to lessons with and without PowerPoint. In 23 out of 42 observed lessons, the teachers used PowerPoint. From my observation, whether their lessons were with or without PowerPoint did not seem to make any significant differences in the teachers' employment of teaching techniques. First, the teachers followed the structure of the textbook lessons. Second, most of the pictures in the lessons were copied from the textbooks and the teachers had hard copies of these pictures. Third, what the teachers wrote on the board was 
not different from what was shown on PowerPoint, mainly new words and structural patterns. Fourth, the games employed (see competition focus) could be done with the board or PowerPoint. One difference was that Family and Friends students could watch the cartoon of their lesson's story with PowerPoint. Most of the teachers believed that lessons with PowerPoint were better than ones with the board for two reasons. That was because it made the lessons look more beautiful and saved the teachers' writing time. Only two teachers did not use PowerPoint, even although they had a projector in their classrooms. These two teachers said that PowerPoint could help to have some interesting games if the teachers could exploit it effectively, and they could not find a big difference between a lesson with or without PowerPoint. They used PowerPoint when they had visitors to prove their ability in technology application in their teaching.

The second concern is whether the lessons observed were truly representative of a normal lesson. There is a common belief in the researched area that teachers always present 'an ideal lesson' to visiting teachers and presenting 'an ideal lesson' is a common culture in interschool professional meetings in Vietnam (Phan, 2017). Some manifestations of trying to present a perfect lesson were found, an example of 'Hawthorne' effect (see Section 4.6). Three teachers borrowed a projector to present a PowerPoint lesson although their school did not have one. One teacher reported spending her own money printing some enlarged pictures for the first time. They were signs of 'more than normal' preparation.

Even though some untypical signs were found, what the teachers tried to do in their lessons is still worth exploring because this suggests what the teachers thought they should be doing in their normal lessons. In addition, in these untypical lessons, the 'more than normal' preparation still seemed to be constrained in the same cycles of activities they employed in their normal lessons, making my findings and interpretations still valid and relevant. Though it was likely that some of the lessons were better-prepared than the normal lessons, it may be argued that the data was reliable.

Below is a summary of 42 lessons observed, with 24 lessons with the Tieng Anh textbook and 18 lessons with the Family and Friends textbook.

23 lessons with a human-dialogue story with Tieng Anh textbook and Family and Friends Textbook

2 lessons 1, part 2 with the Tieng Anh textbook

4 lessons with animal dialogue story with the Tieng Anh textbook 4 lessons with a narrative text (in lesson 3 part 2) the Tieng Anh textbook 4 lessons with a fable or a folklore (lesson 5) with the Family and Friends textbook 
2 review lessons with the Family and Friends textbook

1 extended reading lesson with the Family and Friends textbook

1 lesson 6 with the Family and Friends textbook

1 a song lesson with the Family and Friends textbook

The burden of teaching and reviewing new forms fell on the lessons with human-dialogue stories, with animal-dialogue stories, with narrative texts (Lesson 3, part 2) and with fables. Therefore, the detailed descriptions will centre on the lessons with these texts. Two lessons (one with human-dialogue stories and one with animal-dialogue stories) in the four-period a week English teaching programme with the Tieng Anh textbook were chosen as representative lessons because the teachers in this programme also participated in the second phase of this study. The differences of the lessons in the other two programmes will be clarified right after the descriptions of each representative lesson.

\subsubsection{Lessons with human-dialogue stories}

Typically, in the observed lessons with human-dialogue stories, most of the lesson time was taken up with language input and controlled practice, and this is similar to the findings from other studies in Vietnam primary schools (Bui, 2019; Grassick, 2016; Vi, 2018). As referred to in Section 6.2, teachers' lessons followed the cycle of five main stages consisting of a warm-up activity, a teacher-led presentation of new words, followed by an introduction of new structures through a story, leading into controlled practice and less controlled practice. Table 6.5 shows the stages of a lesson with a human dialogue story in detail (see Appendix 6 for a copy of the corresponding textbook pages for the lesson).

Table 6.7 A lesson with a human-dialogue story

This is T7's 35-minute class with 46 students. The lesson was based on Unit 6

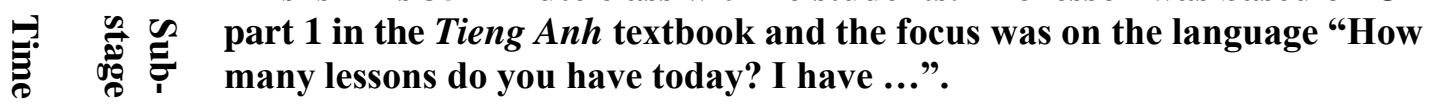
$2.01 \quad 1 \quad$ T and Ss' greeting.

2.022 The whole class sang a song "the wheels on the bus" (this song was studied in Unit 5)

$2.03 \quad 3 \quad$ T told the students that they would play a game. T divided the class into two groups, A and B. T stuck some pictures of book covers with words on school subjects in English: Art, English, Science, IT, music, PE, Maths. Ss were asked to read the English words. Then Vietnamese and word cards with the same school subjects in Vietnamese were stuck on the board. Ss were asked to do the matching of English words and Vietnamese words. Four volunteers from each group did the matching (each, in turn, marched one subject and its meaning with four subjects on the board as fast as they liked in a relay running race). The faster group that won the game received two flowers, and the other received one flower.

2.104 T pointed to the subject words in English and Ss chorally read them in English. T pointed to the subject words in Vietnamese and Ss chorally said them in English. 
$2.08 \quad 5 \quad$ T said that the students start learning Unit 6 Lesson one. T asked Ss a question about the date of their lesson and wrote it on the board and T wrote the unit, the title of the unit and lesson on the top of the board. The class repeated the title after the teacher

$2.196 \quad$ T wrote New words and underlined it and said: "No new words today".

2.20 7 T stuck pictures of the story on page 40 on the board and asked questions "What's the boy's name? What's the girl's name

How many lessons does he have? Does Mai have a lesson today?" Some volunteer students were called to answer the questions

$2.21 \quad 8 \quad$ Ss were asked to open their books and look at the story. T played the story and Ss listened and followed in the book. T played it again and the whole class repeated each line chorally. The teacher paid attention to pronunciation, intonation, and accuracy by giving direct and intermediate correction. A sentence may be broken into several phases and repeated several times if necessary. Then, the story was read aloud in whole class chorus, $\mathrm{T}$ divided the class in two large groups, and they took turns with the roles of the story dialogue saying Mai's part and Long's part. Next, Ss were asked to read the story in pairs. Then, the teacher invited two pairs to read the dialogue in roles in front of the class.

2.239 T asked: "What did Long ask Mai in Picture C?" and "What did Mai answer" and wrote them on the board and made a beautiful box around them (How many lessons do you have today? I have four: Maths, Vietnamese, Music, and PE"). T asked Ss to chorally repeat that structure two or three times, and in half class chorus and three open pairs. Ss were asked to copy what was written on the board. T asked Ss "Who can tell me what the patterns can be used for?" and Ss volunteered to answer "to ask and answer about the number of the lessons? And $\mathrm{T}$ said it again "the patterns are used to ask and answer about the numbers of the lesson."

$2.26 \quad 10 \quad$ T stuck the timetable on the board (exactly the same as Activity 2 Point and say). $\mathrm{T}$ underlined the words in the new structures where they can substitute with other words. (How many lessons do you have today? I have four: Maths, Vietnamese, Music and PE"). Ss chorally repeated the structures with substitution. T divided the class into two large groups, and they took turns to ask and answer. Then, close pairs practised the patterns and three open pairs asked and answered on the timetable in front of the class.

2.3511 Teachers asked the question and invited two volunteers to answer using their real timetable. Ss were asked to ask and answer on their real timetable in close pairs.

$2.36 \quad 12 \quad$ T asked Ss to play a lucky game. Three pairs of Ss in one group was called randomly ( $\mathrm{T}$ had a bag with number cards in it. Ss already knew their number) to ask and answer using the structural patterns they just learned. Each pair got a flower for their groups if they could say them correctly.

$2.40 \quad 13 \quad$ T added the flowers each group got and announced the winner. $\mathrm{T}$ asked Ss talk about the structures they learned and their usages. The lesson ends.

Notes: T=teachers, $\mathrm{Ss}=$ students

Table 6.5, above, exemplifies a typical lesson with a human-dialogue story in the four-perioda-week English teaching programme with the Tieng Anh textbook. The students had to work hard as the lesson had many activities with minimal transition time between activities and phases. Sub-stage 6 will be explained more in 'vocabulary focus'. In sub-stage 8, the teachers designed two variations of repetition to help the students memorize the dialogue. The first was word disappearance. After students repeated a line, the teacher started removing one 
word, then two words, then three words in a line and the students repeated the full line each time. When all the sentences in the story dialogue had been erased, the students tried to produce the whole dialogue by themselves. The second variation was keyword text creation. The teacher read a line and the students repeated. Then the teacher wrote one or two keywords of that line on the board and the students said the whole line. This was repeated for all the lines in the story.

The lessons in the two-period-a-week English teaching programme were conducted similarly but at a much faster pace with one more activity, Activity 4 Listen and tick, after sub-stage 13 and fewer sub-activities in sub-stages 8 and 9 . In sub-stage 8 , the teachers did not ask the students to do open pair reading. In sub-stage 9, the teachers asked the students directly in Vietnamese about the structural patterns they needed to learn and talked about their usages. The explanation for adding one more activity in a 35-minute lesson was due to the end-ofterm tests, which had a listening part. With worries about covering the required content for testing purposes, the teachers were keen to maintain a fast pace during the lesson.

The lessons with a human-dialogue story with the Family and Friends textbook did not include structural pattern learning and practice; therefore, the lessons did not include substages 9, 10,11, 12 and 13 in Table 6.5. In sub-stage 7, there were more activities. The students watched the story cartoon before answering the teachers' questions and, after repeating the dialogue, good students were invited to roleplay the dialogue without dialogue scripts in sub-stage 8. The students in lessons with the Family and Friends textbook seemed to have a more relaxing and enjoyable time in their lesson than the students with the Tieng Anh textbook.

\subsubsection{Lessons with animal-dialogue stories}

It was reported that teachers did not need to follow any cycles of activities in a review lesson. Therefore, the teachers could change the order of activities in the review lessons and the animal-dialogue story section was taught as instructed in the textbook. Table 6.6 shows a lesson with an animal-dialogue story in detail (see Appendix 7 for a copy of the corresponding textbook page for the lesson). 
Table 6.8 A lesson with an animal-dialogue story

\section{Time of This is T8's 35-minute class with 46 students. The lesson was based on Review lesson 1, part 2 in the Tieng Anh textbook and the focus was on the language items learned from Unit 1 to Unit 5.}

\begin{tabular}{|c|c|c|}
\hline 10.7 & 1 & $\mathrm{~T}$ and Ss' greeting. \\
\hline 10.08 & 2 & $\begin{array}{l}\text { Ss were asked to play a matching game: matching the questions with their correct } \\
\text { answers to review the target structures. (This is Activity } 6 \text { in the Tieng Anh } \\
\text { textbook). First, they were asked to do the matching individually. Then the class } \\
\text { was divided into two large groups. Volunteers of each group wrote their answers on } \\
\text { the board (each group gained a star for good work). }\end{array}$ \\
\hline 10.13 & 3 & $\begin{array}{l}\text { Ss were asked to chorally read the question and answers in the warm-up activity. } \\
\text { T asked the students the past tense of go, see, come, have. They answered in } \\
\text { chorus. }\end{array}$ \\
\hline 10.15 & 4 & $\begin{array}{l}\text { T showed the first two pictures of the story on page } 38 \text { without words on the board } \\
\text { and asked Ss about the names of the characters. }\end{array}$ \\
\hline 10.16 & 5 & $\begin{array}{l}\text { Ss were asked to open their books and look at the story. T played the story and Ss } \\
\text { listen and followed in the book. T played it again and the whole class repeated each } \\
\text { line chorally. Ss were asked to read the story silently and individually in two } \\
\text { minutes. They were asked to raise their hands after finishing reading the story. }\end{array}$ \\
\hline 10.21 & 6 & $\begin{array}{l}\text { T asked Ss whether the lesson had any new words. Ss said no. T asked: "What is } \\
\text { the story about?" and one S volunteered to answer. } \\
\text { T asked volunteers, in turn, to read the five questions in the book Activity } 2 \text { Answer } \\
\text { the questions and asked them whether the questions have any new words and Ss } \\
\text { said no. }\end{array}$ \\
\hline 10.24 & 7 & $\begin{array}{l}\text { Ss were asked to work in pairs to answer the questions. Ss were asked to raise their } \\
\text { hands after finishing answering the questions with their friends. }\end{array}$ \\
\hline & 8 & $\begin{array}{l}\text { T organized a lucky game, the class was divided into two groups again, and three } \\
\text { volunteers from each group were called in turn to join the game. Each chose a } \\
\text { number and one of the five questions appeared, he/she read the answer of that } \\
\text { question and got a star for his/her group. }\end{array}$ \\
\hline 10.30 & $\begin{array}{l}9 \\
10\end{array}$ & $\begin{array}{l}\text { Team A read the questions, Team B read the answer and vice versus. } \\
\text { T asked Ss: "Do you understand the story? And Ss said yes. } \\
\text { "How many characters are there in the story?" }\end{array}$ \\
\hline 10.35 & 11 & $\begin{array}{l}\text { T invites two groups of seven volunteers to roleplay the story. Ss were allowed to } \\
\text { read from their books ( } \mathrm{T} \text { encouraged them to memorize the story). }\end{array}$ \\
\hline 10.39 & 12 & $\begin{array}{l}\text { Ss were asked to unscramble the words from the story (Activity } 2 \text { in the textbook. } \\
\text { T organized a game "Who is faster?" in this activity. } \\
\text { First, Ss were asked to work alone. Then, five Ss from each group volunteered to } \\
\text { play. They in turn wrote out the correct words. The fastest group won the game. } \\
\text { (The bell rang signalling time to go home and it was extremely noisy but T asked } \\
\text { Ss to stay and continue the game.) }\end{array}$ \\
\hline 10.45 & & The lesson ended. \\
\hline
\end{tabular}

Notes: $\mathrm{T}=$ teachers, $\mathrm{Ss}=$ students

As seen in Table 6.6, the teacher employed the cycle of pre -, while- and post-activities in the lesson with an animal dialogue story. The lesson consisted of a warm-up activity (sub-stage 2 ), followed by a pre-reading activity that focused on the names of the characters in the story, leading into while reading activities to answer some comprehension questions and into postreading activities that included reading the questions and answers aloud. The sub-activities showed that teachers tried to help the students memorize the stories and target words. 
This cycle of pre-, while- and post- activities was employed in their lessons with a narrative text. Table 6.7 shows an extract from a lesson with a narrative text (see Appendix 8 for a copy of the corresponding textbook page for the lesson).

\subsubsection{Lessons with a narrative text}

Table 6.9 A part of a lesson with a narrative text

This is an extract from T14's 35-minute lesson. The extract lasts 15 minutes on how the teacher conducted activities with narrative texts. The lesson was based on Unit 7, Lesson 3, part 2 in the Tieng Anh textbook and the focus was on the language items learned in lesson 1 and 2 in the same unit.

T drew a figure girl and a figure boy on the board and said: "they are Mai and Akiko and you will read a passage about them". T stuck a list of five sentences about Mai on the board (these five sentences were in the textbook right below the text about Mai). Ss were asked to guess whether they were true or false. Ss were asked to translate them into Vietnamese. Then, Ss were asked to read the texts and decided the answers in 6 minutes. Ss were also asked to underline information in the text that helped them to choose the answers. After six minutes, $\mathrm{T}$ checked the answers from the students. Sometimes the teachers translated parts of the texts into Vietnamese where Ss could find the answers. T wrote the correct answers on the board and ask Ss to copy them into their books. T invited three Ss to read the text aloud.

The lessons started with vocabulary presentations, followed by guessing the answers for the questions (some translation was done), reading the text and checking their guessing. After checking the answers, the students were asked to retell the story. Two prominent points in this kind of lesson were that the teachers added an unmeaningful activity: translation and reading aloud. The teachers believed that translation assisted understanding. According to Nation (2013), translation “will have little effect on the understanding of tomorrow's text on a different topic" (p. 59). Reading aloud in this activity focuses on the language forms and has little room for comprehension.

Lessons with narrative texts, fables and folklores in the Family and Friends textbook were conducted similarly but over much longer time - 35 minutes, and the teacher could add one more post-reading activity: retelling the story. One Family and Friends teacher did this differently. After teaching the vocabulary, she told the story using a lot of pictures on PowerPoint to draw the students' attention. She invited the students to answer some questions about the story. She showed pictures with words from the story and asked the students to repeat sentence by sentence. She invited three groups of three students in turn to read the story in roles in front of the class. Then, she invited a group of three students to volunteer to roleplay the story. One student volunteered to retell the story in front of the class. This teacher told me that this was the first time she changed a reading lesson into a storytelling lesson and, in her opinion, the students were more involved in listening to the story and happier to join other activities in the lesson than in previous lessons. Although this was not one of her normal 
classes, some common features were still found in her lesson. Repetition was dominant and all her activities were aimed at rote learning. However, the fact that she told the story herself reflects the teacher's desire to make some changes in the normal lessons.

Although there were three main differences, including two different textbooks, teaching time (four or two periods per week) and teaching facility (with or without technology support), the teachers' lessons had five common features, which will be presented in the next sections.

\subsubsection{Common features of the observed lessons}

\subsubsection{Mechanical practice}

Heavy repetition is a common feature of the 42 observed lessons. Repetition was found in nearly every section in a lesson such as in warm-up games, writing the title of the lesson, teaching new words, reading the stories and presenting and explaining new structures, and in practicing the new structures. The teachers applied different types of repetition: imitation drills (repeating exactly what is said), substitutional drills (repeating what is said but changing one or two words) and situational drills (repeating the patterns in certain situations with pictures and word prompts). When conducting repetition and drills, the teacher provided immediate feedback on their accuracy by means of teacher correction.

The teachers thought that repetition helped improve learners' speaking competence. In the interviews, most teachers expressed their belief that frequently repeating words and structures correctly would lead to mastery of language and habit formation, as Participant T6 reported: “Đọc nhiều lần cho quen miệng thì mới nói được. Nếu mấy em pháp âm không được thì mình chỉ nó (Repeating many times helps their mouth form a habit. If they can't pronounce the word, I will show them how)." In addition, the teachers believed that repetition and drills helped learners remember the linguistic features that need to be learned and could learn the dialogue by heart. This was a way of fostering communication, as revealed by Participant T8: “Lặp lại nhiều lần giúp các em nhớ bài, rồi các em sẽ nói được khi các em đóng vai (Repetition helps students remember the dialogue, which helps them speak when they role play)." Arguably, underlying T8's comment was a view that role-playing or dramatizing the dialogue by memorizing its utterances showed the learners' speaking competence.

Repetition is important in children's learning but heavy repetition with no opportunities for real cooperative, interactive and creative activities is against children's characteristics, how children learn and how children learn a foreign language. With the focus on repetition, most class time was spent on students' accurate production of target language items rather than meaningful use. Although students had no complaints about repetition, a lot of monotonous 
drilling noise was heard: aloud sound of repetition at the beginning of the activity but tired and slow sound of repetition towards the end. This suggests a more behaviourist view of learning a language and learners have no or very little choice over what is said (Harmer, 2015); This is inconsistent with the communicative approach required in the curriculum.

\subsubsection{Vocabulary and structure focus}

Vocabulary was one of the prominent aspects in the teachers' lessons. The focus on vocabulary is reflected the new words sub-stage in most of the lessons.

It was unusual to find that the classes described in Table 6.5 and Table 6.6 did not show a vocabulary sub-stage. Two teachers in the four-period-a-week English teaching programme with the Tieng Anh textbook taught the same lesson and they did not teach new words in that lesson. They said that Unit 6 Lesson 1 was a special lesson because the students had learned all the necessary words before. Even if they did not teach new words in that lesson, they still wrote 'New Words' on the board as if it were a compulsory part of the lesson.

The teachers used different ways to get across the meaning of a word such as illustration (pictures, drawing, realia), mimes, synonyms, antonyms and translations; however, they still taught vocabulary in mechanically. The following extract shows how a word was transmitted to the students.

Extract of teaching new words from T12's lesson Unit 8 Lesson 1

T: [shows a picture] What is it?

Ss: [two students raised their hands]

T: Mai

Mai: a fox.

T: Good. It's a fox, a fox. [whole class repeats] A fox

Ss: a fox, [T signals Ss to repeat], a fox, a fox.

T: Hung

Hung: [stands up] a fox

T: Minh

Minh: [stands up] a fox

T: My

My: [stands up] a fox

T: a fox là gì? What does a fox mean?

Ss: con sói.

$\mathrm{T}$ : [Writes a fox and its meaning in Vietnamese on the board under the headline New words]

$\mathrm{T}$ : Whole class [points to the word]

SS: a fox

[T continues teaching other words] 
The above extract indicates that the teacher employed four techniques. First, the teacher applied a kind of classroom interaction, taking the form of the Initiate-Response-Feedback (IRF) model (Sinclair \& Coulthard, 1975) or the Initiate-Response-Evaluate (IRE) model (Walsh, 2011). In IRF or IRE, the teacher asks a question, a learner or some learners answer, and the teacher provides feedback. In the extract, the teacher used a picture and prompted "What is it?" This was followed by a student's response "a fox", and then it was followed by the teacher's feedback "Good". The teacher expected the correct word from the students, who already knew the word for that picture. The second technique employed in teaching vocabulary was repetition. All the teachers had a formula for drilling each word: whole-class repetition in chorus, two or three times; three or more individual repetitions for each word; then whole-class repetition in chorus again. The third technique was translation. The teachers asked for the meaning in their mother tongue and wrote the meaning of each word in the first language on the board. The students then wrote them in their notebook in both languages (see Table 6.7). In addition to these three techniques, the teachers also ran another activity for checking the students' new word memorization (see Section 6.3.2.3).

There are problems with the four techniques used in teaching vocabulary to young learners. IRF interaction is a common technique in the classroom around the world, and in this kind of exchange, the teacher not only controls the direction and content of classroom discourse but also involves student participation; however, it tends to limit students' learning opportunities (Van Lier, 2001). Answering the teacher's questions tends to be a chance for students to show that they have previously learned the word, as it "requires students merely to recite previously learned items" (Van Lier, 2001, p. 94). Repetition, as mentioned in Section 6.3.2.1, is a mechanical way of learning. Translation is useful to check the students' mastery of their understanding of the words, but in the observed lessons, there was an overlap because the visual presentation was enough to present the meaning and translation became redundant. Vocabulary games were fun and engaged young learners but the games the teachers employed were mainly for memorizing the meaning of just-learned words, not for cooperation and communication. The four techniques lead the students to rote learning, which goes against how children learn a language: children learn best in natural settings where their attention is focused on constructing meaning (Bloor, 1991; Pinter, 2017).

From the interviews with the teachers, some striking reasons for vocabulary focus were found. The first important reason that vocabulary frequently occupied a part in a lesson was related to the end-of-term tests, as Participant $\mathrm{T} 7$ said: "Không học từ mai mốt không làm bài kiểm tra được (If they do not learn vocabulary, they cannot do their tests.)." An analysis of the end- 
of-term tests in the academic years 2016-2017 and 2017-2018 showed that there was always a vocabulary section (in the form of gap fills with or without words given or writing the correct words for scrambled words) in the listening, reading and writing parts (see Appendix 9). The focus on vocabulary and structures was also expressed in the teachers' worry about their performance in students' inter-school competitions as Participant T6 mentioned: "Sách tiếng Anh có nhiều kiến từ vựng và kiến thức ngôn ngữ hơn sách Family and Friends nên học sinh đi thi có nhiều lợi thế hơn (The Tieng Anh textbook has more vocabulary and language knowledge than the Family and Friends textbook, so the students have more advantages)." The second reason was related to the teachers' beliefs as one of the participants ( $\mathrm{T}$ 16) indicated: "Mình dạy từ vựng trước; nếu không tới phần đọc bài hay luyên mâu câu cũng phải dạy từ trước mấy em mới tập nói được. Không biết từ các em không hiểu bài, không nhớ từ các em không nói được (We need to teach vocabulary first; if not when we move to the reading section or practice section, we have to teach their vocabulary. If they do not know the words, they will not understand the lesson; if they do not remember the words, they can't speak)." The teacher may assume that once learners reviewed old words and were pre-taught with new words, they would have enough vocabulary to understand the texts, to learn the texts by heart well and they could speak automatically later. Their teaching belief was inherent in the premise that "language must first be learned before it can be used" (Gibbons, 2006, p. 17). This assumption has become a challenging issue because it is not supported by researchers who have studied children's second language acquisition. Children acquire words' meanings from processes of use; when they meet an unfamiliar word, children can use information in its context and previous knowledge to properly infer the meaning of a word. Vocabulary is very important for children, but it should be taught within contexts in which it has been used rather than in isolation so that a contextual meaning of a word can be acquired effectively by the students.

Structure was also prominently focused in the teachers' lessons. In sub-stage 9 in Table 6.4, the teachers applied the same three techniques in presenting structural patterns: IRF, repetition and translation. As referred to above, these three techniques could not create real communication for young learners.

In the interviews, the teachers believed there was a big shift in presenting structures. Before the application of the new textbooks, they used to give a detailed grammatical explanation and even had a formula for the structures. For example, T8 reported that Unit 3 included, "What + did +chủ từ+ do+ thời gian?" (What + did +subject + do + time?) and its usage: Cấu trúc này dùng để hỏi bạn đã làm gì trong quá khứ (this pattern is used to ask about what you did in the 
past. In questions about actions in the past, 'did' is used before the subject and the verb is in its bare form). In the application of the new textbooks, they were told not to teach grammar in detail by DOET specialists and textbook designers. In the observed lessons, no teachers gave detailed grammatical explanations. However, they were still affected by their old way of teaching. First, some manifestations of teaching grammar in detail was found in the teachers' lessons; for example, T8 did ask about the past tense of some verbs as in Table 6.6. Second, the teachers asked the students to talk about the usage of the patterns, mainly in Vietnamese. In the reinforcement phase, they checked whether the students remembered the usage of the patterns learned in the lesson.

The practice activities were similar to what was designed in the textbook. The teachers used the same pictures and words designed in the textbook and enlarged them to interest the students. As analysed in Chapter 5, the practice activities did offer some opportunities for noticing and receptive and productive retrieval, but they were not meaningful. To engage the learners, teachers added a competition in the performance phase. This will be explained in the following section.

\subsubsection{Competition focus}

Two kinds of competition were found in the teachers' lessons.

The first is related to games. Games were found in reviewing vocabulary, in checking the students' memory of the meaning of new words, and in the reinforcement stage to review the structure they have learned as seen in Table 6.7 and Table 6.8. Most of the games were vocabulary games such as matching (the students were asked to match pictures with the correct English words or match English words with Vietnamese words), slap the board (the teachers wrote some English/Vietnamese words on the board and asked the students to listen and touch the words), Kim's game (the teachers showed some words and the students had one minute to read and remember the words and then they wrote out all the words they could remember) and make a spider diagram (the teacher wrote a keyword and the students had to write the related words). Some structured games were employed such as lucky matching parts of sentences and lucky numbers (the teacher showed some covered pictures with numbers on the board, two students in a team chose a number, the teachers uncovered the picture, these two students used the structures learned in previous lessons to ask and answer about the picture; if they accidentally chose a lucky number, they got a score without doing anything). The most popular game for reinforcement was Musical Ball. For example, in Unit 8 Lesson 1, after practising the structures: What are you reading? I am reading , a Musical Ball 
game was played. The class was divided into two groups and each group was given a small soft ball. The teacher played a song and the students, in turn, moved the balls from one student to another. When the teacher stopped the music, the two students who were holding the ball had to stand up and one student asked: What are you reading? The other student answered: I am reading For each correct answer, each group would get a score; then the scores were added up to find the wining team. The games appeared to be child-friendly, as the teachers praised both the loser and the winner, such as one flower for the loser, two flowers for the winner, or two claps for the loser and three claps for the winner.

The games, to some extent, could motivate the students; however, there were two problems found in games in the classroom. The first problem was related to the students' participation. A class was divided into two teams, each consisting of more than 12 students. To ensure being in the winning team, good students volunteered to join the game. Some teachers chose the players, but the weaker students felt reluctant to take part in the game because they were afraid of being blamed for the team's loss. The second problem was that there was no social interaction and cooperation. Young learners learn better when they interact with their peers but in these games, they did not have a chance to discuss with their friends and as a result, there was no cooperation in their own team. In a communicative game, students should cooperate to produce their team's outcomes while at the same time competing against other teams (McCallum, 1980). In sum, there were no opportunities for communication in the teachers' games. They were employed mainly just to check the students' memorization of the meanings of words or structures whereas games should create contexts where learners cooperatively engage in the use of the target language for interaction in the classroom (Wright et al., 2005).

Giving points for every correct activity in a lesson is the second kind of competition. The teachers divided the class in two groups at the beginning of the lesson and from then, every activity of each member in a group would affect the group's points, as seen in Table 6.7 and Table 6.8. In controlled practice, some pairs of students were called to perform what they had just practised with their partners. If they did it correctly, the students got one point for their group. As in Table 6.6, in the activity of answering comprehension questions, a student would be called to answer a question, if the answer was correct, the student got one point or one flower for his or her group.

The teachers believed that adding competition in activities engaged learners in their learning. However, some adverse effects occurred. Good students all wanted to perform to gain points 
for the group and weak students became less confident as they were afraid of being blamed for losing the group's points. I saw some happy students when they were in the winning groups and also some disappointed faces in the losing teams. Some students felt they lost face as they were blamed for the group's failure, which increased their fear of making a mistake and being laughed at. Using uncooperative games and unmeaningful competition goes against how young learners learn. As Scott \& Ytreberg (1990) put it “... avoid organized competition. Although it can be great fun and usually leads to a great deal of involvement, there is almost always a winner and a loser, or a winning team and a losing team. Language learning is a situation where everyone can win. Children compete naturally with each other to see who's finished first, etc., but this is something different" (p.11). Instead, cooperation is better for young learners' language development: "Avoid rewards and prizes. Other forms of encouragement are much more effective ... Make room for shared experiences - they are an invaluable source of language work and create an atmosphere of involvement and togetherness. Most of us enjoy the feeling of belonging and this is particularly true of young children" (Scott \& Ytreberg, 1990, p. 6).

In short, games and giving points for every correct activity in the lessons added excitement but little communicativeness and meaningfulness were found in these activities; therefore, the atmosphere of the classroom appeared to be enjoyable but opportunities for learning seemed to be limited.

\subsubsection{Writing and copying from the board}

Another theme emerging from lessons was that the students copied what the teachers wrote on the board in their notebooks. In each lesson, after a warm-up activity, the teachers asked the students about the date, unit, title and page of the lesson they were learning and carefully wrote them on the board. The students had to copy them down in their notebooks. Then, after teaching the new words, the teachers wrote them and their meanings in the first language on the board, and the students had to copy them into their notebooks. If it was a language lesson, after the teacher presented the new structures from the stories, the patterns were written on the board. The words and patterns written on the board were in beautiful displays and handwriting as if they were 'the new words and structures of the day'. In the teachers' opinions, this was an indispensable part of their lessons for three main reasons. The first reason was based on the teachers' beliefs. They thought that copying new words and structures gave the students a chance to review them and learn their written forms. The second reason was parents' desire to keep track of their children's learning. They thought that writing a notebook was a way to 
help them know what their children had learned. Some parents even expressed suspicion about the teacher's teaching if they did not see any words of the new lesson in their children's notebooks. An example of this was a quote from Participant 4:

Phụ huynh nói: Ở trong lớp cô dạy cái gì mà trong tập con tui không con chũ nào? Ho nói ghi bài giúp chúng tui kiểm tra mấy đứa nó học cái gì và xem nó có thuôc bài không? (A parent said: What did you do in class? Why did my kid's notebook not have a word? And they added that writing in their kid's notebook helped them check what their kids learned in the classroom and whether their kids remembered what they learned).

The third reason was from the instructions from local BOET. Participant T11 reported: Theo huớng dẫn của chuyên viên phòng giáo, viết là cần thiết đó cô, ngay cả không ghi tù̀ vưng thì mình cũng nên ghi và cho học sinh ghi ngày tháng dạy và tên bài dạy để phu huynh biết mình dạy tới bài nào. Mấy môn khác cũng viết nhu vậy. (In the specialists' instructions, students' writing in their notebook is necessary; even though there are no new words to write, teachers should ask students to write the date of teaching, the lesson title so that parents know what lesson their kids are learning. The students have to do the same in all other subjects).

From my observations, it took the students four to five minutes in a 35-minute lesson to copy everything from the board. In some classes, the students were frequently interrupted in their learning. They were asked to write the date, unit and title of the lessons right after they were written on the board; they were asked to write the new words right after learning them; then they were asked to write the structures after they were written on the board. Children are easily distracted (Shin \& Crandall, 2014); therefore, this routinely boring activity seemed to discourage them from learning, and it took time to get them back to learning again. This is clear evidence of including an unmeaningful task in the lesson. Importantly, the activity of copying from the board mirrored the teacher-controlled transmission way of teaching.

\subsubsection{Child-friendly features}

Although the majority of the lessons followed a mechanical approach to language presentation and practice, some child-friendly features were found. The first feature was teaching aids. The teachers utilized a variety of visual aids such as enlarged, colourful pictures from the textbooks and created mimes and drawings to draw the students' attention to the texts or to notice the language features or to engage the students in the practice activities. 
Even the magnets to stick pictures on the board were decorated to look appealing to young learners. In competitions, flowers, smiley faces and stars served as child-friendly incentives. The second feature was including songs and chants. Together with activities designed to practice discrete language items in the textbooks, teachers added some more in other parts of the lessons such as in warm-up and practice activities to engage learners. The third was on improving the relationship with the students. The relationship between the teacher and the students was usually formal. The sense of distance was reflected in the layout of the classrooms, as the students sat in rows with little space for moving around in large classes, but a lovely and warm atmosphere was still found in the formal relationship. Teachers tried to reduce the distant relationship with smiles when teaching and when there were some funny activities from the students. Teachers remembered all the students' names and used the students' names to nominate them. Teachers applied some child-friendly ways of praising or feedback after a student answered a question or a group finished an activity. They often used the words such as "good work", "excellent" and "well-done" or asked the students to clap and applaud. Only two teachers still used the traditional way of drawing students' attention: beating a big ruler on the table to make loud sounds.

The teachers' interviews revealed an awareness of child-friendly ways of teaching, as T1 articulated below:

Tạo điều kiện tạo cho các em cái ham muốn học tập Tiếng Anh là cái quan trọng, bên cạnh đó thì cũng phải hiểu tính cách các $\mathrm{em}$, ví dụ phải vừa dạy, các em vừa học và các em vừa chơi, đừng có bắt buộc lúc nào các em cũng học, học, học, viết, viết, viết, đọc đọc hoài đôi khi nó sẽ bị nhàn chán, ví dụ như vừa thấy các em hơi mệt thì tổ chức một cái trò chơi hoặc là mở băng lên cho nó nghe một bài hát gì đó, thì tự nhiên các em đều có một điều gì đó vui vẻ trong học tập. Bắt nó viết cậm cuội hoài nhiều khi nó cũng chán nữa. Với lại tranh ảnh, rồi nhất là các trò chơi nó có liên quan tới bài học đó, giống như hồi nãy cô thấy em sử dụng mấy cái trò chơi nó cũng vui, nó cũng liên quan đến bài học thành ra các em sẽ thích hơn (Making students interested in learning English is important. In addition, we need to understand their characteristics, for example, they need to both learn and play. Don't force them to learn, learn, learn, to write, write, write and read, read all the time; they will get bored. When we notice that they are getting tired, we need to organize a game or play a song or a guessing game, they will feel happy in learning. Forcing them to write a lot is boring. Pictures and games relevant to the lesson, like what I did in my lesson which you just observed, were fun and made the students like learning). 
These child-friendly features appeared to encourage learners. In the interviews, most of the students expressed their preference for learning English. Their common reasons (translated into English) are: "I like learning English because the book has colorful pictures and I can learn a lot of vocabulary", "I like learning English because I like the songs, and chants in the book", "Learning English is interesting and fun because I can play games", "I like learning English because I like my teacher. He is fun" and "I like learning English because the book has the stories I like".

In summary, this section described and analysed common features of the teachers' lesson to see how the teachers implemented storytelling. It was found that the teachers always followed the structure of the textbook lessons. The stories designed in the textbooks were employed exactly as the textbook suggested they be employed: to present or to be the context for introducing target language items. The students experienced lessons with mechanical practice, language focus and competition focus in unmeaningful contexts. The story was not the focus of the lessons and there were few opportunities for the students to participate meaningfully in classroom interactions. Although the lessons had some child-friendly features that could attract the students in their learning, these features were not capable of involving the learners in deep learning as analysed in the following section.

\subsection{Student engagement}

This section presents the analysis of student engagement in Phase 1 classes. The comparison group in Phase 2 had lessons with the same teaching method and learning activities as those in Phase 1; therefore, student engagement of the comparison class is embedded in this section. Some extracts from the comparison class together with those from the classes in Phase 1 are included to clarify the findings. In this section, only the lessons in the Tieng Anh textbook (see Section 5.1.1) were the focus for the analysis of student engagement because they were targeted at the implementation of the storytelling innovation in Phase 2.

\subsubsection{Cognitive engagement}

As stated in Section 3.4, cognitive engagement is manifested in the effort students invest in tasks. To identify the students' cognitive engagement, the main tasks in the lessons were first defined and Bloom's taxonomy was then employed as criteria in the analysis of student cognitive engagement (see Section 3.4.1). 
The students took part in seven main tasks as shown on the observed lessons and the cycle of activities in the lessons (see Sections 6.3.1 and 6.2.2.2). The tasks and their purposes are briefly presented in what follows.

Each lesson always started with a game, whose main purpose was mainly to check the students' memorization of the meanings of words or structural patterns learned in previous lesson. The second activity was vocabulary learning in which the teacher used IRF/IRE and repeating activities; therefore, the students just joined these two activities to memorize the words. The third activity was a vocabulary practice game; similar to the first activities, the students tried to recall the words they had learned and played the game. In the fourth activity, the students listened and repeated the utterances in a story; the teacher also used IRF/IRE to elicit information to guide students about the context of the story. The efforts the students made were to recall what they learned to understand the stories and to remember the utterances of the stories. The fifth activity was role-playing the story dialogue with scripts (like reading in roles) and without scripts (for good students). These activities required the student to memorize the story. The sixth and the seventh activities used substitutional and situational drills to practise the structural patterns.

As analysed, the aims of the activities were to help students memorize the structural patterns and apply them in a similar context. The main tasks and indicators of student engagement are identified and summarized in Table 6.10, below.

Table 6.10 Indicators of cognitive engagement

\begin{tabular}{ll} 
Main tasks & Indicators of cognitive engagement \\
\hline $\begin{array}{l}\text { 1. Playing games } \\
\text { 2. Joining IRF and repeating } \\
\text { vocabulary }\end{array}$ & $\begin{array}{l}\text { Recalling vocabulary } \\
\text { Memorizing vocabulary }\end{array}$ \\
$\begin{array}{l}\text { 3. Playing vocabulary games } \\
\begin{array}{l}\text { 4. Listening and repeating stories and } \\
\text { repeating patterns }\end{array}\end{array}$ & $\begin{array}{l}\text { Memorizing vocabulary } \\
\text { 5. Roleplaying }\end{array}$ \\
$\begin{array}{l}\text { 6. Repeating patterns in substitutional } \\
\text { drills }\end{array}$ & Memorizing the story \\
$\begin{array}{l}\text { 7. Repeating patterns in communicative } \\
\text { drills }\end{array}$ & $\begin{array}{l}\text { Memorizing and applying the target language } \\
\text { items }\end{array}$
\end{tabular}

As can be seen in Table 6.10, the indicators of cognitive engagement were comprised of loworder thinking skills in Bloom's taxonomy as mentioned in Section 3.4.1. The tasks the students participated in did not require much thinking effort and the students' brains worked 
solely to recall and memorize target language items; therefore, memorizing and applying were the main indicators of the students' cognitive engagement.

Pair work and group work activities could not make the activities more effective because peer interactions were low in quality, which are likely to inhibit learning (Baines, Blatchford, \& Webster, 2015; Kutnick \& Blatchford, 2014). This is a common practice in most primary classrooms. Extract 1a, below, shows that the students did not need to put much effort in reading in roles, just reading exactly what was written in the textbook.

Extract 1a (Students were asked to work in pairs and read the story dialogue in roles)

Unit 6, Lesson 2

S1: Nam S2: Akiko

01 S1: Hi, Akiko. It's nice to talk to you again.

02 S2: Nice to talk to you, too, Nam.

03 S2: Are you at school?

04 S1: Yes. I am. It's /rei.tai/

05 S1: Are you at $/ \mathrm{kul} /$, too?

06 S2: No, I'm at home. I'm study English lesson.

07 S1: Good for you. How often you have English?

08 S2: I have it four times a week.

The original text in Unit 6, Lesson 2

The image has been removed by the author of this thesis for copyright reasons.

The student' superficial cognitive engagement was echoed in the students' opinions, as one of the students in the group from school F said: "Nói nhiều nhất là lúc nói theo tập mẫu câu này nè cô. Một bạn hỏi một bạn trả lời. Dễ lắm cô, chỉ cần mình thay thế đúng từ là được (We spoke most when they practiced these patterns; one asked and another answered, it is very 
easy, we just replace the right words)." 'Replacing the right words' in the student's comment above indicates that these activities were not challenging.

More examples of low cognitive engagement can be found in Extracts $1 \mathrm{~b}, 2 \mathrm{a}$ and $2 \mathrm{~b}$ below.

\subsubsection{Emotional engagement}

Emotional engagement refers to the students' feeling of positive interdependence and group accountability. Table 6.11 presents a summary of indicators of emotional engagement found in the patterns of engagement in the comparison group.

Table 6.11 Indicators of emotional engagement

Patterns of engagement

1. Playing games

2. Joining IRF and repeating

3. Playing vocabulary games

4. Listening to and repeating stories

5. Roleplaying

6. Repeating patterns in substitutional drills

7. Repeating patterns in communicative drills

\section{Indicators of emotional engagement}

Low positive interdependence

Weak group accountability

No positive interdependence

Weak group accountability

Low positive interdependence

Weak group accountability

Low positive interdependence

Weak group accountability

Positive interdependence

Weak group responsibility

Low positive interdependence

Weak group accountability

Positive interdependence

Weak responsibility

The students' interdependence in groups was not strong. As mentioned above, they were put into pairs or groups to do simple tasks such as repeating a story dialogue aloud or making short dialogues based on given patterns. These tasks did not require much cooperative effort because they did not involve the students in real interactions. As the products were already designed for them, they could perceive that they did not depend much on their partners. Take Listening and repeating stories engagement patterns as an example. The students were put into the roles of the story dialogue, but they did not have a feeling of being the characters in the story; therefore, they read the utterances of their roles quickly in only about 30 seconds without pauses, repetitions and errors (this was also found in Grassick (2016)).

Extract $1 \mathrm{~b}$ shows that $\mathrm{S} 1$ read quickly without noticing that she read one of her utterances (turn 5) like another utterance (turn 3) and his partners in the group did not recognize it or care to correct it. This reflects that the students could finish their work without paying attention to their partner's work. 
Extract 1b (Unit 17, Lesson 1) (from the comparison group)

S1: the lady, S2: Mai, S3: Nam

$01 \quad$ S1: Can I help you?

02 S2: Yes, I'd like to some rice with fish, please.

03 S1: What would you like to eat?

04 S3: I'd like a bowl of noodles please.

05 S1: What would you like to eat?

06 S2: I'd like a carton of apple juice please.

07 S1: How about you?

08 S3: I'd like a glass of water please.

09 Ss: Xong rồi cô ơi. (Teacher, we've done)

The original text in Unit 17, Lesson 1

The image has been removed by the author of this thesis

for copyright reasons. 
Extracts $2 \mathrm{a}$ and $2 \mathrm{~b}$ below shows another example of the students' feeling of low interdependence. Extracts $2 \mathrm{a}$ and $2 \mathrm{~b}$, in which the bold words were the patterns provided and unbold words were the students' words, indicated that the students worked together; and imitated the previous activity, mechanically putting words in blanks.

\section{Extract 2a (from Phase 1)}

\section{Unit 6 Lesson 2}

$01 \quad$ S1: Where will you be next week?

02 S2: I think I'll at Ha Long bay.

03 S1: What will you do?

04 S2: I don't know. I may swim in the sea.

05 S1: Lát nữa mình bị kêu mình nói vậy đi. (If we were called, we would say so.)

The orgiginal text in Unit 6, Lesson 2

The image has been removed by the author of this thesis for copyright reasons. 
Extract 2 b (Unit 14, Lesson 2) (from the comparison group)

01 S1: What kinds of story do you like?

02 S2: I like Mai An Tiem.

03 S1: What do you think of An Tiem?

04 S2: I think he's ... hardworking.

05 Ss: Xong rồi, (We've finished. )

The original text in Unit 14, Lesson 2

The image has been removed by the author of this thesis

for copyright reasons.

The students in pairs were together because the task put them together but working together did not result in a group product. The task did not require "a unique contribution to the joint effort" from each of the members (Frey et al., 2009, p. 23). As one of the students commented on their task: "Cái bài này mình đọc theo vai trong sách. Bạn đọc vai của bạn, mình đọc theo vai của mình là được cô ơi (This task is to read in roles, my partner read the utterance of her roles, I read mine)." This reflected that the students did not depend on their peers but depended on the content in the book.

In addition, weak group accountability was found in these meaningless peer interactions. Extract 3 shows that the two students read the dialogue quickly and made a mistake. One of the students (S2) discovered that they were in the wrong roles (turn 9) but they decided to ignore it as suggested by the other student (turn 10). This reflects the students' feeling of low responsibility in doing the tasks. 
Extract 3 (Unit 19, Lesson 2) (the comparison group)

\section{S1: Linda S2: Tom}

$01 \quad$ S1: What did you do yesterday?

02 S2: I visited Tran Quoc Pagoda.

03 S1: Where is it?

04 S2: It's on an island in the middle of West Lake.

05 S1: What do you think of it?

06 S2: It's more beautiful than I expected.

07 S1: The pagoda is really beautiful. I enjoyed the visited very much.

08 S2: That's great. I think I'll visit it one day.

09 S2: Ủa sao tui với ông đổi vai vậy. (Oops. Why were our roles changed?)

10 S1: Thôi kệ đi. Đọc xong rồi. (Don’t mention it. We've finished reading)

The original text in Unit 19, Lesson 2

The image has been removed by the author of this thesis for copyright reasons.

Furthermore, the findings from the textbook analysis in Chapter 5 and the qualities of the teachers' teaching activities in Sections 6.1 and 6.2 showed that the activities in the textbook were not meaningful. If the tasks are not meaningful, students will not have high positive interdependence and strong group accountability (Frey et al., 2009).

In short, the students' indicators of emotional engagement were identified as low positive interdependence and weak group accountability. 


\subsubsection{Behavioural engagement}

Three observable indicators of behavioural engagement are that participants are: attracted to work, show persistence in work despite challenges and obstacles, and show visible delight in accomplishing work. The peer interactions like Extracts $1 \mathrm{a}, 1 \mathrm{~b}, 2 \mathrm{a}, 2 \mathrm{~b}$, and 3 contained evidence of attraction to work. As mentioned earlier, this is partly because young learners are obedient and want to please their teachers (as mentioned in 3.4.3); therefore, they worked together as requested and did not abandon the task even if it had no meaning or value to them. They just did what they were required to do. These on-task behaviours indicate that the students were involved in the tasks, but this reflects acceptance, not engagement; and whether they were attracted to their work is not clear. Furthermore, the peer interactions like those in Extracts 1a, 1b, 2a, 2b and 3 did not provide evidence of student persistence in their work. Reading the story in roles and doing substitutional drills were easy tasks for the students; only communicative drills and role-plays were a little bit challenging for weak students. Little persistence in their work was found because there were no challenges and obstacles in those tasks. Little visible delight in accomplishing work was identified. They looked happy after finishing the work at the end of their task (turn in 09 Extract $1 \mathrm{~b}$ and turn 5 in Extract 2b) because they finished their task quickly. However, the feeling of successfully finishing the task could not be found in their interactions.

In short, the comparison group engaged superficially in the lessons. In terms of cognitive engagement, low-thinking skills were used while they read the story, and did drills and story role-play. In terms of emotional engagement, strong positive interdependence and group accountability were not apparent, as the structures of the tasks made them work together but did not require real cooperative learning. In terms of behavioural engagement, they were involved in the tasks but did not show any persistence in their work. They expressed happiness after finishing their tasks, but no pride in their outcomes was identified.

\subsubsection{Teachers' opinions about students' engagement}

Most of the teachers in Phase 1 and the comparison group teacher expressed their pleasure with the students' participation in the activities, but their opinions about the students' participation in the presentation and practice activities reflect the meaning of the students' obedience and superficial engagement. 
Regarding the presentation activity, the teachers reported that the students paid attention to listening to the story from the tape and the aim of the activity was for pronunciation focus. However, they did not indicate how the students interacted with the story to construct meaning. This could be exemplified from Participant T8's comment: Khi nghe các em cũng rất chú ý để có nghe và bắt chướt cách phát âm (They paid their attention when listening to the dialogue and tried to imitate the pronunciation)."

Regarding the practice activities, the teachers expressed satisfaction with the students' participation but admitted that they were not sure of the quality of the students' participation, as what the students did was repeating, substitutional drills and communicative drills with little personalization. The aim of the students' performance in front of the class was to check what they had done in the activities:

Các hoạt động phân theo vai mấy em làm nhanh lắm cô, mình phải gọi các em đứng lên nói lại xem các em nãy giờ tập có đúng không (They did the activities that required them to work in pairs or groups quickly. I needed to call them to do it again in front of the class to check whether they had practised in the right way).

In the teachers' opinions, student engagement could be gained from additional elements to the main activities such as games, competitions, pictures, drawing and teachers' characteristics such as being friendly and caring (see 6.3.2.3 and 6.3.2.5). As T1 noted:

Để cuốn hút học sinh thì bài học cần có tranh ảnh, games, bài hát, chants và thi đua. Các em đạc biệt thích games (To attract learners, the lessons need to have pictures, games, songs, chants and competition. Young learners particularly like games).

As stated, the additional elements to the main activities are necessary for a good lesson but not sufficient to deeply engage learners. The teachers did not mention the students' process and progression in their learning, when the students were ready and willing to talk, how they performed the activities and how they interacted to construct meaning. The teachers' opinions reflected that the tasks engaged the learners only in superficial learning.

In brief, student engagement in Phase 1 and in the comparison class was low in regard to cognition, emotion and behaviours. The activities could activate their low-order thinking skills, low positive interdependence and weak group accountability and low levels of delight after finishing their work. Low engagement could not make deep learning happen.

\subsection{Chapter summary}

This chapter consists of four main sections reflecting the current state of using stories and storytelling in teaching English at primary schools in Vietnam. The summary of the findings is as follows: 
- Textbook designers, teachers, and students were not completely congruent in their opinions about stories.

- Teachers did not care whether their lesson had a story or not.

- Whether or not the textbook texts were considered stories, the teachers' lessons were quite similar.

- Storytelling was believed to be a simple activity: an exercise or an activity.

- The curriculum was ignored, and the teachers did not know much about CLT.

- Teaching and learning are heavily dependent on the textbooks.

- The overall picture of the primary school students' prior learning with stories and storytelling was that stories were in a PPP lesson or in a pre-, while- and post- reading lesson in which stories were learned separately from other activities in a lesson.

The students were not learning in a way that matched their characteristics and language development. This way of learning fails to enhance learners' communitive competence and student engagement was low. These findings motivated Phase 2 of the study, which investigated the implementation of the storytelling versions of the textbook lessons. The results of this implementation are reported in the next chapter. 


\section{CHAPTER 7 FINDINGS OF PHASE 2}

This chapter presents the quantitative and qualitative findings to investigate the effects of the storytelling innovation in teaching EFL in primary schools in Vietnam. It consists of three main sections to answer the three sub-questions of this research: effects of storytelling innovation, student engagement, and perceptions of and reactions to the storytelling innovation.

\subsection{Effects of storytelling innovation}

In this part, how the data were analysed will be introduced first. Then, the findings will be discussed to indicate whether the storytelling innovation had an effect and the extent of the effect. In addition, an analysis of the end-of-term tests will be presented to examine a different effect of the intervention.

\subsubsection{Data analysis}

\subsubsection{Participants in story retellings}

Thirty-one students in each class joined the pre- and post-test story retellings. However, six students in the comparison group and one student in the intervention group were removed from the analysis of story retellings because they did not supply enough data. Two students in the comparison group watched the cartoon but refused to say anything in the pre-test and post-test; one student in the comparison group moved to another school nearly at the end of the second semester; and two more students in the comparison group and one in the intervention group did not say anything after watching the cartoon in the pre-test but they did tell the story in the post-test). Therefore, the data of story retelling for analysis were from participants of 25 students in the comparison group and 30 in the intervention group.

From the results from piloting (see Section 4.4.2), two stories, LRRH and T\&J, were used in the story retelling. The students were divided into four subgroups depending on which stories they were exposed to in the pre- and post-tests. 
Table 7.1 Subgroups and numbers of students who joined story retellings

\begin{tabular}{l|ccc|ccc} 
& \multicolumn{3}{|c|}{ Intervention group } & \multicolumn{3}{c}{ Comparison group } \\
\cline { 2 - 7 } Subgroups & $\begin{array}{c}\text { No. of } \\
\text { students }\end{array}$ & Pre-test & Post-test & $\begin{array}{c}\text { No. of } \\
\text { students }\end{array}$ & Pre-test & Post-test \\
\hline Subgroup 1 & 9 & LRRH & T\&J & 4 & LRRH & T\&J \\
Subgroup 2 & 7 & T\&J & LRRH & 6 & T\&J & LRRH \\
Subgroup 3 & 8 & T\&J & T\&J & 8 & T\&J & T\&J \\
Subgroup 4 & 6 & LRRH & LRRH & 7 & LRRH & LRRH \\
\hline Total & 30 & & & 25 & &
\end{tabular}

Notes: LRRH: Little Red Riding Hood cartoon, T\&J: Tom and Jerry cartoon

Table 7.1 shows the four subgroups and the numbers of the students in each subgroup who took part in the pre- and post-test story retellings. The students were randomly put in the subgroups. The difference in the numbers of the students was due to the withdrawal of the participants who did not fully participate in the study as mentioned above.

\subsubsection{How the students' story retellings were transcribed}

For each of the students' story retellings, two versions were created. In the first version, everything was transcribed verbatim. The only changes made were when the students pronounced words with mistakes in final sounds. For example, if they pronounced "mouse" as [mau], it was transcribed as a full word [maus]. Grammatical mistakes were not corrected as in the example "the mother cook soup or five dog is run away". In the second version, all the pausing words like "umm" and "ủa" (oops), and unclear words were omitted, and some changes were made based on notes in counting tokens (listing in 7.1.1.3). The two versions were saved as .txt documents, and the latter version was used for data analysis. The story retellings were analysed in relation to the number of tokens and English tokens, English types and idea units.

\subsubsection{Tokens in students' stories}

A token is an individual occurrence of a linguistic unit in speech or in writing. In other words, tokens are the total number of words in a text, regardless of how often they are repeated. Tokens reflect the speakers' language use. In this study, there were two types of tokens in the students' stories: tokens in English and tokens in Vietnamese. For example, in "On the street cô bé quàng khăn đỏ gặp one wolf and then cô bé nói là đang đi đến grandmother home”, there are 22 tokens, consisting of nine English tokens and 13 Vietnamese tokens. To ensure 
consistency in counting tokens, some inclusion and exclusion in counting tokens are explained in the following part.

\section{Some notes in counting tokens}

- Contractions were transferred into full words. For example, "He's..." was transferred as "he is..."

- Students' self-introductions and saying goodbye were removed; for example, "My name __ " or "I am __ or plain "Goodbye" were erased.

- Talking about their class and school were removed; for example, "I am a student of class I' m studying at (name) primary school" were excluded.

- Grammatical mistakes like "walk" in "The wolf walk slowly" were ignored, "walk" were counted as one token.

- Self-correction was included in token counting, as self-correction is part of speaking as speakers do self-correct when they speak. For example, "It they" in "It they are five dog" was counted as two tokens.

- Repetition is part of our fluency. There were three kinds of repetitions in the students' story retellings:

○ repetition showing that the speaker was thinking as in "a a a ...bag..."; the three "a" words were counted as one token; two $a$ were removed.

- repetition showing that the speaker wanted to make clear what he or she wanted to say as "bowl” in "The dog running đến chỗ (to) bowl milk bowl”. In this example, "bowl" was counted as two tokens.

○ repetition emphasizing meaning as in "The wolf walk slowly and slowly" where "slowly" words were counted as two tokens.

- Proper names of the title characters were counted as tokens. For example, "Little Red Riding Hood" was counted as four tokens. Some students just used "Little Red" to name the main character. "Little Red" was counted as two tokens. "Tom" was counted as one token.

\section{How to count tokens}

The second version of story transcriptions was used as mentioned above. Word Count in Microsoft Word was used to count the total tokens of a story. For the stories in both English and Vietnamese, https://www.lextutor.ca/vp/comp/ was utilized for counting English tokens (see how the website was used and its example in 7.1.1.4 ). 


\section{Possible influence of title character names in tokens}

The title character names in English or in Vietnamese might influence the sum of tokens and the central tendency of tokens (the central value for the distribution of tokens). $T \& J$ cartoons are popular in Vietnam and the version applied in this study "Puppy Tale" was released in 1954. Vietnamese people do not have different names for the main characters; therefore, children in Vietnamese also call them Tom and Jerry. Tom and Jerry were counted as two English tokens. Most of the students adopted the title names Tom and Jerry in their stories; only six students in the pre-test and four students in the post-test used nouns and pronouns instead of the proper nouns in English. However, some students told the story completely in Vietnamese with the English title names Tom and Jerry; therefore, their stories had some English tokens. The prevailing use of Tom and Jerry might increase the number of English tokens.

LRRH is a very popular story in Vietnam. There is a Vietnamese version with a Vietnamese equivalent name for the title character: Co Be Quang Khan Đo. Most of the students who go to school in Vietnam know this story well because it is included in the official textbook for studying Vietnamese in state primary schools in Vietnam. Rather than using English proper names when telling stories, the familiarity of the LRRH story could lead to the adoption of Vietnamese character names in retold stories, which might influence the total number and the central tendency of tokens.

In the students' stories, there were English tokens in some T\&J stories but there were no English tokens in some LRRH stories because of the difference in using the title character names. Take one student who told LRRH in the pre-test and T\&J in the post-test as an example. Her LRRH story was in Vietnamese with Vietnamese title character names, her story had no English tokens. Her T\&J story was also in Vietnamese with the title character names Tom and Jerry, so this story had some English tokens. However, it would be misleading to conclude that her English had improved.

Furthermore, if the students used a lot of title character names, they might produce longer stories as Little Red Riding Hood and the Vietnamese title character Co Be Quang Khan Đo had more words than Tom and Jerry or the nouns such as "the dog" or "the cat" or the pronouns used to refer to the characters. To avoid being misleading, the sum of tokens and the average tokens with and without the title character names will be presented below to give a clear picture of the students' language production. 
The students' stories, like any spoken texts, contained a great deal of generalized vocabulary like a lot of, nice, got, many and things like that; and coordinators like and, but, and then. It is necessary to look at the students' English types in their retellings to examine the size of their vocabulary in a text.

\subsubsection{English types in students' stories}

A type is an abstract category of linguistic units, as distinct from tokens or actual occurrences in speech or writing. In other words, word types are the number of different words in the text. For example, in the sentence below there are 15 tokens but 12 types because "a" is repeated four times.

Once upon $\underline{a} \underline{\text { time }}, \underline{\text { in }} \underline{a}$ jungle there was $\underline{a}$ girl wearing $\underline{a} \underline{\text { red }} \underline{\text { scarf. }}$.

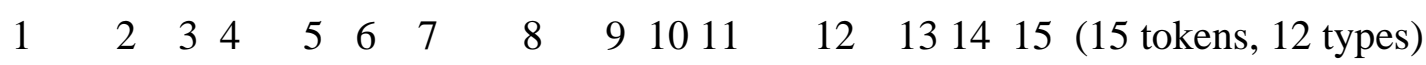

Further decisions made when counting English types:

- Singular nouns and plural nouns were counted as different types. For example, in "one dog, two dogs", "dog” and "dogs" were counted as two types.

- Different forms of the same verb were counted as different types; for instant, "go", "goes", "going" and "went" were counted as four types.

\section{How to count English tokens and types:}

Below is an example of a student's retold story.

The mouse is go the mouse get up at night, and he open the door, and go outside, he see a bag in the river, he open the bag, and he see many dogs in the bag, one dog is lick the mouse, the dogs and a mouse go, the dogs and a mouse go to the house, and the cat see the dog, and he is very angry, the dogs and the cat was in the bed, the cat the mouse cooking soup, and he đổ soup vào miệng con mèo, and the dogs is lick the cat, there are many dogs go to the house, the dogs is lick the bowl of milk.

After putting the text in the input section into https://www.lextutor.ca/vp/comp/ and clicking submit, the number of English tokens and English types can be seen in https://lextutor.ca/cgibin/vp/comp/output.pl. Care is needed because some Vietnamese words are falsely recognized as English words. Then using Edit-to-a-profile where the original text and the profiled text were compared (as seen in Figure 7.1) to check whether there were unrecognized or misrecognized English tokens. 
Figure 7.1 Text comparison

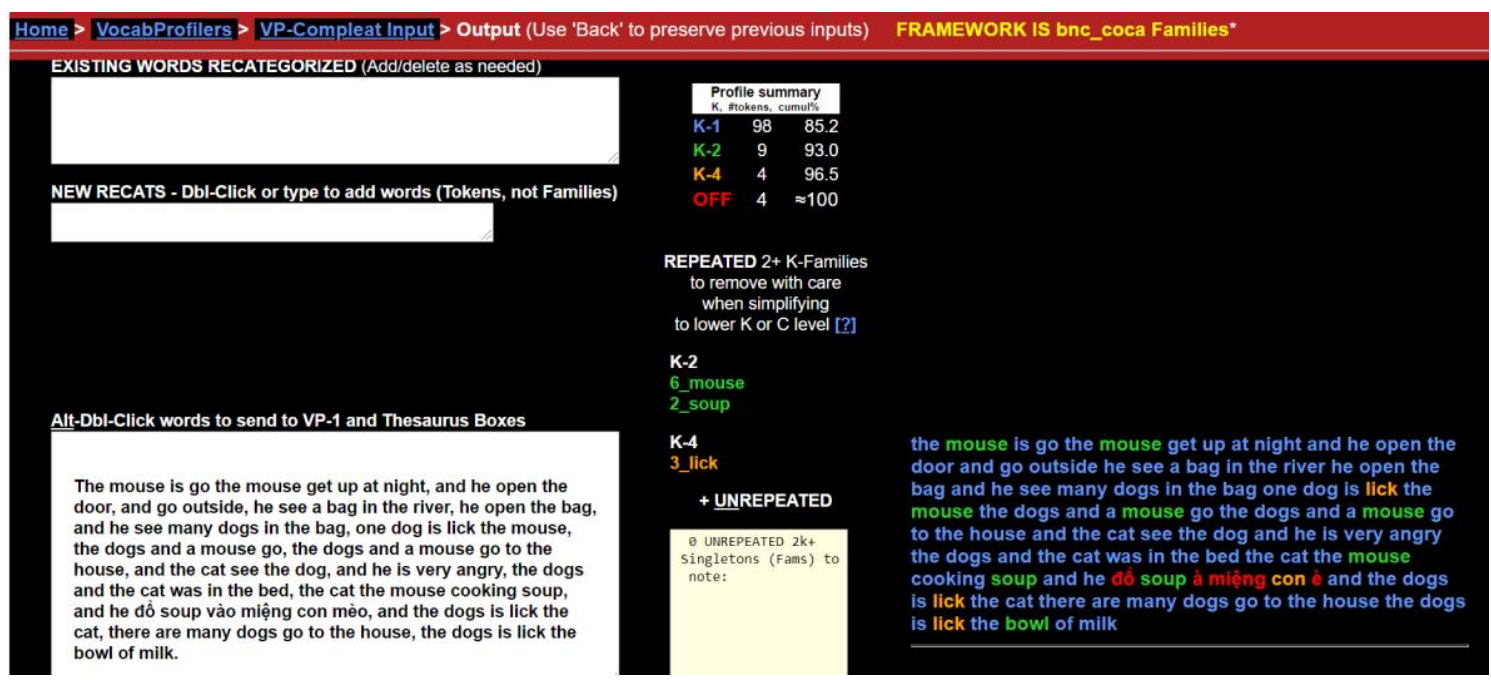

The profile text con is misrecognized as an English token. In Figure 7.2 below, in the Type list section where the English tokens and types are displayed in detail, the profiled text, "con" is misrecognized as an English type.

Figure 7.2 Details of tokens and types in a text

BNC-COCA-1k types: [ fams 30 : types 33 : tokens 98 ]

Affix Profile Extract List

a [3] and [10] angry [1] are [1] at [1] bag [3] bed [1] cat [4] cooking_[1] dog_[2] dogs [7] door [1] get [1] go_[5] he_[6] house_[2] in_[3] is_[5] many_[2] milk_[1] night_[1] of_[1] one_[1] open_[2] outside_[1] river_[1] see_[3] the_[22] there_[1] to_[2] up_[1] very_[1] was_[1]

BNC-COCA-2k types: [ fams 3 : types 3 : tokens 9 ] Affix Profile Extract List

bowl [1] mouse_[6] soup_[2]

BNC-COCA-3k types: [ fams : types : tokens ]

BNC-COCA-4k types: [ fams 2 : types 2 : tokens 4 ]

Affix Profile Extract List

con_[1] lick_[3]

BNC-COCA-5k types: [ fams : types : tokens ]

BNC-COCA-6k types: [ fams : types : tokens ]

OFFLIST : [?: types 4 : tokens 4$]$

Extract List

miệng_[1] à_[1] è_[1] đổ_[1] 
The above extracts show that con is also misrecognized as an English token and type. If we do not count con, altogether, there are 110 English tokens and 37 English types.

\subsubsection{Idea units in students' stories}

Idea units are the basic elements that are used by the speakers to successfully transmit a message. In speaking, they can be identified as spurts of language that are typically separated by a long pause; therefore, pausing is an important factor that serves to identify idea units while transcribing an oral text (Chafe, 1985; Gee, 2018). An idea unit is associated with a clause: "It is spoken with a single coherent intonation contour, ending in what is perceived as a clause-final intonation" and "clauses usually (but not always) express the basic idea units in writing" (Chafe, 1985, p. 106). In story retellings, the participating students rarely had clear rising and falling intonation in their English speech as they were affected by the way they spoke their mother tongue and were just English language beginners. Therefore, the keys to identify idea units were brief pauses, and commas were used to show their pauses; after the retellings were transcribed, clauses were the main tool for counting idea units.

Grammatical mistakes were ignored when counting idea units. For example, a student said: "The dog is lick Tom" instead of saying: "The dog licked Tom". "The dog is lick Tom" was counted as one idea unit.

There were four types of idea units in the students' stories.

- (1) Idea units in Vietnamese such as "Ngày xửa ngày xưa ở làng kia có một cô bé quàng khăn đỏ" (Once upon a time, in a village lived Little Red Riding Hood).

- (2) Idea units in English such as "The wolf walk slowly and slowly".

- (3) Idea units in Vietnamese and English such as "He see one cái bọc is trôi trên water" (He saw a bag floating on the water).

- (4) Idea units in Vietnamese with English characters' names such as "Jerry nấu cháo cho Tom ăn" (Jerry cooked soup for Tom).

\section{Some notes on counting idea units}

To be consistent in counting idea units, the following inclusions and exclusions were taken into consideration. Some examples will be diagrammatically presented to make clear the explanations of what are or are not taken in idea units.

- Any clauses with bilingual words were counted as idea unit in English and Vietnamese because they have Vietnamese. For example, in "Và and then the Riding 
Hood is and her grandma was happy, "Và and" is a bilingual word and this clause was counted as one idea unit in Vietnamese and English.

In a compound sentence, the first clause that had bilingual words was counted as an idea unit in Vietnamese and English and the second clause was an idea unit in only English as displayed in the example:

one idea unit-in E.\&V. one idea unit-in-E.

và con sói and the wolf run away, and never come back.

Translation

Total: two idea units

- In direct speech, the embedded clause was counted as one idea unit and the main clause was counted as one idea unit. Their examples were diagrammatically presented as follows:

Little Red Riding Hood ask: "I am going to go visit grandparent".

Embedded clause $=$ one idea unit

Main clause $=$ one idea unit

Total: two idea units

She said she is going to visit her grandma.

Embedded clause: one idea unit

Main clause: one idea unit

Total: two idea units

- Similarly, in a complex sentence, its subordinate clause or its hidden subordinate clause was counted as one idea unit and its main clause was counted as one idea unit. For example:

So because of scare, he ran to the forest, and never come back.

hidden subordinate clause main clause main clause

Total: three idea units

- The numbers of idea units in a compound sentence depended on the number of main verbs. For example, in "The wolf gave her some flower, and then run away", two idea units were counted.

The wolf gave her some flower, and then run away.

one idea unit one idea unit


In "He just go outside and call and bark', "Go go", "call” and "bark" have similar meanings. Therefore, this compound sentence has two idea units.

He just go outside and call and bark: "Go go".

One idea unit

one idea unit

- In speaking, the subject and the main verb were sometimes missed but listeners could understand the missing information as they listened to the story from the beginning. For example, in "Tom run follow Jerry, and extremely angry", “Tom was" was missed but the sentence was understandable. Therefore, the example sentence was counted as having two idea units.

(Tom was)

$\underbrace{\text { Tom run follow Jerry, and } \sqrt{ } \text { extremely angry. }}_{\text {one idea unit }}$

Likewise, as in "Tom throw it outdoor, and Jerry too, and then he goes to sleep", the speaker meant "Tom throw Jerry outdoor too." "Jerry too" was counted as an idea unit.

(throw Jerry outdoor)

$\underbrace{\text { Tom throw it outdoor }}_{\text {one idea unit }}, \underbrace{\text { and Jerry } \sqrt{ } \text { too, }}_{\text {one idea unit }} \underbrace{\text { and then he goes to sleep }}_{\text {one idea unit }}$

- Children sometimes used wrong names in telling a story, but the listeners still understood what the speaker meant because they were in the story context. For example, in "Tom think $\underline{\text { Tom }}$ think him a bad guy because he throw Tom and the dog outside", the second "Tom" and the third "Tom" meant "Jerry". The example sentence was counted as having two idea units.

- Repeated clauses were counted as one idea unit. For example, in "The girl is funny. The grandparent is funny, and the girl is funny." The two instances of "The girl is funny" were counted as one idea unit. A repeated clause to make the meaning of the previous clause clear was counted as one idea unit, as in 'because it's a bowl it's a Tom bowl" (Tom's bowl), in which two idea units was counted.

- Meaningless sentences and phrases were not counted, as in "He get the dog a bowl of milk, but Tom doesn't want to drink of the dog, so he throw the dog to the window", "but Tom doesn't want to drink of the dog" was not counted, and in "He dream dream 
he take Jerry and the dog, he dream he doesn't love Jerry and the dog", "He dream dream he take Jerry and the dog" was excluded.

- Introduction of names; saying good-bye was excluded in counting idea units.

\section{How to count idea units:}

Due to the complication of identifying idea units, they were counted manually with high caution in three main phases: first, kinds of idea units were identified; second, columns of each type were created and a mark representing an idea unit put in the right-hand columns; third, the marks in each column were counted and these revealed the members of each type of idea unit. Consider the following extract of a story and how its idea units were classified and summed. The extract has 12 idea units in English and three idea units in English and Vietnamese.

(1) one day in the night Tom and Jerry go out (one idea unit in English)

(2) but he look the car (one idea unit in English)

(3) Jerry is look the car (one idea unit in English)

(4) the car is stop (one idea unit in English)

(5) và một người thanh niên đã lấy và quăng a bag (one idea unit in English and Vietnamese)

(6) the bag is có cái gì nhúc nhích cái gì nhúc nhích (one idea unit in English and Vietnamese)

(7) he open the bag (one idea unit in English)

(8) in the bag is the one dog and some dog is go out and ran away (three idea units in English)

(9) the dog is liếm Jerry (one idea unit in English and Vietnamese)

(10) Jerry is angry and go home (two idea units in English)

(11) but the dog is go with Jerry (one idea unit in English)

\begin{tabular}{|l|l|l|l|l|l|}
\hline Students & Stories & $\begin{array}{l}\text { Idea units in } \\
\text { Vietnamese }\end{array}$ & $\begin{array}{l}\text { Idea units in } \\
\text { English }\end{array}$ & $\begin{array}{l}\text { Idea units in } \\
\text { English and } \\
\text { Vietnamese }\end{array}$ & $\begin{array}{l}\text { Idea units in } \\
\text { Vietnamese with } \\
\text { English characters' } \\
\text { names }\end{array}$ \\
\hline SC1 & LRRH & & & & \\
\cline { 2 - 6 } & J\&J & & HH HHII & III & \\
\hline
\end{tabular}

\subsubsection{Findings}

This quantitative research was conducted to find the answer whether the storytelling innovation improves primary school students' oral communicative competence and, if so, to what extent. The independent variables were the normal lessons for the comparison group and 
the storytelling lessons for the intervention group and dependent variables were the outcomes of the students' pre-test and post-test story retellings. Dependent variables of tokens, English types and ideas units in the students' retold stories were analysed to examine their central tendencies and degrees of deviation to measure the language development within the participating groups and between them. Because the data were collected from mixed-ability classes, preliminary analyses of the data were performed to examine their normality, homogeneity of variance and outliers in order to choose precise statistical tests. The results of Shapiro-Wilks tests demonstrated violations of normal distribution and box-plots showed some outliers, while Levene tests showed the data had equal variances. After receiving mathematical consultancy from the School of Mathematics and Statistics, Victoria University of Wellington (23 October 2018), medians (not means) were determined to be better measures of the centres of the data and Wilcoxon signed rank test and Mann-Whitney U test were used to determine whether the differences of story retelling measurements within and between the comparison group and the intervention group were statistically significant. In addition, their size effects were also calculated on the formulas recommended by Clark Carter and Cohen (cited in Allen, Bennett, and Heritage (2014, pp. 257-259)). All the tests were computed with the Statistical Package for the Social Science (IBM SPSS statistics 25), a statistical software programme.

\subsubsection{Tokens}

Tokens were examined to determine whether the choice of texts affected the students' language production and whether or not the length of their stories improved.

Figure 7.3 Medians of total tokens in each kind of stories

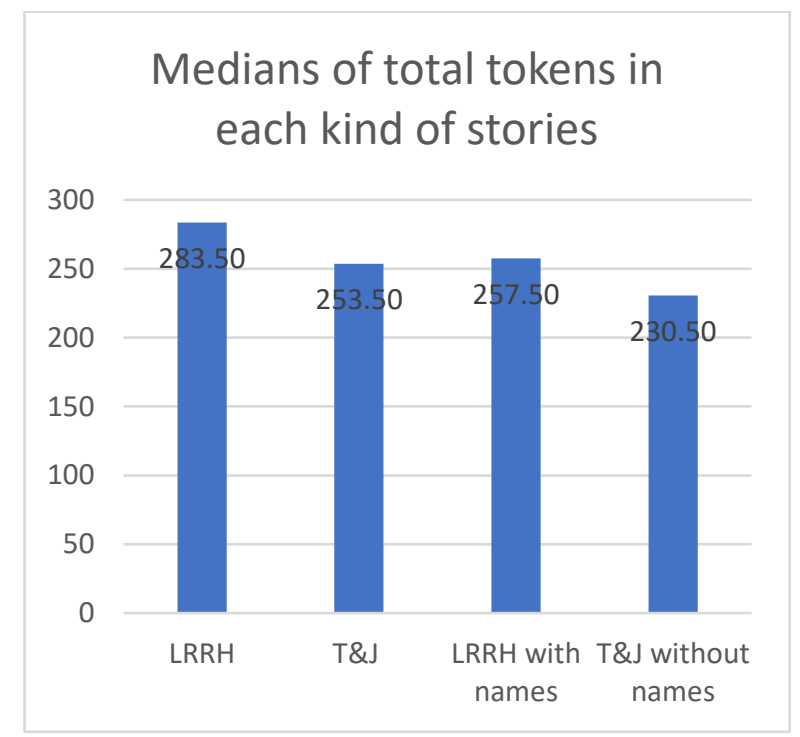


As seen from Figure 7.3, the median of total tokens in LRRH retellings was higher than T\&J retellings. The middle number for LRRH tokens is 183.50 or 257.50 excluding names and for T\&J is 253.50 or 230.50 excluding names. The median difference between T\&J and LRRH with names is about 30 and without names is about 27 . The longer characters names of LRRH than in T\&J possibly made LRRH longer; however, although characters names were taken out, the mean of LRRH is still higher than T\&J.

Figure 7.4 Medians of total tokens in each kind of stories in each group

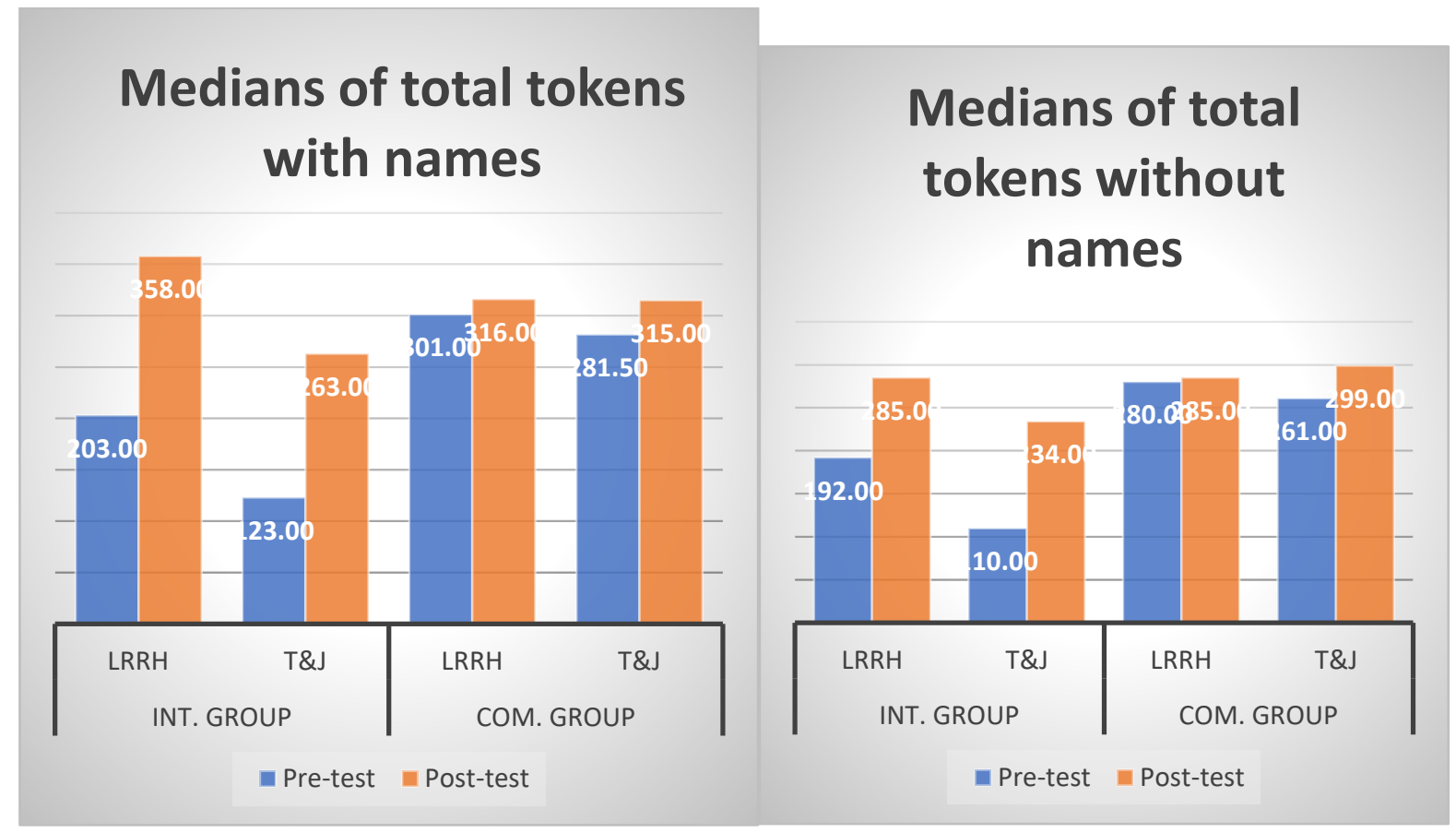

Figure 7.4 shows that both groups produced longer stories in the post-test than they did in the pre-test in both LRRH and T\&J. The comparison group produced longer stories than the intervention group in both pre-and post-test. The comparison group and the intervention group produced longer LRRH than T\&J stories in both pre- and post-test. When the characters names are taken out, the medians of stories were a little lower than the medians with names, but the tendencies of language production did not appear to be changed. In sum, the finding from the examination of the central tendencies of total tokens of two stories and of tokens in each story in the pre-test and in the post-test possibly lead to a conclusion that the choice of texts (two different cartoons, one with and one without speaking characters) might have little effect on the students' language production.

\subsubsection{Central tendency and deviation degree of tokens}

Figure 7.5 reveals that both participating groups produced more tokens in the post-test than in the pre-test. From the pre-test to post-test, the median scores increased relatively modestly in 
the comparison group from 293 to 316 but more dramatically, from 187.5 to 287.50 , in the intervention group.

Figure 7.5 Medians of tokens in each story in pre-test and post-test

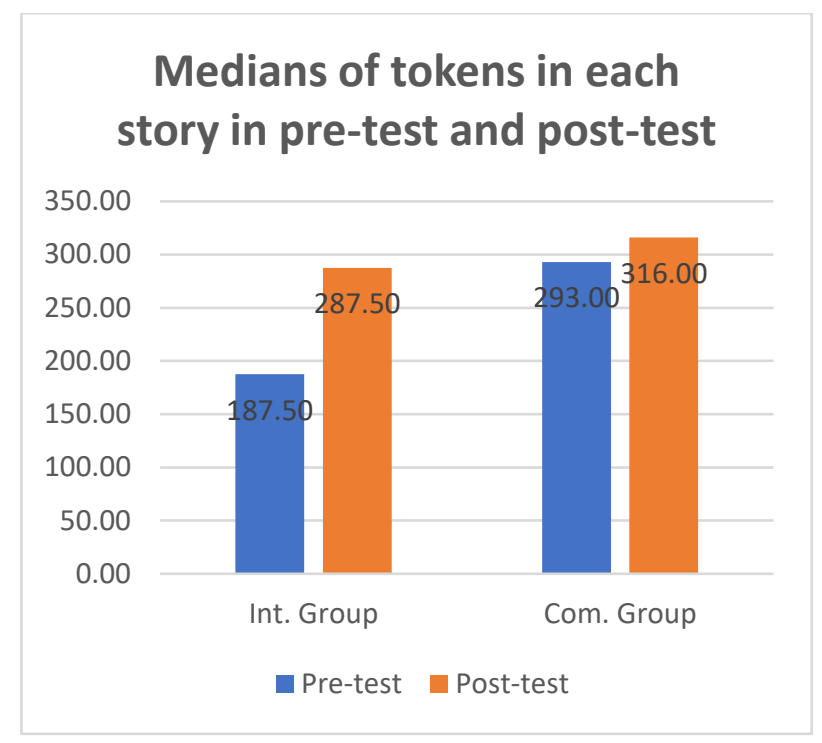

The central tendencies showed that both groups produced longer stories in the post-test than in the pre-test. The comparison group produced longer stories as the central tendencies of the comparison group's tokens were higher than those of the intervention group in both the pretest and post-test. However, it is misleading to conclude that the comparison group was more proficient in English than the intervention group. It is important to recall that up to this point the discussion has included both Vietnamese and English tokens. The following parts will present the analysis of English tokens, types and idea units to examine whether the students improved their oral English production.

\subsubsection{English tokens}

As can be seen in Figure 7.6, the intervention group produced a few more English tokens than the comparison group in the pre-test. The results of a Mann-Whitney U test showed that the intervention group's production of English tokens was not statistically significantly higher than the comparison group (Mean Rank $=24.64$ for the comparison group and Mean Rank $=$ 30.80 for the intervention group, $U=291, \mathrm{z}=1.420, \mathrm{p}=0.155)$.

The central tendencies in Figure 7.6 shows that both groups produced more English tokens in the post-test than in the pre-test. From the pre-test to post-test the median scores increased from 44 to 53 in the comparison group and from 51 to 154 in the intervention group. 
Figure 7.6 Medians of English tokens

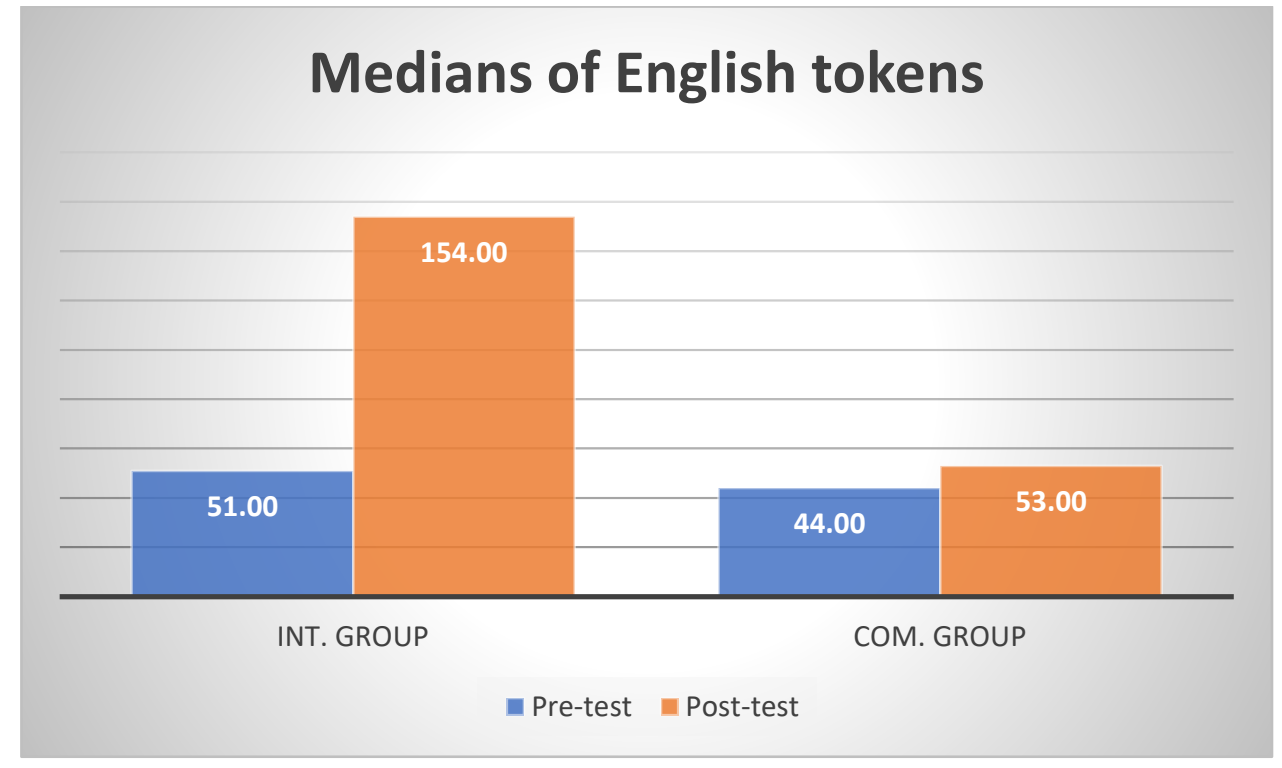

Unlike the results of token analysis, a Wilcoxon signed rank test for the comparison group indicated that its improvement of English tokens was statistically significant in the post-test, $\mathrm{T}=229.50, \mathrm{z}=2.272, \mathrm{p}=0.023$, with 18 participants ranked as more improved, six participants ranked as negatively improved and one participant ranked as unchanged; this effect can be considered rather large, $r=0.45$. Similarly, a Wilcoxon signed rank test for the intervention group indicated that the growth of their English tokens was statistically significant, $\mathrm{T}=$ 445.00, $\mathrm{z}=4.371, \mathrm{p}<0.000$, and the size effect can be considered large, $\mathrm{r}=0.8,28$ participants ranked as more improved and two participants produced less in the post-test. The improvement of the comparison group was much higher than the comparison group as a Mann-Whitney U test indicated that the difference of English tokens between them (Mean Rank $=20.56$ for the comparison group and Mean Rank $=34.20$ for the intervention group) was statistically significant, $U=189, z=3.144, p=0.002$, which can be described as a medium size effect, $\mathrm{r}=0.42$.

The intervention group created more English tokens than the comparison group in the posttest as the deviation of English tokens was significantly different.

\subsubsection{English types}

The intervention group produced more English types than the group in the pre-test. The results of a Mann-Whitney U test showed that the intervention group's production of English tokens was statistically significantly higher than the group (Mean Rank $=23.22$ for the group and Mean Rank $=31.98$ for the intervention group, $\mathrm{U}=255.5, \mathrm{z}=2.021, \mathrm{p}=0.043$ ). 
As can be seen from the data in Figure 7.7, below, both groups produced more English types in the post-test than in the pre-test. From the pre-test to post-test the median scores increased from 11 to 21 in the comparison group and from 20 to 43 in the intervention group.

Figure 7.7 Medians of English types

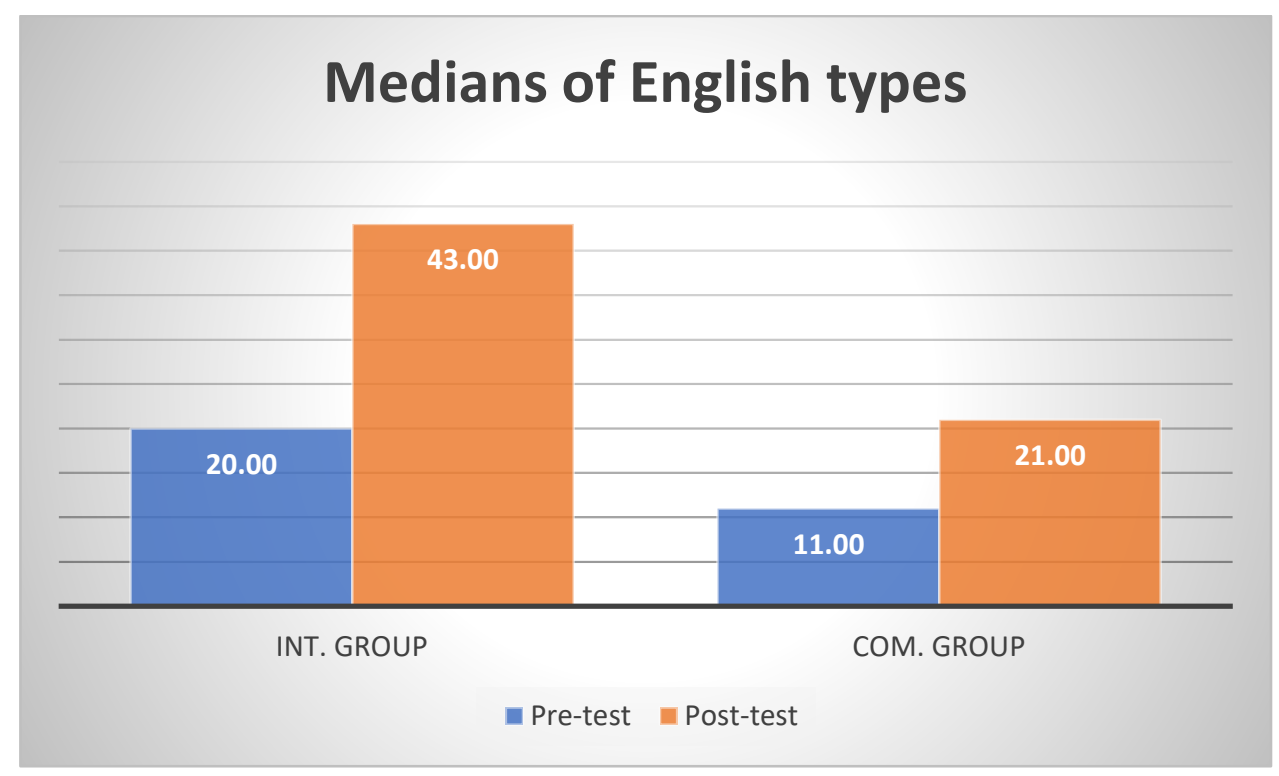

Similar to the findings of the tests for English tokens, a Wilcoxon signed rank test for the comparison group and the intervention group's English types indicated that their improvements were both statistically significant. For the comparison group, the results were $\mathrm{T}=254, \mathrm{z}=2.977, \mathrm{p}=0.003$, with 18 participants ranked as more improved, six participants ranked as negatively improved and one participant ranked as unchanged; this effect can be considered rather large, $r=0.45$. For the intervention group, the results were $\mathrm{T}=381, \mathrm{z}=$ 4.054, $\mathrm{p}<0.000$, with 28 participants ranked as more improved and two participants produced less in the post-test; it is considered a large effect, $r=0.8$. The difference of English types between the comparison group (Mean Rank =23.18) and the intervention group (Mean Rank $=32.02$ ) was statistically significant as a Mann-Whitney $U$ test was computed, $U=254.50, \mathrm{z}$ $=32.039, \mathrm{p}=0.041$. This effect can be described as medium, $\mathrm{r}=0.42$.

Like the result of the analysis of English tokens, the English types in the intervention group's retellings were much more than in the comparison group's as the deviation was significantly different in the post-test. A proper name, no matter how many times it is used, is counted as one type. Therefore, the students' growth in language use was not strongly affected by naming the characters. Obviously, the number of tokens and types in the students' stories improved, but how did they use them to create meaningful units in their stories? 


\subsubsection{Idea units}

It is apparent in Figure 7.8, below, that the comparison group did not increase their idea units while the intervention group increased their idea units in the post-test compared to those in the pre-test; specifically, they created longer idea units in English from 3 to 10.5 and idea units in English and Vietnamese from 3.5 to 4 and shorter idea units in only Vietnamese from 4.5 to 3, and they did not produce more idea units in Vietnamese with English characters' names.

Based on these central tendencies, nonparametric tests were run for idea units in English and idea units in English and Vietnamese only.

Figure 7.8 Medians of idea units

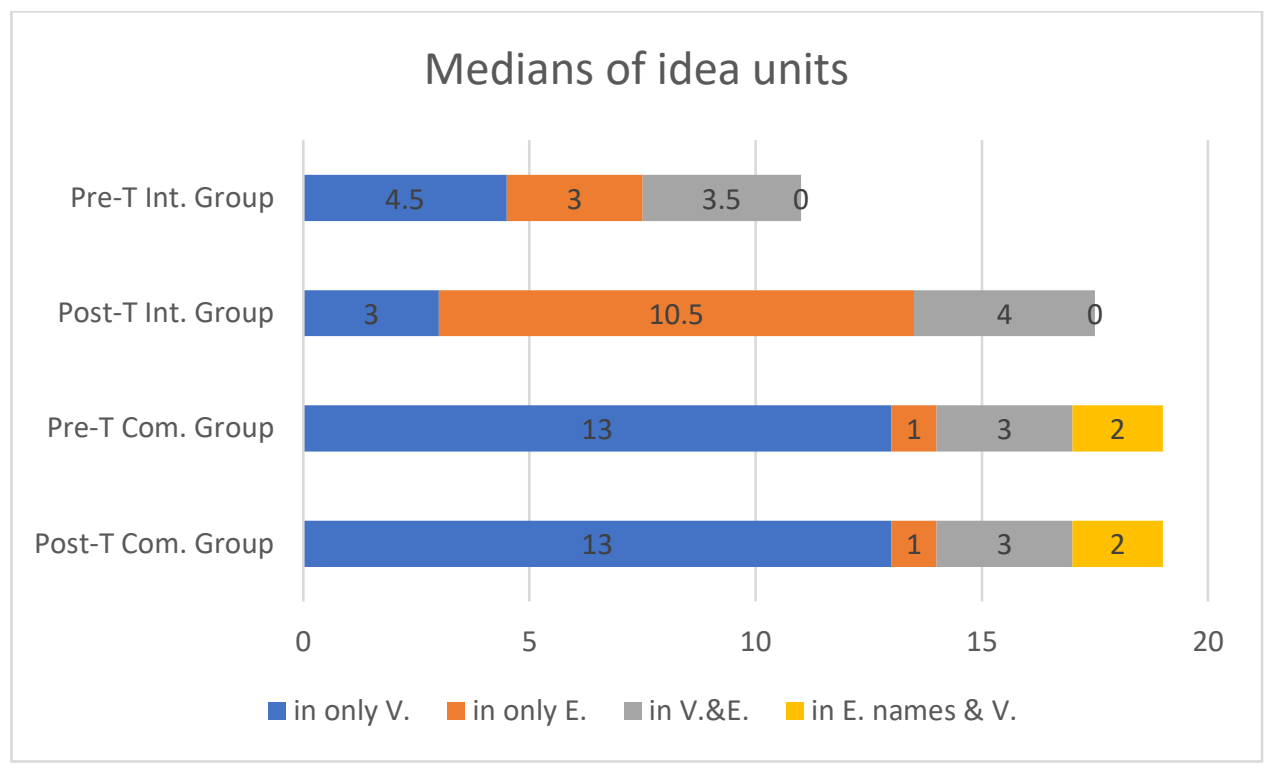

In the pre-test, the intervention group produced more for idea units in English and idea units in English and Vietnamese than the comparison group. The results of a Mann-Whitney U test showed that the differences were statistically significant (for idea units in English: Mean Rank $=24.28$ for the comparison group and Mean Rank $=30.10$ for the intervention group, $U$ $=2.562, \mathrm{z}=2.021, \mathrm{p}=0.043$; for idea units in English and Vietnamese: Mean Rank =27.64 for the comparison group and Mean Rank $=28.30$ for the intervention group, $\mathrm{U}=366, \mathrm{z}=$ $0.154, \mathrm{p}=0.877)$.

In the post-test, the results of Wilcoxon signed-rank tests for idea units in English and idea units in English and Vietnamese for both groups were similar. For the comparison group, the improvements of these two kinds of idea units were not statistically significant. The Wilcoxon test results for idea units in English were $\mathrm{T}=97, \mathrm{z}=0.974, \mathrm{p}=0.33$, with 10 participants ranked as more improved, seven participants ranked as negatively improved and 
eight participants ranked as unchanged. Those for idea units in English and Vietnamese were $\mathrm{T}=116, \mathrm{z}=1.333, \mathrm{p}=0.183,10$ participants ranked as more improved, eight participants ranked as negatively improved and seven participants ranked as unchanged.

Unlike results of the non-parametric t-test for the comparison group, the improvement of the intervention group's idea units in English and idea units in English and Vietnamese were statistically significant. For idea units-in-English, the Wilcoxon test results were $\mathrm{T}=323, \mathrm{z}$ $=3.749, \mathrm{p}=0.000$, with 22 participants ranked as more improved, four participants who produced less and four ranked as unchanged in the post-test; the effect can be considered large, $r=0.68$. For idea units in English and Vietnamese, the results were $\mathrm{T}=189.50, \mathrm{z}=$ 2.047, $\mathrm{p}=0.041$, with 16 participants ranked as more improved, six participants who produced less and eight ranked as unchanged in the post-test. The effect can be considered large, $\mathrm{r}=$ 0.68 .

Again, Mann-Whitney U tests indicated that the differences of idea units in English and idea units in English and Vietnamese between the comparison group (Mean Rank =21.30 and 25.98 respectively) and the intervention group (Mean Rank $=33.58$ and 29.68 respectively) were statistically significant; (for idea units in English $U=207, z=2.848, p=0.004, r=$ 0.38; for idea units in English and Vietnamese $U=189, z=3.144, p=0.002, r=0.42$. The size effects were medium.

In sum, the major findings show that at the beginning of the study, there was no significant difference in the English-speaking competence in terms of tokens, idea units in English and idea units in English and Vietnamese between the comparison and the intervention groups. At the end of the study, both groups improved their speaking competence, but the changes were quite different. The comparison group improved their oral English production but as not much as the intervention group. The students in the storytelling innovation class improved their oral English communication in dependent variables of English tokens, English types, idea units in English and idea units in English and Vietnamese; and their improvements were statistically significant not only inside each group but also compared to the comparison group (all $\mathrm{p}<0.05$ in Wilcoxon signed-rank tests and Mann-Whitney U tests).

\subsubsection{End-of-term tests}

This section will present the results of the end-of-term tests that were officially carried out at the end of each term. The analysis of the tests aims not to evaluate the students' language improvement. It was to respond to the intervention group teacher's worry that the storytelling 
intervention was mainly to improve the students' speaking while the normal tests focused on the four skills and her students might suffer as a result of the intervention.

Grade 5 students in Vietnam have two end-of-term tests per year. The test scores play a part in determining of the students' primary schooling achievement. One was done at the end of the first term, one week before they started the second term and one was done at the end of the second term. The storytelling intervention was conducted in term two; therefore, the endof-term-one test was used as a form of pre-test and the end-of-term-two test was used as a form of post-test in this study.

The structure and the content of the tests were designed by the participating schools' teachers of English on the basis of DOET's test guides and test matrix. Although the tests (see Appendix 9) appeared child-friendly with lovely pictures and clear instructions with examples, it is necessary to examine their validity and reliability. In terms of validity, the tests were not well-designed enough to measure what they were supposed to measure. The end-ofterm tests aimed to measure the four language skills and each macro-skill having just 10 questions. In speaking, each student answered 10 questions that were previously learned in the textbook; the focus was on vocabulary and the structures learned in each lesson in the textbook. In the interviews with the participant teachers, they reported that the students wrote the answers of the questions and learned the answers by heart. The listening part had six questions in gap-fills and four multiple-choice questions, which were also on vocabulary and the structures learned in each lesson in the textbook. Half of the reading part was on vocabulary and grammar, and half was on reading comprehension. The first part of writing was about vocabulary and the second was about words or grammar. In term of reliability, the tests could not produce stable and consistent results. The first possible reason for this inconsistence is that the same pictures and texts in their current textbook were used in the tests, which seems to test memory rather than language use. This was similar to what was found in other research mentioned in Section 2.5.2. The second cause for the tests' inconsistency was that the speaking tests highly involved the tester's ideas and judgments as they were conducted by the class teacher as the examiner in his/her own classroom. In the interview, the participant teachers said that there was no schedule for the speaking tests; therefore, the teachers had to use their teaching time for the speaking test, and they might not ask all the 10 questions as designed. In addition, the end-of-term tests were focused on the textbook content. For example, the listening text had two parts, taken from the same texts and the same audio clips of Activities 1 and 2 in the textbook; therefore, the comparison group, in 
their normal class, listened to the tape more often than the intervention group. Last, the tests were not piloted to check their reliability and validity.

Together with the question of accountability of the tests, the tests might negatively affect the intervention group students' performance in tests. As mentioned above, most of the test items focused on the language target items. Therefore, the comparison group students might be more advantaged because the form of the test matched with the normal learning that focused on language features as found in Chapter 6. In contrast, the intervention group students might be disadvantaged because the process of their learning, which involved meaning-focus activities like listening to a story, constructing a story and creating a story, was not reflected in normal tests.

In short, while the validity and reliability of the tests were not completely ensured, it is still worth considering whether the intervention affected the results of the student's normal tests.

\section{Central tendency of test cores}

Looking at Figure 7.9, it is apparent that both the comparison group and the intervention group got higher scores in the post-test than they did in the pre-test. In terms of means scores $^{4}$, the comparison group increased slightly about 0.2 from 7.12 in the pre-test to 7.30 in the post-test. The students in the intervention group improved their test scores a little more than the comparison group over 0.3 from 7.98 in the pre-test to 8.32 in the post-test. In terms of median, the test scores increased 0.25 for both of the groups. Basically, the intervention had no discernible negative effect, and so allayed teacher concerns.

Figure 7.9 Means and medians of test scores

\begin{tabular}{lrccc} 
Groups & \multicolumn{2}{c}{ Means } & \multicolumn{2}{c}{ Medians } \\
\cline { 2 - 5 } & Pre-test & Post-test & Pre-test & Post-test \\
\cline { 2 - 5 } Intervention & 7.98 & 8.32 & 8.5 & 8.75 \\
Comparison & 7.12 & 7.30 & 7.5 & 7.75
\end{tabular}

\subsubsection{Summary}

This quantitative analysis compared the students' pre- and post-story retellings to examine their oral English language development. The analysis examined tokens (the length of the story and the number of English words), English types and idea units. Three important findings were found. The first finding was that the choice of the cartoons had little effect on

\footnotetext{
${ }^{4}$ The Vietnamese grading system is based on a 1-10-point scale.
} 
the students' language production, as the length of the T\&J stories in the pre-test and post-test was a little shorter than the LRRH ones. The second finding reveals the English language production of the comparison group and the intervention group both improved. Both groups produced more English tokens, English types, idea units in English, and idea units in English and Vietnamese in the post-test than in the pre-test. The third and most important finding was that the degrees of their improvements were very different: after the intervention, the English language production of the comparison group slightly increased whereas that of the intervention group nearly doubled in terms of English tokens. In other words, the students in the intervention group created much more English language in their stories than those in the comparison group. The non-parametric t-test results made clear the degrees of their improvement. The group showed statistically significant improvement in English types $(\mathrm{p}=$ 0.003 ) and English tokens ( $\mathrm{p}=0.023)$. The improvement of the intervention group's language production was statistically significant as all p-values were less than the significance level. Comparing the two groups, there were statistical differences between comparison group and intervention group in English tokens $(p=0.002)$, English types $(p=0.041)$, idea units-inEnglish $(\mathrm{p}=0.004)$ and ideas units in English and Vietnamese $(\mathrm{p}=0.002)$. In short, the central tendencies and the results of t-tests showed that the students in the storytelling innovation improved their English language production in speaking, their improvement was statistically significant and the size effects of the difference were from medium to large, which evidentially serves to answer the question as to whether and to what extent the storytelling innovation improved primary school students' oral communicative competence.

\subsection{Student engagement}

\subsubsection{Cognitive engagement}

In the intervention lessons, the indicators of cognitive engagement included high-order thinking skills. The main tasks and indicators of cognitive engagement are identified and summarized in table 7.2 , below. 
Table 7.2 Indicators of cognitive engagement in the intervention class

Main tasks

1. Participating in games with meaning construction

2. Listening to a story and telling the main ideas

3. Listening to the story and reconstructing the story with the teacher

(orally)

4. Reconstructing the story (in writing)

5. Comparing reconstructed stories with the original story.

6. Creating a new ending or a new story

7. Sharing their created stories

\section{Indicators of cognitive engagement}

Recalling words and constructing meaning of new words

Understanding the story and summarizing

Activating prior knowledge and constructing

Constructing

Comparing

Creating

Comparing and evaluating

The indicators of cognitive engagement were manifested via the efforts the student invested in the task and different structures of the tasks resulted in different mental processes. These will be presented in the following parts, particularly focusing on the three main tasks of constructing, comparing and creating.

\subsubsection{Constructing}

The tasks of reconstructing the story forced the students to think and to produce the language at the same time. In this task, the students needed to construct the story utterances by using what they knew as well as language they had not mastered. During the production of the language, the learners could notice the gap between what they wanted to say and what they could say in the target language; in other words, they continuously identified their linguistic errors and lack of knowledge. This process can stimulate the consolidation of prior knowledge and the cognitive generation of new linguistic knowledge. Extract 4 shows how a group of the students invested their effort in reconstructing the story. 


\section{Extract 4 (Unit 15, Lesson 1)}

\section{S1: The narrator, S2: Mai, S3: Tony}

01 S1: Hello, I am the narrator.

02 S2: Hello, I am Mai.

03 S3: Hello I am Tony.

04 Ss: Let's start our story.

05 S1: Mai and Tony where ....where ... (Ss: were, were) ... were. in the school gym. Mai ask.

06 S2: What would ... would you like to be to be in the in the ... future?

07 S1: Tony answer.

08 S3: I ... I like to be to be to be ... (Ss: nhìn hình này nè [look at this picture]) pilot. I like to be the pilot.

09 S1: Tony ... (Ss: ask) (Ss: Mai ask, Mai ask, Mai ask) Mai ask.

10 S2: Is that so much ... Is that work is so much in the gym?

11 S1: (Ss: Tony) Tony answer.

12 S3: Yes. Pilots have to be trong ....strong.

13 S1: Mai answer ủa [oops] ask, Mai ask.

14 S2: What that no so would ... so would you like to fly ... to fly a plane.

15 S1: Tony answer.

16 S3: Yes, only one problem. I am scared of of... (Ss: height, height) height.

The orgiginal text in Unit 15, Lesson 1

The image has been removed by the author of this thesis for copyright reasons.

Turns 05, 06, 08, 09, 10 and 16 in Extract 4 showed that the interlocutors appeared to construct their sentences by repeating words and pausing a lot and receiving peer assistance. The cognitive process could be seen through repeating (turns 05, 06 and 18), pauses, peercorrection (turn 05), self-correction (turns 12 and 13), and giving and receiving peer assistance (turns 08, 09 and 16), which reflects that the learners' language production is 
confirmed and modified. The language episode the group made was highly cooperative as the students engaged in the joint construction of the story. Such a cooperative dialogue "allows performance to outstrip competence. It is where language use and language learning can occur. It is language use mediating language learning" (Swain, 2000, p. 97).

\subsubsection{Comparing}

In the task of comparing the students' written stories with the original story, cognitive comparison (Ellis, 1995) occurred when they were "comparing what they have noticed in the input with what they currently produce in their output" (p. 90). The students noticed their errors in production, leading them to discover linguistic deficits and consequently to consciously attending to the way the new language features are used, and this made them want to work on these features of language. This contributes to the internalization of the target language. Extract 5 and Sample 1 show this cognitive process through the students' writing and correcting their written utterance of the story. In Extract 5, the students wrote their first draft in purple ink (the compulsory writing colour in this primary school) and they corrected their errors with their pencils. During the task, the students' discussion (Extract 5) reflected their cognition via error identification (turns 01, 05 and 07), peer correction (turns 01, 03, 05, 07 and 09) and self-correction (turn 08), and reviewing what they have learned (turn 09). Although the students could not recognize all the errors in their written story, their cognitive process kept happening.

Sample 1 (Unit 18, Lesson 2, Group 3)

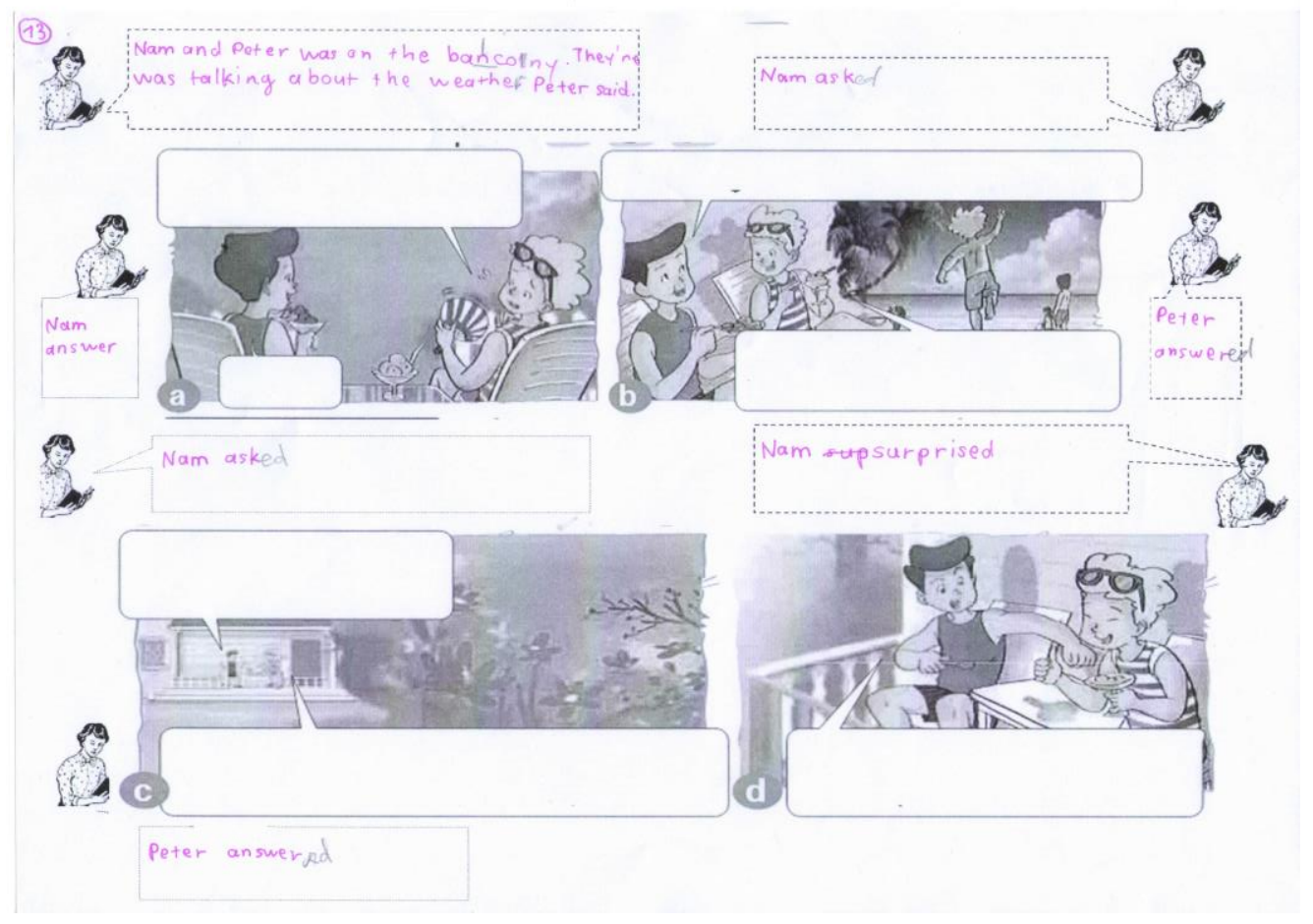



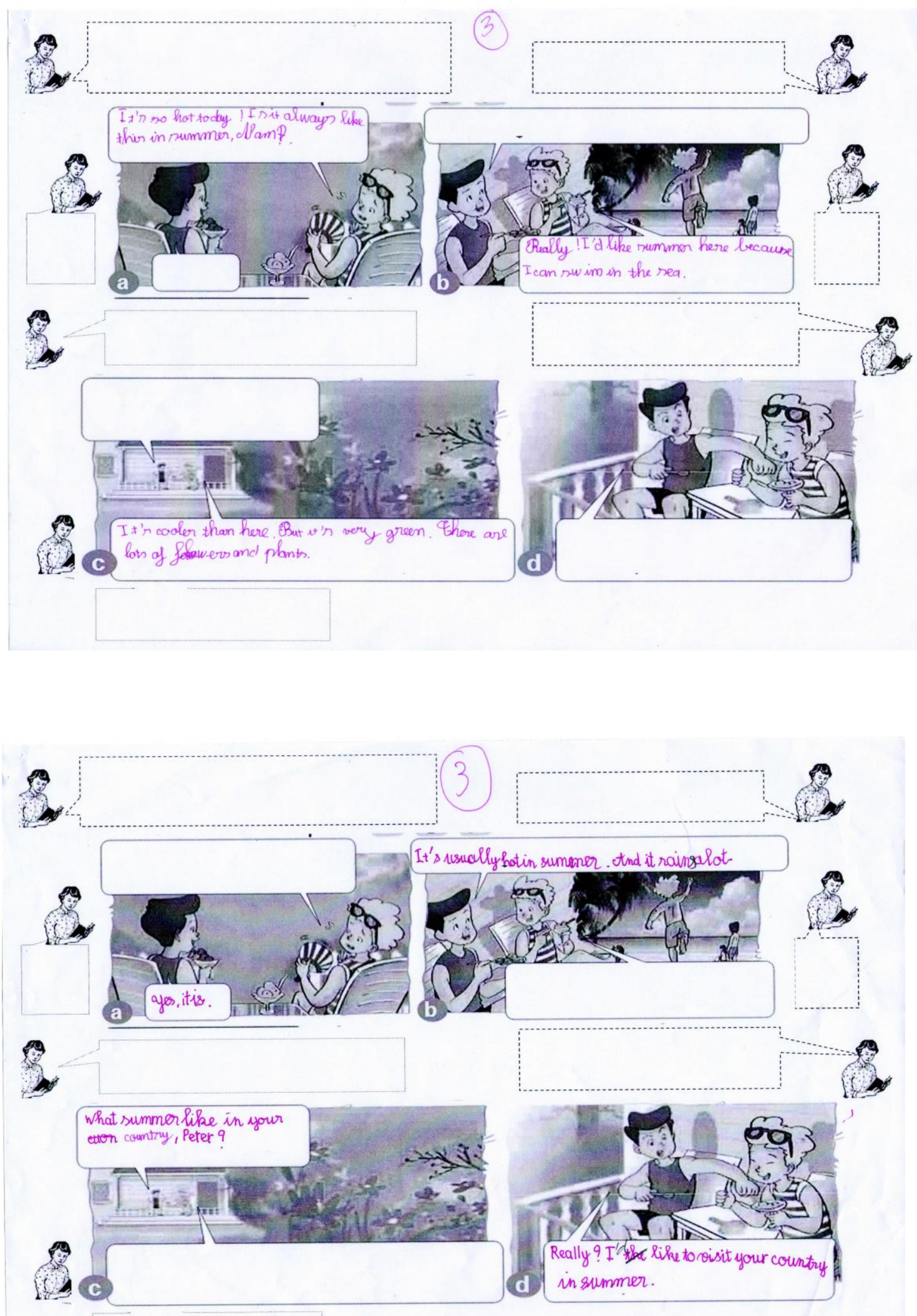


\section{Extract 5}

01 S3 Chữ "bancolny" ông viết sai rồi. This word "bancolny" is not correct. This must be chữ này là chữ "l" mà. "l" here.

02 S1 Chử gì?

What word?

03 S3 Chữ này, "balconly". Phải viết là "b-a-l-c-o-n-y" mới đúng

This word "bancolny. The correct word is "b-a-l-co-n-y”.

04 S1 Ù’, Ông sửa lại đi.

OK, you correct it.

05 S3 Còn chữ "weathe", thiếu "r" rồi.

06 S1 Ù.

This word "weathe" lacks "r".

07 S3 Mấy chữ này không có ed. Tôi sửa lại nhe.

OK.

These words lack "ed". I correct them.

08 S3 Chữ "rains" này có s "It rains". Sửa lại đi.

09 S2 Chổ này "I the like" không phải viết như vầy mà (chỉ vô sách). Hôm trước cô nói "I'd like" là "I would like".

This word "rains" has a "s" "it rains". Correct it.

"I the like" is wrong. It must be "I'd like" (point to the book). In previous lessons, our teacher said that "I'd like" was "I would like".

The image has been removed by the author of this thesis for copyright reasons.

Not only did the students compare the sentences in their written story with the original ones to identify and correct their errors, but they also identified equivalent utterances. One of the students in Group 15 discovered that one of the utterances she wrote: "OK, I will visit your country next summer" (Sample 2) was corrected to look exactly like the original sentence "Really? I'd like to visit your country in summer". She asked the teacher whether her new utterance was accepted. The teacher advised that her created utterance was quite acceptable in the context. 
Sample 2 (Unit 18, Lesson 2)

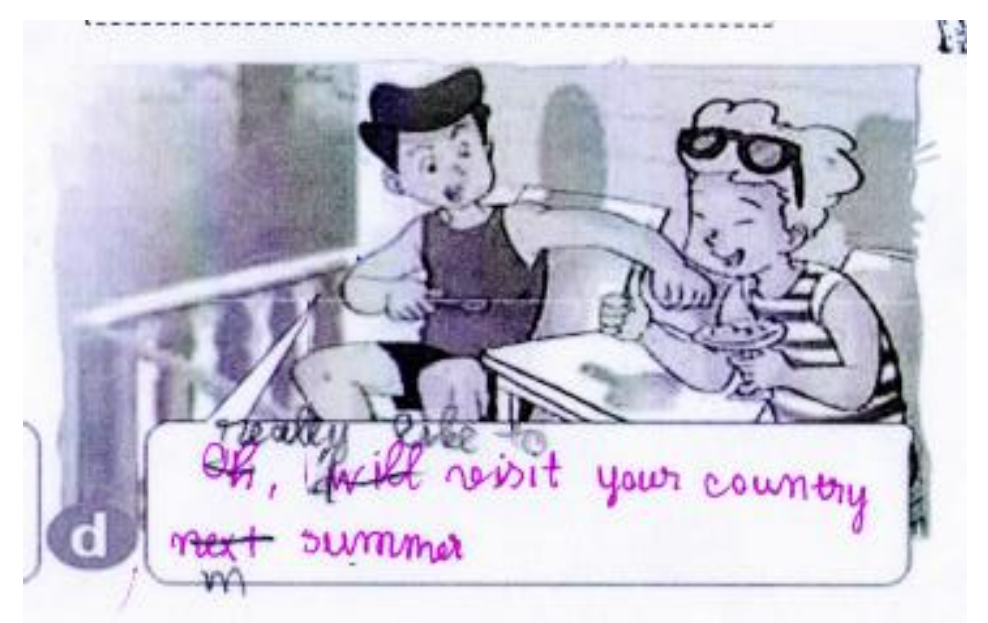

The common errors and equivalent utterances were noticed on the board by the teacher so that the students could have another chance of comparing what they had known and what they needed to know.

Obviously, via comparing their constructed story with the original one, the students went through a mental process of noticing their errors or equivalent utterances in production, which helped them acquire the language naturally.

\subsubsection{Creating}

Extract 6 shows an example of a discussion and practice to create a group story. Most of the students created a more target-like version by using the same structure as the original story, changing the settings (the time, place and characters' names) and some key content words and/or adding an ending to the story. To prepare the group story, they discussed and practiced in Vietnamese and English. First, they spoke in Vietnamese to discuss the content of the story before they created the story (turn 01). Next, they chose their roles in the story, also in Vietnamese. Then they started practicing their story. While they were practicing, they added more information about the characters to make their story more interesting (turns 18, 22 and 26). They said in Vietnamese to help their friends understand what they needed to add (turns 18 and 22. They praised their friends for adding information in the story (turn 27). They agreed on what to say in their story in Vietnamese. They practiced their story again before sharing it with another group. 
Extract 6 (Unit 14, Lesson 2)

S1: the narrator, S2: Quan, S3: Linda

01 Ss: Mình nói về Tam cám đi, Tấm Cám có hai chị em giống The Golden Starfruit.

(I suggest that we talk about Tam and Cam, Tam and Cam has two sisters, like two bothers in The Golden Starfruit)

02 Ss: Ù bài đó đi. (OK, I agree)

03 S1: Tôi làm narrator. (I will be the narrator)

04 S2: Tôi làm Quân cho (I will be Quan)

05 S3: Tôi làm Linda (I will be Linda)

06 S1: Ù, vậy Let's start.

07 S1: Hello, I am the narrator.

08 S2: Hello, I am Quan.

09 S3: Hello I am Linda.

10 Ss: Let's start our story.

11 S1: Linda and Quan were in the park. Quan was coming to the table. He ask Linda.

12 S2: What are you doing Linda?

13 S1: Linda answer.

14 S3: I am reading the story of Tam and Cam

15 S1: Then ... Quan sat down... and ask.

16 S2: Oh, I read it last week. What do you think of Tam and Cam?

17 S1: Linda answer.

18 S3: I think Cam is very greedy (SS: lazy, Cám lười lắm, thêm lazy đi Cam is lazy, add lazy to this utterance), I think Cam is ... lazy and greedy.

19 S1: Quan ask

20 S2: Yes. You are right. How about Tam?

21 S3: Linda answer.

22 S3: She's very kind (SS: and hard-working Tam siêng năng nữa Tam is also hardworking) and hard-working.

23 S1: Linda ask.

24 S3: Do you like the story?

25 S1: Quan answer.

26 S2: Yes, I do. We can learn a lesson from it. Don't be so greedy and you should be generous.

27 Ss: Ông hay quá (you are excellent).

28 Ss: Vậy mình nói câu truyện như vậy nhe (So, we will present our story like this)

29 Ss: 'U', câu chuyện vậy đi. Hay rồi. (OK. This story is rather good)

30 Ss: Tập lại rồi mình báo cô xong rồi nhe (Practise again and tell the teacher we've finished).

The original text

The image has been removed by the author of this thesis

for copyright reasons. 
Extract 7 shows the last version of a group story. The groups shared their last version with another group. In this activity, another cognitive process happened again as they compared their created stories together and evaluated the similarities and differences. When they listened to their friends' group, the students discovered what the other group had changed.

Extract 7 (Unit 15, Lesson 1)

S1: the narrator, S2: Mai, S3: Tony

01 S1: Tony were in the school gym. Mai ask.

02 S2: What would you like to be in the future?

03 S1: Tony ans ... answered.

04 S3: I would like to be a sailor.

05 S1: Mai ask.

05 S2: Is that why you like to work out so much in the gym?

07 S1: Tony answer.

08 S3: Yes, sailors have to be strong.

09 S1: Mai ask.

10 S2: So you like to work in in on a ship?

11 S1: Tony... answer.

12 S3: Yes, there is one problem.

13 S1: Mai surprise.

14 Ss: What is that?

15 S1: Tony answer.

16 S3: I am s...scared of water.

17 S1: Mai say.

18 S2: So so, you should be a pilot.

As can be seen in Extracts 6 and 7, a degree of personalization can be found in the students' stories; this significantly reflects a developmental cognitive process. This is an active process of thinking and producing through activating student thinking ability to apply prior knowledge to new situations and assimilating information in different ways. This cognitive process is in alignment with Vygotsky's conception of the developmental and creative process and internalization, which "is not just copying but rather a transformation or reorganization of incoming information and mental structures based on the individual's characteristics and existing knowledge" (Moran \& John-Steiner, 2003, p. 4). The students mastered the lesson's target structural patterns by using them in reconstructing the story and creating their own story. They still made some mistakes such as forgetting to add 'ed' to the verbs, but their fluency and accuracy were much improved thanks to the two main cognitive processes.

The students' cognitive engagement could be found from their explanation of how they created their group's story. Extract 8 is from an interview with Group 4. In the extract, "my group" or "our group" means the group the students were in in the storytelling lessons. 


\section{Extract 8 (translated into English)}

S1 For example, in this lesson What do you do in your free time? When we were telling the story and said "What do you do in your free time?", we said we did another thing, not watching cartoon any more, we replace your mother by your father, and go fishing by go shopping.

S2 In that lesson our group made the story longer by adding another question. We added your brother.

S3 My group not only replaced words but also changed the characters' names.

I Did you remember how you changed the characters' names?

S3 Lan for Akiko, Quan for Tony. I like changing names, but we made a lot of mistakes with names.

I What do you mean with made a lot of mistakes with names?

S3 We sometimes used the names in the original story.

The students could feel their cognitive work. Storytelling activities assisted them to learn new language items, put them in use and improve different aspects of their English language such as content knowledge and language knowledge (vocabulary, structural patterns and pronunciation). These were found in the following extracts from different groups:

Extract 9 I like storytelling because when I am telling a story, I memorize more learnt patterns and learnt words and I learn more new patterns and new words.

Extract 10 It helps me check my memory, how well I can memorize.

Extract 11 Creating helps combine many things that have been learned.

Extract 12 Working with friends makes work easier. They help me with words, old words, new words, their pronunciations and patterns. 


\subsubsection{Emotional engagement}

Unlike what was found in the normal classes and the comparison group, the indicators of emotional engagement in the intervention class were identified as having high positive interdependence and strong group accountability, as can be seen in Table 7.3, below.

Table 7.3 Indicators of emotional engagement in the intervention class

Patterns of engagement

1. Participating in games with meaning construction

2. Listening to a story and telling the main ideas

3. Listening to the story and reconstructing the story with the teacher (orally)

4. Reconstructing the story (in writing)

5. Comparing reconstructed stories with the original story.

6. Creating a new ending or a new story

7. Sharing their created stories

\section{Indicators of emotional engagement}

High positive interdependence

Strong group accountability

High positive interdependence

Strong group accountability

No group work

High positive interdependence

Strong group accountability

High positive interdependence

Strong group accountability

High positive interdependence

Strong group accountability

High positive interdependence

Strong group accountability

The indicators of emotional engagement were manifested via how the students participated in work. These will be presented below, particularly focusing on their feelings during the process of constructing and creating a story.

The feeling of strong interdependence starts right at the beginning of the task when the students stated their roles in the story in these two main activities, as noted in Extracts 1a, b and Extract 3. During the story construction and creation (as in Extracts 4, 5, 6 and 7), they needed to be truly cooperative through listening to their friends' utterances and helping one other when necessary. Interactive interactions kept happening in the process of constructing and creating a story because each student could not construct the story unless the other members of the group contributed and vice versa. In other words, the feeling of strong interdependence made them finish their work and voluntarily help each other for the group's success.

In their group work, the students showed strong feeling of group accountability. First, the students' responsibility was reflected in their effort to accomplish their work and they did not give up when the work became challenging, as in Extract 4. Second, the students' responsibility was also reflected in their efforts to help their friends and they asked their 
teacher for help when they met difficulties. Their willingness to encourage and support other group members when needed was found in their interaction, as in Extracts 4, 5 and 6. One sudden event that happened served as evidence of the students' strong accountability. After the time for reconstructing the story, the teacher asked the students to stop and they moved to another activity, then one the student suddenly cried and said: "Thưa cô em chưa xong vai của em, em sẽ không nói tốt cho hoạt động kế tiếp, rồi nhóm của em sẽ không tạo được câu truyện (I did not finish my role, I will not do well on the next activity and my group will not create a good story)." She asked the teacher to give her group more time to accomplish the activity.

The feeling of competence also made the students feel more accountable. The cooperation and mutual support in interactions make them feel competent although the task was challenging. With their friends' scaffolding, they could complete their utterances without being afraid of losing face by being corrected in front of the class (see Section 7.3.2.2).

The feeling of interdependence and group accountability increased when the student could find values and meaning in their tasks (Frey et al., 2009). In their interactions, their opinions were valued as found in turn 27 in Extract 6 when one student in the group praised their friend's contribution to the group. They agreed on what they would say, as shown in turn 28 in Extract 6. Furthermore, when one group member was talking, the group members were listening so they could give support when necessary. This gave them a feeling that what they said was valued and their performances were appreciated.

Constructing the story and creating a story were meaningful activities that strengthened positive interdependence and group accountability. The first meaningful task was one that required the students to reconstruct a story. The students knew their parts contributed to the group's story, which made the task meaningful to them. This could also feed the feeling of connectedness due to the value the students could feel by reconstructing the story with other members of the group. The second meaningful task was the activity in which the students were asked to create the story. Being able to successfully create the story may have been meaningful and valuable to the students because it connected to their lives.

\subsubsection{Behavioural engagement}

Unlike what was found in the normal classes and comparison class, the on-task behaviours in the intervention class indicated that the students were genuinely engaged in the interaction with clear evidence of attraction to work, persistence in work despite challenges and obstacles, and visible delight in accomplishing work. 
First, the peer interactions like Extracts 4, 5, 6 and 7 contained evidence of participation, and the students' attraction to their work through their efforts in constructing and creating their stories. The noise they made from 15 groups of three or 11 groups of four were not monotonous sounds from repeating anymore but a mixture of noise in English and in Vietnamese for discussion or error correction, which is also a manifestation of attraction to work. That each group's work resulted in a product of their own was strong proof of the students' involvement.

Second, as mentioned in emotional engagement, the peer interactions like Extracts 4, 5, and 6 provided plenty of evidence of the students' persistence in their work. When they met difficulties, they sought assistance from their friends or the teacher. The process of the students' practice from the rough version of the constructed story (Extract 4) to the rather smooth version of the created story (Extract 7) showed their persistence. This is partly because the tasks of constructing and creating a story were much more challenging than reading a story or doing substitutional drills and communicative drills with provided patterns. As one of the students on Group 7 said: "Kể truyện khó hơn trước cô vì mình phải nhớ từ, mẫu câu thì mình mới nói được vai của mình cô, nhưng mà vui cô, có bạn giúp (Teacher, storytelling is more difficult than before [learning previously] because I have to remember words and patterns so that I can speak my role, but it is fun because I can get help from my friends)."

The third feature of behavioural engagement, visible delight in accomplishing work, was exemplified in Extract 6. In line 29, the students in the group expressed their satisfaction at completing the task and then, in line 30, they appeared to be proud of their outcome as they wanted to tell the teacher they had finished the task and created their own product. This evidence of learners' delight with their product was quite different from the feeling of finishing a meaningless task as found in the normal classes and the comparison class. In the students' comment in the previous paragraph, their enjoyment of work is mutuality in peer scaffolding. The students' enjoyment can also be found in their opinions about the benefits of group work in Section 7.3.2.2.

\subsubsection{Summary}

In short, the intervention group engaged in storytelling activities at a profound level. In terms of cognitive engagement, they engaged in high-thinking skills while they constructed and created a story. In terms of emotional engagement, there was high positive interdependence and strong group accountability as the tasks required genuine cooperative learning. In terms 
of behavioural engagement, they persisted in tasks that are challenging, from reconstructing the story to creating their stories. The students' delight and pride in their products after accomplishing their tasks, and enjoyment in group work, were expressed explicitly. These indicators of engagement resulted from the teaching instructions that gave learners opportunities for constructive interactions. These constructive interactions help transform superficial into deep engagement with language, making learning more constructive and active, which is more appropriate for young learners (Cameron, 2001).

\subsection{Perceptions of and reactions toward storytelling innovation}

This part of the chapter explores in-depth the implementation process of the storytelling innovation by seeking insights into the teachers' and students' perceptions and reactions. The following sections present the findings collected from the analysis of the teachers' and students' interviews, and fieldtrip notes. The participants' comments in this part are translated versions from the native language of the teachers and the students.

\subsubsection{Teacher's perceptions and reactions toward the storytelling innovation}

The intervention group teacher perceived positive changes in her practices and the students' learning as a result of the implementation of storytelling lessons. Many aspects of her classroom behaviours contributed to the development of her perceptions of the storytelling innovation. They will be presented in two subsections: initial perceptions and reactions, and perceptions of and reactions to the whole storytelling innovation.

\subsubsection{Initial perceptions and reactions}

The intervention group teacher's overall positive feelings gradually built up during the process of the storytelling innovation implementation, especially after the modelling lessons and during the first three lessons.

\subsection{The researcher's modelling teaching}

After the teacher agreed to join the study, I did another modelling lesson with one of the teacher's real classes which was similar in class size and student background to the real intervention class. This modelling teaching lesson was not very successful because I could only conduct four of the five activities. However, the teacher valued the lesson as she recognized three main features of her class that should be changed so she could have successful storytelling lessons. First, the students had been trained to follow models strictly and this was also the way they learned other subjects; therefore, it took them time to adjust to the new instructions. Second, the students were used to working in pairs to read the story 
aloud and to practise the lessons' sentence patterns with patterns provided; they rarely worked in a group of three or more. Third, the students were afraid of making mistakes when constructing or creating the story because in their normal classes, they said exactly what was taught to them and mistakes were corrected immediately. The teacher highly appreciated the attraction of telling the story rather than the students' listening to the story from the tape as she usually did in her normal classes, as well as the students' reconstructing the story and the absence of boring repetition. These early realizations made the teacher feel worried, but they increased her determination to make changes in her classroom.

\subsection{The first lesson}

The teacher's first lesson was still affected by her normal way of teaching. She did not conduct the full storytelling lesson, and the students were confused about group work. The lesson started about eight minutes later than scheduled (due to a sudden meeting of the form teacher and the students). She taught vocabulary as in normal lessons and used only 20 minutes for the storytelling lesson with four of the five activities. In Activity 2 (after a warnup activity), she told the story twice rather quickly, and she forgot to ask students to work in pairs to tell what the story was about. In Activity 3, she told the story again and tried to let the students tell the story with her. In this activity, the students seemed to be afraid of making mistakes; therefore, it took them time to decide roles for each member in the group. In Activity 4, she asked them to work in groups to reconstruct the story and then, she asked them to open the book and compare their stories with the story in the book. She prepared the students for their collaborative work by assigning the students to groups and emphasizing mutual help. Activity 5, asking the students to create the next events of the story, was not omitted because the time was up.

From my observation, although the teacher told the story quickly, the students still paid serious attention. It was perhaps because they were told an English story for the first time and it was more attractive than their normal listening to the tape, even though they did not have a purpose for their listening, as the teacher forgot to tell them what they would do after listening to the story. The students did not know how to compare their story with the original one and she skipped the writing activity. After the lesson, the teacher told me that the students needed to learn vocabulary explicitly and she commented that the way she told the story was not very engaging. She said that next time she would tell the story more slowly and use more body language. I tried to convince her to follow the framework of the storytelling innovation and she agreed. The teacher and I discussed more about how to make the group work more 
effective; for example, the teacher choosing a group leader and the group leader deciding the roles for each person.

\subsection{The second lesson}

The teacher felt her second storytelling lesson was much better. She realized that she had omitted two sub-activities in Activity 1 but she could recognize the more genuine cooperation of her students' group work. The four steps in her lessons were clearer. In Activity 2, she told the story more slowly, with correct pauses, more body language, and more eye contact. The students were attracted by the teacher's story, but she realized that she forgot to ask the students what the story was about. In Activity 3 , she told the story again, letting the students join in telling the story with her. Students worked in groups to tell the story again.

From my observation, the students seemed to know what to do. Each student in a group had a role and they tried to reconstruct the story together, while some groups still argued about the roles. In Activity 4, the students were asked to open their books and compare what they had said. Because the instruction was not clear, the students did not know what to do. That was the reason the teacher asked the students to read the story aloud, which reflects that she fell back on the teaching technique she normally did in her classes: repetition.

In Activity 5, she asked the students to work in groups to create next events for the story. In her opinion, the students showed interest in this creative activity. After the lesson, the teacher expressed her happiness at successfully telling the story and the students' ability to reconstruct and create a story. Approaching each group to observe their work for the first time and helping them when necessary made her feel valued by her students. She noticed real cooperation in the students' group work for the first time, although she also observed some students who did not work well; perhaps because they did not know the meaning of their roles and the task. Although the second lesson was not fully conducted, most students seemed to be happy with the new way of learning. The teacher and I discussed how to make group work more effective. One example was that it took time for the students to assign roles for their group members. We decided to have a method that each member in a group would have a number and the teacher would control the first role in the reconstructing story activity. Another example was that the teacher could rearrange the students' seats before starting the lessons to make sure that they cooperated well in group work. 


\subsection{Perceptions after the third lesson and other lessons}

By the third lesson, the teacher and the students were becoming familiar with each activity. However, some students still wanted to speak and write exactly as in the textbook because they were afraid of making mistakes. The students liked the creating-a-story activity. The teacher still wanted the students to perform the story in front of the class. The students showed disappointment when their group was not chosen to perform their own story in front of the class. Most students wanted their creative stories to be heard. The teacher reported that she could see the students' real cooperation from working together and that the variety of created stories by the students brought her pleasure.

In the fourth lesson, the students became comfortable with making mistakes and giving and receiving mutual help in group work. The teacher changed the last activity into the sharing activity and, from the fifth lesson, she could manage by herself. The teacher and the students' progress could be seen lesson after lesson in the implementation of storytelling lessons. All these resulted in positive feelings from the teacher and the students after 20 lessons of the storytelling innovation over 16 weeks.

\subsubsection{Perceptions and reactions to the whole storytelling innovation}

In this section, I embed the comparison group teacher's comments to clarify the intervention group teacher's development of her perceptions on her teaching and the students' learning.

The intervention group teacher expressed her satisfaction in the interview, shifting from worry at the beginning when she thought the stories were not every different from the original ones - "I felt worried because it was new and it was partly because the stories were made from the dialogues in the textbook which were not interesting" - to happiness when she noticed how the students responded to the innovative way of teaching and learning - "I could perceive that the students' learning was happening and their engagement in the lessons had gradually increased." The teacher's positive feeling was supported in her comments on student engagement and benefits for her and her students which will be presented in 7.3.1.3 and 7.3.1.4.

In contrast to the intervention group teacher's overall good feelings and lack of worry about the students' memorization of the story, the comparison group teacher expressed dissatisfaction with her teaching. Her displeasure came from her evaluation that her students were unable to memorize the dialogues: 
First, the dialogue was too long. Second, when they read the dialogue, the majority of the students did not understand the new patterns, how they were used in that context; they did not have any impression of these patterns; therefore, they met difficulties in speaking, in memorizing the dialogue as well as they could not read the dialogue fluently.

Compared with what she did in Term 1, she thought that the main cause for the students' inability to memorize the story dialogues was from her teaching the structural patterns:

Regarding my teaching method in the first semester, if the lesson had new words, I taught new words first. After the warm-up activity, I taught new words, next I taught patterns and then the dialogue. But in the second semester, I taught the dialogue before I taught the patterns. When it came to the end of the second semester, some dialogues were too long and the patterns in the dialogues rather differed to the patterns they practiced. After each lesson, I thought that the effectiveness of the lesson was not high.

She expressed regret for not teaching the structural patterns prior to the dialogue as she felt it would be better for her students' memorization of the dialogue. She said: "If I had had a chance to reteach, I would have taught the patterns before the dialogue so that the students got familiar with the patterns."

These comments indicate that the comparison group teacher considered teaching patterns to be the focus of the lessons, and any failure of the lessons was from inappropriate teaching of patterns. She expressed her desire to change the order of the PPP lesson, which means she wanted to conduct the practice phase before the presentation. The comparison group teacher's dissatisfaction seemed to express doubt about the effectiveness of what she was doing and that she wanted to go back to what she had done. That was the grammar-translation method, which she used to learn and apply in her teaching.

The intervention group teacher expressed strong belief in the effectiveness of the new teaching method in terms of engagement and benefits for both the students and the teachers, which will be presented in the next parts.

\subsection{Perceptions of student engagement}

Teachers' classroom experiences influence their cognition unconsciously and through their conscious reflection (Borg, 2006) and teaching experiences undoubtedly shape teachers' beliefs (Li \& Walsh, 2011). It is true in this study, as the comparison group teacher and the intervention group teacher had contradictory perceptions of student engagement due to their different teaching practices. 
The comparison group teacher's perception of student engagement did not change compared with her previous perception. In her opinion, like those in Phase 1 (see 6.4), additional elements to the main activities engaged her students:

As you had observed, they like my drawings and gestures. They enthusiastically participated in games and like competitions. They expressed their dissatisfaction if I forgot to sum up their competition in a lesson.

In her opinion, her students were attracted by child-friendly features in her lessons. These included games, competition in activities, pictures, drawings and the teacher's characteristics such as being friendly and caring in teaching.

In addition, she believed that pair work and group work could be inclusive of all students as she reported that reading the dialogue in pairs or in groups and practising speaking activities involved all the students and each student had a chance to speak in these activities. She knew these pair work activities aimed to help students learn the patterns by heart. However, she did not recognize that these activities could involve low engagement in terms of cognition, emotions and behaviours, as analysed in Section 6.4. Placing students in small groups where their engagement was strictly controlled did not promote any real cooperation and interaction and the quality of the learners' talks and cooperation in pairs and groups were ignored. Learning rarely happens in these kinds of pair and group work (Webb, 2009).

In contrast with the comparison group teacher's unchanged perception of student engagement, the intervention group teacher's perception of student engagement shifted. She could see that the quality of her students' participation in each activity engaged her students (Mihaljevic Djigunovic, Nikolov, \& Otto, 2008; Webb, 2009). The quality of each input and output activity resulted in the learners using cognitive processes to combine their prior knowledge and the clues given by the teacher and their partners in a group to construct the meaning of the story, reconstruct the story and finally create a story.

The teacher recognized the engagement elements of the input activity contributed to the student's understanding in her storytelling lessons. The input activity engaged students when the story was told with appropriate body language by the teacher and with pictures, and the students were aware of the interesting task afterward: reconstructing the story. When asked about the difference between listening to the teacher's story and listening to the tape, she emphasized the advantage of the teacher telling the story in person for the students' understanding as she commented: "The teacher points to the pictures, using gestures and her voice tones to make the content clear." Compared with listening to the story from the tape as 
she did in her normal lessons, she admitted that the students did not really listen: "In fact, now I notice that they did not concentrate on listening because the story is in the textbook."

Because the intervention group teacher had two experiences to compare, she could see some failures in her normal lessons. What she normally did was whole-class teaching and she interacted only with some good and interested students. She admitted that her teaching styles favoured a few dominant students:

In lessons with my old teaching, I introduced the lesson by using pictures. Next, the students named the characters. Next, they listened to the story from the tape. Next, they answered my questions about the story. Only a few good students could understand the story and they were eager to give their answer.

By contrasting normal and intervention lessons, the intervention group teacher noticed the inclusion of all the students in the activity and the significance of peer interactions in improving the students' confidence and speaking, which were not found in her normal lessons:

In the storytelling lessons, after listening to the story, the students had time to talk about what they had heard, to discuss the content with their friends, which helped the students become confident in speaking. All the students were included. That is the difference I could see.

Compared with the superficial working together to finish the assigned task in her normal lessons, she found there was real cooperation in group work toward the group's outcome in the storytelling lessons:

The students had worked in pairs and groups before but in storytelling lessons group work was different; they had to genuinely work together to produce their group's story.

The teacher perceived various elements of cognitive engagement in the output activities. The first element was that each student had a role in the context of a story. The teacher noticed how hard they tried to reconstruct the stories and the students' feeling of excitement when they were in the roles of a story to reconstruct and create their story:

Each student had a role, therefore, they tried to accomplish their role. Seeing each student in groups happily reconstruct each utterance made me happy. When they reconstructed each utterance, they tried to remember words and patterns they had learned and what I said when I told the stories. This is quite different from helping them to learn by heart the dialogue mainly through repetition.

The teacher uses the word "remember" to refer to the cognitive activity happening in her students' minds. She used that word because she was still affected by her normal lessons. In fact, her perception of the students' cognition activity had changed as she could notice that 
they tried to use their prior knowledge in combination with their new knowledge from the teacher's story and from their friends' assistance.

The second element of engagement was creating stories, as she noted:

Creating a story was really appealing because they [the students] could create new stories in the way they want. Speaking in this way was challenging but interesting for them.

The teacher's words indicate that storytelling lessons met learners' desires to explore and extend their language (Tin, 2013). In this way, learners develop their language via innovating and using language to construct new meanings.

The third element was comparing the stories, which was completely different from what she normally did. The teacher reported that in her normal classes, she sometimes asked the students to compare their answers for reading comprehension questions. They mainly compared whether their answers were similar or different, or whether they were true or false. In her storytelling lessons, the students compared the utterances they reconstructed with those in the original story. This kind of comparison enables the students to notice the target language. The teacher expressed contentment with one of the effective techniques she used that helped her observe the students' engagement and cooperative outcome. This technique was the use of different inks to notice the difference they could find between their written stories and the original ones (see Section 7.2 for their papers). She reported that the techniques helped her observe the effectiveness of the students' work.

The student's engagement was reflected in their genuine work in their groups and the value of mutual help in group work. These values were not mentioned by the teachers in Phase 1 or the comparison group teacher. In the intervention group teacher's opinion, she could observe clearly how students engaged in group work by helping each other, discussing their group's story and making on-task noises (see Section 7.3.1 for teacher perception of noises in her classes).

In my normal classes, the students practised the structural patterns in pairs. They practised so quickly; therefore, I can check only a couple of students by asking them to perform it again in front of the class. While the first couple were performing in front of the class, the rest of the students may listen to them, but when the second couple did, most of the class did not listen. In storytelling lessons, in practice, the students practised in the roles of the story, I could observe how they practised, how they assigned roles and how they helped each other. They worked hard and helped each other so that their group would have a good story. Sometimes they argued and made noises, but all these noises were for creating the group's story. They felt happy when their group created a good story. 
Changing roles in reconstructing and creating stories provided more participation, which improves the quality of group work, as she noted:

I did not allow the students to be in one role in order to ensure that they evenly participate and meet nearly similar challenges of constructing their story roles.

As a result, the activities were not dominated by a few members; instead, the good members tried to include their group members by providing assistance, as mentioned in 7.2.1.

In summary, the teacher's comments indicated that the teacher positively perceived learning engagement and social interactions in storytelling. The students set up social relationships within their groups, to show respect to the members of their learning groups by being good listeners and assisting one another. They were on-task, listening actively and participating fully in all activities. These everyday classroom behaviours cultivated a sense of interdependence and a sense of accountability. The comments also reflected important features of cognitive, emotional and behavioural engagement discussed previously (see Section 7.2).

\subsection{Strong points of storytelling lessons over normal lessons}

In the teacher's opinion, there were some strong points of the new teaching method that could not be found in the normal teaching method.

The first strong point was a lack of mechanical repetition in storytelling lessons. To some extent, she realized the boredom and meaninglessness of repetition in her normal lessons, which she had previously perceived as a good technique for the students' memorization (see Section 6.3).

In storytelling lesson, there was not any repetition, the students always had new things to do in each activity. The teacher did not need to do reading modelling a lot. The repetition method we often use is repeating the story utterances, new words, and patterns to help students remember them.

The second is that learning outcomes were visibly productive in each activity while in the old lessons, products of each activity were mainly repeating what was written in the textbook.

I could see the students' outcomes from each activity such as reconstructing the story, writing the story and creating a new story. In my old teaching method for this class, I could see that the students could ask and answer with the new patterns provided in activity 2 and in activity 3 . They used the newly learned patterns with little creativity. In the new teaching method, the students made the story longer and the new patterns were put in the context. 
Third, storytelling brought significant benefits for the teacher, such as better pronunciation, more confidence and more student respect than in normal lessons and each storytelling lesson required just a little teacher preparation time.

Storytelling just required the teachers to do a little preparation, which means it required the teacher to read the story a little more carefully than usual. It depended on the teachers. For me, I needed about five to six minutes to practise telling the story. Before, I did not do anything. In class, I opened the tapes for the students to listen to the story. In storytelling lessons, I told the story. When I told the story, I saw the students attentively listening to my story, I felt happy. This gave me a motivation for continuing practising telling stories. In addition, my storytelling became a model for the students. Practising telling the story brought me some advantages. My English pronunciation seemed to be improved and I became a little more confident in my English speaking and the students liked me more.

Fourth, storytelling increased the students's speaking competence. Reconstructing and creating stories provided students with opportunities to practise and use patterns and vocabulary; as a result, the teacher reported that most of her students could answer the questions using the learned patterns and vocabulary effectively in the speaking test. The teacher reported that the students' speaking ability improved greatly and some shy students became more confident in English speaking, volunteering to be the first test-takers in the speaking test. The analysis of the end-of-term tests in 7.1 supported her satisfaction. In addition, the teacher stated the positive effect on students' speaking if it could possibly be popularly included in regular lessons in the future, as she noted: "If it [storytelling innovation] continues being conducted regularly, I am sure that students can speak well, and I will not worry about students' speaking ability."

\subsection{Perception of creativity}

Before presenting the intervention group teacher's concept of creativity, it is worth considering the comparison group teacher's perception of creativity.

Like the lessons in Phase 1, personalization and creativity were rarely found in the comparison group class. The majority of the lessons focused on teaching vocabulary and structural patterns. Sometimes, the teacher ended the lessons with a real question related to the lesson, for example, Lesson 13 What do you do in your free time? This was the only point in the lessons where the students had the opportunity to personalize the language and use it to talk about themselves and their own lives. However, there was enough time for two or three volunteering students to give an answer. For the teacher, Activity 3 'Let's talk' in the comparison group's lessons provided opportunities for learners to be able to use the language in real situations. When asked if the students were able to use English with others beyond the 
classroom, she commented that only good students could use English beyond the textbooks while the majority of the students could not because they did not have any chance to speak English outside the classroom.

At home they have no chance to speak English. Their parents do not know English, except one or two of them whose parents are teachers of English, or they have a brother or a sister who learn English well and can practise a little. They only speak English in the classroom. Speaking exactly what is written in the textbook is difficult for students, saying differently little may be beyond their ability.

She mentioned almost nothing about teaching for creativity. The fact that she reported little potential for creative development for the students in her teaching is not a rare phenomenon. Like the comparison group teacher, all the teachers in Phase 1 put little effort into fostering creativity in their teaching practices. Studies have shown that developing creativity in children is not a focus in popular teaching methods (Thanh, Viet, \& Hiep, 2015) and in English education in Vietnam (Grassick, 2016). It seemed that creative development was something beyond the primary school teachers' abilities or they may be uncertain about the relationship between creativity and foreign language teaching (Wang \& Kokotsaki, 2018). It may be because of the teacher's limited knowledge and training in fostering students' creative characteristics to use and learn a language (Nedjah \& Hamada, 2017). Teachers' poor knowledge about creativity may prevent them from providing the appropriate conditions that nurture learners' creative potential (Al-Qahtani, 2016; Odena \& Welch, 2009; Rubenstein, McCoach, \& Siegle, 2013).

In contrast, the intervention group teacher expressed happiness that her storytelling lessons could help include students' creative development and give students more responsibility for their learning instead of the teacher taking responsibility for everything that happened in the classroom. This also changed her perception of creativity and incorporating it into her storytelling lessons.

I also like that activity because the students have freedom to create what they want. This follows today's orientation of teaching which has to improve their thinking and activeness. The teacher should not do everything for the students, we have to offer them opportunities to learn by themselves. Previously, I thought it [creativity] was a big thing and including it in my classrooms was beyond my ability.

In fact, this comment about 'today's orientation of teaching' indicates that her new teaching methods could fulfil the aims of English education as stated in the curriculum: to improve the students' participation and creativity (MOET, 2010a), although the teacher did not mention that official document. 
However, the teacher expressed concern about the students' creativity and created stories which she thought were not attractive. In her opinion, the topics of weather and the folklore tale The story of Mai An Tiem caused difficulties for the students to create new stories and this adversely affected the students' motivation in learning. She stated: "They could create a story for their group, but they were not interesting”.

In the teacher's opinions, students' creativity was limited by previous experience.

I think that the students' limited creativity is affected by the way they learned other subjects in their mother tongues. Opportunities for students' creativity are rare. They mainly learned their lessons by heart.

Her opinion is supported in many studies. Education in Vietnam is characterized by repetitive, rote learning, memorization and reproduction and there is little room for creativity (Behr, 2005; Grassick, 2016; Lan Chi, Hamid, \& Renshaw, 2015; Vi, 2018). This way of learning has been criticized for minimizing the creative thinking and creative abilities of children (Fielding, 1997).

The teacher expected the students could create "something that is both interesting and appropriate". In her opinion, the stories about the weather were not appealing because "what they created was just the replacement of the weather words and places, so their story was similar to the original story". In contrast with the teacher's opinion about their created stories, the students expressed favour for all the topics in the textbooks and they felt happy with their created stories, including about the weather forecast.

It may be that the teacher's perception of creativity was still unclear, although she changed her perception about creativity and incorporating creative activities in the classes. The teacher did not completely accept the personal and developmental aspects of creativity. As mentioned in the literature review (see Section 3.2.2.4), creativity does not need to be original or even meaningful to others. It is important to recognize "the creativity inherent in students' unique and personally meaningful insights and interpretations as they learn new subject matter" (Kaufman \& Beghetto, 2009, p. 4). As the way the teacher perceives creativity has an impact on how they nurture it in their classroom (Nedjah \& Hamada, 2017). In my opinion, the teacher needs to accept minimal creativity in the students' stories.

\subsection{Roles of the teacher}

In the teacher's opinion, the roles of the teacher in her storytelling lessons were not changed but she recognized her other roles as an organizer and helper in the student group work. The roles improved the activeness and creativity in the students' learning. 
I think the roles of the teacher are the same. The teacher has to organize activities, observe how the students work, help them when necessary, especially when they work in groups. The difference is that most students talked more and helped each other more. I could see that they become more active in the way that they constructed the story together and making the story more interesting in their own way instead of trying

to learn by heart the new words, patterns.

In terms of the classroom management in a large class of young learners, her opinion is supported by Ramirez (2005) who put it that during group work "the teacher is still the director and manager of the class and needs to make students aware of this" (p.4). The teacher still recognized her role as the manager of the class, but she did not recognize that she had changed her other roles. In fact, the teacher's role shifted from transmitter of knowledge to learning facilitator, from the only source of knowledge to an organizer and consultant of knowledge and social skills. This is reflected in the teacher's low-level control in practice, the choice of language and the teacher's assistance, as has already been highlighted. The students were not forced to memorize the new patterns and the dialogue; instead, they constructed them and had freedom in creating their own stories.

\subsection{Perception of storytelling}

The intervention group teacher also shifted her perception of storytelling from an exercise to a process of teaching. Although she still used the very traditional word "transmit" to refer to her teaching, she indicated that the whole process is interactive between the teacher and students and between the students.

Storytelling is a process including some interactive activities. The teacher transmits the story to students in the form of telling and using some attractive tools such as pictures, voices and intonation to help students interact with the story. Then, students practise telling a story in groups, so students interact in their groups. The teacher tells a story, students tell the story and create a story after practising in speaking and writing to increase their communicative ability.

In her comment, she paid attention to the role of the teacher in scaffolding the process of the students' building products to increase their communicative and creative abilities and the active role of the students in their learning. This opinion is contrary to Phase 1 teachers, who emphasized the role of the teacher in helping students memorize their learning products and ignore the students' role in their learning. The teacher defined her perception of storytelling by describing what she usually did in storytelling lessons. This reflects that the teacher's cognition was formed from her own experience. This will further be discussed in 8.2.5. 


\subsection{Feasibility of storytelling innovation lessons}

The teacher's development in her perceptions of student engagement and benefits of storytelling can exert a positive influence on her teaching practice and motivation. As a result, she stated the feasibility of the storytelling innovation: "Storytelling innovation implementation is not beyond the teacher's ability and primary school teachers do not need any special training to apply storytelling innovation." As mentioned earlier, she commented that the teacher just needed a few minutes to practise telling the story and manage group work. Her opinion echoed my field notes presented in 7.3.1; after three lessons the teacher could control a storytelling lesson well.

When asked about the main challenges associated with storytelling the teacher pointed out the large class size, classroom environment, and workload.

First, although the teacher knows that noise is necessary and unavoidable when the students work in groups, she expressed concern that the noise of a large class affected the quality of sharing-story activities: "When they told their group story to the other group, the noise from the crowded class partly limited their listening." Her concern about the high level of noise affecting the students' work was also reported in Newton and Nguyen (2019). The noise was unavoidable in a large class when all the students participated in interactive activities.

Second, the classroom environment and layout influenced the quality of students' work:

The room was small, and the desks were heavy and unmovable; therefore, the class looked condensed and the students could not move around. I could not change the group members, so they had to work with the same members all the time. I could not give students opportunities to work with others to improve their cooperation with different kinds of friends and I want to know how different kinds of groups work.

Her opinion reflects a common view that the physical setting of the classroom does not contribute to cooperative learning (Weinstein, 1979) and seating arrangement may inhibit communication between children (Kutnick \& Blatchford, 2014). However, this disadvantage did not prevent her from having effective group work activities. She set up the conditions and supported group work by giving clear instructions, modelling and encouraging learner development. 
The third challenge was the workload. Like most Vietnamese teachers, she was not only busy in teaching but also with other duties, which affected the quality of lesson preparation and delivery.

Working load is too much, I have to teach 18 periods a week and have at least one meeting a week and sometimes unexpected meetings and organizing English clubs and training students for competitions. I do not think I have enough energy for implementing the new teaching method in every class.

Although the teacher perceived those challenges, when asked about a broader pedagogical implication of the storytelling innovation, she commented that:

I think storytelling can be applied in other parts of the book such as reading activity, writing activity and speaking activity in Lessons 3 and review units. This teaching method can be used to teach other books such as Family and Friends.

The teacher's comment indicated that the storytelling innovation could be applicable in teaching other parts of the textbooks and other textbooks. Furthermore, this new teaching method could be applied to teach other primary school grades (Grades 4 and 5). She showed uncertainty when talking about Grade 3 when students officially start to learn English, but a minute later she suggested that this teaching method should be applied as soon as students start to learn English because of its two main benefits for young learners: cooperation and creativity. These ideas could be found in the following extract:

In my opinion, this teaching method could be applied to teach Grade 4 and Grade 5. I have some experiences in teaching Grades 4 and 5. Students have already had some English knowledge. For Grade 3, it is a little difficult. They do not have enough knowledge of English, they have to listen to a story, it is difficult for them to understand stories and they do not have enough vocabulary to create stories. I think if we boldly apply it to teach Grade 3, it is still feasible. Offering opportunities for cooperation and creativity for the students should be done as soon as possible.

She then commented on the change in approach of teaching and learning: "It changes the way to teach and the way to learn, and students like it because it engages them."

Despite the teacher's positive comments and feelings about the storytelling innovation, she expressed hesitation about applying it after the study. In her opinion, the first main obstacle was related to the popularity of PPP, which was expected by the textbook, designers and experts from DOET and which was believed to be the official teaching method. Her second concern was that the students' creativity may go beyond the textbook which was not supported by most of the teachers. When giving comments on a teacher' lesson, the teachers in the researched areas based their comments on the textbook methodology, not on the principles of CLT. 
The aim of the lesson is to practise the structural patterns and vocabulary in Activity 2. My worry is on students' creativity which may go beyond the pictures in that activity [she means that when the students create their group story, they may not use the patterns and vocabulary that are required to be learned and practised mainly in activity 2 in the textbook]. I am worried because other teachers may criticize that students have not used the new patterns and vocabulary in the lesson. When students create, the teacher cannot force them to use any patterns and vocabulary. The teacher's lessons have not fulfilled the aim of the lesson.

The teacher mentioned the freedom the teachers should have: "When teachers have freedom in teaching, this teaching method can be applied." In addition, she stated that the teachers only applied the new way of teaching if there is an official document from DOET: "There are not any official documents, no teachers are brave enough to teach differently." Her comment reflects her desire to feel safe in applying the new teaching method.

\subsubsection{Students' perceptions of and reactions toward the storytelling innovation}

The intervention group students perceived positive changes in their learning as a result of their participation in storytelling lessons. Genuine group work, which offered them communication, meaning construction and cooperation, contributed to the shift in their learning. To clarify this finding, I include the comparison group students' opinions to contrast the development of the intervention students' perceptions of their learning. Throughout this part, I also include extracts from student interviews (translated into English). The names of the students in those extracts have been changed.

Both classes reported their desire to have more English lessons like those they had in the second semester. The overall reason was due to my presence, but the main reasons were completely different as found in Extracts 1 and 2:

Extract 1 (from one of the groups in the comparison class)

01 S1: I liked to study English when you were present in my class.

02 I: Why?

03 S1: Because my classmates paid more attention and made less noise.

04 S2: We were allowed to play more games.

Extract 2 (from one of the groups in the intervention class)

01 S1: I liked to study English when you were present in my class.

02 I: Why?

03 Ss: (in chorus) allowed to do storytelling.

04 S2: We were allowed to speak more

05 S3: We were allowed to create stories. 
The comparison group students associated my presence in their class with their friends' better behaviours and more games, that is, their lessons were more prepared for them and their friends had better behaviours than their lessons in the first semester. Unlike the comparison group, the intervention group students associated my presence in their class with storytelling lessons, and they enjoyed the activities in storytelling. Their choral answer showed how happy they felt indicating that their attitude shifted from a preference for traditional lessons to storytelling lessons. Details of the differences in opinions are examined more below.

\subsubsection{The comparison group}

\subsection{General perceptions and reactions}

Like the students in Phase 1, the students in the comparison group expressed their satisfaction with learning English because the lessons contained some child-friendly features such as colourful pictures, stories, songs and chants, games and the teacher's drawings (in 6.3.4). The students from different groups expressed favourable attitudes to all the activities the teacher prepared for them, as the following extracts illustrate:

Extract 3a S: I liked listening to the dialogue because it helped me improve my pronunciation.

Extract $3 b \quad S$ : I liked repetition because it was easy.

Extract 3c S: I liked learning patterns because it helped me speak better.

Extract 3d S: I liked role-play because I became a character [in reading in roles].

Extract $3 \mathrm{e} \quad$ S: I liked playing games because they were fun.

Although they appeared to enjoy all the activities, the students' comments reflect that their learning environment lacked a meaningful focus and they were not absorbed in the challenge of their activities. In other words, what the students experienced in the learning community was vocabulary and patterns, reading aloud and pronunciation practices without deep engagement. This finding was echoed in the observation data presented in Chapter 6 and reflects the results of Phase 1 in which the students experienced discrete language skills learning.

\subsection{Group work activities}

Most students also expressed pleasure with group work in practice activities. This can be seen in turn 3 where $\mathrm{S} 1$ states they have opportunities to speak in these activities, as found in Extract 4: 


\section{Extract 4}

01 S1: I like studying English because I can speak English.

02 I: When do you speak in a lesson?

03 S1: I speak most when I read the dialogue, doing activity 2, practising these patterns.

The comparison group students were in favour of their teacher's teaching, which mainly focused on reading and repetition.

What is striking are the benefits of group work and how they interacted in working with friends. In their opinion, accuracy and pronunciation were the main focus in a group work activity as seen in turns 07, 08 and 09 in Extract 5. They seemed to be familiar and felt happy with the teacher's pronunciation correction (turn 9).

\section{Extract 5}

$01 \quad$ I: What did you usually do in groups?

02 S1: Read as assigned.

03 S2: Reading the first roles, we exchanged our roles.

04 I: Did reading in roles help bring you any benefits or difficulties?

05 S1: Benefits.

06 S2: Help us read.

07 S3: Improve my pronunciation

08 S4: Memorize vocabulary and patterns.

09 S5: If I read a word incorrectly, the teacher will help me to correct it.

In Extract 5, the students do not display mutuality and connectedness as the students in the intervention group do. This reveals a lack of genuine interaction and cooperation in their learning activities. In other words, interactive and meaningful learning was not found in their normal classes.

\subsection{Disadvantages of learning activities}

No students referred to the difficulties in working in groups, but three disadvantages of their learning activities were discovered in their opinions.

The students made funny comments on some of the activities which could reflect negative perceptions on some of their learning activities. One was their comment about repetition: "Sometimes repeating many times made my mouth tired." They did not want to criticize their teacher; therefore, they innocently said their mouth was "tired". From my observation, sometimes the students expressed tiredness and disappointment when being asked to repeat many times by responding by saying: "Again, teacher?" 
Another comment was about games. Turns 03 and 07 in Extract 6 suggested that only good students could join the games:

Extract 6 (Group 5, the comparison class)

01 S1: When having a competition, the girl group usually lost.

02 I: Why?

03 S1: Because the boy group was better. They had Tan.

04 S2: Tan was very good at English.

05 S3: The girl group had the monitor.

06 S4: The monitor was good.

$07 \quad$ S5: The teacher rarely invited the monitor.

The third comment was about competition. To encourage every student to participate, the teacher added competition to Activity 3, as mentioned in 6.3. Competition created more pressure for many students who were not able to do the activity, as found in turns 08 and 09 in Extract 7.

Extract 7 (Group 5, the comparison group)

$01 \quad$ I: Why did you like games?

02 S1: Because they had competition.

03 S2: I like games before the lessons more than those after the lessons.

04 I: Why do you like games before the lessons more than those after the lessons?

05 S2: In games before the lessons, the teachers chose volunteers. In games after the lessons, the teachers used Lucky Numbers.

06 S3: I called them Angel Numbers.

[The teacher had a bag of numbers and the students all knew which number represented which student]

07 S4: The teacher picked a number, a student with that number had to stand up and join the game.

08 S5: Some liked it because it improved the excitement. Some shook their heads because they could not speak.

09 S6: They call them Deadly Numbers because they did not know who would be chosen.

Extracts 6 and 7 reveal that most students could not use the target language items in the last activity. This is the communicative drill with patterns provided (as analysed in Chapter 6) which was believed by the teacher to allow students to use the newly learned target language items in real-life situations.

In short, the comments from the comparison group students reflect that they were involved in the learning process and appeared to actively join in the activities but, in fact, the students did not have opportunities for meaning construction, cooperation and creativity. In the practice activities, they did not have much chance to take responsibility for what they were doing and use their knowledge in order to communicate. Unlike the intervention group students (as 
analysed in 7.3.2.2), they had little chance to view what they were doing as practical or get mutual help from their friends. The comparison group students' opinions echoed the analysis of student engagement in 6.3.4 that, in this kind of learning process, the students could only be involved in low cognition, low interdependence and responsivity. They still liked what they were doing in the lessons because they had some child-friendly activities, but the learning activities did not provide them with deep engagement due to the lack of meaningfulness and communicativeness of each activity in their lessons.

\subsubsection{The intervention group}

\subsection{General perceptions and reactions}

The children in the intervention group reported enjoying learning English and appreciated storytelling lessons that offered them meaningful and communicative activities. In Extract 8, they recognized the opportunities as actively involved in meaningful interaction in the target language in developing their linguistic competence (Fushino, 2010):

\section{Extract 8}

$01 \quad$ S1: I like studying English because I like storytelling.

$02 \quad$ I: Why do you like storytelling?

03 S1: With storytelling, I can speak English more with my friends.

04 S2: Knowing more words and how to create a story.

05 S3: I like making changes for stories.

06 S4: I like creating stories.

The intervention group students also liked the teacher telling the story and activities as can be seen in Extract 9.

\section{Extract 9}

01 S1: Because sometimes the teacher taught in a rather fun way.

02 I: In a fun way. How did she teach?

03 S2: She told stories rather well.

04 S1: I don't know how but I felt she told stories well.

05 S3: She used pictures.

06 S4: She spoke in the characters in the pictures.

07 S5: She repeated new words when she told a story.

Extract 9 shows that the attraction of the teacher telling the story was based on the quality of the activity. This gave the students opportunities to interact with the story by using their prior knowledge in combination with the new knowledge highlighted by the teacher's clues (pictures, gestures and tones) in telling the story to construct the meaning of the story and to reconstruct it later. 
As already mentioned in turns 04 and 05 in Extract 2, the students reported that the teacher allowed then to speak and create. This indicated a desire to communicate meaningfully in the target language and storytelling enabled them to fulfil their desire.

It is apparent that the intervention group students were in favour of storytelling activities. Their learning became more active, interactive, engaging and meaningful. This is evident in observational findings. They had a chance to compare two types of lessons and expressed their preference for listening to storytelling, reconstructing and creative activities as they benefited them, especially group work activities.

What is also striking was that parents appeared to support the study. The teachers reported that no parents met her or the form teacher to complain about the new way of teaching. This was backed further by more parents giving permission for their children to join my study. As a reminder, at the beginning of the study, only 31 students in each class had permission to join the study, then more students expressed their desire to participate. This may be because of the children's positive reports about storytelling lessons to their parents.

\subsection{Benefits of group work}

There is a correlation between the quality of group work and the quality of learning (Senior, 2002). The intervention group students' enjoyment from working in groups is found their recognition of its benefits.

Most students reported increased in confidence in their communication. Group work activities seemed to offer them a safe atmosphere where they felt comfortable trying out the target language and a reduced fear of making mistakes. Extracts $10 \mathrm{a}, \mathrm{b}$ and c show that they were not afraid to speak in front of the whole class or of losing face if they made mistakes in front of their classmates.

\section{Extract 10 a (Group 1)}

01 S1: At first, I was afraid of making mistakes, so I was not brave enough to say. Then, my friends helped me when I spoke, and I was getting more confident.

02 S2: Being more confident when speaking.

03 I: Why were you more confident?

04 S3: Because I could cooperate with friends.

05 S4: I became a storyteller. 
Extract 10 b (Group 6)

S: Making mistakes is ok, they are corrected by my friends or by myself later.

Extract 10 c (Group 7)

S: When speaking I kept making mistakes, but my friends helped me.

Some students enjoyed working with good friends as their friends were often more tolerant and patient with their mistakes. Group work could promote students' active involvement and participation and communication confidence. Studies found that communication confidence increases the willingness to communicate, which means that the more confident students feel, in their group, the more willing they are to communicate in the target language during group work (Fushino, 2010).

The students perceived an increase in student engagement in learning, especially in speaking as revealed in Extract 11:

Extract 11 (Group 3)

$01 \quad$ S1: We had more opportunities to speak.

02 I: When did you speak?

03 S2: When we retold the story and created a story.

The students' more active engagement in communication led to another benefit of learning in groups - the improvement of in-class-relationships. Group work promotes a positive affective climate in the classroom, reducing anxiety, especially through interactions among students (Brown 2007; Hess, 2001). The students reported that they had a better atmosphere and enjoyment when learning in groups as in turn 07 in Extract 12. Their enjoyment came from the positive feeling of working together. What was prominent is that the students felt that the group work made their practice easier than learning in the traditional class or working with the teachers or alone as in turns 03, 04 and 05 in Extract 12. Their words implied that working with friends would help to reduce the power distance barriers that normally exist in teacherlearner interaction, which mainly include repetitions to memorize patterns and vocabulary. 
Extract 12 (Group 3)

01 S1: Working with friends is easier.

$02 \quad$ I: Easier than what?

03 S2: Easier than learning the dialogue by heart.

04 S3: Easier than working alone.

05 S1: Easier than speaking with the teacher.

06 S4: If I can't speak something, my friends will instruct me, it is easier to speak.

07 S5: In my opinion, working in groups is fun because I am allowed to speak.

An increase in their feeling of interdependence and responsibility in group work was found in Extracts 13 a and $\mathrm{b}$ below:

\section{Extract 13 a (Group 5)}

S: Working in groups makes us more united.

\section{Extract 13 b (Group 1)}

S: I feel closer to my friends when working in groups.

The students got this feeling from genuine cooperation and communication in group work, which was analysed in 7.2. When they worked toward the group's outcome, they become more connected and more accountable in their group work.

The students' feeling of values and inclusiveness was shown through their comments on getting and giving help. Some low-ability students expressed their pleasure about working in groups because group work enables them to get help from their peers and they showed appreciation for their friends' assistance. Some high-ability students expressed that they were happy to offer help in group work and they could feel how helpful they were to their group. Although they could get help from their teacher, they seem to be more comfortable with friends' assistance as shown in Extracts 14 a, b, c and 15.

Extract $14 \mathrm{a}$

S: When I could not speak a word or a sentence, my friends instructed me. I felt happy in working in groups.

\section{Extract $14 \mathrm{~b}$}

S: When my friends could not speak, I helped them. I like instructing my friends.

\section{Extract $14 \mathrm{c}$}

S: Sometimes when I could I help my friends, sometimes I could not speak, my friend helped me. If no one in our group remembered how to say a word or a sentence, we asked our teacher. We once asked members in a neighbouring group. Lan is very good at English. 


\section{Extract 15}

$01 \quad$ I: When writing did you meet any difficulties?

02 S1: If we did not know how to write any words, we asked our teachers. If we could not get help from the teacher, we wrote their sounds. Later, we saw them in the story, we corrected them.

03 S2: If there was something we did not know, Lan instructed us. If Lan did not know them, we asked our teacher.

04 S3: Lan was our group's heart.

The opinions in these above extracts also indicated how the students took responsibility for their learning and became less dependent on the teachers.

They felt proud of their stories and shared them with friends. Extracts 16a and $\mathrm{b}$ indicate the feeling of accomplishment and achievement, which resulted in the enjoyment of learning in the intervention group students.

Extract 16 a

S: Group work helped us create stories and expressed our ability by sharing stories with another group.

Extract 16 b

S: It was fun to tell our story to other groups.

The above extracts show that the students were included, even pupils with limited proficiency. They could engage imaginatively and enthusiastically in classroom activities as long as a supportive environment was offered (Markova, 2015). Low ability students felt included and high ability students felt helpful and valued. Importantly, group work gave them opportunities to participate in and contribute to the group outcomes and increased their creativity and responsivity in their learning. Based on social constructivism, storytelling with group work activities is within psychological and linguistic knowledge. Group work engaged students in developing speaking and shaping language learning experiences and social behaviours (Vygotsky, 1978). It helped learners learn from other members of the group while engaging in social interactions. The enjoyment of group work will be discussed further in 8.2.3.

\subsection{Difficulties in group work}

No students reported being ignored in group work, but four students refused to work in groups and three of them joined in after their group's negotiation. The negotiation was to re-allocate roles so that all group members were happily involved even although the teacher did not allow them to change roles, as in Extracts 17 and 18. 


\section{Extract 17}

01 S1: In my group, when a member could not speak his role, we changed roles and assigned him an easy role so that he could speak.

02 I: You gave him an easy role. Can you give an example?

03 S1: He was assigned to be the narrator, but this role was too difficult for him. So, I took his role as the narrator. He took my role.

\section{Extract 18}

01 S1: In my group, Quang did not join in any activities.

02 I: What did your group do with him?

03 S1: We asked him what role he liked, we would have given him that role, but he said nothing.

04 I: What did you do then?

05 S2: We told the teacher about him?

07 I: What did the teacher say?

08 S1: She said he did not like working. He liked watching and listening to us, so we took his role and let him watch.

Three of them reported they accepted the solution. This indicated that the students improved their social skills in group work. They tried to solve the problem in their own group to include all the members.

Only one student was reported as not joining group activities. According to the teacher, this student never took part in pair work or group work not only in this study but before the study. He was a full participant in all other parts of this study. In the pre-storytelling test, he produced a small amount of speech and in the post-storytelling test, he talked longer. Although his speaking was short, all was in English. In the interview, he told me that he did not like working with his friends. This case could be explained by his personality type (Svalberg, 2009) because this learner seemed not to have any complaints about other factors influencing learner engagement, such as topics of discussion, task requirement, relationship among learners, peer proficiency level and peer cooperation.

Five students from four different groups reported their friends cheating by opening their textbooks when they wrote their stories. This might have caused a little annoyance among group members. Another group complained about not having enough members for roles in a story, causing difficulty when working. Talking about these difficulties showed that most students were really engaged. They helped the teacher mentor and inspire their friends, becoming more responsible for their learning and less dependent on the teacher. 
No students complained about the noise when working in groups. Most of the noise was evidence of the students being on task. Among those noises was the noise from speaking in Vietnamese. The analysis of students' comment supported her opinion, as they reported that they made noise in their discussion to settle their opinions to create the content for their group's stories as they reported in the following extract (from Group 5):

01 S1: In group, we sometimes had a quarrel.

02 I: Why did you quarrel?

03 S1: Because one member did not agree with another member's opinion.

04 I: What did you disagree with?

05 S1: Ideas for creating a new story.

06 I: How did you solve the problem?

07 S2: We played rock or scissors.

Further evidence could be from their discussion to compare their stories. This was found in the analysis of the students' discourse in Extract 5 in 7.2 during group work. The discourse was an example that they were on-task to practise speaking or to discuss the meaning of their groups' stories.

Obviously, the fact the students spoke all at once trying to accomplish their activity caused noise in such a large class. Most of the noise showed that the students engaged in learning tasks. The use of Vietnamese in the EFL class could become a tool to understand, use the target language more accurately and accomplish their work (Storch \& Aldosari, 2010). In short, the students' comments reflect their active participation and indicate that students positively perceived real cooperation and social interactions in group work. Group work could provide opportunities to use the target language in a safe environment, allowing children to support each other. These benefits are found through their expression of learning enjoyment, speaking confidence, their positive in-class relationship and feelings of interdependence and responsibility. In other words, this storytelling innovation focused students' attention on exploring the meaning of the story, reconstructing the story, creating a story and sharing their stories. In addition, group work activities were considered by the students to be valuable opportunities to communicate in the target language, by which they could improve on different aspects of their English language such as content knowledge and language knowledge. This echoes the findings of the cognitive, emotional and behavioural student engagement analysis in 7.2. 


\subsubsection{Summary}

The teachers' and students' perceptions of teaching and learning English differed considerably between the classes after 15 weeks of the storytelling innovation implementation. Having experienced two different methods of learning in the classroom, both the teachers and the students stated the benefits of the storytelling innovation over their past inactive and uncooperative learning. They had become more confident and more engaged in learning in the classroom. The main factors that lead to the difference in their perceptions were from the teacher's and students' recognition of student engagement in genuine group work and the meaningfulness of the activities.

In the following chapter, I draw together and discuss my key findings in reference to the literature discussed in Chapter 2. 


\section{CHAPTER 8 DISCUSSION}

The purpose of this chapter is to examine the results in the context of the rationale for the study and on the basis of the theoretical framework reviewed and discussed in Chapter 3. Section 8.1 discusses the results of Phase 1. Section 8.2 discusses the results of Phase 2. I will use insights from the research literature to suggest possible links between the learners' experience of the storytelling innovation, and its effects on their learning and on teacher cognition.

\subsection{Phase 1}

Phase 1 of the study investigated how Vietnamese EFL primary teachers implemented lessons with stories and storytelling and how the teachers perceived story and storytelling lessons related to their lessons with stories. Drawing from the results from Chapters 5 and 6, this section discusses the instructional practices in TEYL in Vietnam in 8.1.1 and the teachers' cognition in 8.1.2.

\subsubsection{Instructional practices in TEYL in Vietnam}

Chapter 6 reveals limitations in the quality of texts and activities used to teach young learners. As a result, student engagement was found to be low in terms of cognition, emotion and behaviours.

A variety of texts, referred to as stories, were designed to contextualize and practise the target language items in each lesson. This reflects the textbook designers' plan to introduce childfriendly methods in teaching and learning. However, as found in Chapter 5, the texts in the Tieng Anh textbook lacked key elements of good stories that make them meaningful to learners. The stories in the textbook lacked a clear setting, characters and a conflict. The stories did not rouse emotion for young learners.

Teachers' lessons had a PPP structure, following the textbook lesson structure exactly, as found in Chapter 6. The activities had two features.

The first feature was non-communicative pair work and group work. Ineffective group work is a common phenomenon in primary schools (Kutnick \& Blatchford, 2014). In most lessons in the current study, the students were put in groups to read the story text aloud and to do substitutional and situational drills. In these activities, the children did not have a chance to help one another. They still depended on the texts and practices with written utterances. These 
activities lacked two out of three important aspects of cooperation mentioned in Brown (2001): self-initiated language use and real cooperation (see Section 3.2).

The second feature was unqualified interaction. Interaction in the classroom was found not to be meaningful (see Section 6.3). Interaction in the classroom mainly consisted of (1) IRF between teacher and students in vocabulary learning and answering questions after reading or listening to the story text, and (2) mechanical interaction in reading the story dialogues in roles, or interactions with structural patterns provided. These activities could not exploit the students' willingness to speak. Teaching used a combination of audio-lingualism and behavioural concepts of learning and repetition of basic language patterns through rigid dialogues and drills. Activities focused on discrete language features, including vocabulary, pronunciation and mechanical practice which is pedagogically inappropriate for young learner learning. These activities reflect a structural way of learning, which reflects the cultural issues of power distance, group harmony and face protection (see Section 2.4).

Structural learning is also found around the world and in many studies in Vietnam. Studies show that in EFL environments, such as South Korea (Choi \& Andon, 2014) and Japan (Shintani, 2016), most classroom activities for young learners focus on forms in PPP lessons (Anderson, 2017). These resemble the results of an international survey conducted by Copland et al. (2014). In Vietnam, Nguyen (2011) discovered that Vietnamese EFL primary teachers at a state school "emphasize mastery of sentence patterns and words rather than stimulating creative or real-world communicative use of language" (p. 20) and lack the awareness, skills and resources to develop a more communicative pedagogy. Moon (2009) found classroom focus on accuracy, language and pronunciation, with the teacher providing linguistic input and students copying the model with little room for creativity or deviation from the textbook. Moon's (2009) study was conducted before curriculum change and the new textbook. Nguyen (2011) research was carried out at a time when the new curriculum had just been introduced and the new textbook had not been used, and so teachers had had little experience with the new curriculum. In recent studies, conducted more than five years after the new curriculum, the teaching has not changed much. From Grassick's (2016) observation, the teachers strictly follow the PPP lessons in the textbook, and no creativity beyond the text in the textbook was found. Similarly, in Vi (2018), the teachers' lessons were textbookdirected and focused on mechanical practice of vocabulary and grammar, involving repetition and rote-learning. 
Putting stories in PPP lessons normalized the stories and does not exploit the meaningful context the story provides for other activities in the lesson. Instead of focusing on the meaning of the story, the students concentrate on the structures presented in the story. Most EFL young learners are still learning in classrooms where most instructional routines aim at discrete language features in unreal interactions, which are ineffective for young learners. The focus on forms is not recommended by Cameron (2003) who notes that "[i]f teaching or materials do not enable children to find meaning in new language, learning will be stultified" (p. 107). This is consistent with the criticism that PPP lessons attempt to segment language and do not reflect how language should be learnt (Lewis, 1993) .

Scholars agree that PPP lessons present "a strictly linear approach to language learning" (Nunan, 1998, p. 101) which processes from language presentation and tightly controlled language drills to communicative drills. PPP cannot deal with the individual challenges that learners face during a lesson (Lewis, 1993) as their prior knowledge is different from each other. In the current study, it was found that there was a story in each lesson, but the student's imagination and creativity were not employed for their learning. In PPP lessons, the learners are "passive recipients" (Thornbury, 1999, p.54), which does not align with young learners' characteristics, as mentioned in 3.2. This structural approach to language teaching restricts students' ability to use the language in real communication (Thornbury, 1999).

Overall, the results suggest that the teachers' lesson implementation reflects an absence of interactive, meaningful and cooperative processes that are argued to promote acquisition for young learners' language learning. Stories and storytelling were not fully exploited as a promising approach for young learners.

\subsubsection{Teacher cognition}

Together with the teachers' instructional practices, their perceptions and beliefs reflected their lack of awareness of the underlying principles of communicative language teaching and learning of young learners.

Chapter 6 shows that the teachers still perceived learning as memorizing and reproducing knowledge provided by the teacher (Larsen-Freeman, 2011). The teachers believed that repetition made the students form a habit and remember words and structures. Together with this belief, the fact that the teachers followed the textbooks reflects their lack of understanding of the principles of communicative language teaching, of meaningful interaction in real-life situations indicated in the curriculum, and of the ideas that young learners should be putting language into use rather than just drilling and meaningless communication. 
The teachers understood they played a role in motivating young learners, but they were unaware of the principles of effective group work and the importance of meaningful, communicative language use that are important for language acquisition. The teachers seemed to equate enjoyment of activities with learning.

The teachers were unaware that they were putting their students through a passive learning process in which they were the recipients of knowledge, instead of being the constructors. The teachers believed that putting students into pairs or groups (see Section 6.3) could give students opportunities for communication and that language learning took place as soon as students did pair work activities. However, they did not recognize that their lessons had little evidence of effective group work. As analysed, their group work lacked opportunities to initiate language use and cooperation. Even the production stage did not allow the students to use their initiative. In the teachers' professional meetings, although they could share some techniques of teaching vocabulary or games, they did not enjoy opportunities to work together on the issues of instructional planning and to learn from one another through mentoring, peer observation and coaching. Professional meetings were aimed at reinforcing the textbook methodology. What the teachers were doing in the lessons was to put the textbook designers' methodology into practice.

Unlike findings by Grassick (2016) and Bui (2019), the teachers had no negative comments on the PPP lessons and they knew almost nothing about the curriculum and communicative approach. As presented in Section 6.4, they viewed the textbook as their curriculum and most associated communicative language teaching with teaching speaking. The reason for the lack of criticism of the normal lessons might be for professional and security reasons. First, they were not well trained in TEYL; therefore, they seemed not to be confident enough to give any criticism. Second, they did not want to criticize the method instructed by the authorities, DOET, BOET and the textbook designers. However, the common opinion from the teachers was that most students did not speak English well, so when they took part in the end-of-term speaking tests, they gave them the questions in advance and answers were by heart. It can be concluded that although the teachers did not have any negative comments, they were not content with the methods they were using in their normal classes.

None of the teachers were aware of any more effective ways to enhance communicative language use in the classroom. The teachers' opinions on improving their lessons only focused on the techniques used in each stage of the PPP lessons. For example, the comparison group teacher expressed regret for not teaching the structural patterns prior to the dialogue as 
she felt it would be better for her students' memorization of the dialogue. In addition to the teachers' lack of awareness of CLT, their lack of knowledge about stories and storytelling discussed in Chapter 6 also indicated a lack of knowledge of CLT and teaching and learning of young learners.

In brief, the teachers' cognition was affected by many factors mainly stemming from their teaching contexts. As discussed in the literature review, the psychological construct of teaching is primarily established and shaped by its relationship with schooling, professional coursework, contextual factors, and classroom practice. As analysed, the teachers held a preconceived notion about teaching young learners in terms of learning discrete language skills. This perception was rooted primarily in a range of settings from their school education, professional courses and teaching contexts. They were not trained to teach young learners and CLT. The professional development programmes did not provide qualified continuing professional development that could upgrade teacher pedagogic knowledge and skills (Phan, 2017) but only imposed the predesigned method. They were obliged to cover the textbooks and use the predetermined method of teaching PPP lessons. In this study, the main factor that helped shape the teachers' cognition was the professional meetings, one of the contextual factors, where instructions from authorities played a significant role. As a result, PPP has become an instructional routine, which might be difficult to change.

\section{Summary}

In summary, mechanical practice played a dominant role in the classroom, and stories and storytelling were marginal. Teaching young learners discrete language items is routine. The teaching context seemed to prevent the teachers' professional development. This situation will continue unless immediate action is taken concerning classroom practices. Below I discuss the results of the storytelling innovation taken to address the aforementioned issues in TEYL in Vietnam.

\subsection{Phase 2}

Phase 2 of the study investigated the effects of the storytelling innovation and teachers' and students' perceptions of it. Drawing on Chapter 7, this section discusses five sub-topics: proficiency development, features of the storytelling innovation that contribute to language learning, student engagement, features of interactions in the storytelling innovation and teacher cognition. 


\subsubsection{Proficiency development}

In the present study, the results of English oral language development measured by language units indicated that the storytelling innovation with its focus on meaning construction led to a difference in oral language development between the innovation and the typical instruction groups. This was demonstrated by a statistically significant effect on the production of oral language on the measure of the language units of story retellings produced by the group who received the storytelling innovation, when compared to their counterparts who received normal instruction. The results were in presented in Section 7.1 and Tables 8.1, 8.2 and 8.3 below summarize the findings.

Table 8.1 shows that both the comparison and the intervention groups produced more English tokens and types, but in the post-test, the comparison group idea units did not improve while the intervention group produced more idea units in their stories.

Table 8.1 Medians of English tokens, types and idea units

\begin{tabular}{|l|l|l|l|l|l|l|l|l|l|}
\hline Groups & No. & \multicolumn{2}{|c|}{ English tokens } & \multicolumn{2}{|c|}{ English types } & \multicolumn{2}{|c|}{$\begin{array}{l}\text { Idea units } \\
\text { (in only English) }\end{array}$} & \multicolumn{2}{|c|}{$\begin{array}{l}\text { Idea units } \\
\text { (in English and } \\
\text { Vietnamese) }\end{array}$} \\
\cline { 3 - 10 } & & $\begin{array}{l}\text { Pre- } \\
\text { test }\end{array}$ & $\begin{array}{l}\text { Post- } \\
\text { test }\end{array}$ & $\begin{array}{l}\text { Pre- } \\
\text { test }\end{array}$ & $\begin{array}{l}\text { Post- } \\
\text { test }\end{array}$ & $\begin{array}{l}\text { Pre- } \\
\text { test }\end{array}$ & $\begin{array}{l}\text { Post- } \\
\text { test }\end{array}$ & $\begin{array}{l}\text { Pre- } \\
\text { test }\end{array}$ & $\begin{array}{l}\text { Post- } \\
\text { test }\end{array}$ \\
\hline Intervention & 30 & 51 & 154 & 20 & 43 & 3 & 10.5 & 3.5 & 4 \\
\hline Comparison & 25 & 44 & 53 & 11 & 21 & 1 & 1 & 3 & 3 \\
\hline
\end{tabular}

Non-parametric t-test Wilcoxon signed-rank tests in Table 8.2 showed that there was an improvement within both the comparison group and the intervention group. The comparison group's improvement of English tokens and types was statistically significant ( $\mathrm{p}=0.023$ and $\mathrm{p}=0.003$ respectively), but their idea units in English $(\mathrm{p}=0.33)$ and idea units in English and Vietnamese $(\mathrm{p}=0.183)$ were not significantly improved. Within the intervention group, the results of Wilcoxon signed-rank tests for English tokens, types, idea units in English and idea units in English and Vietnamese were statistically significant (all $\mathrm{p}<0.05$ ). 
Table 8.2 Summary of results of Wilcoxon signed-rank tests on language units

\section{Language units $\quad$ Results of Wilcoxon signed rank tests}

Intervention group

English tokens

English types

Idea units in only English

Idea units in English and in Vietnamese

\section{Comparison group}

$$
\begin{array}{ll}
\mathrm{T}=445.00, \mathrm{z}=4.371, \mathrm{p}=0.000 & \mathrm{~T}=229.50, \mathrm{z}=2.272, \mathrm{p}=0.023 \\
\mathrm{~T}=381, \mathrm{z}=4.054, \mathrm{p}=0.000 & \mathrm{~T}=254, \mathrm{z}=2.977, \mathrm{p}=0.003, \\
\mathrm{~T}=323, \mathrm{z}=3.749, \mathrm{p}=0.000 & \mathrm{~T}=97, \mathrm{z}=0.974, \mathrm{p}=0.33 \\
\mathrm{~T}=189.50, \mathrm{z}=2.047, \mathrm{p}=0.041 & \mathrm{~T}=116, \mathrm{z}=1.333, \mathrm{p}=0.183
\end{array}
$$

Table 8.3 reveals that there was a significant difference in story retelling measurements between the comparison group and the intervention group. The results of Mann-Whitney U tests on language units show that the improvement of the intervention group's English proficiency was statistically different from that of the comparison group, as all p-values were below 0.05 . This shows that the innovation group improved much more than the other group and the improvement was statistically significant.

Table 8.3 Summary of results of Mann-Whitney U tests on language units

\begin{tabular}{ll} 
Language units & Results of Mann-Whitney U tests \\
\hline English tokens & $\mathrm{U}=189, \mathrm{z}=3.144, \mathrm{p}=0.002$ \\
English types & $\mathrm{U}=254.50, \mathrm{z}=32.039, \mathrm{p}=0.041$ \\
Idea units in only English & $\mathrm{U}=207, \mathrm{z}=2.848, \mathrm{p}=0.004$ \\
$\begin{array}{l}\text { Idea units in English and in } \\
\text { Vietnamese }\end{array}$ & $\mathrm{U}=189, \mathrm{z}=3.144, \mathrm{p}=0.002$
\end{tabular}

The results indicate that four months of practising storytelling with meaningful interaction in the form of collaborative dialogues does affect the lexical richness and the idea units in the students' language production. 


\subsubsection{Features of storytelling innovation}

The storytelling innovation had three outstanding features that contribute to young learners' language learning. They were (1) integrated language skills lessons, (2) imagination and (3) group work.

\subsubsection{An integrated skills structure}

The literature reviewed in Chapter 3 addresses the importance of integrated skill learning which helps children use multiple-senses and facilitates young learners' learning. The storytelling innovation has an integrated skill structure in which language skills are closely linked and every activity is structured around the story. Learning happens multi-modally.

The first mode is listening. Through the storytelling innovation, the amount of verbal input to which the students were exposed was considerable, through both explicit and implicit listening. In normal lessons, the students listened to the texts once or twice from the tapes or from the teacher for noticing the pronunciation or finding the structures that needed to be learned in the lesson. Other opportunities for listening were just from listening to structural patterns in the forms of questions and answers in substitution drills and all of them were devoid of meaningful contexts. In the storytelling innovation, explicitly listening to the story from the teacher was meaningful and engaging. The students listened and talked about the main idea of the lesson story. The first element of engagement in listening was from the nonverbal language employed by the teacher in telling the story. Not only were pictures fully exploited (as the teacher pointed to the characters and details in the pictures), but also the teacher's gestures and pitch of voice made the language input more comprehensible. In this way, the story was dramatized by the teacher. They listened to the story as if they were watching a drama. The second element of engagement in listening related to the tasks they did after listening to the story. They became more willing to listen to the story because they knew they would talk about the main ideas of the story and, based on that story, they would reconstruct and create their group story. The extent to which learners understand what they have to do affects the quality of their learning (Swain, 2000). These were the reasons the learners commonly expressed their preference for listening to the teacher's telling of the story. The teacher noticed the students' heightened concentration when listening to the story told by the teacher.

In addition to explicit listening, the students had many opportunities for implicit listening. These opportunities were from the students' constructing, creating and sharing stories. They had to listen to their group members to understand, respond properly and assist their peers. 
Listening to the stories from the teachers and from their friends was significant for learning in terms of the amount of input, its value, relevance and interest to the learners (Breen, 2001). This reflects one of the four learning principles suggested by Nation (2007) that learning happens through meaning-focused input, where learners' attention is primarily on the content (meaning) of the story, not on the form.

The second learning mode is writing. Writing in the storytelling innovation was meaningful because of two features: reconstructing the story and group writing. Reconstructing the story gave the students a good reason to write and a feeling of challenge. Group writing created a feeling of support for the challenging work; as one student said: "Writing in a group is easy because you can get to help each other" (student S2 in Group 7). Writing is a way to improve lexical and structural knowledge, coming from a need that can be defined both as a requirement imposed by others and an individual desire (Laufer \& Hulstijn, 2001).

In contrast with writing in normal lessons, which consisted of copying new words and structural patterns on the board into their notebook, writing in storytelling was valuable for the students. One benefit of group writing is that writing helps students learn new words and to spell better. One of the students mentioned that "Writing helped me learn words" (student S2 Group 5). In their writing, words (both old and new ones) were sometimes spelled and used incorrectly. Writing allowed students to make connections between words and display knowledge that goes beyond form and meaning (Szpotowicz, 2009). Another benefit of group writing is that the students could see their products. This means that it was easier for them to compare what they had just produced with what was expected. When the learners wrote, their prior knowledge was activated and they tried to use the new words, together with assistance from friends. By doing so, their interlanguage development was displayed, and the learners became aware of a sense of progress. Together with speaking, writing in the storytelling innovation resonates with meaning-focused output (Macalister \& Nation, 2020), where the learners' attention is primarily focused on building utterances of the story text (meaning), not on the form.

The third learning mode is reading and comparing. Reading and comparing gave the students a chance to notice the language. Noticing language features when reading a meaningful story was more productive than learning these features out of context. In normal lessons, reading was mostly mechanical: repeating and pair reading. In the storytelling innovation, reading was done silently and was not for comprehension but for comparison and language focus. Although they spoke mainly in their native language, the students' cognitive efforts when 
comparing their stories are identified, as found in Section 7.2. While reading and comparing, the students were highly likely to consciously and unconsciously pay attention to the form of the language; that is, they were forced into some kind of noticing, which is a vital factor in language acquisition (Schmidt, 2012). This finding is also consistent with one of the perspectives in Macalister and Nation (2020) that deliberate attention to language features enhances learning.

The fourth learning mode is speaking. In the normal lessons, the learners did not have many opportunities to speak English together. In some cases, several students used English only when answering the teacher's questions or when they spoke English with structural patterns provided. In the storytelling lessons, however, they had at least four opportunities to speak with their peers: talking about the main ideas of the story in pairs, reconstructing the story in groups, creating the story in groups and sharing the story with other groups. Speaking pushes learners to process language deeply, creating linguistic forms and meaning to meet the communicative goals. In so doing, they encounter a gap in their linguistics knowledge (Swain, 2000). The students greatly appreciated the chance to speak as mentioned in Section 7.3. Through using language, the students acquired new lexical and syntactical knowledge and also greater accuracy in using and consolidating existing knowledge.

Sharing the group's story gave the students a chance to show off their products and a chance to use what they had learned. Because the students went through a process of practice from reconstructing to creating the story, all language items involved were already familiar to them. Therefore, it was a chance for them to improve their fluency. The sharing aimed to present their product, focusing on communicating the content of their created story. Ending the lesson in this way increased the retention of the key points of the lesson. This activity helps increase students' confidence and strengthen the connection in the brain that helps them learn. Sharing created stories is a good practice for low-proficiency learners (Nation \& Newton, 2009).

The structure of the storytelling innovation reflects a balanced view of instructed language learning principles that promotes meaning-focused input and output, language-focused learning and fluency development through the use of storytelling activities in multi-modalities (Nation, 2007). All the learning skills interweave in positive ways, encouraging young learners to learn in different modalities, which reflects what language experts believe to be important for teaching young learners. 


\subsubsection{Imagination and creativity}

Imagination and creativity are the outstanding features of the storytelling innovation. The literature review showed that imagination and creativity are powerful learning tools in young learners' learning (see Section 3.2). Storytelling makes use of the characters and content of the story and develops learners' creative competence.

In the storytelling lessons in this study, imagination was linked with characters and the story. First, the innovation employed a kind of dramatized-storytelling in which students were asked to perform their roles orally, with actions in an imaginary situation (Rew \& Moon, 2013). In this kind of storytelling, tension is reduced and learners are encouraged to act an imaginary role and this benefits language development when a learner engages in another persona (Haught \& McCafferty, 2008). Their willingness to engage with this persona has positive implications for their language learning. The students were happily involved in their characters, talking on behalf of the characters in all activities; as one of the students in Group 7 said: "I could be one of the characters in the story". Second, the story was a good reason to link all the activities and contextualized the students' language practice. Reconstructing and creating stories in the form of dramatizing storytelling became meaningful reasons for real cooperation in groups. The students tried to make the stories more interesting when creating their group story.

The innovation offered the students opportunities to use their daily creativity in learning English. By changing the content words, adding an event or creating the ending of the story, the students' stories were creative enough for the young learners. In other words, they made the stories original or meaningful in their own way (Beghetto \& Kaufman, 2007). They could recognize a change in the content, characters, ending or an event as being different from the textbook and other groups. The feeling of being creative and going beyond the textbook was evident as the students happily reported that they were allowed to create stories and tell stories.

Storytelling gave them opportunities to foster and develop their creative thinking competencies. This development was evident and observed on the basis of three core areas for primary school learners in the Cambridge University Press Framework for creative thinking (Cambridge University Press, 2019). First, they participated in creative activities. One example is that they acted out the roles of various characters in stories, engaging activities with fantasy. Second, they created new content from their own ideas or other resources. They used strategies such as changing the content words, changing the characters names, or making 
up the end of the story (see Section 7.2). Third, sharing their created stories gave them opportunities to use newly created content to satisfy their communication needs.

\subsubsection{Genuine pair and group work}

Pair and group work were used in five main activities of the storytelling lessons and worked effectively due to self-initiated language use, real cooperation, equality, freedom, friendship and the teacher's own techniques. These factors will be discussed below.

The students had opportunities for self-initiated language use (Moon, 2005b), which was almost absent from normal lessons. Chances for self-initiated language use occurred when reconstructing the story in speaking, writing and in creating stories. The students used what they knew and had learned in class to communicate; that is, they reconstructed and created utterances for their group stories. Self-initiated language use is one of the factors that involves learners (Brown, 2001), stimulating the students to make efforts, and to take an active role in the classroom.

In groups, the students had to genuinely work together for the completion of the task (Brown 2001). Cooperation provides a kind of experiential learning, which is said to be valuable for young learners (Enever, 2016; Nunan, 2011). Their cooperation was reflected via coconstruction and peer assistance, as analysed in Section 7.2. Cooperation benefited both the more and the less proficient students. The more proficient students were likely to consult and support the less proficient students and the less proficient could participate equally (Crandall, 1999) because each learner had a role. The more proficient tried to help the less proficient so that in the end they had a story to share with the teacher and other students. The more able students also benefited by consolidating and displaying their knowledge while giving their support (Wells, 1999). Most of the groups reported that they enjoyed shared mutuality as weak and strong students felt included in mixed-ability group work. Less proficient students received help and became confident in speaking. More proficient students were not hindered from gaining the maximum benefits from the activities by providing help as a way to reinforce their knowledge. As mentioned in the literature review, young learners can be easily distracted if their interest wanes, with more proficient learners often persevering the least because they expect to understand immediately and do the task quickly. In the storytelling activities, they were not distracted as they were happily busy helping friends in their groups.

Even though more proficient and active learners offered more help than the less proficient, group work in storytelling provided the students with equal opportunities to talk in all activities. Equality is one of the key determiners in the effectiveness of group cooperation 
(Klingner \& Vaughn, 2000). When they noticed their group member could not complete an utterance, they immediately provided the rest of the sentence (see Section 8.2.4 for more information), and the less proficient students repeated the utterance. They had equal turns in the story. In the interviews with the students, none of them mentioned others being dominant. Being involved equally seemed to stimulate the learners in this study to try hard, taking an active rather than a passive role.

Another factor that leads to effective cooperation was the freedom the student had in their group work activities (Sullivan, 2000). Although the students were not allowed to choose their partners due to large classes and space constraints, they had other choices. First, they could choose their roles in practising and sharing the story; and second, they could choose the way they created the story and their roles in the story as pointed out in Section 7.2. These choices gave them freedom from the teacher's control, at least from the control of what was to be said. The power of the teacher within the group was diminished or neutralized.

One more factor that led to effective group work was the exploitation of the students' friendships. The familiarity between the students, as they had stayed with the same peer group through the primary school period since Grade 1, was taken advantage of to create a positive socio-affective context to help them overcome their psychological barriers. Their friendship created a sense of security, reducing self-consciousness in making mistakes. The homogeneous nature of the groups fostered the kind of warm and supportive atmosphere considered to be a pre-requisite to effective learning (Moon, 2005a; Van Lier, 2005). The group work and the amount of work the learners did within groups created a sense of community where the learners co-operated and supported each other in accomplishing the work. They were caring about each other's work. Although there was one student who refused to work with others, most of the students enjoyed the social climate in the classroom, which is considered to be created by the learners themselves (Allwright, 2003; Philp \& Duchesne, 2008). The students valued opportunities to work with their friends, helping them overcome their lack of self-confidence, shyness and fear of making mistakes (see Section 7.3). Group work in meaningful activities in the large class was successfully conducted when taking advantage of the students' familiarity and friendly relationships.

The success of group work in storytelling was in part due to the teacher's techniques in group work management. The first technique is time management. Although the teacher set the time for each activity, she observed the groups well, giving enough time for all the groups to finish the assigned activities. This also related to the teacher's implementation decision, giving more 
help to the slower groups than others. Some groups who finished faster were asked to change roles or create a different story for their groups. The second technique the teacher used is grouping. Due to the large class with unmovable tables in a small classroom space, the teacher conducted the groupings before the lesson started. A limitation of this kind of grouping is that learners worked with the same friends all the time, but it is beneficial as they worked to improve the group's image. The third technique is the way she dealt with learners' characteristics and proficiency as some learners appeared to be more active and fluent than others. Putting the students in a mixed ability group (based on the teacher's own rating) and giving roles to each member ensured that no one took more frequent turns, and that they helped their group members to finish their turns.

The friendship among the students and the teacher's techniques were beneficial for the students. Prior to the implementation of storytelling, the learners in the current study did work in groups, but they had little cooperation and their kinds of group work did not need any social skills. In the storytelling innovation, their output had many mistakes and they needed support from one another. In contrast with the consensus in the research literature, that young learners require training in social skills (Dornyei, 2001), the students in the current study got used to group work quickly and did not need any special training. Data from classroom observation and the teacher's opinion (see Sections 8.2 and 8.3) showed that after three lessons, they overcame their fear of making mistakes and successfully supported one another. In the interviews, the students valued group work as fun activities and chances for them to speak. In the teacher's judgment, some less proficient students made progress because they spoke more in storytelling lessons. The general willingness to speak English in the tasks improved, perhaps as the learners become more comfortable in using the language and in knowing what to do (Pinter, 2005).

In summary, the six factors discussed above - self-initiated language use, real cooperation, equality, freedom, friendship and the teacher's own techniques - positively affected the quality of group work in the storytelling innovation. Stimulating students' imagination and using group work resulted in a positive impact on student engagement (Section 7.2). Student engagement will be addressed in the next section.

\subsubsection{Student engagement}

The literature on young language learners emphasizes the connection between learner engagement and learning. The observational analysis indicated that student engagement in Phase 2 was high in terms of cognition, emotion and behaviours. 
Regarding cognitive engagement, the extracts in 7.2 show how the students engaged in activities: reconstructing, comparing and creating stories. In each activity, the students made mental effort to achieve the learning outcomes. For example, when they were producing utterances in their stories, the students noticed gaps in their own and friends' linguistic knowledge. These mental activities were significant for learning as "the learner's engagement in seeking situational meaning is a pre-requisite before attention to linguistic form can be expected to be effective" (Dornyei, 2009, p. 281).

In terms of emotional engagement, the findings show students' strong positive interdependence. Their mutuality and reciprocity were evident, as one could not construct the story unless the other group members finished their work. The findings also revealed that the students had a feeling of high group accountability. They accomplished their work and did not give up when the work became challenging; they helped their friends and asked for help when meeting difficulties. Other kinds of feelings were identified, including a feeling of being valued and supported (through peer assistance) and a feeling of competence (through accomplishing work together).

Regarding behavioural engagement, the results indicate that the students were attracted to their work, through the noise in English and Vietnamese for discussion, suggestions or error correction. The students' persistence in their work was clear: they tried to practise speaking from a rough version of the reconstructed story to a smoother version of the created story. Persistence can have a positive impact on learning (Dornyei, 2001). After each activity, the students not only felt happy, but they were proud of their outcome as well.

The three dimensions of engagement interplay, and each dimension mediates the other (Philp $\&$ Duchesne, 2016). In some situations, one dimension supports engagement in other dimensions. This is the case in the intervention group. However, in the comparison group, the engagement components inhibited each other.

In the comparison group, low cognitive engagement in group work weakened emotional and behavioural engagement. Asking students to read the story dialogues or completed situational drills did not require them to think deeply. As a result, the students were eager to finish their work and ignored mistakes. The focus on the procedural aspects of the task (behavioural engagement) inhibited cognitive and emotional involvement, making the students approach their learning in a superficial manner. They showed a way of learning in which learners passively comply to fit the expectations of traditional classroom norms. 
In contrast, the power of cognitive engagement in the intervention group awakened emotional and behavioural engagement. Having the students reconstruct and create a story required them to think deeply. Consequently, students were intent on their stories and kept working until the story was created and told. The students' interest was caught by a challenging activity which was to create their own group story. The challenge made them more cooperative in their work and they supported each other. Their friends' support increased their interest and concentration on working out their group story. The focus on constructing a story (cognitive engagement) strengthened emotional and behavioural involvement, making the students approach their learning in a profound manner. They showed a way of learning where learners were active and creative in learning, which meets the requirement of the learners' role as specified in the curriculum (see Section 2.3).

Higher student engagement may have been a result of intrinsic motivation, created from the link between learning and fun (see Section 7.3). In Phase 1, "vui” (fun) came from games and competition, which could stimulate extrinsic motivation (see Section 8.1). "Vui" Phase 2 was from storytelling in constructing and creating stories and from their opinions about group work: "Working in a group is fun". According to Carreira (2011), "enjoyment is a positive predictor of intrinsic motivation for EFL and interest in foreign countries" (p. 90). In this current study, enjoyment appeared to have come from the whole process of learning in each lesson. The extent to which the learners were motivated to engage with an activity depended on a range of factors, many linked to the nature of tasks, particularly in real cooperation in group work and the learners' positive self-image. These two factors will be discussed in turn in the following paragraphs.

The nature of storytelling activities created four sources of intrinsic motivation: challenge, fantasy, curiosity and control (Schunk et al., 2014). First, the students could feel the challenge from the activities they joined. It is evident in the students' opinions that reconstructing and creating the stories were more challenging than repeating the story dialogues. Second, as discussed in 8.2.2 about imagination, the students employed fantasy, putting themselves in the roles of the characters in the stories. Third, the students were curious about their own group stories and the other groups' stories. They would wonder what their group story and the other groups were like. Fourth, as discussed in 8.2.2 about group work, the students could control the speed of their practice and the content of their groups' stories. Challenge, fantasy, curiosity, and control emerged from the activities creating enjoyment in their learning. 
Storytelling activities helped create a positive self-image for the students. Emotional engagement and behavioural engagement provided evidence that they were proud of working together and of their products. The positive image came from a feeling of success in using English. In the storytelling co-construction (see Section 8.2.4), the less proficient learners did not feel inferior because of their proficiency. The feeling of being valued and supported helped to create a positive relationship for the students. The view young learners have of themselves impacts on their language learning and is influenced by the perception of their peers (Alanen, 2003; Moon, 2005a) and a positive self-image is linked with motivation (Dornyei, 2001).

In brief, student engagement was much improved in Phase 2 of the study for two main reasons. First, the students were intrinsically motivated by the nature of the activities, especially by real cooperation and the positive self-images they tried to create for themselves and for the group. Second, the students were highly engaged due to the successful interactions they created in each activity. The next section will look at the students' interaction in the storytelling innovation.

\subsubsection{Characteristics of interactions}

In this section, I discuss co-construction and using the structure of the original story. These two features prominent in the students' interactions in the storytelling activities are discussed below.

\section{Co-construction}

In classroom interactions, co-construction in the storytelling innovation was in the form of collaborative dialogue. Collaborative dialogue benefits learners because it is "a knowledgebuilding dialogue, ... in which language use and language learning can co-occur. It is language use mediating language learning. It is a cognitive activity and a social activity" (Swain, 2000, p. 97). Collaborative dialogue happened in learner-learner interactions as they built the story dialogue utterances together. It occurred on two levels. The first was the discourse level. Each student had a role and together they co-constructed and created the story scripts. Co-construction allows learners "to participate in forming utterances that they cannot complete individually" (Foster \& Ohta, 2005, p. 420). Therefore, classroom discourse is jointly produced as participants act on each other (Mehan, 1979). The second was sentence level. Co-construction can be identified "when a learner struggled to finish his or her utterance and another learner supplied the rest of the sentence" (Sato, 2017, p. 262). These two kinds of co-construction could be found in Extract 4 in Section 7.2. 
Co-construction created a supported friendship among the students. It involved assistance such as peer-and self-correction, L1 use and recasts, as mentioned in the discussion of cooperation in group work in Section 8.2.1. What is significant is the feeling and relationship they had during the process of co-construction. In the interviews, some students mentioned they felt happy to get help and some said they were happy to give help. The feeling of being supported and valued was created in co-construction. They did not have a perception of dominant or submissive roles, although there were students who gave more help than others.

Co-construction helped the students overcome their linguistic barriers including the lack of vocabulary, pronunciation mistakes, and grammatical mistakes. In co-construction, the students paid attention to the form of the language. They gave peer corrections like recast, providing English words and giving suggestions in Vietnamese (see 7.2). They explicitly focused on language forms in comparing their stories. In other words, they were involved in noticing which is a vital factor in language learning (Schmidt, 2012). The co-construction emerging in interactions was evident in the students' language learning as it led to an increase in language knowledge or skills (Crabbe, 2003). This finding is consistent with the sociocultural perspective that learners are potential communicative achievers; they can communicate effectively in spite of their imperfect command of grammatical structures and lexis.

Co-construction in storytelling reflects the nature of young learners' interactions. Students are sensitive to the difficulties their partners are experiencing and immediately give assistance. The students who receive assistance from peers monitored their own speech and incorporated it into their own utterances by self-correcting. Therefore, the students in the current study scarcely interrupted the flow of the interaction in order to verify what their conversation was about or to ask for explicit assistance; that is, the students did not use negotiation of meaning, one of the popular techniques students used in interaction (Long, 1983, 1996; Pica \& Doughty, 1985) and in recent studies on EFL young learners' interactions (Azkarai \& Imaz Agirre, 2016; Garcia Mayo \& Imaz Agirre, 2016), including Vietnam (Bui, 2019).

Negotiation of meaning is valuable due to its "productive connection of input, internal learner capacity, selective attention, and output"; however, negotiation of meaning can be "face threatening” (Foster \& Ohta, 2005, p. 407). Interaction is a social and language learning activity. Its social dimension cannot be disregarded. Before using negotiation techniques, comprehension checks, confirmation checks and clarification requests, learners must acknowledge not understanding or being understood. This would make them appear frustrated 
and embarrassed and they may avoid interrupting to request clarification or comprehension. Face protection is a cultural feature in Vietnam (see Section 2.4). The face threatening nature of negotiation of meaning explains why none could be detected in the current study. This is evidence that a storytelling activity is designed as "a social event to which learners bring their instinct to be cooperative and helpful and to express a natural interest in what their interlocutors are saying" (Foster \& Ohta, 2005, p. 425).

\section{Using the structure of the original story}

Previous studies of young learners creating discourse show that low proficiency learners (Seedhouse, 1999; Swan, 2005) and young learners (Bui, 2019) cannot produce high quality discourses. They use fixed turn-taking patterns - asking and answering each other using the target structural patterns - which are quite similar to substitution drills and communicative drills with little personalization; only a few highly-proficient students use a wider variety of language. In addition, most of their interactions are limited to words or phrases. These limitations have three main reasons: (1) the students are familiar with the PPP approach in which the occurrence of fixed turn-taking patterns prevails; (2) they are also familiar with learning the target vocabulary and structures before using them in communication, so they have difficulties communicating in English when the target vocabulary and structures are not explicitly pre-taught and repetitively practised; and (3) young foreign language learners have limited cognitive and linguistics resources (Butler \& Zeng, 2014). Using fixed turn patterns and producing poor quality discourse limits language production and carries limited language learning value (Seedhouse, 1999; Swan, 2005).

In the current study, a feature of interaction in storytelling was that the students followed the structures of the original story in each lesson. This could not only help minimize the limitations identified in prior studies and discussed above but facilitated learning as well. This brought three main benefits for the students.

First, creating the story based on the original story helped students access high quality discursive discourse in the form of co-construction, although the structures were similar to the original stories. They could create their own stories by using many strategies like changing the content words, the names of the characters and adding an ending to the story. Their cooperation in re-constructing the story and creating the story could result in high quality language-related episodes "where students reflect consciously on the language they are using" (Swain \& Lapkin, 2001, p. 53). 
Second, mixed proficiency students could interact confidently in a challenging but supporting environment. The students were free from the worry of creating their own stories from scratch. This resulted in a feeling of accomplishment as they could create their own story in a short period of time. Furthermore, using the structure of the original story, the tasks were not too challenging for low proficiency learners and the students were likely to have confidence from peer-assistance. Using the structure of the original story could deal with the caution against having too great a difference between the levels of ability: the less proficient cannot benefit from the knowledge of the more proficient and the latter may not trust the proficiency of the weaker counterparts (Watanabe \& Swain, 2007).

Third, creating a story using the structure of the original story was suitable for young learners. The five main activities in the innovation framework are all practical and language-based, which are intended to challenge the learners within their ZPD. The activities serve the purpose of developing the story and provides cohesion, enabling learners to see the connection between concepts, words and grammatical structures and to combine new with existing knowledge. This helped young learners activate their daily creativity in learning English and developing their creative thinking at the right stage of their learning journey (Section 8.2.2.2). The features of storytelling lessons and interaction reflect the keywords describing the CLT in the curriculum: cooperative, interactive, meaningful and learner-centred. The adaptation of the lessons, changing from mainly language-focused learning to meaningful learning, made the lessons more engaging. Storytelling used group work to enhance communication. Interactions in group work resulted from construction and cooperation. Instead of emphasizing the significance of allowing learners to learn English for communication, in storytelling innovation lessons, language is picked up through such communication; that is, learners learned English by using it. Learning activities focus on learners producing texts in the form of speaking or writing after they interact with language in a text that is provided (Holliday, 1994). The students can help each other solve language problems. The students were active members in the learning process and were assigned roles and therefore constantly engaged in their learning, resulting in language learning as "learners [constructed] their own knowledge and meanings on the basis of personal experiences" (Firth \& Wagner, 2007, p. 806). The features of interaction in storytelling lessons help to remove the students' linguistic (in Section 8.2.2.3) and psychological barriers (see co-construction in Section 8.2.4), as well as barriers to student participation like limited opportunities to talk, uneven distribution of talking opportunities across the classroom and limited access to high-quality discursive resources in the form of peers. 


\subsubsection{Teacher cognition}

The interviews with the teacher indicated a change of perception on teaching and learning. The teacher perceived that the storytelling innovation matched the teaching context. These two main opinions are discussed below.

\subsubsection{Change of perception on teaching and learning}

The teacher's perception changed throughout the storytelling innovation. The results from Section 7.3 indicate that her positive feelings were gradually built up during the process of implementation. This is evident (1) in her initial perception of and reactions to the model lessons and her first three lessons, and (2) in her perception of and reactions to the whole storytelling innovation.

What she shared with me after the two model lessons and each of her first three lessons was that she, step by step, paid more attention to student engagement and student learning. The teacher valued the model lessons because they helped her recognize some key characteristics of her classes and some strong points of the storytelling lesson over her normal lesson. In her first lesson, the first time she told the story, she was surprised and happy that the students listened attentively to her story. However, the fact that she could not conduct a full storytelling lesson, and her perception that the students needed to learn vocabulary, explicitly showed that she was still affected by her old way of teaching. After the third lesson, she was more skilful in the storytelling lesson, and she recognized the positive effects of the storytelling lessons on her students' learning.

In the interview after the implementation of 22 storytelling lessons, the teacher expressed satisfaction, shifting from worry at the beginning when she thought the stories were not very different from the original lessons to happiness when she noticed how the students responded to the innovative teaching and learning.

The intervention group teacher's expressions were more inclined to learning rather than teaching. Most of her talks started with what the student could do, such as "The students worked well in groups" or "they paid attention to the pictures when I pointed to it" or "This review story is longer than other stories, they paid more attention". In contrast, in Phase 1 of the current study, most teachers started their talk with what the teacher could do; for example, one of the teachers said: "In this activity, I teach new words first. In the second activity, I teach structural patterns" (Participant T7). The teacher mentioned the quality of group work 
and student engagement. She recognized that the quality of activities attracted the students more effectively than child-friendly features including games and pictures.

\subsubsection{Matching to the teaching context}

The teacher's opinions suggest that storytelling may be appropriate to the teaching and learning situation. This will be discussed in terms of feasibility, relevance and acceptability (Kennedy, 1988).

The first aspect is the feasibility of storytelling. The interview findings (see Section 8.3) showed that her own experience from implementing 22 lessons had built her confidence in the feasibility of storytelling lessons. Regarding preparation time, it is feasible for busy teachers, as learning to tell stories did not take time and each lesson followed the same structure. Time seemed not to be a pressure on the teacher. This goes against the opinion that pedagogical change requires more time for classroom interaction and preparation which can burden teachers (Wang, 2011). The teacher's opinion was grounded in the fact that she could run the adaption of the stories and lessons from the fifth lesson by herself. With regard to teaching aids, the teachers used pictures that they used in their normal classes. The only extra work was to print handouts for the writing activities. The feasibility of storytelling is also shown by the students successfully finishing all the activities and expressing their desire to have more storytelling lessons.

The second aspect is the relevance of storytelling. The findings indicated that storytelling matches the teaching context in terms of content and activities. First, the content is relevant. The stories and the lessons are adapted from the textbook; therefore, they contain all the content, vocabulary and structures the teacher needs to cover in each lesson, which could relieve the teacher's worries about what to cover for the end-of-term tests. Second, the activities are relevant. Reconstructing and creating the story was all familiar with their daily life. Group work is not new to the teacher or the students. In Phase 1, there were work activities, but the students did not really cooperate and interact. In storytelling lessons, the students appreciated the group work the teacher offered them as they had opportunities to tell stories with friends and could feel the enjoyment of working in groups.

The third aspect is the acceptability of storytelling. According to Kennedy (1988), acceptability refers to how "the teachers match their teaching styles and philosophy against that presented by the innovation" (p. 337). In the current study, acceptability is reflected via the teacher's change of perception on teaching and learning from experiencing storytelling, as 
mentioned above. It is also supported by the teacher's perception of gains for both the students and the teacher and the feeling of ownership, all of which will be discussed below.

The teacher believed the storytelling innovation was beneficial for the students. Data from the teacher's own experience and the students' engagement supported her belief. She mentioned the quality of the students' participation. In the input activities, the students engaged in the teacher telling a story. In output activities, she noticed how hard the students tried to reconstruct, compare and create the stories and their feeling of excitement in these activities. Their active involvement meant that they were exposed a lot to practice which helped them boost their speaking and confidence. The teacher could also see that they tried to use their prior knowledge in combination with their new knowledge from the teacher's story and from their friends' assistance. She valued the role of learning through imagination and creativity and the importance of developing students' creativity.

For the teacher, it helped improve her English, as her pronunciation became better. The practice of telling stories gave her opportunities to use English. She pointed out that she gained more respect from the students because she provided them with lessons they liked. In her opinion, storytelling gave the students no mechanical repetitions, one of the factors that increased the students' preference. She also pointed out that this teaching method helped develop her professionalism and confidence. During the innovation, after each lesson, I met with the teacher to have a talk about the lesson, and she had many opportunities to reflect on her teaching and evaluate each activity in her lessons. She compared her normal lessons with what she did in the storytelling lessons. Working with me as a researcher, she also learned the benefit of cooperative instruction, which shaped and fostered her teaching and was beneficial for her own application and professional journey. She gradually formed a feeling of ownership of the process of professional improvement. Ownership is "the degree to which the participants feel that the innovation 'belongs' to them" and "a highly centralized administrative structure is unlikely to distribute ownership very far down from the hierarchy" (Kennedy, 1988, p.338). This is the case in Vietnam, where the educational system is highly centralized, as mentioned in Chapter 2. The division of responsibilities between the authorities and teachers results in a lack of ownership on the part of the teachers, who feel the materials have been imposed by the authorities. However, with the self-perception of gains for the students and the teacher in terms of the feasibility and the relevance of the innovation, this teacher has formed some ownership of the change. The teacher recognized that storytelling was more effective than her usual teaching method. Her desire for an official document to apply the storytelling method in normal classes (see Section 7.3.1) does not indicate that she 
did not have a feeling of responsibility for the change. In my opinion, this refers to personal threat (Wedell \& Grassick, 2020), because of the common belief that the normal classes' current methodology is the official method imposed by the authorities. What the teacher needed was permission for change in the future.

In brief, the intervention group teacher's change of perception on teaching and learning and her acceptance of the storytelling innovation was gradually built-up during the intervention teaching stage. As mentioned in the literature review, when considering the construction of language teacher cognition, there are several contributing factors that need to be taken into consideration: experience as learners, contextual factors, professional coursework, classroom practices and BAK (Borg, 2006; Macalister, 2010; Woods, 1996). In this study, the main factors that helped shape the intervention group teacher's cognition were the classroom instructional practice through a conscious reflection of her own experience and working with me, as a researcher, through the implementation process. It has been noted earlier (Section 3.5) that teacher cognition can be resistant to change and once teachers' beliefs are formed, and discrete beliefs become consolidated and incorporated into a system (Pajares, 1992). However, the findings provided a picture of the teacher's cognition changing after the implementation of the storytelling innovation.

\subsection{Chapter summary}

This chapter first discussed the results of Phase 1, teachers' instructional practice with stories and storytelling and their cognition. Through this discussion, it can be concluded that the teachers' lessons did not fully make use of the story and they followed the PPP lessons as designed by the textbook designers. Their cognition was strongly impacted by contextual factors, especially from professional group meetings. This chapter then focused on the results of Phase 2: the effects of the storytelling innovation on TEYL. Through storytelling, students' speaking proficiency significantly increased and student engagement was high in regard to cognition, emotion, and behaviours. This results from many factors. The first factor is linked to the characteristics of storytelling lessons, which were found to be appropriate to young learners' learning. They were integrated lessons that used students' imagination and group work. Group work was effective because of many factors including self-initiated language use, real cooperation, equality, freedom, friendship, and the teacher's own techniques. All these factors are claimed to be conducive to more effective language engagement and learning. The students' and teacher's perceptions of the storytelling innovation were positive. Classroom practices appear to have had an important impact on the intervention group 
teacher's cognition on teaching young learners. Drawing from the discussion, important implications for instructional practice and future research directions will be addressed in the following chapter. 


\section{CHAPTER 9 CONCLUSION}

This chapter begins with a summary of the key findings. Next, it highlights the contribution the study makes to TEYL and discusses the implications of the findings for teachers and educational managers. It, then, assesses the limitations of the research and goes on to look ahead to possible further areas of study.

\subsection{Summary of the findings}

The current study set out to explore the effects of a storytelling innovation in English language teaching and learning in Vietnamese primary schools. The exploration process was conducted through two interconnected phases.

\subsubsection{Phase 1}

Phase linvestigated the current state of using stories and storytelling in teaching and learning English in state primary schools in Vietnam. Data collection focused on four areas: teachers' and students' perceptions of stories and storytelling, learners' prior learning experience with stories and storytelling, teachers' implementation of storytelling in their classroom practice, and learners' engagement and participation with storytelling. Forty-two teachers from 18 primary schools and 21 Grade 5 classes voluntarily joined the study.

With regard to teachers' and students' perceptions of the stories in the textbooks, the participant teachers and students had different opinions from the textbook designers. Twothirds of the teachers and one-third of the students said the textbook texts were not stories. Storytelling was considered a simple activity or an exercise in which students retold the story and was rarely conducted in normal lessons.

In terms of learners' prior learning experience with stories and storytelling, the textbook story was learned separately from other activities in a lesson and stories in the textbook were treated as normal texts.

Regarding teachers' implementation of storytelling in their classroom practice, it was found that the teachers' lessons had stories, but their lessons did not have storytelling lessons. Their lessons focused on targeted vocabulary and structural patterns with a great deal of mechanical practice. The teachers, who used the Tieng Anh textbook, closely followed the PPP sequence specified in the textbook. Most class time involved the students in the presentation stage to introduce target vocabulary and structural patterns, and in the practice stage for mechanical drills of these target language items. The five last minutes of the lesson was for the production 
stage with little personalization. To make the lesson more engaging, besides a language game as a warm-up activity, the teachers added another language game to the presentation phase, particularly vocabulary games after presenting them, and added a competitive activity to the production stage. Some stories were conducted as a reading lesson and the main activities were answering the questions and some translation. The teachers who used the Family and Friends textbook had the whole period (35 minutes) for the presentation phase and for a reading lesson.

In most of the lessons, student engagement was low in terms of cognition, emotion and behaviours. Teaching and learning were strictly regulated and were heavily dependent on textbooks. A teaching approach focusing on discrete language features and mechanical practice has been found to be pedagogically ineffective for young learners' learning.

\subsubsection{Phase 2}

In Phase 2, a classroom-based intervention investigated the impact of the storytelling innovation on Grade 5 primary school students' speaking competence and learning engagement, and the teacher's and the students' perceptions. The storytelling innovation provides a structure to redesign the textbook lessons into storytelling lessons.

Two teachers who participated in Phase 1 joined Phase 2 of the study. One employed the innovation and the other taught normally. Two classes, 46 students in each class, participated in this phase. The implementation lasted for 16 weeks with 22 lessons (35 minutes each lesson). The intervention group teacher was provided with the storytelling lesson structure, and instructed in how to adapt the stories, and helped to rehearse the new lessons. By the fifth lesson, the experiential teacher was confidently adapting the story and could use the lesson structure for other lessons.

Quantitative and qualitative data were gathered in this phase. Quantitative data analysis aimed to answer the research question about the effects of the storytelling innovation on the students' speaking production. A pre-storytelling test (each student watched one of two chosen cartoons) was administered prior to the implementation. After the implementation, the storytelling test was re-administered to both classes to determine whether the implementation improved speaking proficiency. Qualitative data aimed to answer the research questions about the students' engagement and the teacher's and the students' perception of the innovation. Classroom observations were conducted in both classes to investigate what the students experienced in storytelling lessons and normal lessons. The group interviews were conducted with the students in the two classes to identify their perceptions of learning in two different 
learning conditions. Semi-structured interviews with the two teachers were also implemented to investigate their perceptions of the two different teaching approaches.

Quantitative findings from non-parametric t-tests showed that the storytelling innovation led to significant improvement of the students' speaking performance. Classroom observation results showed that the teacher successfully implemented all the storytelling lessons in her normally scheduled classes. She had some difficulties in the first four lessons, but she then skilfully managed her lessons on her own.

Their engagement was high in terms of cognition, emotion and behaviours. Instead of attending mechanical activities involving low-order thinking skills, the students joined in meaningful activities that activated their high-order thinking skills. They became more positively inter-dependent and responsible in group work than they used to be in their normal lessons. They understood that they were together for the outcomes of their groups. Unlike the students in Phase 1, the Phase 2 students' persistence in their work was clear as they tried to practise speaking from a rough version of the reconstructed story to a smoother version of their created stories. They felt happy after accomplishing their work because they were proud of their outcomes (their group stories), which was not found in Phase 1.

The interview results indicated that both teachers and students had positive perceptions of the storytelling lessons. The intervention group teacher acknowledged that the lessons resulted in better communicative production, more confidence and higher levels of student engagement compared with their PPP versions. The findings from the story retelling tests and students' perceptions of their experiences with the storytelling lessons provided evidence to support the teacher's perceptions. Most of the students reported positive experiences of working with the storytelling lessons. Through the storytelling process, the students employed scaffolding strategies to facilitate their performance such as self- and peer-correction and giving help in English and in L1.

The intervention group teacher's perceptions of student learning changed throughout the process and she gradually accepted storytelling as a more effective teaching approach than the traditional one in her normal class. The teacher's opinions suggest that the innovation suits the teaching and learning situation.

The study has provided empirical evidence to show that storytelling can be implemented in the Vietnamese EFL primary school contexts. The evidence comes from the improvement of the students' oral language production, the high engagement and the positive perspectives on this approach from the teacher and the students. The results, therefore, lead to the conclusion 
that storytelling can be successfully applied as long as it is adapted to the teaching context to let students experience communication that is more real than drilling and pattern practice.

\subsection{Contribution of the study}

This research contributes to TEYL in several areas.

The first contribution is that this study investigated natural settings, focusing on real classrooms, real teachers and real students using their textbooks. This research focused on storytelling in primary school classrooms where teachers have limited freedom in teaching, an under-researched educational sector. Although it was difficult to control what happened in the classroom, it provided insights into the nature of the implementation. The findings show that storytelling could be used effectively in such classrooms.

The second main contribution rests in the analysis of student engagement in the coconstruction of stories in the form of dialogues. This study contributes to the understanding of students' mental efforts, emotions and behaviour in classrooms. The low level of engagement with simple interactions without meaning construction compared unfavourably with the high level of engagement in meaningful and constructive interactions. In addition, peer support is evidence of learner engagement in the language learning process. The analysis of classroom interaction provides "a realistic idea of what actually happens in pedagogical talk" (Seedhouse \& Jenks, 2015, p. 3), contributing to the understanding of language learning engagement through interactions.

Third, the findings of the study suggest that it is important to examine interactions through both cognitive and sociocultural perspectives. The cognitive perspective enables understanding of how mental efforts happen during interactions. The sociocultural theoretical perspective provides insights into the ways learners support each other's learning through social interactions. Through the lens of these two perspectives, the process of primary school students performing storytelling in the classroom and how storytelling facilitates language learning is fully uncovered. The findings contribute to understanding of the variety of ELT classroom engagement in interactions (Seedhouse \& Jenks, 2015), and support the claim that ELT classroom interactions are better understood by exploring them from different perspectives (Foster \& Ohta, 2005).

Fourth, the results confirm the values of cooperative learning and viewing primary English education as a socio-cognitive phenomenon. Throughout the storytelling process, learners collaborate with peers to create their groups' outcome. Specifically, through collaborative 
dialogues in reconstructing and creating stories, supportive and friendly discourses were created. Cooperation can enhance "both academic and social skills" (Brown \& Thomson, 2000, p.11) and "maximize their [students'] own and each other's learning" (Johnson et al., 1994, p. 6). Cooperation and group work that provide experiential learning with peers through interactions is valuable for young learners (Enever, 2016). Storytelling activities become social events for children to work naturally to be cooperative and helpful.

\subsection{Implications}

\section{Implications for teachers}

The implications concern the adaption of the textbook stories, of the textbook lessons and the implementation of the storytelling lessons.

Making the textbook stories more meaningful had a positive impact on learning. The intervention group teacher successfully made a small change to the stories in the textbook by adding a few sentences to make clear the setting and the characters, which made the stories more acceptable and more interesting. It is suggested that the adapted stories should not be too long and to let students use their creativity to develop the content of stories.

The innovation provides a framework to empower the teacher and students to move away from mechanical practice to meaningful and enjoyable activities. The students expressed a high level of interest in the storytelling lessons. Their engagement was high, and their speaking performance was significantly improved. These findings indicate that the adapted lessons had positive effects on the students' learning, highlighting the importance of adopting and adapting already-published materials to "optimize language learning” (Macalister, 2016, p. 57).

The findings highlight the importance of group management in a large class and a variety of activities. In storytelling, the learners worked predominantly in small groups. They worked with the same group most of the time because the students could not be moved due to the crowded classroom and heavy desks. Teachers can make a group of mixed proficiency before starting the lessons by exchanging seats for some children. In addition, although the students could resolve many linguistic problems through peer support and assistance, they also initially need to understand the value of assisting each other so the students get used to group work quickly.

A new story in each lesson interests learners and the repetition of the activities improve the quality of the tasks. However, if the activities become over-familiar, students may lose their 
interest and the activities might lose the benefits they offer. Employing new tasks is necessary for increasing young learners' interests and attention span. For example, the teacher can ask the students to change a dialogue story into prose and one student of the group will tell the story or a group secretary will write their story on paper. Another suggested activity is that students are asked to work in a bigger group, and they are given different roles: one works as a story writer, one as a storyteller, one as a checker and one as character in the story. They retell the story together. After five minutes, they change roles. As young learners like showing off their group stories, a storytelling performance in front of the class can be employed as an alternative activity.

\section{Implications for education managers}

Education managers, especially at BOET level, need to have knowledge and experience of TEYL and encourage teachers to introduce innovations and provide necessary support for teachers. Therefore, providing on-going training concerning theoretical and pedagogical aspects of how young learners learn, storytelling and engagement is essential. PELT need opportunities to develop knowledge of teaching young learners and to practise the transition from normal teaching to storytelling.

The storytelling innovation could have a considerable impact on learning if it is supported by relevant school-based professional development. This could happen in inter-school meetings to involve teachers in the analysis of classroom interactions. When introducing storytelling, teachers may need guidance and support regarding how the textbook stories and lessons can be redesigned to reflect the principles of teaching young learners, how the redesigned lessons can be effectively implemented, how to manage group work and how to help learners' noticing new language items. These should be the topics of discussion in their professional meetings.

\section{Future challenges}

The findings of this research could be used to inform the development of contemporary and future teacher education and training to support more effective implementation of the curriculum and to ensure better learning outcomes for learners in the future. To integrate this innovation into the Vietnamese primary educational system, follow-up training courses for EFL teachers should be conducted. Especially for in-service training, it could be popularized via cooperating with BOET and DOET specialists in English education and introducing the storytelling innovation in professional learning groups. 


\subsection{Limitations and future research direction}

Although the current study has theoretical and pedagogical implications for TEYL in EFL contexts, it has certain limitations that warrant acknowledgment, and which provide areas for potential future research.

This study used intact classes, which reflects the true nature of the existing learning environment in the EFL primary school contexts. I did my best to minimize the impact of different variables through the data triangulation method (interview, observations, pre- and post-testing). However, some factors might affect the results of the study and supplementary education (học thêm) (Dang, 2011), such as extra classes or private tutoring, which not addressed in the research. Dang (2011) notes that "Some poor families in Vietnam are reported to either borrow money at high interest rates or even take mortgages on their property in order to send their children to private tutoring classes" (p. 2). This leaves a question about the effect of supplementary education on the students' speaking performances. Therefore, future research should take this into consideration.

The second phase involved two teachers and two classes participating in Phase 2. The small number limits generalization of the findings of the current study. Future research could consider incorporating more intervention groups and participating teachers in a wider range of schools.

The pre- and post- storytelling tests focused on tokens, types and idea units, but whether the students used the language items in stories they learned in each lesson in the speaking posttest was not mentioned. Whether the linguistic knowledge gained from interactions in the storytelling innovation is retained is another aspect for more study.

In addition, it would be of value if future studies explore the effectiveness of storytelling in developing students' reading, writing and listening.

It would be valuable to conduct studies with different levels of students. The intervention group teacher's belief in the expansion of the storytelling innovation, as mentioned in Section 7.3.1.2, suggests further research with Grade 3 and Grade 4 students. Many students in the intervention class expressed a preference to have more English lessons with storytelling when moving to secondary schools: "Lên cấp 2 mấy em muốn gặp lại cô, vì có cô tụi em mới được học với storytelling (We want to see you in secondary schools because we can learn with storytelling with your presence)." It is possible to adopt the innovation framework for some textbook lessons for secondary level learners. The teacher and students' opinions stimulate 
further research projects with storytelling. The projects should encourage the teachers to reflect on their current teaching practice, adopt the storytelling innovation, implement it in their lessons, reflect on their implementation process and finally compare students' interactions and engagement. Teachers' reflections on their research projects will offer an insightful understanding of the implementation of storytelling in classrooms, which in turn benefits education managers and policymakers.

\subsection{Concluding remarks}

The storytelling innovation, which was designed based on interaction theories, young learners' characteristics and the storytelling approach, could meet curriculum initiatives promoting communicative teaching and learning and the active roles of learners. The study has shown that the innovation framework is able to create communicative opportunities in the classroom. It can provide conditions in which young learners are comfortable speaking English in meaningful contexts and practising aspects of the language. The innovation uses group work to create a learning environment in which learners naturally cooperate and support each other. These features create high-level engagement, which the literature review places at the heart of the learning process. The research shows that conversational efforts facilitated language acquisition. Significantly, this study has proven that learning has actually emerged from the students' meaningful interactions in which they were able to put language to use for real communicative purposes, and, in doing so, to develop their communicative competence. The storytelling innovation could be used effectively to replace the common adult-oriented methodology as it is more compatible with young learners' cognitive and language development. It helps to change from traditional practice to communicative teaching. This study suggests that including the storytelling innovation in teaching can facilitate language engagement and development for young learners.

Personally, this research will be of great value to me when I resume my job as an EFL teacher and a teacher trainer. Through this research, I have gained a better understanding of the primary school teaching context in Vietnam and in the world, of teaching young learners, and of benefits and challenges in the implementation of storytelling in authentic classrooms. I strongly believe in the possibilities of incorporating the innovation into primary school classrooms in Vietnam and in primary school teachers' capability for change through appropriate training. I am eager to rise to future challenges to support more effective teaching of young learners in Vietnam. 


\section{References}

Ahlquist, S., \& Lugossy, R. (2015). Stories and storyline. Hong Kong: Candlin \& Mynard ePublishing.

Ajzen, I. (2005). Attitudes, personality, and behavior (2nd ed.). Poland: Open University Press.

Al-Qahtani, A. A. (2016). Do Saudi EFL teachers promote creativity in their classrooms? English Language Teaching, 9(4), 11-23.

Alanen, R. (2003). A sociocultural approach to young language learners' belief about language learning. In P. Kalaja \& A. M. F. Barcelos (Eds.), Beliefs about SLA: New research approaches (pp. 55-85). New York: Springer.

Alexander, R. J. (2001). Culture and pedagogy: International comparisons in primary education. Singapore: Blackwell Publishing.

Aljaafreh, A., \& Lantolf, J. P. (1994). Negative feedback as regulation and second language learning in the zone of proximal development. Modern Language, 78(4), 465-483.

Alkaaf, F., \& Al-Bulushi, A. (2017). Tell and write, the effect of storytelling strategy for developing story writing skills among grade seven learners. Open Journal of Modern Linguistics, 7(02), 119.

Allen, P., Bennett, K., \& Heritage, B. (2014). SPSS statistics version 22: A practical guide (3rd ed.). South Melbourne: Cengage Learning.

Allwright, D. (2003). Exploratory practice: Rethinking practitioner research in language teaching. Language Teaching Research, 7(2), 113-141.

Anderson, J. (2017). A potted history of PPP with the help of ELT Journal. ELT Journal, 71(2), 218-227.

Anderson, L. W., Krathwohl, D. R., Airasian, P. W., Cruikshank, K. A., Mayer, R. E., Pintrich, P. R., . . . Wittrock, M. C. (2001). A taxonomy for learning, teaching, and assessing: A revision of Bloom's taxonomy of educational objectives. White Plains, NY: Pearson Education.

Arnold, J., Dornyei, Z., \& Pugliese, C. (2015). The principled communicative approach: Seven criteria for success. London: Helbling Languages.

Azkarai, A., \& Garcia Mayo, M. D. P. (2017). Task repetition effects on L1 use in EFL child task-based interaction. Language Teaching Research, 21(4), 480-495.

Azkarai, A., \& Imaz Agirre, A. (2016). Negotiation of meaning strategies in child EFL mainstream and CLIL settings. TESOL Quarterly, 50(4), 844-870.

Baines, E., Blatchford, P., \& Webster, R. (2015). The challenges of implementing group work in primary school classrooms and including pupils with special educational needs. Education 3-13, 43(1), 15-29.

Baker, A. (2014). Exploring teachers' knowledge of second language pronunciation techniques: Teacher cognitions, observed classroom practices, and student perceptions. TESOL Quarterly, 48(1), 136-163.

Baralt, M., Gurzynski-Weiss, L., \& Kim, Y. (2016). Engagement with the language: How examining learners' affective and social engagement explains successful learnergenerated attention to form. In M. Sato \& S. Ballinger (Eds.), Peer interaction and 
second language learning: Pedagogical potential and research agenda (pp. 209-240). Amsterdam: John Benjamins Publishing.

Becker, C., \& Roos, J. (2016). An approach to creative speaking activities in the young learners' classroom. Education Inquiry, 7(1), 9-26.

Beghetto, R. A., \& Kaufman, J. C. (2007). Toward a broader conception of creativity: A case for "mini-c" creativity. Psychology of Aesthetics, Creativity, and the Arts, 1(2), 73-79.

Behr, H. (2005). Comparing rural and urban primary education in the Mekong Delta. Independent Study Project (ISP) Collection, 414. Retrieved from https://digitalcollections.sit.edu/isp_collection/414

Belet, S. D., \& Dala, S. (2010). The use of storytelling to develop the primary school students' critical reading skill: The primary education pre-service teachers' opinions. Procedia-Social and Behavioral Sciences, 9, 1830-1834.

Blatchford, P., \& Baines, E. (2010). Peer relations in school. In K. Littleton, C. Wood, \& K. Staarman (Eds.), International handbook of psychology in education (pp. 227-276). Bingley, UK: Emerald.

Bloor, M. (1991). The role of informal interaction in teaching English to young learners. In C. Brumfit, J. Moon, \& R. Tongue (Eds.), Teaching English to children: From practice to principle (pp. 127-141). Glasgow: Collins Educational.

Bock, A. K., \& Erickson, K. A. (2015). The influence of teacher epistemology and practice on student engagement in literacy learning. Research and Practice for Persons with Severe Disabilities, 40(2), 138-153.

Bogaert, N., Van Gorp, K., Bultynck, K., Lanssens, A., \& Depauw.V. (2006). Task-based language training in science education and vocational training. In K. Van den Branden (Ed.), Task-based language education (pp. 106-128). Cambridge: Cambridge University Press.

Borg, S. (2001). The research journal: A tool for promoting and understanding researcher development. Language Teaching Research, 5(2), 156-177.

Borg, S. (2003). Teacher cognition in language teaching: A review of research on what language teachers think, know, believe, and do. Language teaching, 36(2), 81-109.

Borg, S. (2006). Teacher cognition and language education: Research and practice. London: Continuum.

Borg, S. (2019). Language teacher cognition: Perspectives and debates. In X. Gao (Ed.), Second handbook of English language teaching (pp. 1179-1170). Cham: Springer Nature.

Bourke, J. M. (2006). Designing a topic-based syllabus for young learners. ELT Journal, 60(3), 279-286.

Boutorwick, T. J. (2017). Vocabulary development through reading: a comparison of approaches. (unpublished $\mathrm{PhD}$ thesis). Victoria University of Wellington, New Zealand.

Breen, M. P. (2001). Learner contributions to language learning: New directions in research. London: Longman.

Brenes, C. A. N. (2005). Analyzing an oral narrative using discourse analysis tools: Observing how spoken language works. Actualidades Investigativas en Educación, 5(1), 1-19. 
Brewster, J., Ellis, G., \& Girard, D. (2002). The primary English teacher's guide. London: Penguin.

Brooks, R., Te Riele, K., \& Maguire, M. (2014). Ethics and education research (5th ed.). Los Angeles, CA: SAGE.

Brophy, J. (2008). Developing students' appreciation for what is taught in school. Educational Psychologist, 43(3), 132-141.

Brown, D., \& Thomson, C. (2000). Cooperative learning in New Zealand schools. Palmerston North: Dunmore Press.

Brown, H. D. (2001). Teaching by principles: An interactive approach to language pedagogy (2nd ed.). White Plains, NY: Person Education.

Brown, H. D. (2007). Teaching by principles: an interactive approach to language pedagogy (3 ed.). White Plains, NY: Pearson Education.

Bruner, J. S. (1985). Vygotsky: A historical and conceptual perspective. In J. V. Wertsch (Ed.), Culture, communication, and cognition: Vygotskian perspectives (pp. 21-34). Cambridge: Cambridge University Press.

Bruner, J. S. (2002). Making stories: Law, literature, life. Cambridge, MA: Harvard University Press.

Bui, L. D. T. (2019). The implementation of task-based language teaching in EFL primary school classrooms: A case study in Vietnam. (Unpublished $\mathrm{PhD}$ thesis). Victoria University of Wellington, New Zealand.

Bundick, M. J., Quaglia, R. J., Corso, M. J., \& Haywood, D. E. (2014). Promoting student engagement in the classroom. Teachers College Record, 116(4), 1-34.

Butler, Y. G. (2019). Assessment of young English learners in instructional settings. In X. Gao (Ed.), Second handbook of English language teaching (pp. 477-496). Cham: Springer Nature.

Butler, Y. G., \& Zeng, W. (2014). Young foreign language learners' interactions during taskbased paired assessments. Language Assessment Quarterly, 11(1), 45-75.

Bygate, M. (2016). Sources, developments and directions of task-based language teaching. Language Learning, 44(4), 381-400.

Bygate, M., \& Samuda, V. (2009). Creating pressure in task pedagogy: The joint roles of field, purpose, and engagement within the interaction approach. In A. Mackey \& C. Polio (Eds.), Multiple perspectives on interaction (pp. 96-122). New York: Routledge.

Caine, R. N., \& Caine, G. (1997). Education on the edge of possibility. Alexandria, VA: National Association of Secondary School Principals.

Cambridge University Press. (2019). Cambridge life competencies framework: Creating thinking. Retrieved 16 November 2019, from https://www.cambridge.org/elt/blog/2018/04/05/cambridge-framework-lifecompetencies/

Cameron, L. (2001). Teaching languages to young learners. Cambridge: Cambridge University Press.

Cameron, L. (2003). Challenges for ELT from the expansion in teaching children. ELT Journal, 57(2), 105-112. 
Cao, T. H. P. (2019). Teaching English to young learners in Vietnam: From policy to implementation. The Asian Journal of Applied Linguistics, 6(1), 96-104.

Carless, D. (2002). Implementing task-based learning with young learners. ELT Journal, 56(4), 389-396.

Carreira, J. M. (2011). Relationship between motivation for learning EFL and intrinsic motivation for learning in general among Japanese elementary school students. System, 39(1), 90-102.

Carter, R. (2010). Mapping the mind. London: Phoenix.

Cenoz, J. (2003). The influence of age on the acquisition of English: General proficiency, attitudes and code-mixing. In M. d. P. Garcia Mayo \& M. L. Garcia Lecumberri (Eds.), Age and the acquisition of English as a foreign language (pp. 77-93). Clevedon: Multilingual Matters.

Chafe, W. L. (1985). Linguistic differences produced by differences between speaking and writing. In D. R. Olson, N. Torrance, \& A. Hildyard (Eds.), Literacy, language, and learning: The nature and consequences of reading and writing (pp. 105-123). Cambridge: Cambridge University Press.

Chinh, N. D., Quynh, T. H., \& Ha, N. T. (2014). Inequality of access to English language learning in primary education in Vietnam. In H. Zhang, P. W. K. Chan, \& C. Boyle (Eds.), Equality in education (pp. 139-153). Rotterdam: Sense Publishers.

Choi, T.-h., \& Andon, N. (2014). Can a teacher certification scheme change ELT classroom practice? ELT Journal, 68(1), 12-21.

Chwo, G. S. M., \& Chen, B. H. (2015). Storytelling to young EIL learners in Taiwan: A cautionary tale. 弘光學報, 76, 75-94.

Clark, R. C. (2015). Evidence-based training methods: A guide for training professionals (2nd ed.). Alexandria, VA: ATD Press.

Cohen, L., Manion, L., \& Morrison, K. (2018). Research methods in education (8th ed.). London: Routledge.

Copland, F., \& Garton, S. (2014). Key themes and future directions in teaching English to young learners: Introduction to the special issue. ELT Journal, 68(3), 223-230.

Copland, F., Garton, S., \& Burns, A. (2014). Challenges in teaching English to young learners: Global perspectives and local realities. TESOL Quarterly, 48(4), 738-762.

Corrie, L. (2002). Investigating troublesome classroom behaviour: Practical tools for teachers. London: RoutledgeFalmer.

Costenaro, V. (2008). Language acquisitional storytelling: Psycholinguistics in action in the Italian EFL classroom. Studi di Glottodidattica, 3, 65-88.

Crabbe, D. (2003). The quality of language learning opportunities. TESOL Quarterly, 37(1), 9-34.

Crandall, J. (1999). Cooperative language learning and affective factors. In J. Arnold (Ed.), Affect in language learning (pp. 226-245). Cambridge: Cambridge University Press.

Cremin, T., Flewitt, R., Mardell, B., \& Swann, J. (Eds.). (2017). Storytelling in early childhood: Enriching language, literacy and classroom culture. New York: Routledge. 
Creswell, J. W. (2005). Educational research: Planning, conducting, and evaluating quantitative and qualitative research (2nd ed.). Saddle River,NJ: Pearson Education.

Creswell, J. W. (2014). Research design: Qualitative, quantitative, and mixed methods approaches (4th ed.). Thousand Oaks, CA: SAGE.

Creswell, J. W., \& Plano Clark, V. L. (2007). Designing and conducting mixed methods research. Thousand Oaks, CA: SAGE.

Criado, R. (2013). A critical review of the presentation-practice-production model (PPP) in foreign language teaching. In R. Monroy (Ed.), Homenaje a Francisco Gutiérrez Díez (pp. 97-115). Murcia: Edit.um.

Curtain, H. A., \& Dahlberg, C. A. (2010). Languages and children: Making the match, New languages for young learners (4th ed.). Boston, MA: Pearson.

Dang, H. A. H. (2011). A bird's-eye view of the private tutoring phenomenon in Vietnam. The Newsletter, 76, 26-27.

Deci, E. L., \& Ryan, R. M. (1985). Intrinsic motivation and self-determination in human behavior. New York: Plenum Press.

Dekker, S., Lee, N. C., Howard-Jones, P., \& Jolles, J. (2012). Neuromyths in education: Prevalence and predictors of misconceptions among teachers. Frontiers in psychology, $3,1-8$.

Djigunovic, J. M. (2006). Role of affective factors in the development of productive skills. In M. Nikolov \& J. Horvath (Eds.), Empirical studies in English applied linguistics (pp. 9-24). Pesc: Lingua Franca Csoport.

Djigunovic, J. M. (2012). Attitudes and motivation in early foreign language learning. Ceps Journal, 2(3), 55-74.

Djigunovic, J. M., \& Lopriore, L. (2011). The learner: Do individual differences matter? In J. Enever (Ed.), Early language learning in Europe (pp. 29-45). London: British Council.

Dolff, A. (1988). Teach English: A training course for teachers. Cambridge: Cambridge University Press.

Donato, R. (1994). Collective scaffolding in second language learning. In J. P. Lantolf \& G. Appel (Eds.), Vygotskian approaches to second language research (pp. 33-56). Norwood, NY: Ablex.

Donato, R. (2004). Aspects of collaboration in pedagogical discourse. Annual Review of Applied Linguistics, 24, 284-302.

Dornyei, Z. (1994). Motivation and motivating in the foreign language classroom. Modern Language 78(3), 273-284.

Dornyei, Z. (2001). Motivational strategies in the language classroom. Cambridge: Cambridge University Press.

Dornyei, Z. (2007). Research methods in applied linguistics. Oxford: Oxford University Press.

Dornyei, Z. (2009). The psychology of second language acquisition. Oxford: Oxford University Press.

Dornyei, Z., \& Kormos, J. (2000). The role of individual and social variables in oral task performance. Language Teaching Research, 4(3), 275-300. 
Dudzik, D. L., \& Nguyen, T. N. Q. (2015). Vietnam: Building English competency in preparation for ASEAN 2015. In R. Stroupe \& K. Kimura (Eds.), ASEAN integration and role of ELT-CAMTESOL (Special ed., pp. 41-71). Phnom Penh: Language Education in Asia.

Egan, K. (1986). Teaching as story telling: An alternative approach to teaching and curriculum in the elementary school. Chicago, IL: University of Chicago Press.

Egan, K., \& Nadaner, D. (Eds.). (1988). Imagination and education. Milton Keynes: Open University Press.

Elkılıc, G., \& Akca, C. (2008). Attitudes of the students studying at Kafkas university private primary EFL classroom towards storytelling and motivation. Language and Linguistic Studies, 4(1), 1-27.

Elley, W. B. (1989). Vocabulary acquisition from listening to stories. Reading Research Quarterly, 24(2), 174-187.

Elley, W. B. (2000). The potential of book floods for raising literacy levels. International Review of Education, 46(3), 233-255.

Elley, W. B., \& Mangubhai, F. (1983). The impact of reading on second language learning. Reading Research Quarterly, 19(1), 53-67.

Ellis, G. (1995). Storytelling and storybooks: A broader version of the communicative approach. ESOL France- British Council, 2(1), 89-100.

Ellis, G., \& Brewster, J. (2014). Tell it again! The storytelling handbook for primary English language teachers. London: British Council.

Ellis, R. (2003). Task-based language learning and teaching. Oxford: Oxford University Press.

Ellis, R. (2005). Principles of instructed second language acquisition. System, 33, 209-224.

Ellis, R., \& Barkhuizen, G. (2005). Analysing learner language. Oxford, NY: Oxford University Press.

Enever, J. (2016). Primary ELT: Issues and trends. In G. Hall (Ed.), The Routledge handbook of English language teaching (pp. 353-365). London: Routledge.

Essig, W. (2005). Storytelling: Effects of planning, repetition and context. In C. Edwards \& j. Willis (Eds.), Teachers exploring tasks in English language teaching (pp. 201-213). Basingstoke: Palgrave Mamillan.

Farrell, T. S. C. (2019). 'My training has failed me': Inconvenient truths about second language teacher education. The Electronic Journal for English as a Second Language, 22(4). Retrieved from http://www.teslej.org/wordpress/issues/volume22/ej88/ej88a1/

Ferlazzo, L., \& Sypnieski, K. H. (2018). Textbooks. In L. Ferlazzo \& K. H. Sypnieski (Eds.), The ELL teacher's toolbox: Hundreds of practical ideas to support your students (pp. 423-426). San Francisco, CA: Jossey-Bass.

Fielding, R. M. (1997). A socio-cognitive perspective on cross-cultural attitudes and practices in creativity development. Australian Art Education, 20, 27-33.

Fikriah. (2016). Using the storytelling technique to improve English speaking skills of primary school students. English Education Journal, 7(1), 87-101. 
Finn, J. D., Folger, J., \& Cox, D. (1991). Measuring participation among elementary grade students. Educational and Psychological Measurement, 51(2), 393-402. Retrieved from https://doi.org/10.1177/0013164491512013

Firth, A., \& Wagner, J. (2007). Second/foreign language learning as a social accomplishment: elaborations on a reconceptualized SLA. Modern Language, 91, 800-819.

Fisher, R. (2005). Teaching children to think (2nd ed.). Cheltenham: Nelson Thornes Ltd.

Flewitt, R. (2014). Interviews. In A. Clark, R. Flewitt, M. Hammersley, \& M. Robb (Eds.), Understanding research with children and young people (pp. 136-153). Los Angeles, CA: SAGE.

Foley, J. (1994). Key concepts in ELT: Scaffolding. ELT Journal, 48(1), 101-102.

Foster, P., \& Ohta, A. S. (2005). Negotiation for meaning and peer assistance in second language classrooms. Applied Linguistics, 26(3), 402-430.

Fredricks, J. A., Blumenfeld, P. C., \& Paris, A. H. (2004). School engagement: Potential of the concept, state of the evidence. Review of Educational Research, 74(1), 59-109.

Fredricks, J. A., \& McColskey, W. (2012). The measurement of student engagement: A comparative analysis of various methods and student self-report instruments. In S. L. Christenson, A. L. Reschly, \& C. Wylie (Eds.), Handbook of research on student engagement (pp. 763-782). Boston, MA: Springer US.

Frey, N., Fisher, D., \& Everlove, S. (2009). Productive group work: How to engage students, build teamwork, and promote understanding. Alexandria, VA: ASCD.

Fushino, K. (2010). Causal relationships between communication confidence, beliefs about group work, and willingness to communicate in foreign language group work. TESOL Quarterly, 44(4), 700-724.

Garcia, F. V. (2017). Storytelling and grammar learning: A study among young - elementary EFL learners in Colombia. International Journal of English and Education, 6(2), 6381.

Garcia Mayo, M. D. P., \& Hidalgo, M. d. L. A. (2017). L1 use among young EFL mainstream and CLIL learners in task-supported interaction. System, 67, 132-145.

Garcia Mayo, M. d. P., \& Imaz Agirre, A. (2016). Task repetition and its impact on EFL children's negotiation of meaning strategies and pair dynamics: An exploratory study. Language Learning, 44(4), 451-466.

Garcia Mayo, M. D. P., \& Imaz Agirre, A. (2019). Task modality and pair formation method: their impact on patterns of interaction and LREs among EFL primary school children. System, 80, 165-175.

Garcia Mayo, M. D. P., \& Lazaro Ibarrola, A. (2015). Do children negotiate for meaning in task-based interaction? Evidence from CLIL and EFL settings. System, 54, 40-54.

Gardner, R. C. (1985). Social psychology and second language learning: The role of attitudes and motivation. London: Edward Arnold.

Gardner, R. C. (2010). Motivation and second language acquisition: The socio-educational model. New York: Peter Lang.

Gardner, R. C., \& MacIntyre, P. D. (1993). A student's contributions to second-language learning. Part II: Affective variables. Language teaching, 26(1), 1-11. 
Garvie, E. (1990). Story as vehicle: Teaching English to young children. Bristol: Multilingual Matters.

Gee, J. P. (1991). A linguistic approach to narrative. Narrative and Life History, 1(1), 15-39.

Gee, J. P. (2018). Introducing discourse analysis: From grammar to society. Abingdon: Routledge.

Gibbons, P. (2006). Bridging discourses in the ESL classroom: Students, teachers and researchers. London: Continuum.

Gibbs, R., \& Poskitt, J. (2010). Student engagement in the middle years of schooling (Years 7-10): A literature review report to the Ministry of Education. Retrieved from Ministry of Education, New Zealand: https://www.educationcounts.govt.nz/_data/assets/pdf_file/0010/74935/940_StudentEngagement-19052010.pdf

Gieve, S., \& Miller, I. s. K. (2006). Understanding the language classroom. New York: Palgrave Macmillan.

Gomez, A. B. (2010). How to use tales for the teaching of vocabulary and grammar in a primary education English class. RESLA, 23, 31-52.

Gonzalez, N. I. P. (2010). Teaching English through stories: A meaningful and fun way for children to learn the language. PROFILE Issues in Teachers' Professional Development 12(1), 95-106.

Gordon, C. J. (1989). Teaching narrative text structure: A process approach to reading and writing. In K. D. Muth (Ed.), Children's comprehension of text: Research into practice (pp. 79-102). Newark, DE: International Reading Association.

Graesser, A., Golding, J. M., \& Long, D. L. (1991). Narrative representation and comprehension. In R. Barr, M. L. Kamil, P. B. Mosenthal, \& P. D. Pearson (Eds.), Handbook of reading research (Vol. 2, pp. 171-205). White Plains, NY: Longman.

Grassick, L. J. (2016). Complexity, connections and sense-making: Stakeholder experiences of primary English language curriculum change in one province in Vietnam. (unpublished $\mathrm{PhD}$ thesis). University of Leeds, United Kingdom.

Gupta, A. (2009). Vygotskian perspectives on using dramatic play to enhance children's development and balance creativity with structure in the early childhood classroom. Early Child Development and Care, 179(8), 1041-1054.

Guthrie, G. (2010). Basic research methods an entry to social science research. New Delhi, India: SAGE.

Guvenc, H. (2015). The relationship between teachers' motivational support and engagement versus disaffection. Educational Sciences: Theory and Practice, 15(3), 647-657.

Halliwell, S. (1992). Teaching English in the primary classroom. London: Longman.

Hamamorad, A. (2018). Incorporating task based language learning approach into a Kurdish young EFL learners' classroom through storytelling technique in a basic school in Kurdistan region. European Journal of Multidisciplinary Studies, 3(2), 174-180.

Hamid, M. O., \& Erling, E. J. (2016). English-in-education policy and planning in Bangladesh: A critical examination. In R. Kirkpatrick (Ed.), English language education policy in Asia (pp. 25-48). Cham: Springer International.

Harmer, J. (2003). The practice of English language teaching (3rd ed.). Harlow: Longman. 
Harmer, J. (2015). The practice of English language teaching (5th ed.). Harlow: Pearson.

Hashemi, M. R., \& Babaii, E. (2013). Mixed methods research: Toward new research designs in applied linguistics. Modern Language, 97(4), 828-852.

Haught, J. R., \& McCafferty, S. G. (2008). Embodied language performance: Drama and the ZPD in the second language classroom. In J. P. Lantolf \& M. E. Poehner (Eds.), Sociocultural theory and the teaching of second languages (pp. 139-162). London: Equinox.

Hayes, D. (2008). Primary English language teaching in Vietnam: A research study. Paper presented at the Primary Innovations, Bangkok, Thailand.

Hayes, D. (2014). Factors influencing success in teaching English in state primary schools. London: British Council.

Hendrickson, J. M. (1992). Storytelling for foreign language learners. Washington, D. C.: ERIC Clearing House on Language and Linguistics. (Eric Document Reproduction No. ED 355-824)

Hess, N. (2001). Teaching large multilevel classes. Cambridge: Cambridge University Press.

Hoang, V. V., Nguyen, Q. T., Phan, H., Do, T. N. H., Dao, N. L., \& Truong, T. M. N. (2015a). English grade 5 - Classbook (3rd ed.). Ho Chi Minh City: Vietnam Education Publishing House and Macmillan.

Hoang, V. V., Nguyen, Q. T., Phan, H., Do, T. N. H., Dao, N. L., \& Truong, T. M. N. (2015b). English grade 5 - Teachers' guidebook (3rd ed.). Ho Chi Minh City: Vietnam Education Publishing House and Macmillan.

Holliday, A. (1994). Appropriate methodology and social context. Cambridge: Cambridge University Press.

Holliday, A. (2007). Doing and writing qualitative research (2nd ed.). Los Angeles, CA: SAGE.

Howatt, A. P. R. (1984). A history of English language teaching. Oxford: Oxford University Press.

Huang, Y. Y., Liu, C. C., Wang, Y., Tsai, C. C., \& Lin, H. M. (2017). Student engagement in long-term collaborative EFL storytelling activities: An analysis of learners with English proficiency differences. Educational Technology \& Society, 20(3), 95-109.

Huong, L. P. H., \& Yeo, M. (2016). Evaluating in-service training of primary English teachers: A case study in central Vietnam. Asian EFL, 18(1), 34-51.

Hutchinson, T., \& Torres, E. (1994). The textbook as agent of change. ELT Journal, 48(4), 315-328.

Isbell, R., Sobol, J., Lindauer, L., \& Lowrance, A. (2004). The effects of storytelling and story reading on the oral language complexity and story comprehension of young children. Early Childhood Education, 32(3), 157-163.

Jang, H., Reeve, J., \& Deci, E. L. (2010). Engaging students in learning activities: It is not autonomy support or structure but autonomy support and structure. Educational Psychology, 102(3), 588-600.

Jin, L., \& Cortazzi, M. (2018). Early English language learning in East Asia. In S. Garton \& F. Copland (Eds.), The Routledge handbook of teaching English to young learners (pp. 477-492). London: Routledge. 
Johnson, D. W., Johnson, R. T., \& Holubec, E. J. (1994). The new circles of learning: Cooperation in the classroom and school. Alexandria, VA: ASCD.

Johnson, R. B., \& Christensen, L. (2014). Educational research: Quantitative, qualitative, and mixed approaches (5th ed.). Thousand Oaks, CA: SAGE.

Jolliffe, W. (2015). Learning to learn together: Cooperation, theory and practice. Education 3$13,43(1), 1-4$.

Kalantari, F., \& Hashemian, M. (2016). A storytelling approach to teaching English to young EFL Iranian learners. English Language Teaching, 9(1), 221-234.

Kaufman, J. C., \& Beghetto, R. A. (2009). Beyond big and little: The four C model of creativity. Review of General Psychology, 13(1), 1-12.

Kennedy, C. (1988). Evaluation of the management of change in ELT projects. Applied Linguistics, 9(4), 329-342.

Kennedy, T. J. (2006). Language learning and its impact on the brain: Connecting language learning with the mind through content-based instruction. Foreign language annals, $39(3), 471-486$.

Kiernan, P. (2005). Storytelling with low-level learners: Developing narrative tasks. In C. Edwards \& J. Willis (Eds.), Teachers exploring tasks in English language teaching (pp. 58-68). Basingstoke: Palgrave Macmillan.

Kim, S. (2013). Comparison of task-based and storytelling-based English classroom interaction in Korean elementary schools. English Teaching, 68(3), 51-83.

Kim, T. Y., \& Seo, H. S. (2012). Elementary school students' foreign language learning demotivation: A mixed methods study of Korean EFL context. Asia-Pacific Education Researcher, 21(1), 160-171.

Kirsch, C. (2008). Teaching foreign languages in the primary school. London: Continuum.

Kirsch, C. (2016). Using storytelling to teach vocabulary in language lessons: Does it work? Language Learning, 44(1), 33-51.

Kitzinger, J. (1995). Introducing focus groups. British Medical Journal, 311(7000), 299-302.

Klingner, J. K., \& Vaughn, S. (2000). The helping behaviors of fifth graders while using collaborative strategic reading during ESL content classes. TESOL Quarterly, 34(1), 69-98.

Kramsch, C. J. (1987). Interactive discourse in small and large groups. In W. M. Rivers (Ed.), Interactive Language Teaching (pp. 17-30). Oxford: Oxford University Press.

Krashen, S. D. (2009). Anything but reading. Knowledge Quest, 37(5), 18-25.

Krashen, S. D., \& Terrell, T. D. (1995). The natural approach: Language acquisition in the classroom. Padstow: Prentice Hall Europe.

Krueger, R. A., \& Casey, M. A. (2009). Focus groups: A practical guide for applied research. Thousand Oaks, CA: SAGE.

Kumaravadivelu, B. (2006). Understanding language teaching: From method to post method. Mahwah, NJ: Lawrence Erlbaum Associates.

Kutnick, P., \& Blatchford, P. (2014). Effective group work in primary school classrooms: The SPRinG approach. Dordrecht: Springer 
Ladd, G. W. (2013). Peer influences in elementary school. In J. Hattie \& E. M. Anderman (Eds.), International guide to student achievement (pp. 205-208). New York: Routledge.

Lai, C. (2015). Task-based language teaching in the Asian context: Where are we now and where are we going? In M. Thomas \& H. Reinders (Eds.), Contemporary task-based language teaching in Asia (pp. 12-29). London: Bloomsbury Publishing Plc.

Lamb, M. (2016). Motivation. In G. Hall (Ed.), The Routledge handbook of English language teaching (pp. 324-338). New York: Routledge.

Lan Chi, N., Hamid, M. O., \& Renshaw, P. (2015). English in the primary classroom in Vietnam: Students' lived experiences and their social and policy implications. Current Issues in Language Planning, 17(2), 1-24.

Lantolf, J. P. (2000). Sociocultural theory and second language learning. Oxford: Oxford University Press.

Lantolf, J. P. (2006). Sociocultural theory and the genesis of second language development. Oxford: Oxford University Press.

Larsen-Freeman, D. (2011). Techniques and principles in language teaching (3 ed.). Oxford: Oxford University Press.

Laufer, B., \& Hulstijn, J. (2001). Incidental vocabulary acquisition in a second language: The construct of task-induced involvement. Applied Linguistics, 22(1), 1-26.

Laufer, B., \& Nation, P. (1995). Vocabulary size and use: Lexical richness in L2 written production. Applied Linguistics, 16(3), 307-322.

Le, V. C. (2007). Teachers' beliefs about curricular innovation in Vietnam: A preliminary study. In Y. H. Choi \& B. Spolsky (Eds.), English curriculum innovation in Asia (pp. 191-216). Seoul: Asia TEFL.

Le, V. C. (2015). English language education innovation for the Vietnamese secondary school: The Project 2020. In B. Spolsky \& K. Sung (Eds.), Secondary school English education in Asia: From policy to practice (pp. 182-200). London: Routledge.

Le, V. C. (2019). Unpacking the complexity of learning to teach English to young learners: A narrative inquiry. In S. Zein \& S. Garton (Eds.), Early language learning and teacher education: International research and practice. Bristol: Multilingual Matters.

Le, V. C. (2020a). English language teaching in Vietnam: Aspirations, realities, and challenges. In V. C. Le, T. M. H. Nguyen, T. T. M. Nguyen, \& R. Barnard (Eds.), Building teacher capacity in English language teaching in Vietnam: Research, policy and practice (pp. 7-22). London: Routledge.

Le, V. C. (2020b). Exploring teacher learning in mandatory in-service teacher training courses: Challenges ahead. In V. C. Le, T. M. H. Nguyen, T. T. M. Nguyen, \& R. Barnard (Eds.), Building teacher capacity in Vietnamese English language teaching: Research, policy and practice (pp. 62-79). London: Routledge.

Le, V. C., \& Do, T. M. C. (2012). Teacher preparation for primary school English education: A case of Vietnam. Primary School English Language Education in Asia, 68(3), 106128.

Le, V. C., \& Renandya, W. A. (2017). Teachers' English proficiency and classroom language use: A conversation analysis study. RELC journal, 48(1), 67-81. 
Lee , J., \& Lee , C. H. (2011). Demotivating factors in learning English for elementary school students. Primary English Education, 17(1), 327-356.

Lewis, A. D., Huebner, E. S., Malone, P. S., \& Valois, R. F. (2011). Life satisfaction and student engagement in adolescents. Youth and Adolescence, 40(3), 249-262.

Lewis, M. (1993). The lexical approach: The state of ELT and a way forward. Hove: Language Teaching Publications.

Li, C. Y., \& Seedhouse, P. (2010). Classroom interaction in story-based lessons with young learners. The Asian EFL Journal Quarterly, 12(2), 288-315.

Li, L., \& Walsh, S. (2011). 'Seeing is believing': Looking at EFL teachers' beliefs through classroom interaction. Classroom Discourse, 2(1), 39-57.

Li, Y., Han, Y., \& Gao, X. (2018). Young learners' motivation for learning English. In S. Garton \& F. Copland (Eds.), The Routledge handbook of teaching English to young learners (pp. 60-72). Milton: Routledge.

Lightbown, P., \& Spada, N. (2013). How languages are learned (4th ed.). Oxford: Oxford University Press.

Lincoln, Y. S., \& Guba, E. G. (1985). Naturalistic inquiry. Beverley Hills, CA: SAGE.

Littlewood, W. (1981). Communicative language teaching: An introduction. Cambridge: Cambridge University Press.

Loc, N. (2007). Challenges for primary education in the strategy for teaching and learning foreign languages in Vietnam. Paper presented at the Primary Innovations, Hanoi.

Long, M. H. (1983). Native speaker/non-native speaker conversation and the negotiation of comprehensible input. Applied Linguistics, 4, 126-141.

Long, M. H. (1996). The role of linguistic environment in second language acquisition. In W. C. Ritchie \& T. K. Bhatia (Eds.), Handbook of second language acquisition (pp. 413468). San Diego, CA: Academic Press.

Lucarevschi, C. R. (2018). The role of storytelling in the development of pronunciation of Brazilian learners of English as a foreign language. (unpublished $\mathrm{PhD}$ thesis). University of Victoria, British Columbia, Canada.

Macalister, J. (2010). Investigating teacher attitudes to extensive reading practices in higher education: Why isn't everyone doing it? RELC journal, 41(1), 59-75. doi:10.1177/0033688210362609

Macalister, J. (2011). Today's teaching, tomorrow's text: Exploring the teaching of reading. ELT Journal, 65(2), 161-169. doi:10.1093/elt/ccq023

Macalister, J. (2012). Pre-service teacher cognition and vocabulary teaching. RELC journal, 43(1), 99-111. doi:10.1177/0033688212439312

Macalister, J. (2014). The say-it activity. Modern English Teacher, 23(1), 29-32.

Macalister, J. (2016). Adapting and adopting materials. In M. Azarnoosh, M. Zeraatpishe, A. Faravani, \& H. R. Kargozari (Eds.), Issues in materials development (pp. 57-64). Rotterdam: Sense Publishers.

Macalister, J., \& Nation, I. S. P. (2020). Language curriculum design (2 ed.). New York: Routledge.

Mackey, A., \& Gass, S. M. (2016). Second language research: Methodology and design (2nd ed.). New York: Routledge. 
Mackey, A., Oliver, R., \& Leeman, J. (2003). Interactional input and the incorporation of feedback: An exploration of NS-NNS and NNS-NNS adult and child dyads. Language Learning, 53(1), 35-66.

Mackey, A., \& Silver, R. E. (2005). Interactional tasks and English L2 learning by immigrant children in Singapore. System, 33(2), 239-260.

Maftoon, P., \& Sarem, S. N. (2015). A critical look at the Presentation, Practice, Production (PPP) approach: Challenges and promises for ELT. Broad Research in Artificial Intelligence and Neuroscience, 3(4), 31-36.

Mai, N. K. (2014). Towards a holistic approach to developing the language proficiency of Vietnamese primary teachers of English. Electronic Journal of Foreign Language Teaching, 11(2), 341-357.

Manh, D. L., Nguyen, T. M. H., \& Burns, A. (2017). Teacher language proficiency and reform of English language education in Vietnam, 2008-2020. In D. Freeman \& L. Le Drean (Eds.), Classroom English competence: Learning from the Vietnam experience (pp. 19-33). Phnom Penh: Language Education in Asia.

Markova, Z. (2015). A journey towards creativity: A case study of three primary classes in a Bulgarian state school. In A. Maley \& N. Peachey (Eds.), Creativity in the English language classroom (pp. 165-172). London: British Council.

Mc Donough, D. (2013). Similarities and differences between adult and child learners as participants in the natural learning process. Psychology, 4(3A), 345-348.

McCallum, G. P. (1980). 101 word games for students of English as a second or foreign language. Hong Kong: Oxford University Press.

McGee, L. M., \& Schickedanz, J. A. (2007). Repeated interactive read-alouds in preschool and kindergarten. The Reading Teacher, 60(8), 742-751.

McKay, S. L. (2006). Researching second language classrooms. Mahwah, NJ: Lawrence Erlbaum Associates.

McQuillan, J., \& Tse, L. (1998). What's the story? Using the narrative approach in beginning language classrooms. TESOL Journal, 7(4), 18-23.

Mehan, H. (1979). Learning lessons: Social organization in the classroom. Cambridge, MA: Harvard University Press.

Merriam, S. B. (2009). Qualitative research: A guide to design and implementation (3rd ed.). San Francisco, CA: Jossey-Bass.

Merriam, S. B., \& Tisdell, E. J. (2016). Qualitative research: A guide to design and implementation (4th ed.). San Francisco, CA: Jossey-Bass.

Mihaljevic Djigunovic, J., Nikolov, M., \& Otto, I. (2008). A comparative study of Croatian and Hungarian EFL students. Language Teaching Research, 12(3), 433-452.

Minh, B. T. H. (2016). Developing the speaking competences of primary school students in English as a foreign language classes in Vietnam through drama activities. (Unpublished PhD thesis). Georg-August-University of Göttingen, Germany.

MOET. (2010a). Chưong trình tiêng Anh tiểu học (Curriculum of English language education for primary schools). Hanoi, Vietnam: MOET

MOET. (2010b). Huớng dẫn triển khai dạy thi điểm chuơng trình Tiếng Anh Tiểu họ số: 6003/BGDĐT-GDTH (Guidlines for the implementation of pilot English programmes at primary level). Hanoi, Vietnam: MOET 
MOET. (2016). Thông tu ban hành đánh giá học sinh tiểu học (Joint Circular on assessing primary school learners' learning). Hanoi, Vietnam: MOET

MOET. (2018). Chương trình môn tiếng Anh (ban hành kèm thông tư số 32/2018/TT-BGDĐT về ban hành chương trình giáo dục phổ thông - English education curriculum (issued together with Joint Circular No 32/2018/TT-BGDĐT on the promulgation of the general educational curriculum). Hanoi, Vietnam: MOET

Moon, J. (2005a). Children learning English: A guidebook for English language teachers. London: Macmillan.

Moon, J. (2005b). Teaching English to young learners: The challenges and the benefits. In English! Winter 2005, 30-34.

Moon, J. (2009). The teacher factor in early foreign language learning programmes: The case of Vietnam. In M. Nikolov (Ed.), The age factor and early language learning (pp. 311-336). Berlin: Mouton de Gruyter.

Moran, S., \& John-Steiner, V. (2003). Creativity in the making: Vygotsky's contemporary contribution to the dialectic of development and creativity. In R. K. Sawyer, V. JohnSteiner, S. Moran, R. J. Sternberg, D. H. Feldman, J. Nakamura, \& M. Csikszentmihalyi (Eds.), Creativity and development (pp. 60-90). Oxford: Oxford University Press.

Morrow, L. M. (1989). Using story retelling to develop comprehension. In K. D. Muth (Ed.), Children's comprehension of text: Research into practice (pp. 37-58). Newark, DE: ERIC.

Myhill, D., Jones, S., \& Hopper, R. (2006). Talking, listening, learning: Effective talk in the primary classroom. Maidenhead: Open University Press.

Nation, I. S. P. (2007). The four strands. Innovation in Language Learning and Teaching, 1(1), 1-13.

Nation, I. S. P. (2013). Learning vocabulary in another language (2nd ed.). Cambridge: Cambridge University Press.

Nation, I. S. P., \& Newton, J. (2009). Teaching ESL/EFL listening and speaking. New York: Routledge.

Nedjah, H., \& Hamada, H. (2017). Creativity in the EFL classroom: Exploring teacher's knowledge and perceptions. Arab World English, 8(4), 352- 364.

Newton, J., \& Bui, L. D. T. (2017). Teaching with tasks in primary school EFL classrooms in Vietnam. In M. J. Ahmadian \& M. d. P. Garcia Mayo (Eds.), Recent perspectives on task-based language learning and teaching. Berlin: De Gruyter.

Newton, J., \& Nguyen, T. B. T. (2019). Task repetition and the public performance of speaking tasks in EFL classes at a Vietnamese high school. Language Teaching for Young Learners, 1(1), 34-56.

Ngoc Hung, N. (2015). Vietnam's National Foreign Language 2020 Project: Challenges, opportunities, and solutions. In W. B. Terance \& S. Salbrina (Eds.), English for ASEAN integration: Policies and practices in the region (pp. 62-64). Brunei: Universiti Brunei Darussalam.

Nguyen, P. M. (2019). Culturally appropriate face strategies in cooperative learning with insight from cultural neuroscience. Comparative Education, 55(1), 66-96. 
Nguyen , P. M., Terlouw, C., \& Pilot, A. (2006). Culturally appropriate pedagogy: The case of group learning in a Confucian heritage culture context. Intercultural Education, 17(1), 1-19.

Nguyen, T. M. H. (2011). Primary English language education policy in Vietnam: Insights from implementation. Current Issues in Language Planning, 12(2), 225-249.

Nguyen, T. M. H. (2017). Models of mentoring in language teacher education. Cham: Springer.

Nguyen, T. M. H., \& Nguyen, Q. T. (2007). Teaching English in primary schools in Vietnam: An overview. Current Issues in Language Planning, 8(2), 162-173.

Nikolov, M., \& Djigunovic, J. M. (2019). Teaching young language learners. In X. Gao (Ed.), Second handbook of English language teaching (pp. 577-599). Cham: Springer International Publishing.

Nunan, D. (1998). Teaching grammar in context. ELT Journal, 52(2), 101-109.

Nunan, D. (1999). Second language teaching and learning. Boston, MA: Heinle, Cengage Learning.

Nunan, D. (2003). The impact of English as a global language on educational policies and practices in the Asia-Pacific region. TESOL Quarterly, 37(4), 589-613.

Nunan, D. (2011). Teaching English to young learners. Anaheim, CA: Anaheim University Press.

Nunan, D., \& Bailey, K. M. (2009). Exploring second language classroom research: A comprehensive guide. Boston, MA: Heinle, Cengage Learning.

O'Donnell, A. M. (2006). The role of peers and group learning. In P. A. Alexander \& P. H. Winne (Eds.), Handbook of educational psychology (pp. 781-802). Mahwah, NJ: Lawrence Erlbaum Associates.

Odena, O., \& Welch, G. (2009). A generative model of teachers' thinking on musical creativity. Psychology of Music, 37(4), 416-442.

Oduolowu, E., \& Oluwakemi, A. (2014). Effect of storytelling on listening skills of primary one pupil in Ibadan North local government area of Oyo State, Nigeria. International Journal of Humanities and Social Science 4(9), 100-107.

Oga-Baldwin, W. Q., \& Nakata, Y. (2017). Engagement, gender, and motivation: A predictive model for Japanese young language learners. System, 65, 151-163.

Ohta, A. S. (2001). Second language acquisition processes in the classroom: Learning Japanese. Mahwah, NJ: Lawrence Erlbaum Associates.

Oxford University Press. Lesson plans \& syllabi - Grade 5. Family and Friends. Special edition. Retrieved from http://www.oup.com.vn/family\&friendsspecialedition/family\&friendsspecialedition_v ersion2/index.html

Pajares, M. F. (1992). Teachers' beliefs and educational research: Cleaning up a messy construct. Review of Educational Research, 62(3), 307-332. doi:10.3102/00346543062003307

Paris, A. H., \& Paris, S. (2008). Narrative bridges to comprehension. In A. DeBruin-Parecki (Ed.), Effective early literature practice: Here's how, here's why. Baltimore, MD: Paul H. Brookes Publishing Co., Inc. 
Park, B. (1982). The Big Book trend: A discussion with Don Holdaway. Language Arts, 59(8), 815-821.

Patton, M. Q. (1987). How to use qualitative methods in evaluation. Newbury Park, CA: SAGE.

Patton, M. Q. (2015). Qualitative research \& evaluation methods: Integrating theory and practice (4th ed.). Thousand Oaks, CA: SAGE.

Peck, S. (2001). Developing children's listening and speaking in ESL. In M. Celce-Murcia (Ed.), Teaching English as a foreign language (3 ed., pp. 139-149). Boston: Cengage Learning.

Pham, H. N. (2013). Obstacles to primary school teachers' implementation of methodological innovations to teach English to young learners. Tạp chí Khoa hoc Đại học Huế, 80(2), 135-146.

Phan, Q. N. (2017). Professional learning communities: Learning sites for primary school English language teachers in Vietnam. (Unpublished $\mathrm{PhD}$ thesis). University of Technology Sydney, Australia.

Phillips, S. (1993). Young learners. Oxford: Oxford University Press.

Philp, J., \& Duchesne, S. (2008). When the gate opens: The interaction between social and linguistic goals in child second language development. In J. Philp, R. Oliver, \& A. Mackey (Eds.), Second language acquisition and the younger learner: Child's play? (pp. 83-103). Philadelphia, PA: John Benjamins Publishing Co.

Philp, J., \& Duchesne, S. (2016). Exploring engagement in tasks in the language classroom. Annual Review of Applied Linguistics, 36, 50-72.

Philp, J., \& Tognini, R. (2009). Language acquisition in foreign language contexts and the differential benefits of interaction. International Review of Applied Linguistics in Language Teaching, 47(3-4), 245-266.

Phuong, H. (2016). Đề án ngoại ngữ gần 9.400 tỷ sau 8 năm làm được những gì (Project 2020, what 9,400 billion VND could do after 9 years). VnExpress. Retrieved from https://vnexpress.net/giao-duc/de-an-ngoai-ngu-gan-9-400-ty-sau-8-nam-lam-duocnhung-gi-3470788.html

Piaget, J. (1970). Science of education and the psychology of the child. New York: Oxford University Press.

Pica, T., \& Doughty, C. (1985). The role of group work in classroom second language acquisition. Studies in Second Language Acquisition, 7(2), 233-248.

Pinter, A. (2005). Task repetition with 10-year-old children. In C. Edwards \& J. Willis (Eds.), Teachers exploring tasks in English language teaching (pp. 113-126). New York: Macmillan Palgrave.

Pinter, A. (2017). Teaching young language learners (2nd ed.). Oxford: Oxford University Press.

Pinter, A. (2018). Research issues with young learners. In S. Garton \& F. Copland (Eds.), The Routledge handbook of teaching English to young learners (pp. 411-424). London: Routledge.

Pinto, C. F. (2012). Using children's literature in ELT: A story-based approach. Revista do Centro de Investigação e Inovação em Educação, 2(2), 23-39. 
Pintrich, P. R. (2003). Motivation and classroom learning. In W. M. Reynolds \& G. E. Miller (Eds.), Handbook of psychology (pp. 103-122). Hoboken, NJ: John Wiley \& Sons, Inc.

Platt, E., \& Brooks, F. B. (1994). The "acquisition-rich environment" revisited. The Modern Language Journal, 78(4), 497-511.

Ponce, O. A., \& Pagán-Maldonado, N. (2015). Mixed methods research in education: Capturing the complexity of the profession. International Journal of Educational Excellence, 1(1), 111-135.

Pressley, M., Johnson, C. J., Symons, S., McGoldrick, J. A., \& Kurita, J. A. (1989). Strategies that improve children's memory and comprehension of text. Elementary School, 90(1), $3-32$.

Putney, L. G., Green, J., Dixon, C. N., Duran, R., \& Yeager, B. (2000). Consequential progressions: Exploring collective-individual development in a bilingual classroom. In C. D. Lee \& P. Smagorinsky (Eds.), Vygotskian perspectives on literacy research: Constructing meaning through collaborative inquiry (pp. 86-126). Cambridge: Cambridge University Press.

Quynh, N. (2019, 4 August 2019). 70\% giáo viên tiếng Anh phổ thông đạt chuẩn năng lực chương trình mới (70\% of school teachers of English meets the new requirement of language proficiency). Dân Trí Retrieved from https://dantri.com.vn/giao-duc-khuyenhoc/70-giao-vien-tieng-anh-pho-thong-dat-chuan-nang-luc-chuong-trinh-moi20190804100127689.htm

Ramirez, M. (2005). Grouping techniques in an EFL classroom. Actualidades Investigativas en Educación, 5, 1-14. Retrieved from http://revista.inie.ucr.ac.cr/

Read, C. (2015). Foreword. In J. Bland (Ed.), Teaching English to young learners: Critical issues in language teaching with 3-12 year olds (pp. xi-xiii). London: Bloomsbury Publishing.

Read, J. (2000). Assessing vocabulary. Cambridge: Cambridge University Press.

Resnick, L. B. (1987). Education and learning to think. Washington, DC 20418: National Academies Press.

Rew, S., \& Moon, Y. (2013). The effects of using English drama on the learning of target expressions for primary school students. ASIA TEFL, 10(4), 215-239.

Reyes, M. R., Brackett, M. A., Rivers, S. E., White, M., \& Salovey, P. (2012). Classroom emotional climate, student engagement, and academic achievement. Educational Psychology, 104(3), 700-712.

Richards, J. C. (1998). Beyond training: Perspectives on language teacher education. Cambridge: Cambridge University Press.

Richards, J. C., \& Rodgers, T. S. (2014). Approaches and methods in language teaching (3rd ed.). Cambridge: Cambridge University Press.

Richardson, C., \& Mishra, P. (2018). Learning environments that support student creativity: Developing the SCALE. Thinking Skills and Creativity, 27, 45-54. doi:10.1016/j.tsc.2017.11.004

Riener, C., \& Willingham, D. (2010). The myth of learning styles. Change: The Magazine of Higher Learning, 42(5), 32-35. doi:10.1080/00091383.2010.503139

Rimm-Kaufman, S. E., Baroody, A. E., Larsen, R. A., Curby, T. W., \& Abry, T. (2015). To what extent do teacher-student interaction quality and student gender contribute to 
fifth graders' engagement in mathematics learning? Educational Psychology, 107(1), 170-185.

Rubenstein, L. D., McCoach, D. B., \& Siegle, D. (2013). Teaching for creativity scales: An instrument to examine teachers' perceptions of factors that allow for the teaching of creativity. Creativity Research, 25(3), 324-334.

Safdarian, Z., \& Ghyasi, M. (2013). The influence of storytelling on elementary level students: A triangulated study among foreign language learners. International Journal of English and Education, 2(3), 78-89.

Saito, E., Tsukui, A., \& Tanaka, Y. (2008). Problems on primary school-based in-service training in Vietnam: A case study of Bac Giang province. International Journal of Educational Development, 28(1), 89-103.

Samana, W. (2013). Teacher's and students' scaffolding in an EFL classroom. Academic Journal of Interdisciplinary Studies, 2(8), 338-343.

Samuda, V., \& Bygate, M. (2008). Tasks in second language learning. Basingstoke: Palgrave Macmillan.

Sato, M. (2017). Interaction mindsets, interactional behaviors, and L2 development: An affective-social-cognitive model. Language Learning, 67(2), 249-283.

Saucedo, A. R. (2005). Task-based instruction and storytelling with young learners: Analysis of its advantages. The Greta Magazine, 13(1\&2), 61-70.

Schlechty, C. P. (1994). Increasing student engagement. Jefferson, MO: Missouri Leadership Academy.

Schlechty, C. P. (2011). Engaging students: The next level of working on the work. San Francisco, CA: Jossey-Bass.

Schmid, M. S. (2011). Language attrition. New York: Cambridge University Press.

Schmidt, R. (1990). The role of consciousness in second language learning. Applied Linguistics, 11(2), 129-158.

Schmidt, R. (2012). Attention, awareness, and individual differences in language learning. In A. U. Chamot \& W. M. Chan (Eds.), Perspectives on individual characteristics and foreign language education (pp. 2-27). Berlin: Walter de Gruyter, Inc.

Schunk, D. H. (2012). Learning theories: An educational perspective (6th Ed.). Boston, MA: Pearson.

Schunk, D. H., Meece, J. L., \& Pintrich, P. R. (2014). Motivation in education: Theory, research, and applications (4th ed.). Boston, MA: Pearson.

Schweisfurth, M. (2011). Learner-centred education in developing country contexts: From solution to problem? International Journal of Educational Development, 31(5), 425432.

Scott, W. A., \& Ytreberg, L. H. (1990). Teaching English to children. London: Longman.

Seedhouse, P. (1999). Task-based interaction. ELT Journal, 53(3), 149-156.

Seedhouse, P., \& Jenks, C. J. (2015). International perspectives on ELT classroom interaction: An introduction. In C. J. Jenks \& P. Seedhouse (Eds.), International perspectives on ELT classroom interaction (pp. 1-9). London: Palgrave Macmillan.

Senior, R. M. (2002). A class-centred approach to language teaching. ELT Journal, 56(4), 397-403. 
Seo, H. S., \& Kim, T. Y. (2011). Collaborative dialogues and L2 learning: Korean junior high school students' pair-work in English composition. Korean Journal of Applied Linguistics, 27(1), 345-380.

Shin, J. K., \& Crandall, J. (2014). Teaching young learners English: From theory to practice. Boston, MA: National Geographic Learning.

Shintani, N. (2016). Input-based tasks in foreign language instruction for young learners. Amsterdam: John Benjamins Publishing Company.

Sinclair, J., \& Coulthard, R. M. (1975). Towards an analysis of discourse: The English used by teachers and pupils. London, United Kingdom: Oxford University Press.

Skinner, E. A., \& Pitzer, J. R. (2012). Developmental dynamics of student engagement, coping, and everyday resilience. In S. L. Christenson, A. L. Reschly, \& C. Wylie (Eds.), Handbook of research on student engagement (pp. 21-44). New York: Springer.

Smith, K. A., Sheppard, S. D., Johnson, D. W., \& Johnson, R. T. (2005). Pedagogies of engagement: Classroom-based practices. Engineering Education, 94(1), 87-101.

Soe, M. L. (2016). It's story time!: Exploring the potential of multimodality in oral storytelling to support children's vocabulary learning. Literacy, 50(2), 72-82.

Soh, K. (2017). Fostering student creativity through teacher behaviors. Thinking Skills and Creativity, 23, 58-66.

Song, S. (2015). Cambodian teachers' responses to child-centered instructional policies: A mismatch between beliefs and practices. Teaching and Teacher Education, 50, 36-45.

Spangler, D. E. (2009). Effects of two foreign language methodologies, communicative language teaching and teaching proficiency through reading and storytelling, on beginning-level students' achievement, fluency, and anxiety. (unpublished $\mathrm{PhD}$ thesis). Walden University, Minneapolis, MN, United States.

Stelma, J., \& Onat-Stelma, Z. (2010). Foreign language teachers organising learning during their first year of teaching young learners. Language Learning, 38(2), 193-207.

Storch, N. (2002). Patterns of interaction in ESL pair work. Language Learning, 52(1), 119158.

Storch, N., \& Aldosari, A. (2010). Learners' use of first language (Arabic) in pair work in an EFL class. Language Teaching Research, 14(4), 355. doi:10.1177/1362168810375362

Storch, N., \& Aldosari, A. (2013). Pairing learners in pair work activity. Language Teaching Research, 17(1), 1-18. doi:10.1177/1362168812457530

Sullivan, P. (2000). Playfulness as mediation in communicative language teaching in a Vietnamese classroom. In J. P. Lantolf (Ed.), Sociocultural theory and second language learning (pp. 115-131). Oxford: Oxford University Press.

Svalberg, A. M.-L. (2009). Engagement with language: Interrogating a construct. Language Awareness, 18(3-4), 242-258.

Swain, M. (1985). Communicative competence: Some roles of comprehensible input and comprehensible output in its development. In S. M. Gass \& C. G. Madden (Eds.), Input in second language acquisition (pp. 235-253). Rowley, MA: Newbury House.

Swain, M. (1995). Three functions of output in second language learning. In G. Cook \& B. Seidlhofer (Eds.), Principles and practice in applied linguistics: Studies in honor of H.G. Widdowson (pp. 125-144). Oxford: Oxford University Press. 
Swain, M. (2000). The output hypothesis and beyond: mediating acquisition through collaborative dialogue. In J. P. Lantolf (Ed.), Sociocultural theory and second language learning (pp. 97-114). New York: Oxford University Press.

Swain, M. (2010). Talking it through: Languaging as a source of learning. In R. Batstone (Ed.), Sociocognitive perspectives on language use and language learning (pp. 112130). Oxford: Oxford University Press.

Swain, M., \& Lapkin, S. (2001). Focus on form through collaborative dialogue: Exploring task effects. In M. Bygate, P. Skehan, \& M. Swain (Eds.), Researching pedagogic tasks: Second language learning, teaching and testing (2 ed., pp. 99-118). London: Routledge.

Swan, M. (2005). Legislation by hypothesis: The case of task-based instruction. Applied Linguistics, 26(3), 376-401.

Szpotowicz, M. (2009). Factors influencing young learners' vocabulary acquisition. In M. Nikolov (Ed.), Early learning of modern foreign languages: Processes and outcomes (pp. 195-211). Bristol: Multilingual Matters.

Tedjaatmadja, H. M., \& Renandya, W. A. (2012). Hook, Book, Look, Took: Keep it simple. Modern English Teacher, 21(4), 58-61.

Thanh, N. C., Viet, N. M., \& Hiep, T. P. (2015). Effects of Confucian ideology on the creativity of students and how do the teachers and the parents stimulate creative ability of their students and their children. American Journal of Educational Science, 1(4), 97-101.

Thompson, T., \& Simmons, N. (2016). Family and Friends Grade 5 (Special ed.). Oxford: Oxford University Press.

Thornbury, S. (1999). How to teach grammar. Edinburgh: Pearson Education Limited.

Tin, T. B. (2013). Towards creativity in ELT: The need to say something new. ELT Journal, 67(4), 385-397.

Tognini, R., \& Oliver, R. (2012). L1 use in primary and secondary foreign language classrooms and its contribution to learning. In E. A. Alcon Soler \& M.-P. Safont-Jorda (Eds.), Discourse and language learning across L2 instructional settings (pp. 53-78). Amsterdam: Rodopi.

Tomlinson, B. (2015). Developing principled materials for young learners. In J. Bland (Ed.), Teaching English to young learners: Critical issues in language teaching with 3-12 year olds (pp. 281-295). London: Bloomsbury Publishing.

Tomlinson, B., \& Masuhara, H. (2004). Developing language course materials. Singapore: RELC.

Tompkins, G. E., \& McGee, L. M. (1989). Teaching repetition as a story structure. In K. D. Muth (Ed.), Children's comprehension of text (pp. 59-78). Newark, DE: ERIC.

Tragant, E., \& Vallbona, A. (2018). Reading while listening to learn: Young EFL learners' perceptions. ELT Journal, 72(4), 395-404.

Trang, N. T. T. (2012). English language policies for Vietnamese primary schools and issues of implementation in rural settings. ASIA TEFL(Special Issue), 115-134.

Tudor, I. (1993). Teacher roles in the learner-centred classroom. ELT Journal, 47(1), 22-31.

Ur, P. (2012). A course in language teaching. Cambridge: Cambridge University Press. 
Van Hout, R., \& Vermeer, A. (2007). Comparing measures of lexical richness. In H. Daller, J. Milton, \& J. Treffers-Daller (Eds.), Modelling and Assessing Vocabulary Knowledge (pp. 221-138). Amsterdam: Benjamins.

Van Lier, L. (1990). Classroom research in second language acquisition. Annual Review of Applied Linguistics, 10, 73-186.

Van Lier, L. (2001). Constraints and resources in classroom talk: Issues of equality and symmetry. In C. Candlin \& N. Mercer (Eds.), English language teaching in its social context: A reader (pp. 90-107). London: Routledge.

Van Lier, L. (2005). Case study. In E. Hinkel (Ed.), Handbook of research in second language teaching and learning (pp. 195-208). Mahwah, NJ: Lawrence Erlbaum Associates.

Van Lier, L. (2013). Interaction in the language curriculum: Awareness, autonomy, and authenticity. New York: Routledge.

Vi, T. S. (2018). English in primary education in Sweden and Vietnam: Teaching practices, learner outcomes and out-of-school exposure. (Unpublished PhD thesis). Lund University, Sweden.

Vietnamese Prime Minister. (2017). Quyết định phê duyệt và điều chỉnh, bổ sung đề án dạy và họ ngoại ngũ trong hệ thống quốc dân giai đoạn 2017-2015 (Decision No. 2080/QD-TTg on the approval, adjustment and supplement of the project "Teaching and learning foreign languages in the national education system in the period of 2008-2020). Hanoi, Vietnam

Vu, M. T., \& Pham, T. T. T. (2014). Training of trainers for primary English teachers in Vietnam: Stakeholder evaluation. ASIA TEFL, 11(4), 89-108.

Vygotsky, L. S. (1962). Thought and language. Cambridge, MA: MIT Press.

Vygotsky, L. S. (1978). Mind in society: The development of higher psychological processes. Cambridge, MA: Harvard University Press.

Walliman, N. (2011). Your research project: Designing and planning your work (3rd ed.). Los Angeles, CA: SAGE.

Walsh, S. (2011). Exploring classroom discourse: Language in action. New York: Routledge.

Wang, D. (2011). The dilemma of time: Student-centered teaching in the rural classroom in China. Teaching and Teacher Education, 27(1), 157-164.

Wang, L., \& Kokotsaki, D. (2018). Primary school teachers' conceptions of creativity in teaching English as a foreign language (EFL) in China. Thinking Skills and Creativity, 29, 115-130.

Wang, Z., Bergin, D. A., \& Bergin, C. A. (2014). Measuring engagement in fourth to twelfth grade classrooms: The classroom engagement inventory. School Psychology Quarterly, Advance online publication. doi:http://dx.doi.org/10.1037/spq0000050

Warrington, M. J., Younger, M., \& Bearne, E. (2006). Raising boys' achievement in primary schools: Towards an holistic approach. New York: Open University Press.

Watanabe, Y., \& Swain, M. (2007). Effects of proficiency differences and patterns of pair interaction on second language learning: Collaborative dialogue between adult ESL learners. Language Teaching Research, 11(2), 121-142.

Watts, M., \& Ebbutt, D. (1987). More than the sum of the parts: Research methods in group interviewing. British Educational Research, 13(1), 25-34. 
Webb, N. (2009). The teacher's role in promoting collaborative dialogue in the classroom. British Journal of Educational Psychology, 79(1), 1-28.

Wedell, M. (2008). Developing a capacity to make "English for Everyone" worthwhile: Reconsidering outcomes and how to start achieving them. International Journal of Educational Development, 28(6), 628-639.

Wedell, M., \& Grassick, L. J. (2020). Innovation in language teaching and learning. In C. A. Chapelle (Ed.), The concise encyclopedia of applied linguistics (pp. 576-580). Singapore: John Wiley \& Sons.

Weinstein, C. S. (1979). The physical environment of the school: A review of the research. Review of Educational Research, 49(4), 577-610.

Wells, C. G. (1999). Dialogic inquiry: Towards a sociocultural practice and theory of education. New York: Cambridge University Press.

Willis, J. (2007a). Brain-friendly strategies for the inclusion classroom: Insights from a neurologist and classroom teacher. Alexandria, VA: Association for Supervision and Curriculum Development.

Willis, J. (2007b). Cooperative learning is a brain turn-on. Middle School, 38(4), 4-13.

Willis, J. (2010). The current impact of neuroscience on teaching and learning. In D. A. Sousa (Ed.), Mind, brain and education: Neuroscience implications for the classroom (pp. 45-68). Bloomington, IN: Solution Tree Press.

Willms, J. D. (2003). Student engagement at school: A sense of belonging and participation, results from PISA 2000. Paris: Organization for Economic Cooperation and Development

Woods, D. (1996). Teacher cognition in language teaching beliefs, decision-making and classroom practice. Cambridge: Cambridge University Press.

Wright, A. (1995). Storytelling with children. Oxford: Oxford University.

Wright, A., Betteridge, D., \& Buckby, M. (2005). Games for language learning (3rd ed.). Cambridge: Cambridge University Press.

Yaghobian, F., Samuel, M., \& Mahmoudi, M. (2017). Learner's use of first language in EFL collaborative learning: A sociocultural view. Malaysian Online Journal of Educational Sciences, 5(4), 36-55.

Yang, C. C. R. (2009). A case study of the use of short stories in a junior secondary ESL classroom in Hong Kong. The International Journal of Learning, 16(1), 35-50. 


\section{Appendices}

Appendix 1 Guide for focus group interviews with students

Appendix 2 Ethics approval

Appendix 3 Ethics for Phase 1

Appendix 4 A lesson plan of storytelling innovation

Appendix 5 Ethics for Phase 2

Appendix 6 A copy of the corresponding textbook pages for a lesson with a human-dialogue story

Appendix 7 A copy of the corresponding textbook pages for a lesson with an animal-dialogue story

Appendix 8 A copy of the corresponding textbook page for a lesson with a narrative text Appendix 9 An example of end-of-term test 